NIST Measurement Services:

\title{
Spectral Irradiance Calibrations
}

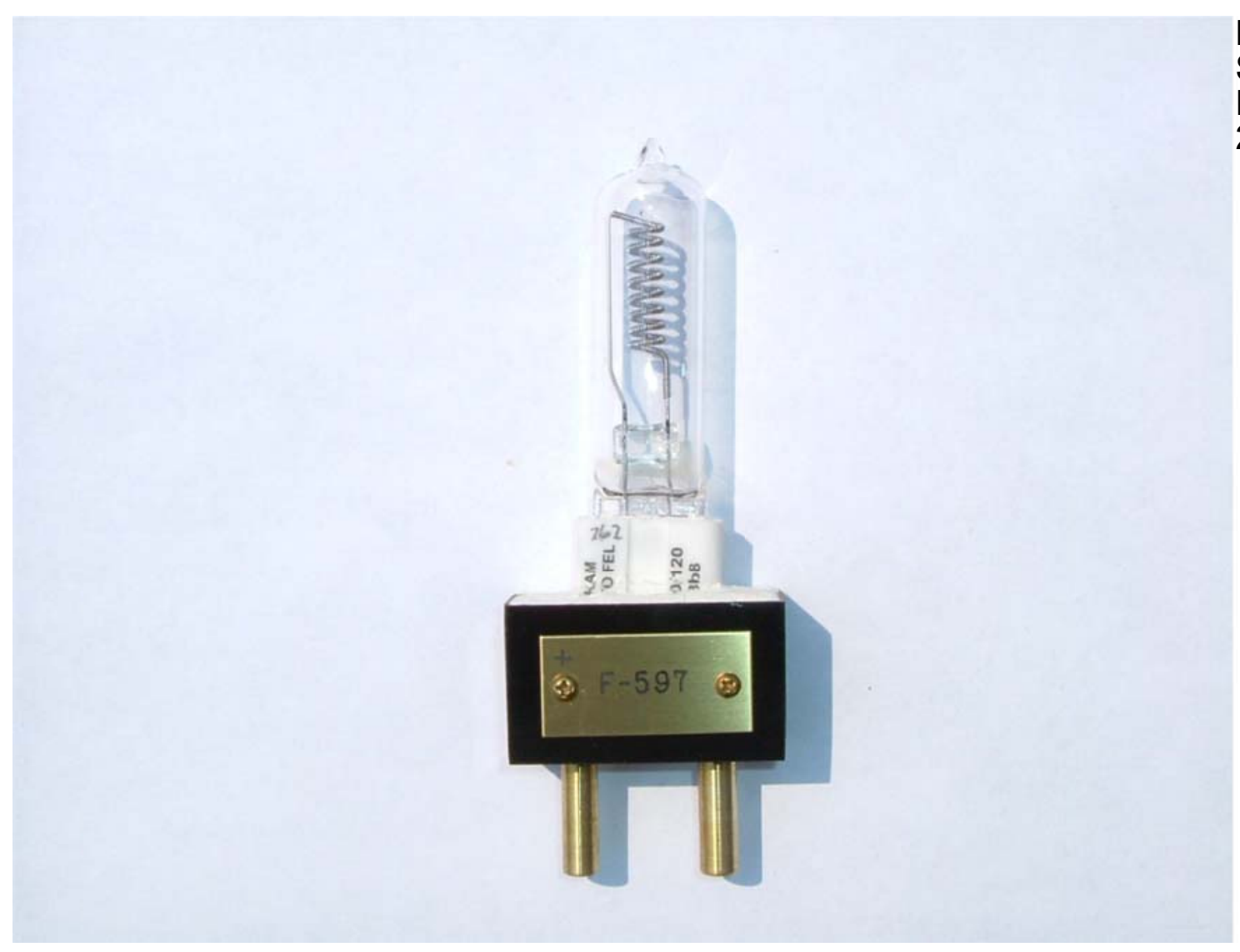

NIST

Special

Publication

250-89

Howard W. Yoon and Charles E. Gibson

U.S. Department of Commerce

National Institute of Standards and Technology 

NIST Special Publication 250-89

\section{NIST MEASUREMENT SERVICES: Spectral Irradiance Calibrations}

Howard W. Yoon and Charles E. Gibson

Optical Technology Division

Physical Measurement Laboratory

National Institute of Standards and Technology

Gaithersburg, MD 20899-0001

July 2011

\section{U.S. DEPARTMENT OF COMMERCE}

Gary F. Locke, Secretary

National Institute of Standards and Technology

Patrick D. Gallagher, Director 
National Institute of Standards and Technology Special Publication 250-89

Nat. Inst. Stand. Technol. Spec. Publ. 250-89, 132 Pages, (July 2011)

CODEN: NSPUE2 


\section{PREFACE}

The calibration and related measurement services of the National Institute of Standards and Technology are intended to assist the makers and users of precision measuring instruments in achieving the highest possible levels of accuracy, quality, and productivity. NIST offers over 300 different calibrations, special tests, and measurement assurance services. These services allow customers to directly link their measurement systems to measurement systems and standards maintained by NIST. These services are offered to the public and private organizations alike. They are described in NIST Special Publication (SP) 250, NIST Calibration Services Users Guide.

The Users Guide is supplemented by a number of Special Publications (designated as the "SP250 Series") that provide detailed descriptions of the important features of specific NIST calibration services. These documents provide a description of the: (1) specifications for the services; (2) design philosophy and theory; (3) NIST measurement system; (4) NIST operational procedures; (5) assessment of the measurement uncertainty including random and systematic errors and an error budget; and (6) internal quality control procedures used by NIST. These documents will present more detail than can be given in NIST calibration reports, or than is generally allowed in articles in scientific journals. In the past, NIST has published such information in a variety of ways. This series will make this type of information more readily available to the user.

This document, SP250-89 (2011), NIST Measurement Services: Spectral Irradiance Calibrations supersedes the NBS Special Publication 250-20 (1987). It describes the calibration of $1000 \mathrm{~W}$ tungsten quartz-halogen lamps over the wavelength region from $250 \mathrm{~nm}$ to $2400 \mathrm{~nm}$ (test numbers 39030C-39046C in SP250, NIST Calibration Services Users Guide). Inquiries concerning the technical content of this document or the specifications for these services should be directed to the author or to one of the technical contacts cited in SP250.

NIST welcomes suggestions on how publications such as this might be made more useful. Suggestions are also welcome concerning the need for new calibrations services, special tests, and measurement assurance programs.

James K. Olthoff

Deputy Director for Measurement Services

Physical Measurement Laboratory
Katharine B. Gebbie

Director

Physical Measurement Laboratory 


\begin{abstract}
This document describes the process of the realization, the maintenance and the dissemination of the spectral irradiance scale and its accompanying uncertainties at the National Institute of Standards and Technology. It describes the measurement procedures for the realization of the scale and the uncertainties of the detector-based spectral irradiance scale. During the realization process, the spectral irradiances are ultimately made Système International d'Unités (SI) traceable to the unit of electrical power through the electrical-substitution cryogenic radiometer and the unit of length through the aperture area and the distance measurements. This document also contains a representative calibration report and values for the NIST-disseminated spectral irradiance standards along with the irradiance calibration procedures manual.
\end{abstract}

KEY WORDS: spectral irradiance scale, calibration, cryogenic radiometer, filter radiometer, high-temperature blackbody, uncertainties, temperature, Planck radiance 


\section{TABLE OF CONTENTS}

ABSTRACT

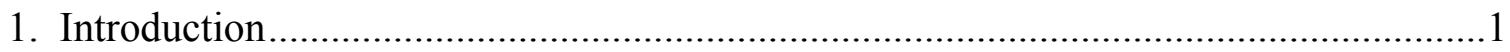

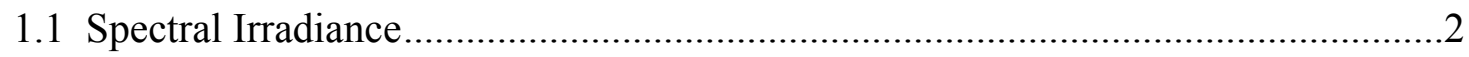

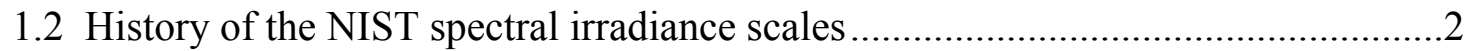

1.3 Description of current services in spectral irradiance calibrations ............................3

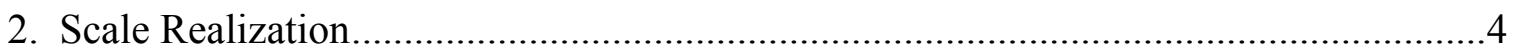

2.1 Measurement equation for temperature determination ..........................................

2.2 Description of the high-temperature blackbody (HTBB) .........................................6

2.3 Validation of the HTBB as a Planckian Radiator.................................................6

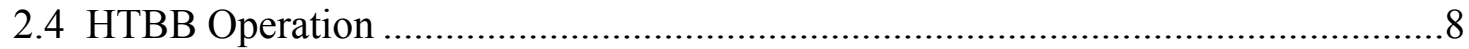

2.5 Spectral Irradiance Transfer to 1000 W FEL Lamps ...............................................

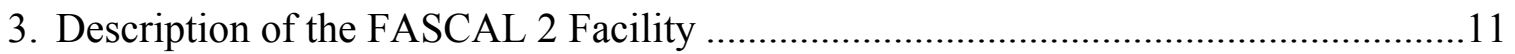

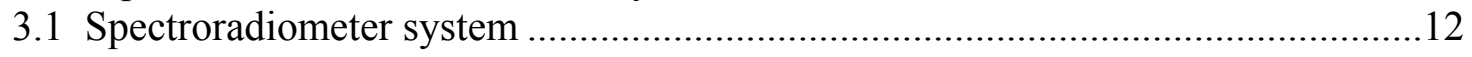

3.2 Performance Characterizations of the FASCAL 2 Facility ……………………......14

4. Uncertainty Analysis of the Spectral Irradiances Issued on FEL Lamps ......................18

4.1 Uncertainties of the HTBB detector-based temperatures ......................................18

4.2 Uncertainties of the spectral irradiance realization to primary working standards 18

4.3 Uncertainties of the issued spectral irradiance standards ....................................19

4.4 International comparisons to support the NIST assigned uncertainties ................20

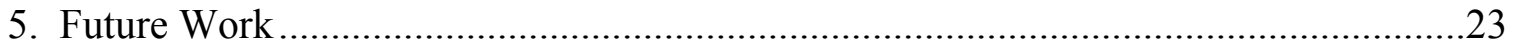

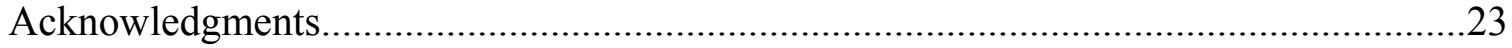

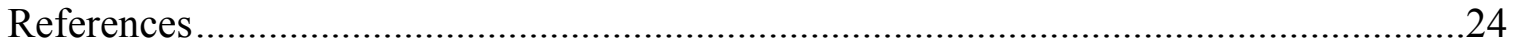

Appendix A: Lamp selection process.......................................... A1

Appendix B: Orientation dependence of the FEL lamp............................... B1

Appendix C: Physical alignment of the FEL lamp.................................... C1

Appendix D: Atmospheric absorption and FEL interpolations....................... D1

Appendix E: Sample calibration report............................................. 1

Appendix F: Irradiance calibration procedures manual............................... F1

Appendix G: Radiation constants.................................................

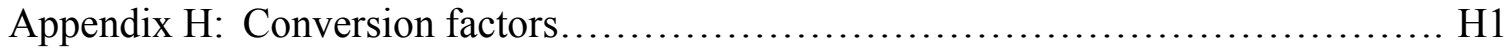

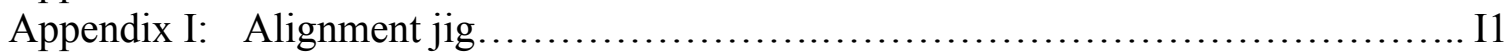

Appendix J: Kinematic lamp socket.............................................. J1

Appendix K: Calibration data points.............................................. K1

Appendix L: Calibration services.................................................. 


\section{LIST OF FIGURES}

Figure 1. The primary scale realization for the NIST spectral irradiance scale. The cryogenic radiometer calibrates the trap detectors for optical power by substitution with electrical power. The aperture areas and distances are traceable to length standards.................................................................... 4

Figure 2. The irradiance responsivities of the filter radiometers used in the realization as measured with the NIST detector-based scale realized from the electrical substitution cryogenic radiometer. The Planck radiance law at $3000 \mathrm{~K}$ is shown plotted on the right axis.

Figure 3. The comparison of spectral radiances found using the radiances determined from the VTBB with the radiances found using the detector-based filter radiometers for the measurements on indicated dates. The agreement within the expanded uncertainties of the comparisons indicates that the emissivity of the HTBB as well as the temperature assignment are within the combined

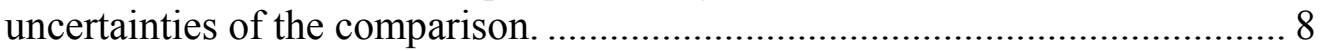

Figure 4. The time-dependent drift of the HTBB. The HTBB was monitored with optical feedback from the rear. Measurements are performed during a time duration of about $30 \mathrm{~min}$. The drift of the HTBB accounted by a component in the total uncertainty budget

Figure 5. The spectral irradiance of the HTBB at $2950 \mathrm{~K}$ with the measurement parameters as described with the spectral irradiances of a typical $1000 \mathrm{~W}$ FEL lamp. The measurement parameters for the HTBB were chosen to closely match the spectral irradiance of the lamp.

Figure 6. The optical layout showing the monochromator table with the positions of the input and the exit optics. A double monochromator in a Czerny-Turner design is used for dispersion and stray-light rejection.

Figure 7. The left axis denotes the percent differences from the mean of the spectral irradiances measured over a duration of $1 \mathrm{~h}$. A total of three consecutive measurements were performed with the individual measurements denoted by squares, triangles, and circles. The right axis indicates the typical spectral irradiance of a $1000 \mathrm{~W}$ FEL lamp. The spectral irradiances were measured using the PMT (open), the Si diode (solid), and the InGaAs diode (opencrossed).

Figure 8. The residuals of the linear fit to the wavelength calibrations performed using various low-pressure lamp sources for the wavelength region from $200 \mathrm{~nm}$ to $1000 \mathrm{~nm}$.

Figure 9. The residuals of the linear wavelength fit to the wavelength calibrated using various spectral line sources for the near IR wavelength region.

Figure 10. The expanded uncertainties of the PWS and the total uncertainties of the issued spectral irradiance standards with respect to SI units.

Figure 11. The percent differences from the mean of three separate, independent spectral irradiance scale realizations performed on four separate days. The differences are shown with the assigned expanded uncertainties of the working standards for the detector-based spectral irradiance scale. 


\section{LIST OF TABLES}

Table 1. The current spectral irradiance calibration tests offered. ................................. 3

Table 2. The specifications of the monochromator system and the detectors used to measure the spectral irradiances.................................................................. 13

Table 3. The order-sorting filters used in FASCAL 2 with the 6-position filter wheel placed at the entrance to the monochromator........................................... 14

Table 4. Uncertainty components for the HTBB temperature determination. At the HTBB temperature of $2950 \mathrm{~K}$, an irradiance response uncertainty of $0.26 \%$

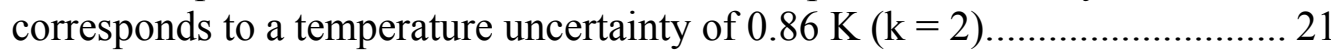

Table 5. Uncertainty budget for spectral irradiance calibrations using FASCAL $2 \ldots .22$ 


\section{Introduction}

This document supersedes the NBS Special Publication 250-20 (1987). In 2000, a new detector-based spectral irradiance scale was realized using a high-temperature blackbody in conjunction with absolute filter radiometers, traceable to the absolute cryogenic radiometer. The filter radiometers are used to determine the thermodynamic temperature of the blackbody. This new scale reduced the uncertainties in the disseminated spectral irradiances as compared to the gold fixed-point blackbody derived scale of 1990 and 1992. Beginning with the calendar year 2001, all NIST-disseminated spectral irradiance standards have been based upon the detector-based scale.

The development and the use of cryogenic radiometers have led the trend toward decreasing uncertainties in the radiometric and the photometric scales due to improvements in the absolute power measurements [1, 2]. Furthermore, detector-based scales can be often maintained with shorter measurement chains and lower uncertainties than source-based scales. For example, the photometric scale at NIST has been detectorbased and traceable to the NIST High-Accuracy Cryogenic Radiometer (HACR) since 1993 [3], and the implementation of the detector-based photometric scale resulted in a factor of two reduction in the expanded uncertainties compared to the previous, sourcebased photometric scale [4]. The establishment of the detector-based spectral irradiance scale is a part of a long-term effort in the Optical Technology Division aimed at reducing the realization chain and lowering the uncertainties in the issued standards.

This document describes the process of the realization, the maintenance and the dissemination of the spectral irradiance scale at the National Institute of Standards and Technology and its accompanying uncertainties. It describes the measurement procedures for the realization of the scale and the uncertainties of the detector-based spectral irradiance scale. During the realization process, the spectral irradiances are ultimately made Système International d'Unités (SI) [5] traceable to the units of electrical power through the electrical substitution cryogenic radiometer and the unit of length and the aperture area through the distance measurements. The uncertainties described in this document have been analyzed according to the ISO Guide to the Expression of Uncertainty in Measurement [6]. The appendix contains a representative calibration report and values for the NIST-disseminated spectral irradiance standards. It also describes the proper handling and alignment of the standards to minimize the transfer uncertainties. The process of lamp selection prior to calibrations is described, and the prior knowledge about the long-term stability of the lamps results in minimization of redundant measurements [7]. 


\subsection{Spectral Irradiance}

Spectral irradiance is the measure of the optical power, $\Phi$, incident on an area, $d A$, per unit wavelength, $d \lambda$, and is denoted by

$$
E_{\lambda}=\frac{d^{2} \Phi}{d A \cdot d \lambda} .
$$

A commonly used unit to denote spectral irradiance is microwatts per square centimeter area per nanometer wavelength or $\mu \mathrm{W} \mathrm{cm} \mathrm{nm}^{-1}$.

The spectral irradiance source standards calibrated at NIST are used in turn to calibrate spectroradiometers which measure the spectral power incident on an area at a set distance from the source. For example, the NIST issued spectral irradiance standards are used to determine the solar terrestrial spectral irradiance, especially in the ultraviolet wavelength region, to provide data on climate change and health of ecosystems [8]. These standards are also used to determine the spectral irradiances of various sources such as lamps and light emitting diodes, and also to determine the color temperature of sources [9]. Photometric source scales such as the lumen can be also be derived from spectral irradiance sources. The spectral irradiance sources could also be used in conjunction with spectral reflectance standards to generate spectral radiance [10]. Many national measurement institutes also use NIST spectral irradiance standards as the basis in generating their own national spectroradiometric and photometric scales.

\subsection{History of the NIST spectral irradiance scales}

Due to the central role of spectral irradiance source standards in many radiometric and photometric calibrations, NIST has long provided these standards. The earliest NIST-calibrated sources were total irradiance standards issued in 1913 by Coblentz who calibrated them by comparison to blackbodies [11]. Much later in 1963, the first spectral irradiance standards were issued using a $200 \mathrm{~W}$ quartz-iodine lamp with a coiled-coil tungsten filament [12]. It was soon recognized that a source with greater radiation was needed to calibrate sources such as the sun, and in 1967, $1000 \mathrm{~W}$ lamps were first issued [13]. Due to the difficulties in scaling up the irradiances to the level of the $1000 \mathrm{~W}$ lamps, the realization of the scales to Système International d'Unités (SI) was performed infrequently. A new scale was realized 1973 [14], and the first Consultative Committee on Photometry and Radiometry (CCPR) comparison performed in 1976 [15]. The next CCPR comparison was piloted by NIST in 1990 coincident with a new realization of the scale [16]. In recognition of the difficulties in realizing a scale from the gold-point blackbody near $1337 \mathrm{~K}$ to calibrate a source with distribution temperature of $3200 \mathrm{~K}$, work was performed to realize the scale using a high-temperature blackbody with detector-based thermodynamic temperature in 2000 [17]. The NIST detector-based spectral irradiance was used in the CCPR K1-a key comparison [18] of spectral irradiance from $250 \mathrm{~nm}$ to $2500 \mathrm{~nm}$, and the detector-based spectral irradiance scale was realized again in 2003. A new facility, the Facility for Automated Spectroradiometric Calibrations 2 (FASCAL 2), was developed in 2001 to reduce the transfer and realization uncertainties and to meet the increased demand for these standards. This document describes the process of realization of the NIST spectral irradiance scale from the SI units and the procedure for the derivation of the spectral irradiance from those units. 


\subsection{Description of current services in spectral irradiance calibrations}

The current calibration services according to the test numbers and the descriptions of the tests are listed in Table 1. The tests are grouped according to the needs of the users such as the ultraviolet community for measurements from $250 \mathrm{~nm}$ to $450 \mathrm{~nm}$, the photometric community for the wavelength region from $350 \mathrm{~nm}$ to $800 \mathrm{~nm}$, and the selected short-wave infrared region along with the full wavelength region from $250 \mathrm{~nm}$ to $1600 \mathrm{~nm}$ or from $250 \mathrm{~nm}$ to $2400 \mathrm{~nm}$. Since many NIST customers also have longstanding history of usage of the same lamp, recalibrations are grouped differently from the issuing of newly calibrated lamps. Such breakdowns of the calibrations into categories are in response to customers request for reducing calibration costs and turnaround times for the calibrations.

Table 1. The current spectral irradiance calibration tests offered.

\begin{tabular}{|c|c|}
\hline Test Number & Description \\
\hline $39030 \mathrm{C}$ & $\begin{array}{l}\text { Spectral Irradiance Standard, } 1000 \mathrm{~W} \text { Tungsten Quartz-Halogen } \\
\text { Lamp (250 nm to } 450 \mathrm{~nm})\end{array}$ \\
\hline $39031 \mathrm{C}$ & $\begin{array}{l}\text { Recalibration of } 1000 \mathrm{~W} \text { Tungsten Quartz-Halogen Lamp } \\
\qquad(250 \mathrm{~nm} \text { to } 450 \mathrm{~nm})\end{array}$ \\
\hline $39032 \mathrm{C}$ & $\begin{array}{l}\text { Spectral Irradiance Standard, } 1000 \mathrm{~W} \text { Tungsten Quartz-Halogen } \\
\text { Lamp ( } 350 \mathrm{~nm} \text { to } 800 \mathrm{~nm})\end{array}$ \\
\hline $39033 \mathrm{C}$ & $\begin{array}{l}\text { Recalibration of } 1000 \mathrm{~W} \text { Tungsten Quartz-Halogen Lamp } \\
\qquad(350 \mathrm{~nm} \text { to } 800 \mathrm{~nm})\end{array}$ \\
\hline $39040 \mathrm{C}$ & $\begin{array}{l}\text { Spectral Irradiance Standard, } 1000 \mathrm{~W} \text { Tungsten Quartz-Halogen } \\
\text { Lamp (250 nm to } 1600 \mathrm{~nm})\end{array}$ \\
\hline $39041 \mathrm{C}$ & $\begin{array}{l}\text { Recalibration of } 1000 \mathrm{~W} \text { Tungsten Quartz-Halogen Lamp } \\
\qquad(250 \mathrm{~nm} \text { to } 1600 \mathrm{~nm})\end{array}$ \\
\hline $39045 \mathrm{C}$ & $\begin{array}{l}\text { Spectral Irradiance Standard, } 1000 \mathrm{~W} \text { Tungsten Quartz-Halogen } \\
\text { Lamp (250 nm to } 2400 \mathrm{~nm})\end{array}$ \\
\hline $39046 \mathrm{C}$ & $\begin{array}{l}\text { Recalibration of } 1000 \mathrm{~W} \text { Tungsten Quartz-Halogen Lamp } \\
\qquad(250 \mathrm{~nm} \text { to } 2400 \mathrm{~nm})\end{array}$ \\
\hline
\end{tabular}




\section{Scale Realization}

At the National Institute of Standards and Technology, the spectral irradiance scale is realized using a detector-based scale. The NIST spectral irradiance scale is realized using filter radiometers (FR) calibrated for absolute, spectral power responsivity traceable to the NIST cryogenic radiometer. The cryogenic radiometer measures the optical power by the substitution of electrical power for comparison [19]. Thus the measured optical power is traceable to electrical power. The aperture areas which are needed for conversion of radiant power to irradiance are measured using interferometric techniques [20]. The calibrated FRs are then used to determine the radiance temperature of a high-temperature blackbody (HTBB) operating near $3000 \mathrm{~K}$. The spectral irradiance of the HTBB is determined using the knowledge of the geometric factors and Planck radiance law and then is used to assign the spectral irradiances of a group of $1000 \mathrm{~W}$ FEL lamps. Thus the NIST spectral irradiance scale is ultimately traceable to the electrical power and the unit of length. The procedure for the realization is shown in Fig. 1.

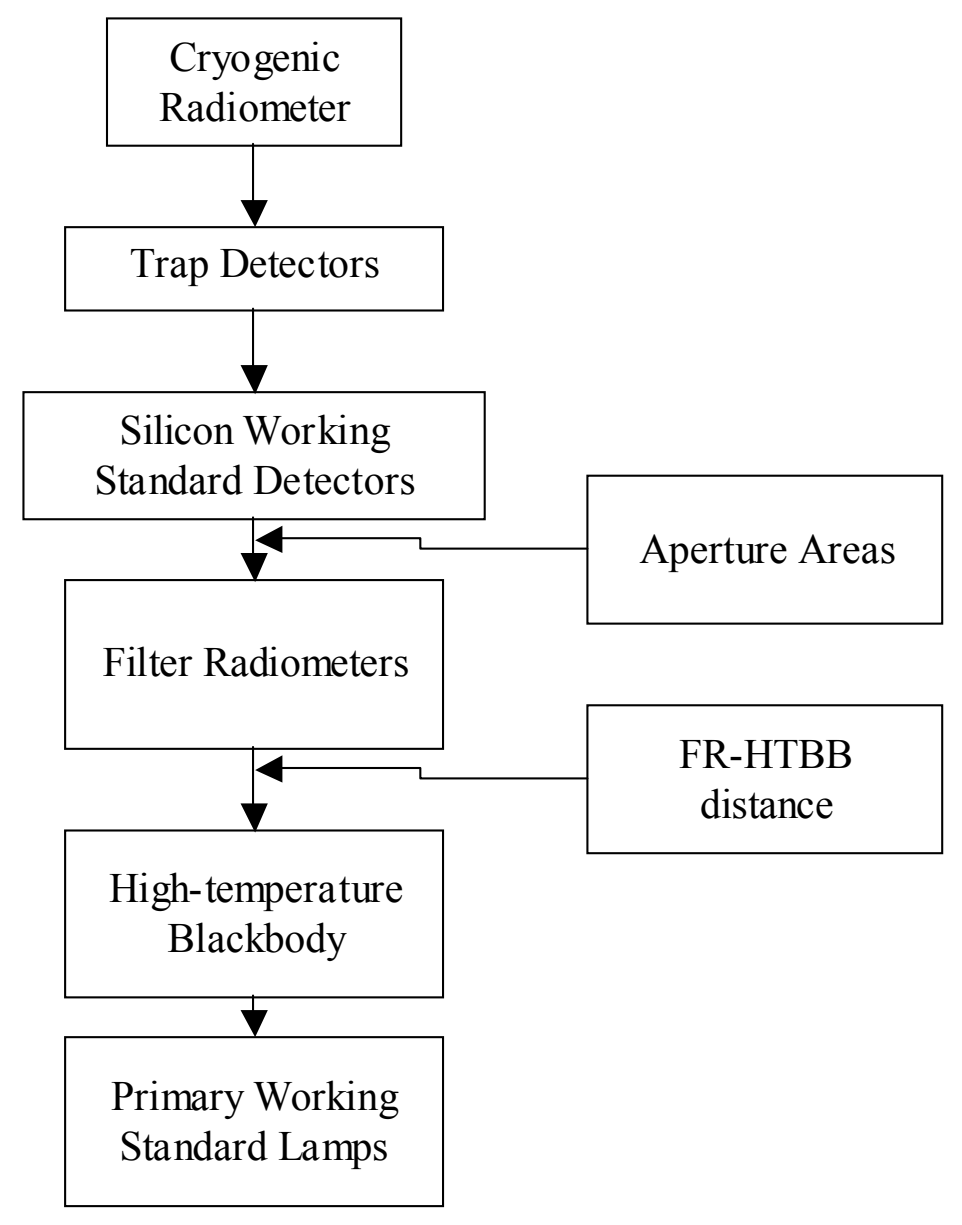

Figure 1. The primary scale realization for the NIST spectral irradiance scale. The cryogenic radiometer calibrates the trap detectors for optical power by substitution with electrical power. The aperture areas and distances are traceable to length standards. 


\subsection{Measurement equation for temperature determination}

The radiance temperature of the high-temperature blackbody is found using a measurement equation, which describes the optical flux transfer with circular and coaxial source and receiver apertures [21]. For a filter radiometer, the signal $S$ is given by,

$$
S=\frac{G \pi r_{\mathrm{BB}}^{2} \pi r^{2}(1+\delta)}{D^{2}} \varepsilon \int R(\lambda) L(\lambda, T) d \lambda,
$$

where $\varepsilon$ is the emissivity, $R$ is absolute spectral power responsivity. The geometric factors $D$ and $\delta$, are given by $D^{2}=d^{2}+r^{2}+r_{\mathrm{BB}}{ }^{2}$ and $\delta=r^{2} r_{\mathrm{BB}}{ }^{2} / D^{4}$, where $r_{\mathrm{BB}}$ and $r$ are the radii of the blackbody aperture and the filter radiometer apertures, respectively, and $d$ is distance between the filter radiometer aperture and the blackbody aperture. $G$ is the preamplifier gain, and $L$ is the spectral radiance found using the Planck radiation law. The spectral power responsivity of the filter radiometers are measured in the NIST Spectral Comparator Facility ${ }^{22}$. The radiance temperatures are found by iteratively changing the blackbody temperature in Eq. 2 until an exact match of the calculated signal to the measured signal is found. The irradiance responsivities of the FRs used for the realization are shown in Fig. 2 along with the Planck radiance at $3000 \mathrm{~K}$.

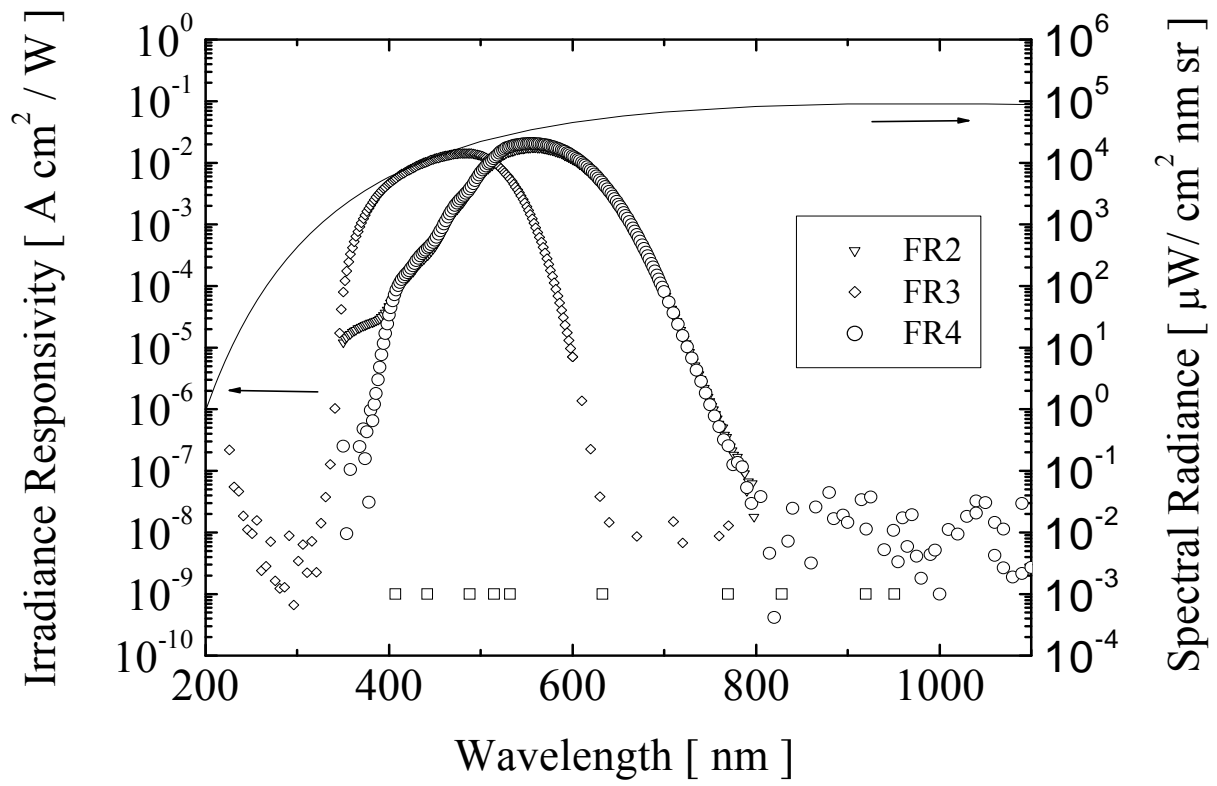

Figure 2. The irradiance responsivities of the filter radiometers used in the realization as measured with the NIST detector-based scale realized from the electrical substitution cryogenic radiometer. The Planck radiance law at $3000 \mathrm{~K}$ is shown plotted on the right axis.

The uncertainties of the radiance temperatures found using the filter radiometers are primarily determined by the uncertainties in the spectral power responsivity. The lowest uncertainties are maintained in the visible wavelength region from $400 \mathrm{~nm}$ to 900 
$\mathrm{nm}$ where the spectral power responsivity of the Si-trap transfer detector can be smoothly interpolated between the discrete laser calibration wavelengths of the cryogenic radiometer. The uncertainties of the spectral power responsivity can be directly converted to uncertainties in temperature using the derivative of the Wien approximation with respect to temperature,

$$
\frac{\Delta L}{L}=\frac{c_{2}}{\lambda} \frac{\Delta T}{T^{2}}
$$

where the relationship between the uncertainty in radiance, $L$, to the uncertainty in blackbody temperature, $T$, and $\mathrm{c}_{2}$ is the second Planck's constant, $1.4387752 \mathrm{~cm} \mathrm{~K}$, and $\lambda$ is the wavelength. The Wien approximation is used to simplify the handling of equations. Under these experimental conditions, no appreciable differences exist between Eq. 3 and the similar differential equation found using the Planck's radiance law in the wavelength between $250 \mathrm{~nm}$ and $2400 \mathrm{~nm}$. Due to the changes in the shape of the blackbody radiance with temperature as described in the Planck radiance law, the temperature uncertainties are both dependent on temperature as well as wavelength.

\subsection{Description of the high-temperature blackbody (HTBB)}

One of the technological advances which makes possible the realization of the detector-based spectral irradiance scale is the development of pyrolytic-graphite blackbodies, enabling extended operations near $3000 \mathrm{~K}$ without rapid degradation of the cavity [23]. The high-temperature blackbody used in this work consists of pyrolyticgraphite rings with an inner diameter of $24 \mathrm{~mm}$ stacked to form a cavity with a depth of $14.5 \mathrm{~cm}$. The cavity bottom consists of an inverted cone with an apex angle of about $150^{\circ}$, and the radiance at the backside of the cavity bottom is imaged through an opening at the rear of the cavity using a fused-silica lens onto a temperature-stabilized photometer for operation in closed-loop configuration. The lens also serves to seal the rear of the blackbody cavity to atmosphere. The current of the HTBB power supply is adjusted using a control loop to maintain a constant output from the photometer. Although the spectral irradiance in the ultraviolet wavelength region could be increased with higher temperatures, the HTBB was operated at near $2950 \mathrm{~K}$ to avoid possible changes in the spectral emissivity of the blackbody due to the sublimation of the graphite [24]. Since the graphite rings expand about $10 \%$ from room temperature to near $3000 \mathrm{~K}$, the current was increased at $0.1 \mathrm{~A} / \mathrm{s}$ to nearly $510 \mathrm{~A}$ at $2950 \mathrm{~K}$ to allow gradual expansion of the cavity. The HTBB was also turned off in a similar manner to avoid thermo-physical shocks.

\subsection{Validation of the HTBB as a Planckian Radiator}

To determine the spectral emissivity of the HTBB, the spectral radiance of the HTBB was measured from $250 \mathrm{~nm}$ to $2400 \mathrm{~nm}$ at discrete wavelengths by comparison to a variable-temperature blackbody (VTBB) with a high emissivity. The VTBB is a NIST-designed blackbody with an internal diameter of $11 \mathrm{~mm}$ with an opening of $2 \mathrm{~mm}$ diameter to result in an estimated emissivity $>0.999$ [25]. The Any temperature nonuniformity of the cavity would lead to deviations of the HTBB spectral radiance from a single-temperature Planck radiance. For these comparisons, the temperature of the 
VTBB was set at $2687 \mathrm{~K}$ and the temperature of the HTBB was set at $2950 \mathrm{~K}$. Although the temperatures are different, the radiance ratios did not differ even at $250 \mathrm{~nm}$, where the differences are greatest, by more than a factor of seven. Furthermore, prior to these measurements, the linearity of the spectroradiometer has been measured at various wavelengths using the portable Beamconjoiner [26] and found to be linear under these experimental conditions. The spectral radiance determinations were performed before and after spectral irradiance transfer to a set of $1000 \mathrm{~W}$ FEL lamps. The checks of the HTBB as a Planckian radiator were performed to verify that the HTBB did not change in the spectral distribution since the FR's are used to measure over a relatively broad spectral region.

The spectral radiance measurements of the HTBB were performed with the aperture in front of the spherical input mirror to the spectroradiometer reduced to $4 \mathrm{~cm}$ diameter resulting in F/25 focused at the opening of the HTBB at the plane of the watercooled aperture. The reduction in the opening of the spherical input mirror resulted in a circular target of $12 \mathrm{~mm}$ diameter at the bottom of the HTBB cavity. To keep the same target area constant for the measurements, in both the spectral irradiance and the spectral radiance modes the HTBB was mounted on a motorized translation stage for control of the distance between the HTBB and the measuring instruments. If possible, the same area at the rear of the HTBB should be viewed for all measurements to avoid errors from the possible spatial non-uniformity of the HTBB.

The temperature of the variable-temperature blackbody was determined using spectral radiance ratios at $655 \mathrm{~nm}$ to a vacuum tungsten-filament lamp maintained at the freezing-temperature of gold as prescribed in the ITS-90. The spectral radiance of the HTBB was determined at discrete wavelengths by comparison to the VTBB and also determined from the radiance temperature found using the filter radiometers. The radiance temperatures of the HTBB found using the filter radiometers were in agreement with those found using the ITS-90 ratios to within $0.5 \mathrm{~K}$ at all instances such comparisons were performed. The respective blackbodies were compared using spectral radiance ratios,

$$
L_{\lambda, H T B B}=L_{\lambda, V T B B} f_{\lambda} \frac{S_{\lambda, H T B B}}{S_{\lambda, V T B B}} .
$$

The $L_{\lambda}$ and the $S_{\lambda}$ denote the spectral radiance and the measured spectral radiance response of the $\mathrm{HTBB}$ and the $\mathrm{VTBB}$, and $f_{\lambda}$ is the possible linearity correction to the response ratios. The spectral radiances of the HTBB were found to conform to a single temperature Planck radiance law to within the combined uncertainties of the measurements as shown in Fig. 3. Figure 3 shows the percent differences from a single temperature Planck radiance law with the temperature of the HTBB determined using the FR's and the spectral radiances determined using the VTBB. The errors bars on the individual comparisons correspond to the expanded uncertainty of $0.86 \mathrm{~K}$ at $2943.4 \mathrm{~K}$ converted to a spectral radiance uncertainty using the derivative of the Wien approximation from Eq. 2. As expected for comparison of two blackbodies, the differences in the spectral radiance becomes smaller with increasing wavelength, but there are no discernible increasing spectral differences toward the shorter wavelengths, as would be expected if either of the temperature assignments of the respective blackbodies were in error. The differences between the detector-based radiance temperatures and the 
source-based determinations also agree with the previous measurements, which also showed differences of $<0.5 \%$ from $250 \mathrm{~nm}$ to $1000 \mathrm{~nm}$ [27].

The spectral radiances from the VTBB are determined using Planck radiance law from the assigned radiance temperatures at $655.3 \mathrm{~nm}$ and the estimated VTBB emissivity [28]. The emissivity is estimated using calculations from the partial reflectivity and the solid angle opening of the VTBB and experimental determinations with changing the solid angle of the opening. The spectral radiances of the HTBB are in turn assigned using the VTBB from the respective signals, $i$, and the gains, $G$,

$$
L_{\mathrm{HTBB}, \mathrm{VTBB}}=\frac{G_{\mathrm{HTBB}} \cdot i_{\mathrm{HTBB}}}{G_{\mathrm{VTBB}} \cdot i_{\mathrm{VTBB}}} L_{\mathrm{VTBB}} .
$$

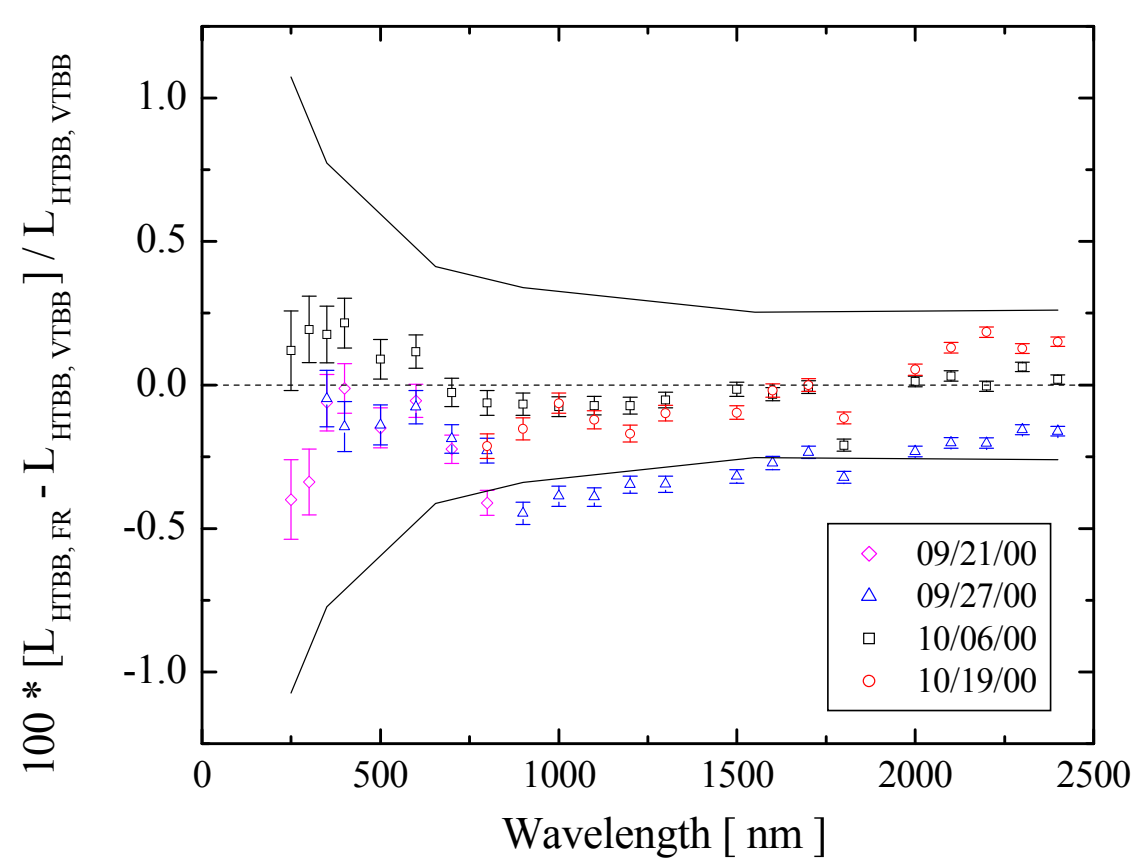

Figure 3. The comparison of spectral radiances found using the radiances determined from the VTBB with the radiances found using the detector-based filter radiometers for the measurements on indicated dates. The agreement within the expanded uncertainties of the comparisons indicates that the emissivity of the $\mathrm{HTBB}$ as well as the temperature assignment are within the combined uncertainties of the comparison.

\subsection{HTBB Operation}

The measurements of the HTBB temperatures are performed with the filter radiometers placed on a motorized table for individual alignment along the optical axis of the HTBB. A water-cooled precision aperture is placed in front of the HTBB, and the distance from this aperture to the filter radiometer aperture is measured using a micrometer. The current to the HTBB is controlled by a servo loop, and an optical detector monitors the rear of the cavity. The radiance temperature measurements over a time period of $4 \mathrm{~h}$ are plotted in Fig. 4. A determination of the spectral radiance of the 
HTBB can be performed in about $30 \mathrm{~min}$, and the temperature of the HTBB is stable during these measurements. For clarity only the temperatures measured using FR4 are plotted with the $0.21 \mathrm{~K}(k=2)$ uncertainties. The temperature determinations using the three FRs are in agreement within their combined uncertainties.

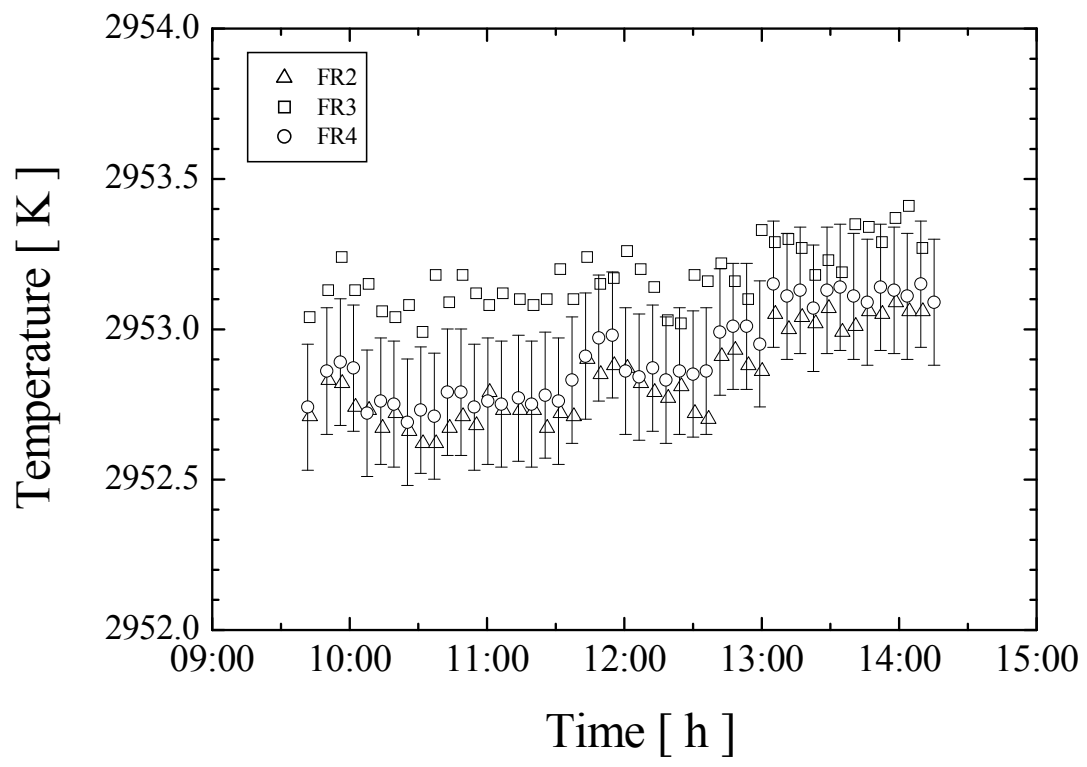

Figure 4. The time-dependent drift of the HTBB. The HTBB was monitored with optical feedback from the rear. Measurements are performed during a time duration of about 30 min. The drift of the HTBB accounted by a component in the total uncertainty budget.

\subsection{Spectral Irradiance Transfer to 1000 W FEL Lamps}

The spectral irradiance assignment of twelve $1000 \mathrm{~W}$ FEL working standard lamps occurred over a two week period from September 28 to October 12, 2000. The spectral irradiances of a group of three lamps were assigned at one time, and the measurements were separated into the ultraviolet and the visible wavelength region, $250 \mathrm{~nm}$ to $900 \mathrm{~nm}$, and the short-wave infrared region, $800 \mathrm{~nm}$ to $2400 \mathrm{~nm}$. Since there are four separate FEL lamp measurement stations, each of the measurements of individual lamp was performed in a different station using different shunt resistors, power supplies, and lamp mounts. Each of the lamp stations were checked for possible position effects, and no perceptible effects due to station-to-station variations were found.

The HTBB was turned on at least $2 \mathrm{~h}$ before use, and temperature-stabilized using the optical feedback. The temperature of the HTBB was assigned using the FR's and the spectral irradiance responsivity of the spectroradiometer assigned using the known spectral irradiance of the HTBB. All the spectral irradiance responsivity transfers to the spectroradiometer were done at a distance of $43.406 \mathrm{~cm}( \pm 0.005 \mathrm{~cm})$ from the HTBB aperture to the $1 \mathrm{~cm}^{2}$ area aperture of the integrating sphere receiver (ISR) resulting in a $24.7 \mathrm{~mm}$ diameter circular target area at the cavity bottom. The spectral irradiance 
responsivity of the spectroradiometer is assigned using the known spectral irradiance of the HTBB at the input aperture of the ISR,

$$
E_{\lambda, H T B B}=\frac{L(\lambda, T) \pi r_{\mathrm{BB}}^{2}}{D^{2}},
$$

with the measurement parameters as defined in Eq. 2.

After the spectral irradiance responsivity assignment of the spectroradiometer, the spectral irradiance of a group of three FEL lamps were assigned with each lamp measured in three separate source positions. The spectral irradiance of each lamp was assigned using,

$$
E_{\lambda, F E L}=E_{\lambda, H T B B} f_{\lambda} \frac{S_{\lambda, F E L}}{S_{\lambda, H T B B}},
$$

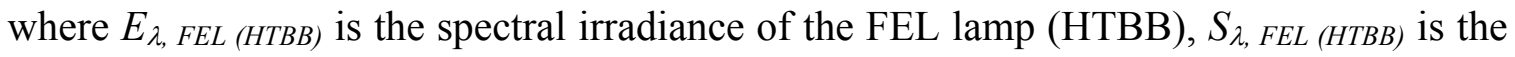
net signal from the FEL lamp (HTBB) measured using the spectroradiometer, and $f_{\lambda}$ is the linearity correction factor for the comparison. With the use of a shutter, the background signals were subtracted from the total signals to obtain the net signals. The distance of the HTBB from the ISR was also chosen such that the same gain factors could be used to measure both the FEL and the HTBB. Figure 5 is a plot of the calculated spectral irradiances of the HTBB at $2950 \mathrm{~K}$ plotted with the spectral irradiances of a typical $1000 \mathrm{~W}$ FEL lamp with the blackbody source aperture of $9.9933 \mathrm{~mm}( \pm 0.0002$ $\mathrm{mm})$ diameter and the ISR receiving aperture of $11.2838 \mathrm{~mm}( \pm 0.0002 \mathrm{~mm})$ in diameter separated by a distance of $43.406 \mathrm{~cm}( \pm 0.005 \mathrm{~cm})$. At all wavelengths, Fig. 5 shows that the HTBB has a greater spectral irradiance than the FEL lamp. Although the spectral irradiance changes by a factor $>10^{3}$ from $250 \mathrm{~nm}$ to $2400 \mathrm{~nm}$, the HTBB/FEL signal ratio does not exceed 2.5. The close match of the irradiances was chosen to minimize possible errors resulting from signal-to-noise, non-linearity, and stray-light effects. 


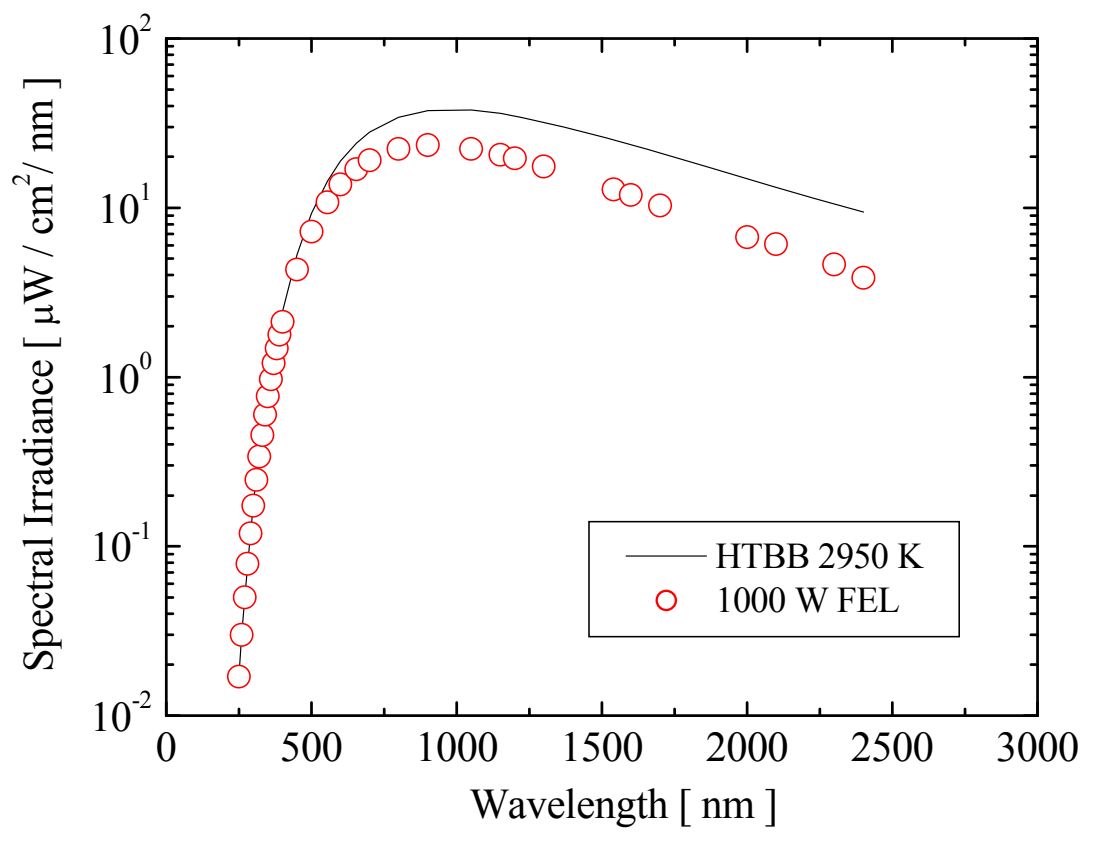

Figure 5. The spectral irradiance of the HTBB at $2950 \mathrm{~K}$ with the measurement parameters as described with the spectral irradiances of a typical $1000 \mathrm{~W}$ FEL lamp. The measurement parameters for the HTBB were chosen to closely match the spectral irradiance of the lamp.

\section{Description of the FASCAL 2 Facility}

Figure 6 shows the physical layout of the FASCAL 2 facility. The sources and the rails for moving the spectroradiometer system are placed on a single $4.23 \mathrm{~m}$ by 1.52 $\mathrm{m}$ fixed optical table, and the spectroradiometer is placed on a smaller, $1.52 \mathrm{~m}$ by $0.91 \mathrm{~m}$ moveable optical breadboard for translation between the separate sources. The optical breadboard is placed on linear rails, and the movement is controlled by a ball screw driven by a DC servo motor with feedback control. The total range of movement is 3.5 $\mathrm{m}$, and the linear position of the spectroradiometer table is measured using a $4 \mathrm{~m} \mathrm{long}$, linear encoder; the linear position of the spectroradiometer is reproducible to $2.5 \mu \mathrm{m}$. The facility has four separate lamp mounts to calibrate the NIST disseminated spectral irradiance sources, FEL lamps, which are placed in kinematic lamp mounts with 6-axes of adjustments for alignment. The electrical power to the lamps is controlled using a calibrated shunt resistor with a temperature coefficient of resistance of $3 \mathrm{ppm} / \mathrm{C}^{\circ}$, and the lamp current is actively controlled using 16 bit current regulation. The lamp voltages

are also recorded. The last station holds the high-temperature blackbody (HTBB) capable of extended operations near $3000 \mathrm{~K}$. The temperature of the HTBB is detectorbased and assigned using filter radiometers calibrated for absolute spectral irradiance responsivity for the realization of the spectral irradiance scale. 


\subsection{Spectroradiometer system}

The spectroradiometer system is also shown in detail in Fig. 6. The spectral irradiances of the sources are measured using an integrating sphere receiver (ISR) with a circular opening with $1 \mathrm{~cm}^{2}$ aperture area. The ISR is a $2.54 \mathrm{~cm}$ diameter packed polytetrafluoroethylene (PTFE) sphere for high transmittance throughout the spectral range of measurements. A $2 \mathrm{~mm}$ by $10 \mathrm{~mm}$ opening is made at the side of the ISR and imaged 1:1 using a $30.48 \mathrm{~cm}$ focal length spherical mirror. A flat folding mirror is used to couple the light into the monochromator. An additive-dispersive double monochromator (McPherson 2035D*) with dual gratings placed in motorized grating turrets is used, and a combination of 5 different filters are used for second-order rejection from the grating and for further stray-light rejection. The entrance and the exit slits of the monochromator are $2 \mathrm{~mm}$ wide and $10 \mathrm{~mm}$ high and unchanged during the course of the measurements. The width of the intermediate slit is opened to $4 \mathrm{~mm}$ with the height kept the same as the entrance and exit slits. The monochromator is a Czerny-Turner design with a focal length of $0.35 \mathrm{~m}$ and an effective aperture of $\mathrm{F} / 4.8$. The angular change of the grating is achieved using a sine-bar mechanism and driven with a DC servo motor with an absolute encoder with $2^{14}$ or 16,384 pulses per revolution attached to the shaft of the sine-bar mechanism for wavelength measurements. The temperatures of the monochromators are also monitored using platinum resistance thermometers, and recorded during the spectral irradiance measurements. To avoid errors in the wavelength arising from thermal changes in the monochromator, the monochromator section is temperature stabilized using forced air from TE coolers set to the ambient temperature of the laboratory prior to turning on the FEL lamps. To avoid stray light, the entire monochromator system including the input optics and the detectors are covered using a light-tight box.

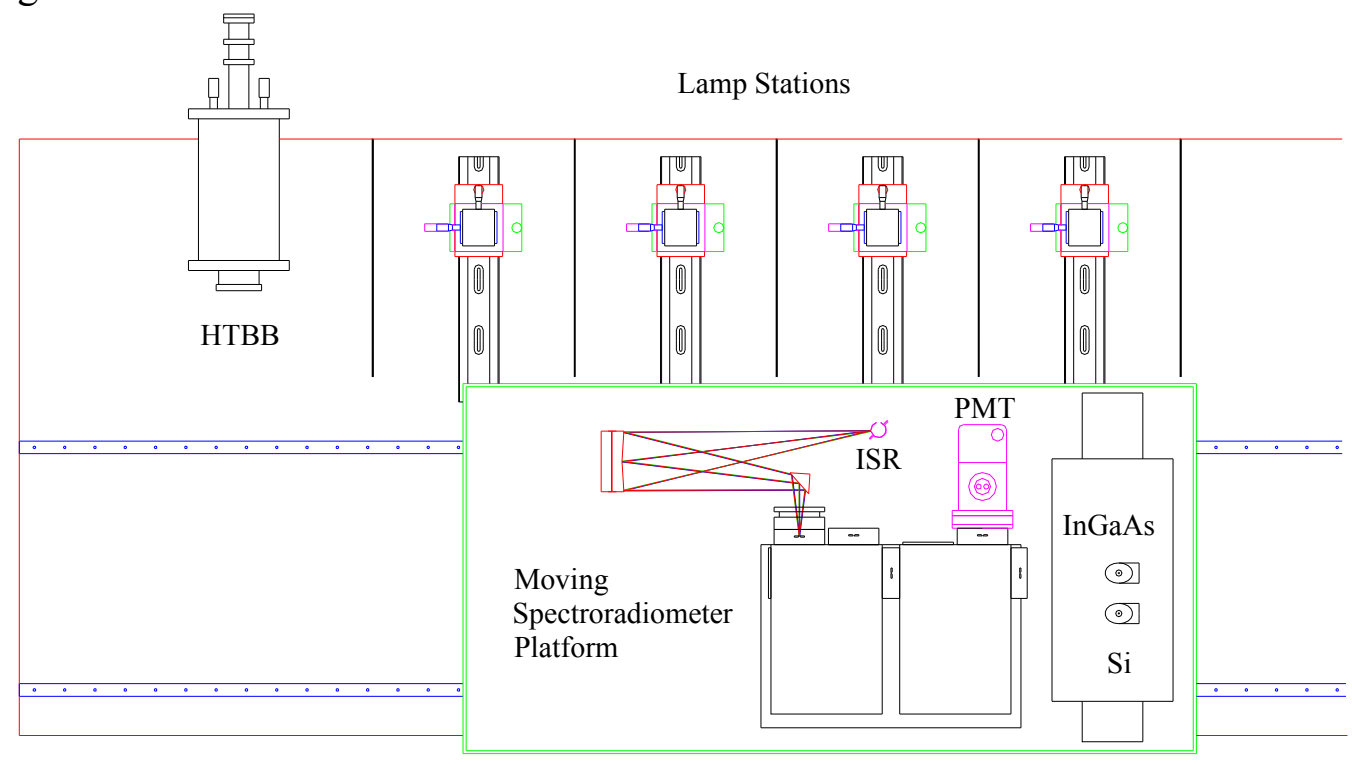


Figure 6. The optical layout showing the monochromator table with the positions of the input and the exit optics. A double monochromator in a Czerny-Turner design is used for dispersion and stray-light rejection.

Three separate detectors with two gratings and spectral selection filters are used for spectral coverage from $200 \mathrm{~nm}$ to $2500 \mathrm{~nm}$. The spectral range of the gratings and the detectors are shown in Table 1, and although the blaze wavelength is outside the range of the Si diode wavelength region, the throughput of the monochromator is adequate. For measurements in the ultraviolet wavelength region, a Hamamatsu R106 low-noise bialkali side-on photomultiplier tube (PMT) is used. The bi-alkali PMT is chosen for low

Table 2. The specifications of the monochromator system and the detectors used to measure the spectral irradiances.

\begin{tabular}{|c|c|c|c|c|c|c|c|}
\hline $\begin{array}{c}\text { Beginning } \\
\text { Wavelength } \\
\text { [ nm ] }\end{array}$ & $\begin{array}{c}\text { End } \\
\text { Wavelength } \\
\text { [ nm ] }\end{array}$ & $\begin{array}{c}\text { Grating } \\
\text { [g/mm] }\end{array}$ & $\begin{array}{c}\text { Grating } \\
\text { Blaze } \\
{[\mathbf{~ n m}]}\end{array}$ & $\begin{array}{c}\text { Dispersion } \\
{[\mathbf{~ n m} / \mathbf{m m}]}\end{array}$ & $\begin{array}{c}\text { Bandwidth } \\
\text { [ nm ] }\end{array}$ & $\begin{array}{c}\text { Type of } \\
\text { Detector }\end{array}$ & $\begin{array}{c}\text { Mode of } \\
\text { Operation }\end{array}$ \\
\hline $200 \mathrm{~nm}$ & $450 \mathrm{~nm}$ & 1200 & 300 & 2 & 4 & $\begin{array}{c}\text { Bi-alkali } \\
\text { PMT }\end{array}$ & DC \\
\hline $350 \mathrm{~nm}$ & $1100 \mathrm{~nm}$ & 1200 & 300 & 2 & 4 & $\begin{array}{c}\text { TE-cooled } \\
\text { Si diode }\end{array}$ & DC \\
\hline $900 \mathrm{~nm}$ & $2500 \mathrm{~nm}$ & 600 & 1250 & 4 & 8 & $\begin{array}{c}\text { TE-cooled } \\
\text { Extended- } \\
\text { InGaAs } \\
\text { diode }\end{array}$ & AC \\
\hline
\end{tabular}

temporal drift and low dark currents. The temperature of the PMT is stabilized to $-26{ }^{\circ} \mathrm{C}$ using a temperature-feedback controller, and the PMT is attached to the output port of the monochromator. A fused silica lens is attached to the PMT housing and focuses the image of the output slit onto the PMT with 2:1 de-magnification factor. Detectors are selected by the use of a motorized $45^{\circ}$ mirror, internal to the monochromator. The 2.4 $\mathrm{mm}$ by $2.4 \mathrm{~mm}$ square silicon ( $\mathrm{Si}$ ) photodiode is temperature stabilized and cooled to $25^{\circ} \mathrm{C}$ for low-noise operation. The $2 \mathrm{~mm}$ diameter indium gallium arsenide (InGaAs) photodiode is cooled to $-80^{\circ} \mathrm{C}$ using 4-stage TE coolers, and the InGaAs diode is selected for extended responsivity to $2500 \mathrm{~nm}$. For the extended wavelength of measurements, order-sorting filters are critical to reduce the second-order radiation generated by the gratings when measuring a broad-band source. Table 3 lists the ordersorting filters used with the filter types and the specifications along with the operational wavelengths listed. For the ultraviolet wavelength region from $250 \mathrm{~nm}$ to $400 \mathrm{~nm}$, ordersorting filters are not used. 
Table 3. The order-sorting filters used in FASCAL 2 with the 6-position filter wheel placed at the entrance to the monochromator.

\begin{tabular}{|c|c|c|c|c|c|}
\hline & & \multicolumn{2}{|c|}{ Filter Specification [nm ] } & \multicolumn{2}{c|}{ Operation Wavelengths [nm ] } \\
\hline Filter wheel position & Filter Type & Beginning $(\mathrm{t}=0.7)$ & End $(\mathrm{t}=0.7)$ & Begin & End \\
\hline 1 & BG-24 & 250 & 425 & 250 & 400 \\
\hline 2 & BG-40 & 370 & 570 & 450 & 550 \\
\hline 3 & OG-550 & 560 & $>2500$ & 600 & 1000 \\
\hline 4 & RG-850 & 860 & $>2500$ & 1050 & 1540 \\
\hline 5 & LP-1500 & 1540 & $>2500$ & 1600 & 2500 \\
\hline 6 & empty & & & 250 & 400 \\
\hline
\end{tabular}

The output of the monochromator is coupled to the Si and the InGaAs diodes using $\mathrm{Al}$ and gold-coated off-axis ellipsoid mirrors, respectively, with 5:1 de-magnification of the exit slit. Both the Si diode and the PMT are used in DC-current measurement mode, and the InGaAs detector is used with a frequency-stabilized chopper wheel (not shown) and phase-sensitive detection techniques for better signal-to-noise ratios in the shortwave infrared wavelength region. The $\mathrm{Si}$ and the InGaAs photodiodes are placed on a computer-controlled translation stage for repeatability. The helium-neon laser (not shown) on the detector stage is used in the alignment of source to the optical axis of the spectroradiometer. For the long-term stability of the system responsivity, both the monochromator and the detector stage are purged using nitrogen gas boil-off from a liquid nitrogen reservoir to reduce the atmospheric absorption and to increase the longterm stability of the internal mirrors and gratings. The fore-optic section is purged with a positive overpressure of dry air to keep out the moisture and other contaminants which can degrade the foreoptics.

\subsection{Performance Characterizations of the FASCAL 2 Facility}

A primary goal of the FASCAL 2 facility is the spectral irradiance calibration of $1000 \mathrm{~W}$ FEL lamps with > 1000:1 signal-to-noise ratio from $250 \mathrm{~nm}$ to $2500 \mathrm{~nm}$ and subsequent spectral irradiance assignment to other lamps. To achieve the desired signalto-noise ratio, the spectral throughput of the spectroradiometer system has to be sufficient. The typical spectral irradiance of an FEL lamp at $50 \mathrm{~cm}$ is plotted in Fig. 7 


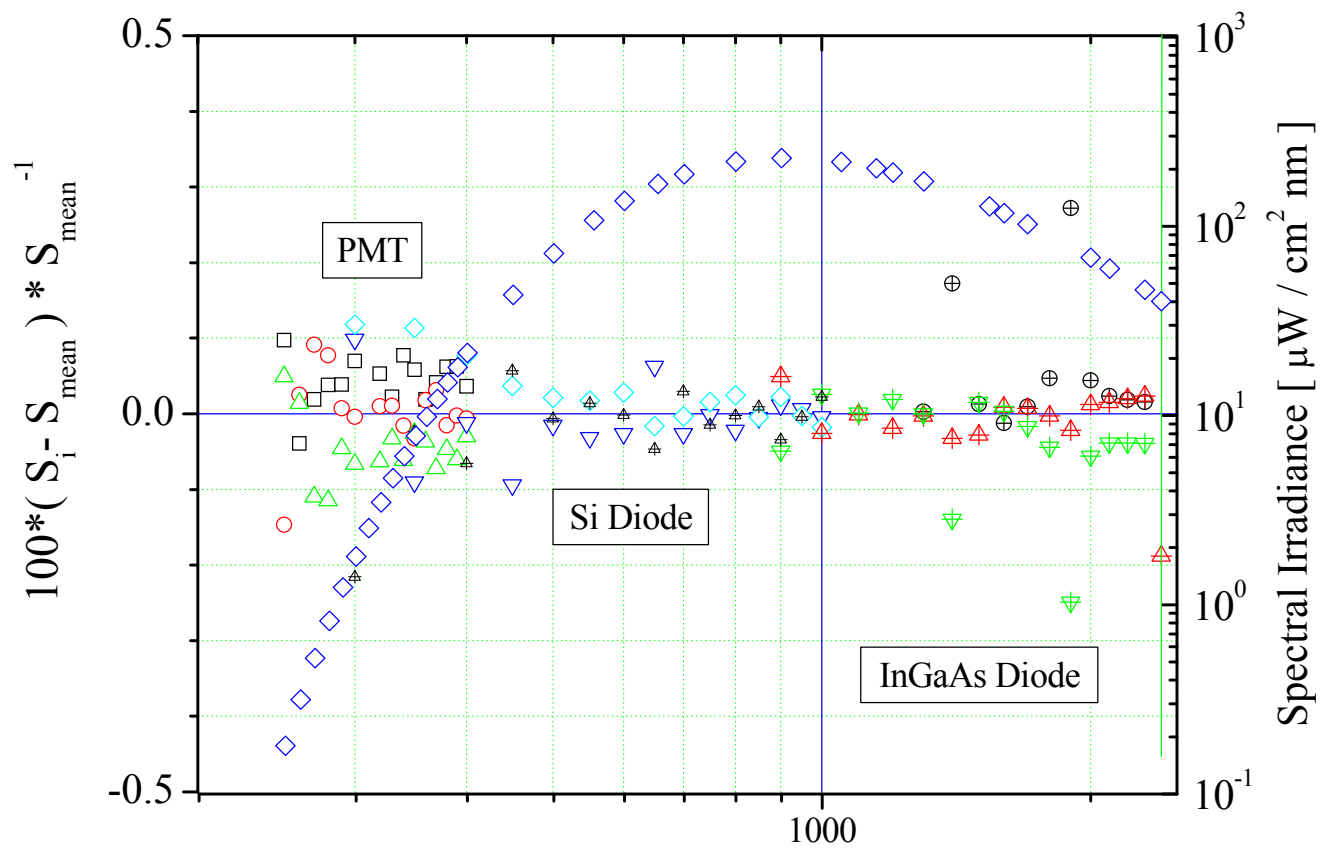

Wavelength [ $\mathrm{nm}$ ]

Figure 7. The left axis denotes the percent differences from the mean of the spectral irradiances measured over a duration of $1 \mathrm{~h}$. A total of three consecutive measurements were performed with the individual measurements denoted by squares, triangles, and circles. The right axis indicates the typical spectral irradiance of a $1000 \mathrm{~W}$ FEL lamp. The spectral irradiances were measured using the PMT (open), the $\mathrm{Si}$ diode (solid), and the InGaAs diode (open-crossed).

along with the percent change in the spectral irradiance response of the spectroradiometer found using the three detectors. Each detector is used to measure the spectral irradiance of an FEL lamp fixed at a distance of $50 \mathrm{~cm}$ and current-stabilized at $8.2 \mathrm{~A}$. The lamp is measured using each detector 3 times over a time period of $\approx 1 \mathrm{~h}$. The percent differences of the individual signals from the mean,

$$
\Delta S=\frac{100 \cdot\left(S_{i}-\frac{1}{n} \sum_{i}^{n} S_{i}\right)}{\frac{1}{n} \sum_{i}^{n} S_{i}},
$$

are plotted in Fig. 7 using the PMT, Si, and InGaAs photodiodes.

The spread in the signals below $300 \mathrm{~nm}$ is due to the combined effects of the instability of the FEL lamp and the low signals, but the spread in the signals is still well below the total uncertainty of the spectral irradiance scale in this spectral region. Although the PMT is sensitive to $600 \mathrm{~nm}$, the Si diode is the preferred detector from 350 $\mathrm{nm}$ to $1100 \mathrm{~nm}$ due to its lower noise and better temporal stability. Since the Si diode is temperature stabilized, any changes in the responsivity due to the temperature-dependent band-gap shift are minimized. In Fig. 7, the measurements with the extended-InGaAs diode show greater fluctuations, especially near $2400 \mathrm{~nm}$. Since the foreoptics of the monochromator is not purged, the increase in the differences of the signals at $1400 \mathrm{~nm}$ 
and at $1800 \mathrm{~nm}$ is due to the presence of water-vapor absorption at these wavelengths leading to increased fluctuations in the measured signals. With the exceptions of the measurements at $1400 \mathrm{~nm}, 1800 \mathrm{~nm}$, and $2400 \mathrm{~nm}$, our goal of achieving a signal-tonoise ratio of 1000:1, as determined by the standard uncertainty of the measurement at a set wavelength, is met.

The wavelength accuracy is critical, particularly in the ultraviolet wavelength region where the slope of the spectral irradiance with respect to wavelength is especially steep. The uncertainties in the spectral irradiance due to the wavelength uncertainty can be estimated by approximating the spectral shape of the FEL lamp with a $3000 \mathrm{~K}$ blackbody. Using the Wien approximation, the derivative with respect to wavelength is

$$
\frac{\mathrm{d} L}{L}=\left(\frac{\mathrm{c}_{2}}{\lambda T}-5\right) \frac{\mathrm{d} \lambda}{\lambda},
$$

where $\mathrm{c}_{2}$ is the second radiation constant, $T$, temperature, and $\lambda$, wavelength. The wavelength accuracy of the spectroradiometer was checked using low-pressure $\mathrm{Hg}, \mathrm{Ne}$, and Ar spectral-line lamps which were placed into an integrating sphere to fill the entrance optics of the monochromator. The residuals of the linear fit to the wavelength calibrations are shown in Fig. 8. The wavelength uncertainties are found to be less than

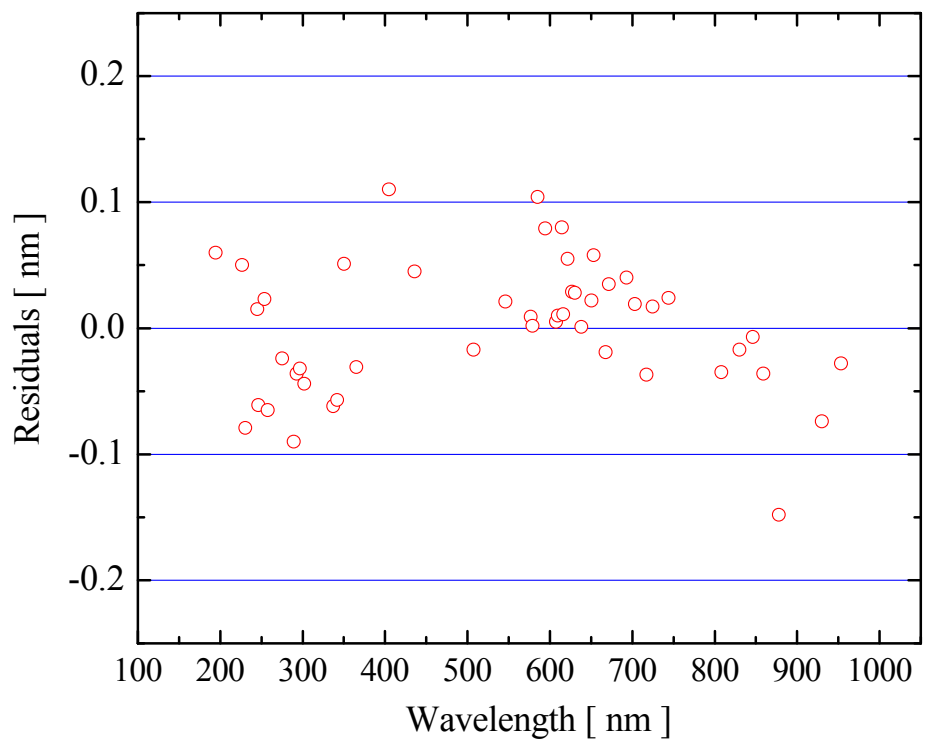

Figure 8. The residuals of the linear fit to the wavelength calibrations performed using various lowpressure lamp sources for the wavelength region from $200 \mathrm{~nm}$ to $1000 \mathrm{~nm}$.

$\pm 0.1 \mathrm{~nm}(k=2)$ from $200 \mathrm{~nm}$ to $1000 \mathrm{~nm}$. The residuals of the linear fits for the shortwave infrared wavelength region are shown in Fig. 9. Higher-order polynomials were also used to correct the wavelength errors, but did not lead to significant reduction in the wavelength uncertainties. The wavelength uncertainties are less than $\pm 0.15 \mathrm{~nm}(k=2)$ from $1000 \mathrm{~nm}$ to $2500 \mathrm{~nm}$. The spectral irradiance uncertainty due to a $0.1 \mathrm{~nm}$ wavelength error is estimated from Eq. 2 to be $<0.6 \%$ at $250 \mathrm{~nm}$, and the spectral irradiance uncertainty decreases with wavelength to $<0.1 \%$ past $500 \mathrm{~nm}$ since the 
spectral irradiance of the FEL lamp peaks near $900 \mathrm{~nm}$. The wavelength positioning is reproducible to $\pm 0.015 \mathrm{~nm}$ with changes in the gratings using the motorized grating turret.

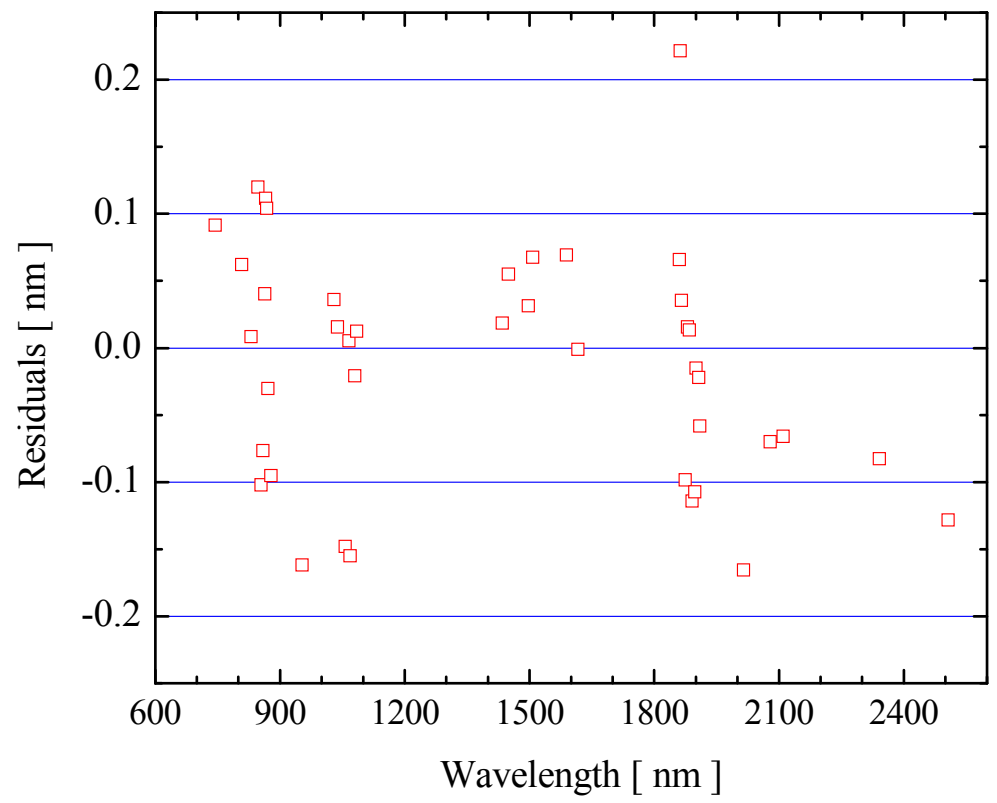

Figure 9. The residuals of the linear wavelength fit to the wavelength calibrated using various spectral line sources for the near IR wavelength region.

Since each NIST-issued spectral irradiance standard is measured at against one working standard lamp in one of the four stations, the invariance of the spectral irradiance of the standards with respect to changing lamp stations was also examined. The measurements with different power supplies and shunt resistors guard against possible systematic errors in the current and the power supply in the calibration of the standard. The use of different lamp stations also makes the spectral irradiance measurement eliminates systematic effects of scattered light and lamp positioning. The measurement of a common FEL lamp in each of the four stations shows reproducibility to $0.1 \%$ in the wavelength region from $350 \mathrm{~nm}$ to $1000 \mathrm{~nm}$. 


\section{Uncertainty Analysis of the Spectral Irradiances Issued on FEL Lamps}

The discussion of the uncertainties associated with the detector-based spectral irradiance scale realization is separated into parts. Since the absolute radiance temperature determination of the HTBB is performed with filter radiometers with peak spectral responsivities near $550 \mathrm{~nm}$, the expanded uncertainties in the spectral irradiance measurement at $550 \mathrm{~nm}$ is first discussed. The spectral irradiance uncertainties are converted into temperature uncertainties using the derivative of the Wien approximation. The Wien approximation is used since the measurements with the FRs are performed at short-wavelengths from the peak wavelength of the $3000 \mathrm{~K}$ Planck spectral radiance. The uncertainties of the spectral irradiances of the primary working standards (PWS) are assigned. Finally, the expanded uncertainties of the issued standards or the lamps-under test (LUT) are assigned with additional uncertainty added to account for the temporal changes of the PWS.

\subsection{Uncertainties of the HTBB detector-based temperatures}

The uncertainties associated with the detector-based temperature determinations of the HTBB can be found from the uncertainty analysis of Eq. (1) as shown in Table 3. The individual components are listed in descending order of importance, with the uncertainty due to the spectral power responsivity dominating. Additional sources of uncertainty from the alignment and aperture area measurements are small. The expanded spectral irradiance responsivity uncertainty at $550 \mathrm{~nm}$ of $0.26 \%$ leads to an expanded temperature uncertainty of $0.86 \mathrm{~K}$, at $2950 \mathrm{~K}$. The increase in the uncertainties in the ultraviolet region in line 1 of Table 4 is due to the sensitivity of the Planck radiance to temperature which is inversely proportional to wavelength.

\subsection{Uncertainties of the spectral irradiance realization to primary working standards}

Table 4 describes the additional uncertainties associated with the HTBB spectral irradiance including the components due to spectral emissivity, spatial uniformity, and temporal stability. Line 1 shows the expanded uncertainty of the spectral irradiance due to the $0.86 \mathrm{~K}$ expanded temperature uncertainty at $2950 \mathrm{~K}$. The uncertainties due to the spectral emissivity in line 2 and the spatial uniformity uncertainty in line 3 of the HTBB are then assigned from the data in Fig. 3 where two different blackbodies were compared. The temporal stability of the HTBB component in line 4 has been measured as shown in Fig. 4 and also constantly monitored using the optical feedback at the rear of the cavity. The uncertainties in the alignment of the apertures and in the distance measurements are included in the geometric factor uncertainty in line 5.

Lines 6 to 9 pertain to the transfer of the spectral irradiance to PWS using the spectroradiometer. The detectors used in the spectroradiometers have shown better than $0.1 \%(k=2)$ stability during the spectral irradiance measurements, but in the ultraviolet wavelength region, the integrating sphere used to collect the irradiance can change in throughput due to changes in the spectral reflectance of the coating [29]. The increase in the uncertainty at $2400 \mathrm{~nm}$ is due to the stability of the spectroradiometer responsivity 
from the performance of the InGaAs detector near its bandgap wavelength. In line 7, a substantial contribution to the total uncertainty comes from the uncertainty in the absolute wavelength, especially in the ultraviolet wavelength region where the responsivity changes rapidly, due to the spectrally dependent coatings on mirrors in the spectoradiometer. To minimize this contribution, the wavelength drive of the spectroradiometer has an absolute optical encoder attached to the shaft, and piece-wise continuous polynomial corrections are applied to achieve $\pm 0.05 \mathrm{~nm}$ standard uncertainty in the wavelength.

\subsection{Uncertainties of the issued spectral irradiance standards}

For determination of the uncertainties on the issued standards, additional components arising from the lamp-to-lamp transfer and long-term stability of the working standards are added in lines 10 and 11. An additional increase in the total uncertainties arises from the possible temporal drift of the PWS. All lamps standards are subjected to screening procedure for temporal drift, and lamps that change by more than $0.5 \%$ at 650 $\mathrm{nm}$ over the duration of 24 operational hours are rejected from further evaluation as possible standards. The temporal drift is found to be inversely proportional to the wavelength, and is accordingly larger at the shorter wavelengths. Figure 10 plots the expanded uncertainties of the PWS along with the total uncertainties of the issued spectral irradiance standards with respect to SI units. The increase in the ultraviolet wavelength region and the increase in the uncertainties at $2400 \mathrm{~nm}$ is discussed above.

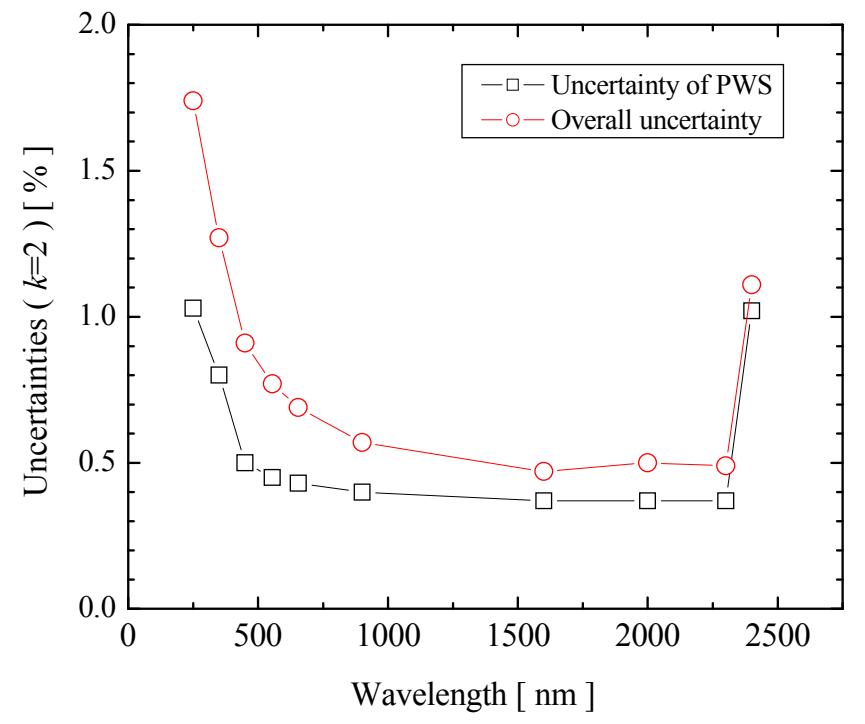

Figure 10. The expanded uncertainties of the PWS and the total uncertainties of the issued spectral irradiance standards with respect to SI units. 
To determine whether the uncertainties have been correctly determined, data from separate independent scale realizations of an FEL lamp (F210) were analyzed. Figure 11 shows the percent differences from the mean in the detector-based spectral irradiance of the lamp with three independent assignments from $250 \mathrm{~nm}$ to $900 \mathrm{~nm}$ and from three other separate assignments $800 \mathrm{~nm}$ to $2400 \mathrm{~nm}$ over four separate days. The spectral irradiance assignments show that the three independent scale realizations for a particular wavelength region are all within the assigned $(k=2)$ expanded uncertainties of the 2000 spectral irradiance scale. The temperature of the HTBB was determined on each of the days during the realization and the spectral irradiance responsivity was assigned about 30 min after a temperature assignment using the filter radiometers. The separate spectral

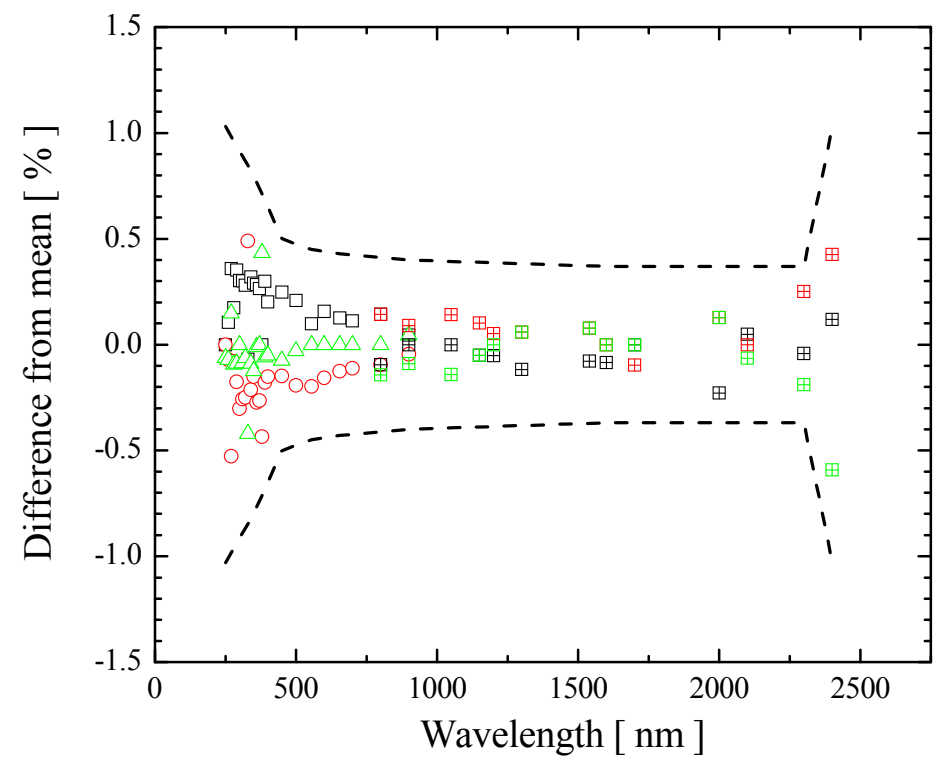

Figure 11. The percent differences from the mean of three separate, independent spectral irradiance scale realizations performed on four separate days. The differences are shown with the assigned expanded uncertainties of the working standards for the detector-based spectral irradiance scale.

irradiance assignments are all within the expanded uncertainties.

\subsection{International comparisons to support the NIST assigned uncertainties}

The NIST assigned uncertainties are used in international intercomparisons of radiometric scales such as the CCPR k1-a key comparison where the spectral irradiance scales of 13 different countries were compared using $1000 \mathrm{~W}$ FEL lamps as the comparison artifacts [30]. The results of the measurements are compared using a weighted mean with the weights being the inverse of the respective national measurement laboratory's (NMI) uncertainties squared. The spectral irradiances measured by the individual NMI are then compared against the weighted mean to determine the degrees of equivalence between the respective NMIs and also to determine if the differences from the weighted world mean or the Key Comparison Reference Value (KCRV) are within 
the expanded uncertainties stated by the respective NMI. The detailed results of the comparison can be seen in Ref. 29. The differences of the NIST measurements from the KCRV were all within the expanded NIST uncertainties.

Table 4. Uncertainty components for the HTBB temperature determination. At the HTBB temperature of $2950 \mathrm{~K}$, an irradiance response uncertainty of $0.26 \%$ corresponds to a temperature uncertainty of $0.86 \mathrm{~K}(\mathrm{k}=2)$.

\begin{tabular}{|c|c|c|}
\hline $\begin{array}{c}\text { Source of uncertainty } \\
{[550 \mathrm{~nm}]}\end{array}$ & $\begin{array}{c}\text { Fractional uncertainty } \\
\text { Spectral power responsivity, FR }\end{array}$ & $\begin{array}{c}\text { Expanded uncertainty [\%] } \\
(k=2)\end{array}$ \\
\hline Solid angle factor, HTBB/FR & $\frac{\Delta R}{R}$ & 0.22 \\
\hline Area of detector aperture & $\frac{\Delta A}{A}$ & 0.026 \\
\hline $\begin{array}{c}\text { Area of HTBB aperture } \\
\text { Measurement precision, } \\
\text { HTBB/FR }\end{array}$ & $\frac{\Delta A}{A}$ & 0.02 \\
\hline $\begin{array}{c}\text { Amplifier gain } \\
{[k=2]}\end{array}$ & $\frac{\Delta G}{G}$ & 0.006 \\
\hline $\begin{array}{c}\text { Combined expanded uncertainty } \\
{[}\end{array}$ & & 0.26 \\
\hline
\end{tabular}


Table 5. Uncertainty Budget for Spectral Irradiance Calibrations Using FASCAL 2.

\begin{tabular}{|c|c|c|c|c|c|c|c|c|c|c|}
\hline \multirow[b]{2}{*}{ Source of Uncertainty } & \multicolumn{10}{|c|}{ Relative Expanded Uncertainties $(k=2)[\%]$} \\
\hline & $\begin{array}{c}250 \\
\mathrm{~nm}\end{array}$ & $\begin{array}{l}350 \\
\mathrm{~nm}\end{array}$ & $\begin{array}{l}450 \\
\mathrm{~nm}\end{array}$ & $\begin{array}{l}555 \\
\mathrm{~nm}\end{array}$ & $\begin{array}{c}654.6 \\
\mathrm{~nm}\end{array}$ & $\begin{array}{c}900 \\
\mathrm{~nm}\end{array}$ & $\begin{array}{c}1600 \\
\mathrm{~nm}\end{array}$ & $\begin{array}{c}2000 \\
\mathrm{~nm}\end{array}$ & $\begin{array}{c}2300 \\
\mathrm{~nm}\end{array}$ & $\begin{array}{c}2400 \\
\mathrm{~nm}\end{array}$ \\
\hline 1. HTBB temperature uncertainty $(0.86 \mathrm{~K}$ at $2950 \mathrm{~K})(\mathrm{B})$ & 0.57 & 0.41 & 0.32 & 0.26 & 0.22 & 0.16 & 0.09 & 0.08 & 0.07 & 0.07 \\
\hline 2. HTBB spectral emissivity (B) & 0.10 & 0.10 & 0.10 & 0.10 & 0.10 & 0.10 & 0.10 & 0.10 & 0.10 & 0.10 \\
\hline 3. HTBB spatial uniformity (B) & 0.10 & 0.10 & 0.10 & 0.10 & 0.10 & 0.10 & 0.10 & 0.10 & 0.10 & 0.10 \\
\hline 4. HTBB temporal stability $(0.1 \mathrm{~K} / \mathrm{h})(\mathrm{B})$ & 0.07 & 0.05 & 0.04 & 0.03 & 0.03 & 0.02 & 0.01 & 0.01 & 0.01 & 0.01 \\
\hline 5. Geometric factors in irradiance transfer (B) & 0.10 & 0.10 & 0.10 & 0.10 & 0.10 & 0.10 & 0.10 & 0.10 & 0.10 & 0.10 \\
\hline 6. Spectroradiometer responsivity stability (B) & 0.60 & 0.60 & 0.30 & 0.30 & 0.30 & 0.30 & 0.30 & 0.30 & 0.30 & 1.00 \\
\hline 7. Wavelength accuracy $(0.1 \mathrm{~nm})(\mathrm{B})$ & 0.58 & 0.26 & 0.13 & 0.07 & 0.04 & 0.01 & 0.01 & 0.01 & 0.01 & 0.01 \\
\hline 8. Lamp/spectroradiometer transfer (B) & 0.10 & 0.10 & 0.10 & 0.10 & 0.10 & 0.10 & 0.10 & 0.10 & 0.10 & 0.10 \\
\hline 9. Lamp current stability $(\mathrm{B})$ & 0.07 & 0.05 & 0.04 & 0.03 & 0.03 & 0.02 & 0.02 & 0.01 & 0.01 & 0.01 \\
\hline Total uncertainty of the primary working standards & 1.03 & $\mathbf{0 . 8 0}$ & 0.50 & 0.45 & 0.43 & 0.40 & 0.37 & 0.37 & 0.37 & 1.02 \\
\hline 10. Lamp-to-lamp transfer $(\mathrm{A})$ & 0.50 & 0.30 & 0.20 & 0.20 & 0.20 & 0.20 & 0.20 & 0.30 & 0.30 & 0.40 \\
\hline 11. Long-term stability of primary working standards (B) & 1.31 & 0.94 & 0.73 & 0.59 & 0.50 & 0.36 & 0.20 & 0.16 & 0.14 & 0.14 \\
\hline Overall uncertainty of the test with respect to SI units & 1.74 & 1.27 & 0.91 & 0.77 & 0.69 & 0.57 & 0.47 & 0.50 & 0.49 & 1.11 \\
\hline
\end{tabular}

Note: The Type A or Type B evaluation of the uncertainty is indicated in parentheses. 


\section{Future Work}

The development of FASCAL 2, a dedicated spectral irradiance realization and calibration facility, and the implementation of the detector-based spectral irradiance scale have lead to lower total uncertainties and faster calibration throughput of the spectral irradiance standards. Currently, lamps in 4 stations can be turned on or off with computer control enabling automated calibrations with the only manual operation that of placing the lamps in their mounts. The implementation of "Once is Enough" program [7] of having quality-control charts and eliminating repetitive measurements requires even better understanding of the calibration process so that the low uncertainties can be routinely maintained. One of the best ways to ensure that the calibration standards are within the specified uncertainties is to measure the same quantity with two different realization chains to compare the different ways of approaching the same quantity. This approach can help discover systematic sources of uncertainties which can be unknown with just a single approach.

The assigned spectral irradiances derived from the HTBB can also validated by direct measurements with a calibrated filter radiometer. The filter radiometers can be calibrated for spectral irradiance responsivity from the NIST Spectral Irradiance and Radiance responsivity Calibrations using Uniform Sources (SIRCUS) facility [31] using monochromatic radiation which overfills the entrance aperture of the filter radiometers. If filter radiometers can be developed to cover a selected wavelength region to measure every FEL lamp operated in FASCAL 2, their measured irradiance response with their calculated irradiance response can be compared. If the entrance aperture is placed at exactly $50 \mathrm{~cm}$ away from the FEL mount, aligned to the optical axis, then the calculated irradiance response, $v_{C}$, is given by,

$$
v_{C}=G \int\left(s_{E} \cdot E\right) d \lambda
$$

where $G$ is the preamplifier gain in volts/amp, $s_{E}$ is the measured absolute spectral irradiance responsivity, and $E$ is the assigned spectral irradiance from FASCAL 2. Since the absolute spectral irradiance responsivity can be determined with expanded uncertainties of $<0.1 \%$ in the visible wavelength region, then the calculated irradiance response should be in agreement with the measure response to within the uncertainties of the NIST assigned values in Table 4 . We are in the process of implementing the above procedure.

\section{Acknowledgments}

The authors gratefully acknowledge the help and encouragement of Gerald Fraser, Robert Saunders and Al Parr of the Optical Technology Division at all stages of this project. The authors would like to also acknowledge the assistance of Tom Larason and George Eppeldauer in the development and the characterization of the filter radiometers used in the scale realization. The authors also acknowledge the assistance from Jim Proctor in setting up the FASCAL 2 facility. 
*Certain commercial equipment, instruments, or materials are identified in this paper to foster understanding. Such identification does not imply recommendation or endorsement by the National Institute of Standards and Technology, nor does it imply that the material or equipment are necessarily the best available for the purpose.

\section{References}

1. A.C. Parr, A national measurement system for radiometry, photometry, and pyrometry based upon absolute detectors, NIST Technical Note 1421, (National Institute of Standards and Technology, Gaithersburg, MD, 1996).

2. T.R. Gentile, J.M. Houston, and C.L. Cromer, Realization of a scale of absolute spectral response using the National Institute of Standards and Technology highaccuracy cryogenic radiometer, Applied Optics 35, 4392-4403 (1996).

3. C.L. Cromer, G. Eppeldauer, J.E. Hardis, T.C. Larason, and A.C. Parr, National institute of Standards and Technology detector-based photometric scale, Applied Optics 32-16, 2936-2948 (1993).

4. Y. Ohno, Improved photometric standards and calibration procedures at NIST, J. Res. Natl. Inst. Stand. Technol. 102-3, 323-331 (1997).

5. The International System of Units (SI), $8^{\text {th }}$. Edition, Bureau International des Poids et Mesures, 2006.

6. Guide to the expression of uncertainty of uncertainty in measurement, International Organization for Standardization, Geneva,(1993).

7. G.T. Fraser, C.E. Gibson, H.W. Yoon, A.C. Parr, Once is Enough in Radiometric Calibrations, submitted to J. Res. Natl. Inst. Stand. Technol.

8. The U.S. Interagency UV-Monitoring Network Plan, United States Global Change Research Program, 1995, USGCRP-95-01

9. Y. Ohno, Photometric Calibrations, NIST Special Publication 250-37, U.S. Government printing Office 1997.

10. G. Meister, P. Abel, R. Barnes, J. Cooper, C. Davis, G. Fargion, R. Frouin, M. Godin. D. Korwan, R. Maffione, C. McClain, S. McLean, D. Menzies, A. Poteau, J. Robertson and J. Sherman, Comparison of spectral radiance calibrations at oceanographic and atmospheric research laboratories, Metrologia 40, S93-S96 (2003).

11. W.W. Coblentz, Bull. Bur. Stds. 11, 87 (1914).

12. R. Stair, W. E. Schneider and J. K. Jackson, A New Standard of Spectral Irradiance, Applied Optics 2, 1151-1154 (1963).

13. R. Stair, W.E. Schneider and W.B. Fussell, The New Tungsten-Filament Lamp Standards of Total Irradiance, Applied Optics 6, 101-105 (1967).

14. R.D. Saunders and J. B. Shumaker, NBS Tech Note, 594-13, 1977. 
15. M. Suzuki and N. Ooba, Metrologia 12, 123 (1976).

16. J.H. Walker, R.D. Saunders, J.K. Jackson, and K.D. Mielenz, J. Res. Natl. Inst. Stand. Technol. 96, 647-668 (1991).

17. H.W. Yoon, C.E. Gibson, P.Y. Barnes, Realization of the National Institute of Standards and Technology Detector-based Spectral Irradiance Scale, Applied Optics 41, 5879-5890 (2002).

18. E.R. Woolliams, N.P. fox, M.G. Cox, P.M. Harris and N.J. Harrison, The CCPR k1-a key comparison of spectral irradiance from $250 \mathrm{~nm}$ to $2500 \mathrm{~nm}$ : measurements, analysis and results, Metrologia 43, S98-S104 (2006).

19. T.R. Gentile, J.M. Houston, J.M. Hardis, C. L. Cromer A. C. Parr, National Institute of Standards and Technology high accuracy cryogenic radiometer, Applied Optics 35, 1056-1068 (1996).

20. J. Fowler and M Litorja, Geometric area measurements of circular apertures for radiometry at NIST, Metrologia 40, S9-S12 (2003).

21. H.W. Yoon, C.E. Gibson, Determination of radiance temperatures using detectors calibrated for absolute spectral power response, Proceedings of the TEMPMEKO99, J. F. Dubbeldam and M. J. deGroot, eds., NMI Van Swinden lab. Delft, Netherlands, 1999, pp. 737-742.

22. T.C. Larason, S.S. Bruce, A.C. Parr, Spectroradiometric detector measurements: part I- ultraviolet detectors and part II- visible to near-infrared detectors, NIST

Measurement Services SP 250-41 (National Institute of Standards and Technology, Gaithersburg, MD, 1998).

23. V.I. Sapritsky, Blackbody radiometry, Metrologia 32, 411-418 (1996).

24. P. Sperfeld, S. Galal-Yousef, J. Metzdorf, B. Nawo, and W. Moller, The use of selfconsistent calibrations to recover absorption bands in the black-body spectrum, Metrologia 37, 373-376 (2000).

25. J.H. Walker, R.D. Saunders and A.T. Hattenburg, Spectral Radiance Calibrations, NBS Special Publication 250-1, U. S. Government Printing Office Washington 1987.

26. A. Thompson, H.M. Chen, Beamcon II, a linearity measurement instrument for optical detectors, J. Res. Natl. Inst. Stand. Technol. 99, 751 (1994).

27. H.W. Yoon, C.E. Gibson, Comparison of the absolute detector-based spectral radiance assignment with the current NIST-assigned spectral radiance of tungsten strip lamps, Metrologia 37, 429-432 (2000).

28. H.J. Kostkowski, D.E. Erminy, A.T. Hattenburg, Advances in Geophysics 14, 111 127 (1970).

29. D.R. Gibbs, F.J. Duncan, R.P. Lambe and T.M. Goodman, Ageing of materials under intense ultraviolet radiation, Metrologia 32, 601-608 (1996). 
30. http://kcdb.bipm.org/

31. S.W. Brown, G.P. Eppeldauer, K.R. Lykke, NIST Facility for Spectral Irradiance and Radiance Responsivity Calibrations with Uniform Sources, Metrologia 37, 579-582 (2000). 


\section{Appendix A. Lamp Selection Process}

Before the FEL lamps are selected as spectral irradiance standards, the lamps are put through an aging and screening processes. Since lamps will typically become more stable with operating hours, the aging process is to accelerate the long-term stable behavior of the lamps by operating the lamps at slightly higher electrical power than their calibrated use. When the FEL lamps are obtained from the vendor, the lamps are aged by operating them at a constant voltage of 120 VDC, higher than their operating voltage, for 4 hours. The lamps are also operated at constant current of 8.2 ADC for 48 hours. The lamps are then placed in brass holders and then potted using ceramic cement.

\section{A.1 Spectral Screening}

The screening of the lamps is performed using a spectroradiometer. The lamps are measured using a double monochromator for the presence of spectral features. The lamps are scanned from $250 \mathrm{~nm}$ to $400 \mathrm{~nm}$ every $0.1 \mathrm{~nm}$ with $0.02 \mathrm{~mm}$ entrance slit width resulting in $\sim 0.04 \mathrm{~nm}$ bandwidth. In order to increase the measured signal this procedure is performed with a mirror in place of the integrating sphere. The result of such a scan is shown in Fig. 1. Although in the past the presence of such lines would

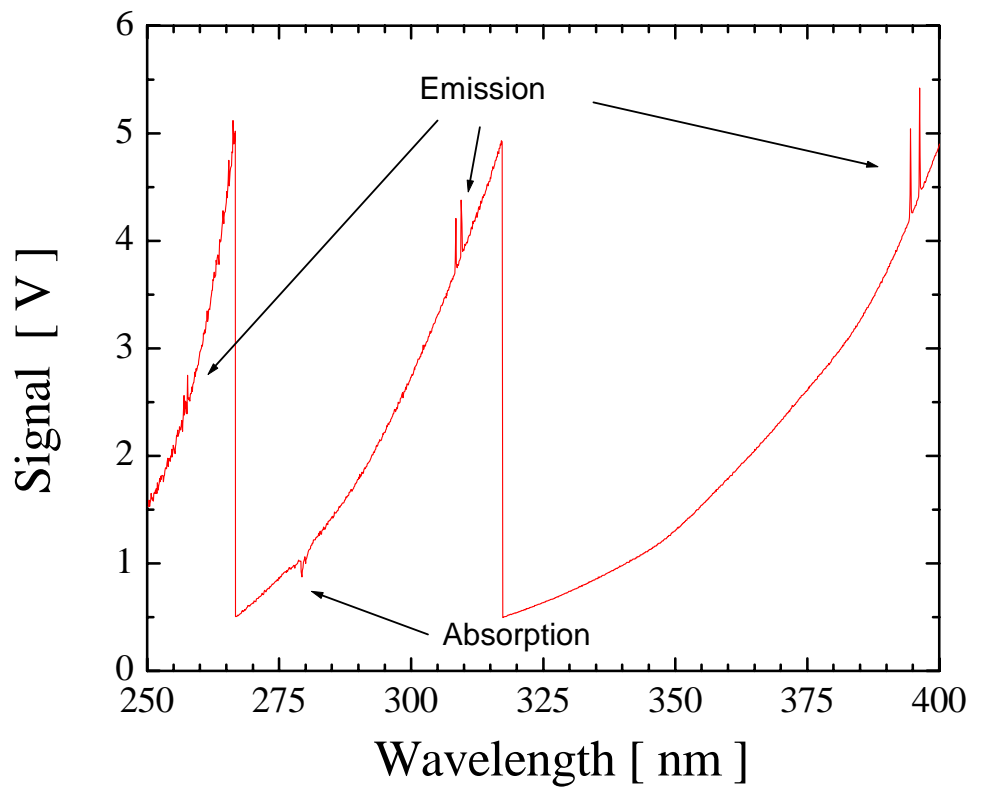

Figure A1. The spectral features from the FEL lamp measured using a double monochromator with bandwidth of $0.04 \mathrm{~nm}$. The step changes are due to the changes in the high-voltage bias of the photomultiplier tube. The emission doublets are due to the presence of aluminum inside the FEL.

lead to rejection of any lamps which exhibit such features, at present, all lamps with the features are accepted since we are not able to find any lamps without the spectral features. The measurements are performed using a photomultiplier tube (PMT) and the abrupt changes in the signal at $\sim 265 \mathrm{~nm}$ and at $\sim 315 \mathrm{~nm}$ are due to the changes in the high-voltage bias of the PMT. The emission lines are indicated in Fig. 1 along with an absorption feature at $\sim 280 \mathrm{~nm}$. The measured emission lines along with the listed aluminum emission wavelengths from the CRC Handbook [1] are listed in Table 1. The 
differences are within the uncertainties of the wavelength setting of the spectroradiometer. The aluminum is attributed to contamination of the tungsten filament during the manufacturing process. The high operational temperature of the tungsten filament in the FEL lamp leads to thermal excitation of the aluminum resulting in the spectral emission.

Table A1. The measured wavelengths and the listed wavelengths from the CRC handbook. The differences are within the wavelength uncertainties of the spectroradiometer.

\begin{tabular}{|c|c|c|}
\hline Measured [nm ] & CRC value [ nm ] & $\begin{array}{c}\text { Measured-CRC value } \\
{[\mathrm{nm}]}\end{array}$ \\
\hline 256.79 & 256.8 & -0.01 \\
\hline 257.49 & 257.51 & -0.02 \\
\hline 308.3 & 308.22 & 0.08 \\
\hline 309.29 & 309.27 & 0.02 \\
\hline 394.43 & 394.4 & 0.03 \\
\hline 396.13 & 396.15 & -0.02 \\
\hline
\end{tabular}

\section{A.2 Temporal stability check}

Lamps are measured for long-term temporal stability of the spectral irradiance at $654.6 \mathrm{~nm}$. These measurements are to ensure that lamps which are calibrated by NIST can maintain their calibrations over an extended period of time. The measurements are performed with the Si diode detector to maintain stable spectral irradiance responsivity. Any lamp calibrated by NIST must be stable to better than $0.5 \%$ in spectral irradiance at $654.6 \mathrm{~nm}$ over a 24 hour period. Figure A2 shows the voltage, current and the signal from a photometer monitoring an FEL lamp over a $48 \mathrm{~h}$ period. All the measured values are plotted as ratios to the initial value. Although the current held stable, the voltage can change leading to changes in the radiation. The optical output can be seen to generally correlated with the electrical power.

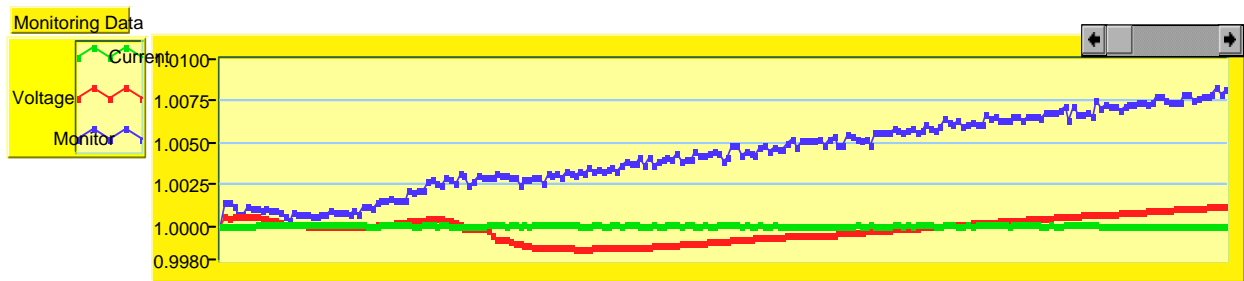

Figure A2. The optical power and the measured voltage across the FEL lamp under constant current conditions. The values plotted are ratioed to the initial values. This FEL lamp would be accepted under the current NIST screening criteria.

Most lamps are stable to $0.3 \%$ over a $24 \mathrm{~h}$ time period. The stability of the responsivity of the spectroradiometer is $<0.1 \%$ over the time period. FEL lamps typically exhibit a slow drift of the spectral irradiance over the monitoring time duration. Rejected lamps change at faster rates or exhibit bi-stable outputs. An example of a lamp showing bistable output is shown in Fig. A3. Although the current to the lamp is held stable, the 
voltage fluctuates leading to a fluctuation in the optical output. The lamp seems to recover after 24 hours.

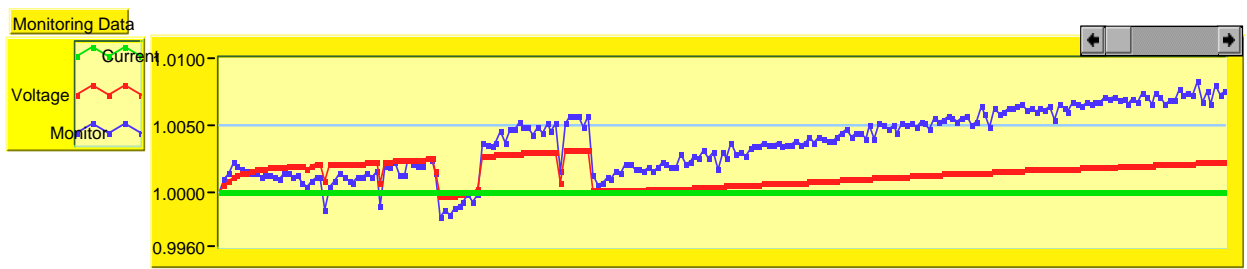

Figure A3. The optical power and the measured voltage across the FEL lamp under constant current conditions. The values plotted are ratioed to the initial values. This FEL lamp would not accepted under the current NIST screening criteria.

Although the changes of the lamp due to slow aging are expected to be faster at the shorter wavelengths, the long-term temporal stability screenings are performed at 654.6 $\mathrm{nm}$ since the radiance temperature realizations are performed at this wavelength. Currently about $90 \%$ of the lamps tested meet this requirement.

\section{A.3 Goniometric Scans}

Since the FEL lamps are sometimes used outside the calibrated $1 \mathrm{~cm}^{2}$ area in the direct optical axis of the alignment jig, the non-uniformity of the projected irradiance is measure by rotation and tilt of the FEL lamp placed in a goniometric cradle. A representative goniometric map is shown in Fig. A4. For the lamps to pass goniometric

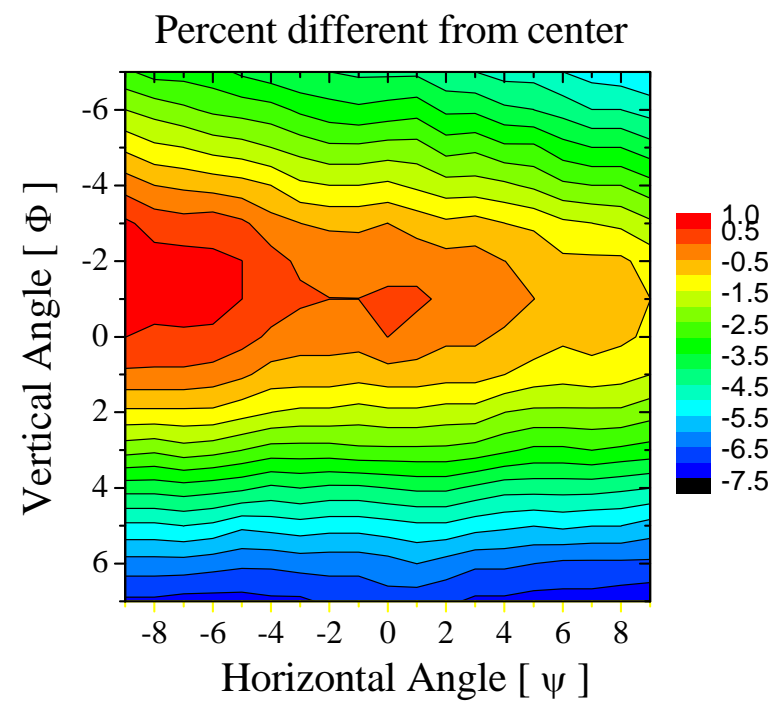

Figure A4. The percent differences in the spectral irradiances at $650 \mathrm{~nm}$ with angular tilts of the FEL lamp. The lamps are uniform with respect to horizontal rotation and are much more sensitive to the vertical rotation. This particular lamp shows $<1.0 \%$ change in the spectral irradiance with $1^{\circ}$ change in any direction. 
screening, FEL lamps must not exhibit more than $1 \%$ change in the spectral irradiance at $654.6 \mathrm{~nm}$ as measured with the integrating sphere in place with a $\pm 1.0^{\circ}$ rotation in any direction. Currently, about $95 \%$ of the lamps measured meet this selection criterion. Upon special request FEL lamps can be further measured at greater angles. Contour plot of the percent difference of the spectral irradiance from the center is shown in Fig. 4. The irradiance is measured as a function of the vertical and horizontal angle of the FEL lamp. The figure shows the large changes in the spectral irradiance with respect to the vertical angle and the slow changes with the horizontal angle. Since the FEL lamp is much more physically symmetric with respect to horizontal rotation, the relative insensitivity of the spectral irradiance is shown.

1. CRC Handbook of Chemistry and Physics, $62^{\text {nd }}$ Edition 1982, R.C Weast and M.J. Astle, eds., CRC Press, Boca Raton, Florida, p. E206. 


\section{Appendix B. Orientation dependence of the FEL lamps}

Due to the electrical heating induced by the close to $\sim 1000 \mathrm{~W}$ of electrical power dissipated by the FEL lamps, the lamp filament and the envelope are at high operating temperatures. Since the lamps are operated in air, steady-state temperature of the lamp envelope and the filament are dependent upon the air convection. Measurements of the spectral irradiance with changing FEL orientation have shown that the orientation of the FEL lamp can affect the spectral irradiance output by changing the filament temperature.

A fixture consisting of the FEL lamp and a filter radiometer was constructed so that the FEL lamp could be operated in each of the three orientations to the reference aperture of the filter radiometer as shown in Fig. 1. Since the mechanical mount of the fixture could be turned in each of the different orientations as a system, the rigid supports allowed reproducible changes in the lamp orientations. The filter radiometer consisted of $\mathrm{Si}$ diodes in a trap configuration with a manually controlled filter wheel to place various filters into the optical path. The filters consisted of narrow-band interference filters from above $300 \mathrm{~nm}$ to close to $1000 \mathrm{~nm}$.

Vertical

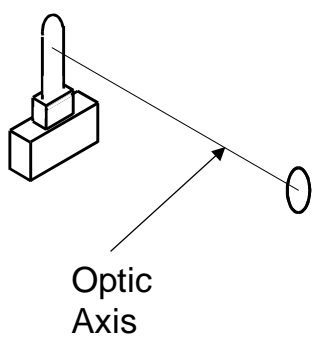

Side

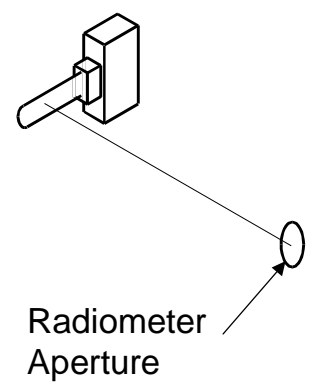

Horizontal

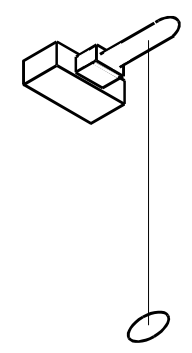

Figure B1. The respective orientations of the FEL lamp during its measurements. A specially designed fixture allowed rigid support of the lamp and the radiometer during the different changes in the orientations. 
The lamp and the filter radiometer were placed to have the FEL in the vertical geometry. The initial signals from the filter radiometer was measured and recorded for comparisons with the later measurements. The lamp was turned off and removed. The entire configuration was rotated to the side position as shown in Fig. 1 and then the lamp placed back for measurements with the filter radiometer. The results of the filter radiometer measurements are shown in Fig. B2. Figure B2 shows the ratios of the signals to the initial vertical signals. The vertical signals, as shown by the triangles in Fig. B2, measured after the side and the horizontal orientations indicate that the FEL and the filter radiometer combined is reproducible to $<0.5 \%$ in this spectral range. The side and the horizontal orientations show spectrally dependent drop in the spectral irradiance indicative of a change in the temperature of the filament and the lamp envelope. If the direction of the long axis of the lamp causes more effective convective cooling, then such cooling could be the cause of the greater change in the shorter wavelengths as observed in Fig. B2. It is not clear why there should be differences between the side and the horizontal configurations.

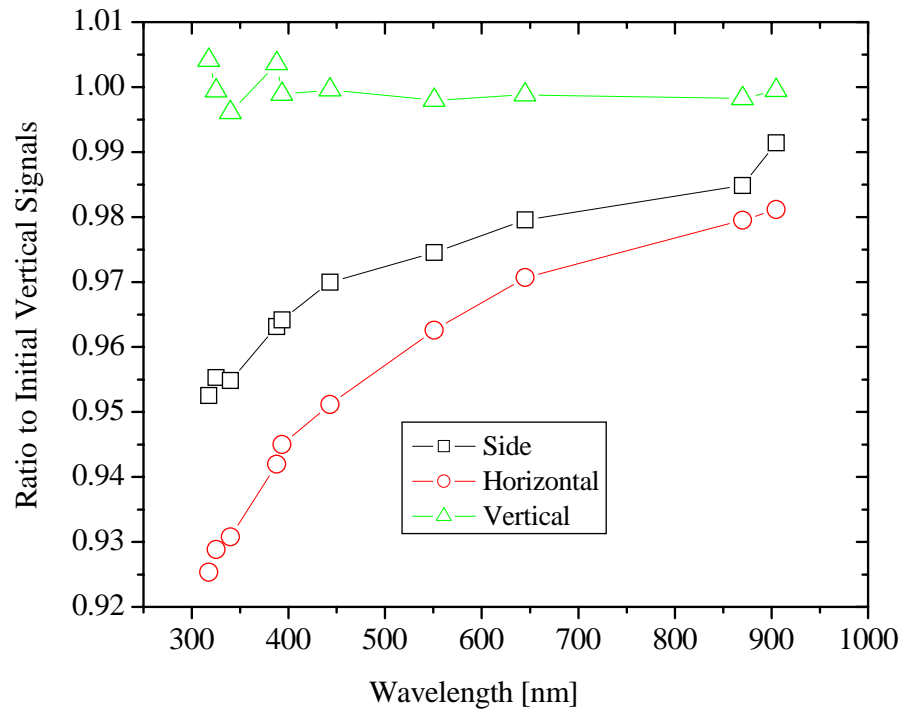

Figure B2. The signal ratios to the initial vertical orientation. After the side and the horizontal configurations, the lamp was returned to the vertical position and shows that the lamp is repeatable to within $<1 \%$ from $300 \mathrm{~nm}$ to $900 \mathrm{~nm}$.

The above study demonstrates the dependence of the spectral irradiance on the angular orientation of the FEL lamp. If the uncertainties as issued by NIST are to be propagated without a substantial increase, then any changes to the spectral irradiances caused by a change in the mounting configuration should be assessed. 


\section{Appendix C. Physical alignment of the FEL lamp}

This section describes the mounting and the alignment procedure for the NIST FEL lamps. The FEL lamps from the manufacturers are mounted into brass adapters which are in turn attached to stainless steel posts for incorporation into NIST lamp assemblies. The alignment of the optical axis is performed using a lamp jig shown in Fig. C1. The lamp mount is first prepared by assembling stable, opto-mechanical

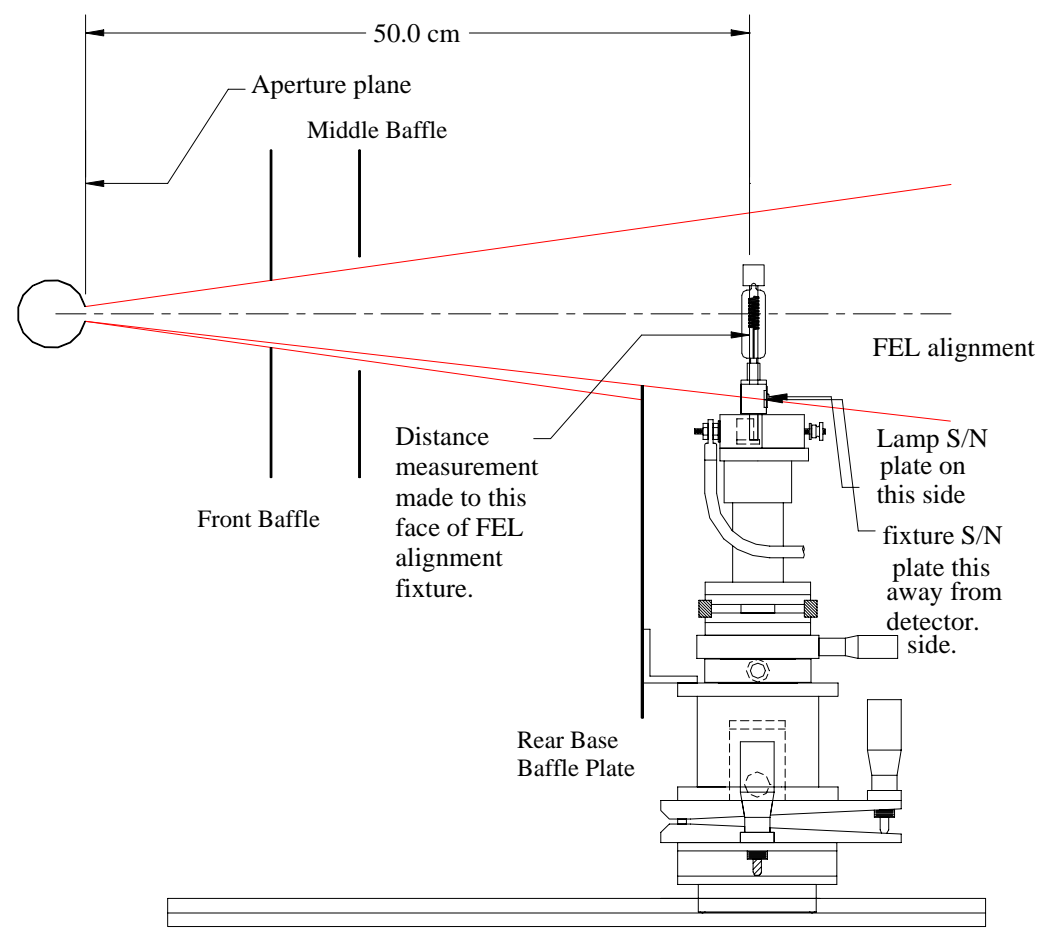

Figure C1. The physical alignment of the FEL lamp in an optomechanical mount in NIST FASCAL 2. The mount should have enough degrees of freedom so that the optical axis can be aligned. The lamp serial number $(\mathrm{S} / \mathrm{N})$ should be on the side facing away from the radiometer.

components as shown in Fig. C1. First the lamp jig is mounted and the lamp fixture is adjusted so that the lamp jig is level with respect to the ground by using a spirit level. Then a laser is placed behind the lamp jig so that the laser is perpendicular to the lamp jig and centered on the opening of the integrating sphere. The optical axis is defined by attaching a flat glass plate to the opening of the integrating sphere at the left and retroreflecting back to the alignment mark on the lamp jig. The distance of $50.00 \mathrm{~cm}$ is set between the opening of the integrating sphere and the front surface of the lamp jig. The front surface of the lamp jig is coincident with the front surface of the stainless steel posts of the FEL lamp. At NIST, two baffles around the optical axis are used to reduce the 
stray light since the integrating sphere receiver is sensitive to a wide-angular field of view. A third, rear-base baffle is used to cover the slightly reflective base of the FEL lamp from the receiver. The height of the rear baffle is adjusted until center of the lamp base is aligned with the lower edge of the integrating sphere opening. The base of the lamp with the serial number carved into the brass plate is placed on the side away from the opening of the spectroradiometer. 


\section{Appendix D. Atmospheric absorption and FEL interpolations}

\section{D1. Atmospheric absorption}

Currently, the spectral irradiance scale is realized on FEL lamps at 35 separate wavelengths from $250 \mathrm{~nm}$ to $2400 \mathrm{~nm}$. In the ultraviolet wavelength region from $250 \mathrm{~nm}$ to $400 \mathrm{~nm}$, due to possible rapid changes in the spectral irradiance from current instability and lamp aging, the spectral irradiances are assigned at every $10 \mathrm{~nm}$. Past $400 \mathrm{~nm}$, the realizations are performed at selected wavelengths chosen to avoid atmospheric absorption. The $1 \mathrm{~m}$ path atmospheric transmittance for standard, sea-level altitude conditions $\left[{ }^{1}\right]$ along with the spectral irradiances from an FEL lamp are shown in Fig. 1. The absorption is from the presence of water and $\mathrm{CO}_{2}$ and will vary with humidity and other atmospheric conditions. Since the FEL lamps are operated standard laboratory environments, if the calibrated wavelengths of the spectral irradiances are coincident with the atmospheric absorption, then the stability of the spectral irradiance will be reduced. The spectral irradiances at the wavelengths where the atmospheric absorption will reduce the stability are purposely avoided.

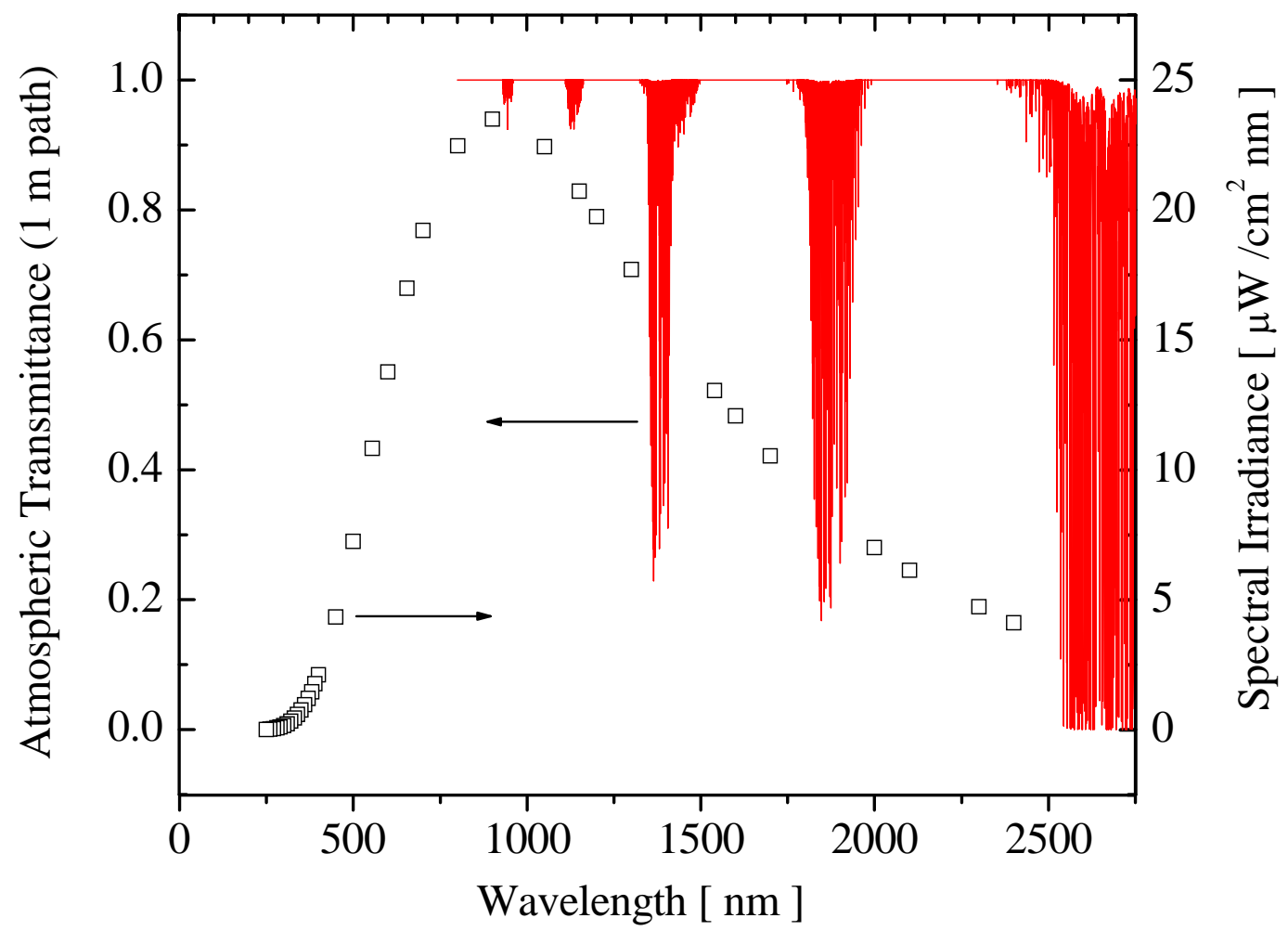

Figure D1. The atmospheric transmittance for a $1 \mathrm{~m}$ path at standard sea level conditions along with the spectral irradiances of an FEL lamp. The spectral irradiance realizations at wavelengths coinciding with atmospheric absorption are purposely avoided. 


\section{D2. FEL interpolations}

FEL lamps are used in photometry to determine correlated color temperatures and distribution temperatures. The lamps are also sometimes used to realize other photometric units such as the lumen. Since the photopic response or the spectral luminous efficiency function for photopic vision and the CIE (Commision Internationale de l'Éclairage) color matching functions for chromaticity are given at $1 \mathrm{~nm}$ intervals $\left.{ }^{2}\right]$, the use of FEL lamps under such conditions requires interpolation of the spectral irradiances at finer wavelength intervals than those realized. Two of the interpolation approaches are described below. Both of these interpolations can be performed using a program $<$ Fitirrad $>\left[{ }^{3}\right]$ which can be provided, on request, by the Optical Technology Division of NIST.

The spectral irradiance from the FEL lamp is determined by factors such as the temperature of the coiled-coil tungsten filament, the tungsten emissivity, the quartz lampenvelope transmittance and the physical structure of the filament. The spectral shape of the FEL lamp can be fitted by an interpolation function which is derived from Planck's radiation law. The interpolation function used at NIST utilizes a $4^{\text {th }}$ order polynomialmodified Wien approximation,

$$
E_{\lambda}=\left(A_{0}+A_{1} \cdot \lambda+A_{2} \cdot \lambda^{2}+A_{4} \cdot \lambda^{3}+A_{4} \cdot \lambda^{4}\right) / \lambda^{5} \cdot \exp \left(A_{5}+\frac{\mathrm{c}_{2}}{\lambda T}\right)
$$

where $\lambda$ is the wavelength, $T$ is the fitted temperature, $\mathrm{c}_{2}$ is the second radiation constant, and $A_{0}$ to $A_{5}$ are fitted parameters. The polynomial term accounts for the emissivity of the FEL lamp. Due to the possible oscillations, which can arise from fitting of high-order polynomials if the data grid is sparse, especially at the endpoints of the fitting, the spectrum is broken into spectral regions. Currently, for the NIST-issued program the spectrum is separated into three sections; $250 \mathrm{~nm}$ to $350 \mathrm{~nm}$ for the ultraviolet region, $350 \mathrm{~nm}$ to $800 \mathrm{~nm}$ for the visible region, and $800 \mathrm{~nm}$ to $2400 \mathrm{~nm}$ for the near-infrared and the short-wave infrared region. Other, modified interpolation functions can be also used $\left[{ }^{4}\right]$. As observed from the atmospheric transmission shown in Fig. 1, interpolation through the wavelength region with absorption lines will lead to larger uncertainties.

Since the polynomial fitting utilizes minimization of the chi-squared sum over the range of the fitted wavelengths, the resulting uncertainties of the interpolated values can have higher correlations with the spectral irradiances at other wavelengths $\left[{ }^{5}\right]$. To avoid additional increases in uncertainties arising from the correlations due to the fitting, the spectral irradiances can also be fit by natural cubic spline. The program issued by NIST has provisions for both types of fitting. The uncertainties of the interpolated values of the spectral irradiance is expected to increase by $<0.5 \%(k=2)$ depending on the region of the fit.

1. L.S. Rothman, et al., Journal of Quantitative Spectroscopy and Radiative Transfer, vol. 96, pp. 139-204 (2005).

2. Colorimetry, $3^{\text {rd }}$ Edition, CIE Publication 15, 2004. 
3. Ftirrad.vbp (program provided by NIST for polynomial or cubic-spline fitting of spectral irradiances)

4. L.K. Huang, R.P. Cebulla and E. Hilsenrath, New Procedure for interpolating NIST FEL lamp irradiances, Metrologia 35, 381-386 (1998).

5. J. Gardner, Uncertainty Propagation for NIST Visible Spectral Standards, J. Res. Natl. Inst. Stand. Technol. 109, 305-318 (2004). 


\section{REPORT OF CALIBRATION}

39045C Spectral Irradiance Standard, 1000 W Tungsten Quartz-Halogen Lamp

(250 nm to $2400 \mathrm{~nm}$ )

for

Osram Sylvania, Model \# T6, Serial \# F-000

Issued to:

Radiometric Systems Incorporated

Attn.: Mr. Art Monk

123 Calibration Court

Measurement City, MD 00000-0000

(See your Purchase Order No. AB123, dated March 28, 2011)

\section{Description of Calibration Item}

A $1000 \mathrm{~W}$, quartz-halogen lamp with a coiled-coil tungsten filament was calibrated by the National Institute of Standards and Technology (NIST) as a standard of spectral irradiance from $250 \mathrm{~nm}$ to $2400 \mathrm{~nm}$. The lamp is mounted in a medium bi-post base. The serial number is located on the rear of the lamp base opposite the side viewed by the spectroradiometer.

Spectral scans of the lamp from $250 \mathrm{~nm}$ to $400 \mathrm{~nm}$ in $0.1 \mathrm{~nm}$ steps revealed emission lines at $257 \mathrm{~nm}, 309 \mathrm{~nm}$, and $395 \mathrm{~nm}$ when using a spectroradiometer with a spectral bandwidth that varies with wavelength from $0.04 \mathrm{~nm}$ at $250 \mathrm{~nm}$ to $0.08 \mathrm{~nm}$ at $400 \mathrm{~nm}$. The intensities of these lines are as much as $20 \%$ greater than the adjacent continuum. A decrease in the lamp output due to absorption was observed at $279 \mathrm{~nm}$. This decrease can be as much as $20 \%$ below the adjacent continuum. While data is reported at $280 \mathrm{~nm}$, care should be taken when measurements are made near $279 \mathrm{~nm}$. Historically, these emission lines and absorption bands have been known to change with burning time. This calibration was performed with a spectral bandwidth that varied from $4 \mathrm{~nm}$ to $8 \mathrm{~nm}$. The emissions lines and absorption bands are not measurable with bandwidths larger than $1 \mathrm{~nm}$. If your instrument has a narrow spectral bandwidth, checks should be made in the area of the emission lines and absorption band.

Laboratory Environment:

Temperature: $23{ }^{\circ} \mathrm{C} \pm 1{ }^{\circ} \mathrm{C} \quad$ Relative Humidity: $23 \% \pm 5 \%$

Calibration Date: March 31, 2011

NIST Test No: 685/123456-11

Page 1 of 6 


\section{Description of Calibration}

The lamp was calibrated in the new NIST Facility for Automated Spectroradiometric Calibrations (FASCAL 2) using the equipment and procedures described in Ref. [1]. The lamp was measured at a distance of $50 \mathrm{~cm}$ from the entrance aperture of the integrating sphere with an aperture area of $1.0027 \mathrm{~cm}^{2}$. The sphere viewed approximately a $9 \mathrm{~cm}$ diameter target in the plane of the front surface of the lamp bi-posts. With this geometry, the entire lamp was viewed from the top of the lamp envelope down to the top half of the black lamp base. Light baffling was used between the lamp and the spectroradiometer integrating sphere to minimize effects of scattered light. The alignment of the lamp is described in the next paragraph.

The lamp was mounted vertically, base down with the brass identification plate facing away from the spectroradiometer. An alignment jig was placed in the kinematic lamp socket and aligned. This was accomplished by placing a spirit level on top of the jig and then by adjusting the angle about the optical axis until the level was balanced. The alignment jig target area, which is indicated by cross hairs, is centered between the bi-posts and located $9.5 \mathrm{~cm}$ above the bottom of the jig bi-posts. This target area was centered vertically and horizontally onto the optical axis. The jig was set perpendicular to the optical axis by reflecting the spectroradiometer laser beam back onto itself. The distance along the optical axis from the target area surface to the surface of the sphere aperture was set at $50 \mathrm{~cm}$. The target area surface is in the plane with the front surface of the bi-posts. This alignment procedure sets the alignment jig bi-posts relative to the optical axis of the spectroradiometer. The jig was removed and the lamp was placed in the aligned socket.

The test lamp was spectrally compared to the following working standards: F-350, F-352, and F-353 to determine its spectral irradiance. The spectral irradiance values for this standard lamp were assigned relative to the 2000 NIST Spectral Irradiance Scale [2].

\section{Results of Calibration}

Table 1 and Figure 1 give the spectral irradiance of the test lamp versus the wavelength in nm.

Table 2 gives the calibration uncertainties in percent relative to the International System of Units (SI Units). The relative expanded uncertainties (coverage factor $k=2$ ) have a level of confidence of $95 \%$. Details on the estimation of these uncertainties are given in Ref. [2]. The NIST policy on uncertainty statements is described in Ref. [3].

Calibration Date: March 31, 2011

NIST Test No: 685/123456-11 


\section{General Information}

To maintain the highest accuracy, keep the lamp envelope clean and have the lamp recalibrated periodically. Appropriate calibration schedules vary with lamp and application and are best determined by the user.

The lamp is operated on DC power. The lamp polarity is indicated on the lamp base identification plate.

The results of this calibration apply only to the lamp referenced in this report. This report shall not be reproduced, except in full, without the written approval of the Spectroradiometric Source Measurements Calibration Service.

Prepared by:

Charles E. Gibson

Optical Technology Division

Physical Measurement Laboratory

(301) 975-2329
Approved by:

Eric L. Shirley

For the Director,

National Institute of Standards and Technology

(301) 975-2349

\section{References}

[1] H. W. Yoon, J. E. Proctor, and C. E. Gibson, "FASCAL 2: A New NIST Facility for the Calibration of Spectral Irradiance Sources,” Metrologia, 40, S30-S34, (2003).

[2] H. W. Yoon, C. E. Gibson, and P. Y. Barnes, "Realization of the National Institute of Standards and Technology Detector-based Spectral Irradiance Scale,” Applied Optics, 41, 5879-5890, (2002).

[3] B. N. Taylor and C. E. Kuyatt, "Guidelines for Evaluating and Expressing the Uncertainty of the NIST Measurement Results,” NIST Technical Note 1297 ( $2^{\text {nd }}$ ed., 1994).

Calibration Date: March 31, 2011

NIST Test No: 685/123456-11

Page 3 of 6 
Table 1. Spectral Irradiance at $50 \mathrm{~cm}$

Lamp current at 8.200 A DC

\begin{tabular}{|c|c|c|c|c|c|}
\hline $\begin{array}{c}\text { Wavelength } \\
\text { [nm] }\end{array}$ & $\begin{array}{c}\text { Spectral } \\
\text { Irradiance } \\
{\left[\mu \mathrm{W} \mathbf{c m}^{-2} \mathbf{n m}^{-1}\right]}\end{array}$ & 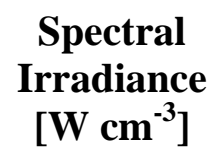 & $\begin{array}{c}\text { Wavelength } \\
\text { [nm] }\end{array}$ & $\begin{array}{c}\text { Spectral } \\
\text { Irradiance } \\
{\left[\mu \mathrm{W} \mathbf{c m}^{-2} \mathbf{n m}^{-1}\right]}\end{array}$ & $\begin{array}{c}\text { Spectral } \\
\text { Irradiance } \\
{\left[\mathrm{W} \mathrm{cm}^{-3}\right]}\end{array}$ \\
\hline 250 & $2.251 \mathrm{E}-02$ & $2.251 \mathrm{E}-01$ & 555 & $1.201 \mathrm{E}+01$ & $1.201 \mathrm{E}+02$ \\
\hline 260 & $3.901 \mathrm{E}-02$ & $3.901 \mathrm{E}-01$ & 600 & $1.509 \mathrm{E}+01$ & $1.509 \mathrm{E}+02$ \\
\hline 270 & $6.441 \mathrm{E}-02$ & $6.441 \mathrm{E}-01$ & 654.6 & $1.838 \mathrm{E}+01$ & $1.838 \mathrm{E}+02$ \\
\hline 280 & $9.959 \mathrm{E}-02$ & $9.959 \mathrm{E}-01$ & 700 & $2.065 \mathrm{E}+01$ & $2.065 \mathrm{E}+02$ \\
\hline 290 & $1.507 \mathrm{E}-01$ & $1.507 \mathrm{E}+00$ & 800 & $2.376 \mathrm{E}+01$ & $2.376 \mathrm{E}+02$ \\
\hline 300 & 2.177E-01 & $2.177 \mathrm{E}+00$ & 900 & $2.466 \mathrm{E}+01$ & $2.466 \mathrm{E}+02$ \\
\hline 310 & 3.071E-01 & $3.071 \mathrm{E}+00$ & 1050 & $2.316 \mathrm{E}+01$ & $2.316 \mathrm{E}+02$ \\
\hline 320 & 4.176E-01 & $4.176 \mathrm{E}+00$ & 1150 & $2.126 \mathrm{E}+01$ & $2.126 \mathrm{E}+02$ \\
\hline 330 & 5.563E-01 & $5.563 \mathrm{E}+00$ & 1200 & $2.019 \mathrm{E}+01$ & $2.019 \mathrm{E}+02$ \\
\hline 340 & 7.255E-01 & $7.255 \mathrm{E}+00$ & 1300 & $1.803 \mathrm{E}+01$ & $1.803 \mathrm{E}+02$ \\
\hline 350 & $9.268 \mathrm{E}-01$ & $9.268 E+00$ & 1540 & $1.315 \mathrm{E}+01$ & $1.315 \mathrm{E}+02$ \\
\hline 360 & $1.164 \mathrm{E}+00$ & $1.164 \mathrm{E}+01$ & 1600 & 1.213E+01 & $1.213 \mathrm{E}+02$ \\
\hline 370 & $1.440 \mathrm{E}+00$ & $1.440 \mathrm{E}+01$ & 1700 & $1.056 \mathrm{E}+01$ & $1.056 \mathrm{E}+02$ \\
\hline 380 & $1.749 \mathrm{E}+00$ & $1.749 \mathrm{E}+01$ & 2000 & $6.980 \mathrm{E}+00$ & $6.980 \mathrm{E}+01$ \\
\hline 390 & $2.102 E+00$ & $2.102 E+01$ & 2100 & $6.086 \mathrm{E}+00$ & $6.086 \mathrm{E}+01$ \\
\hline 400 & $2.490 \mathrm{E}+00$ & $2.490 \mathrm{E}+01$ & 2300 & $4.674 \mathrm{E}+00$ & $4.674 \mathrm{E}+01$ \\
\hline 450 & $4.972 \mathrm{E}+00$ & $4.972 \mathrm{E}+01$ & 2400 & $4.124 E+00$ & $4.124 \mathrm{E}+01$ \\
\hline 500 & $8.155 E+00$ & $8.155 E+01$ & & & \\
\hline
\end{tabular}

For reference only: The voltage drop across the lamp during the calibration was $113.13 \mathrm{~V}$.

Calibration Date: March 31, 2011

NIST Test No: 685/123456-11 


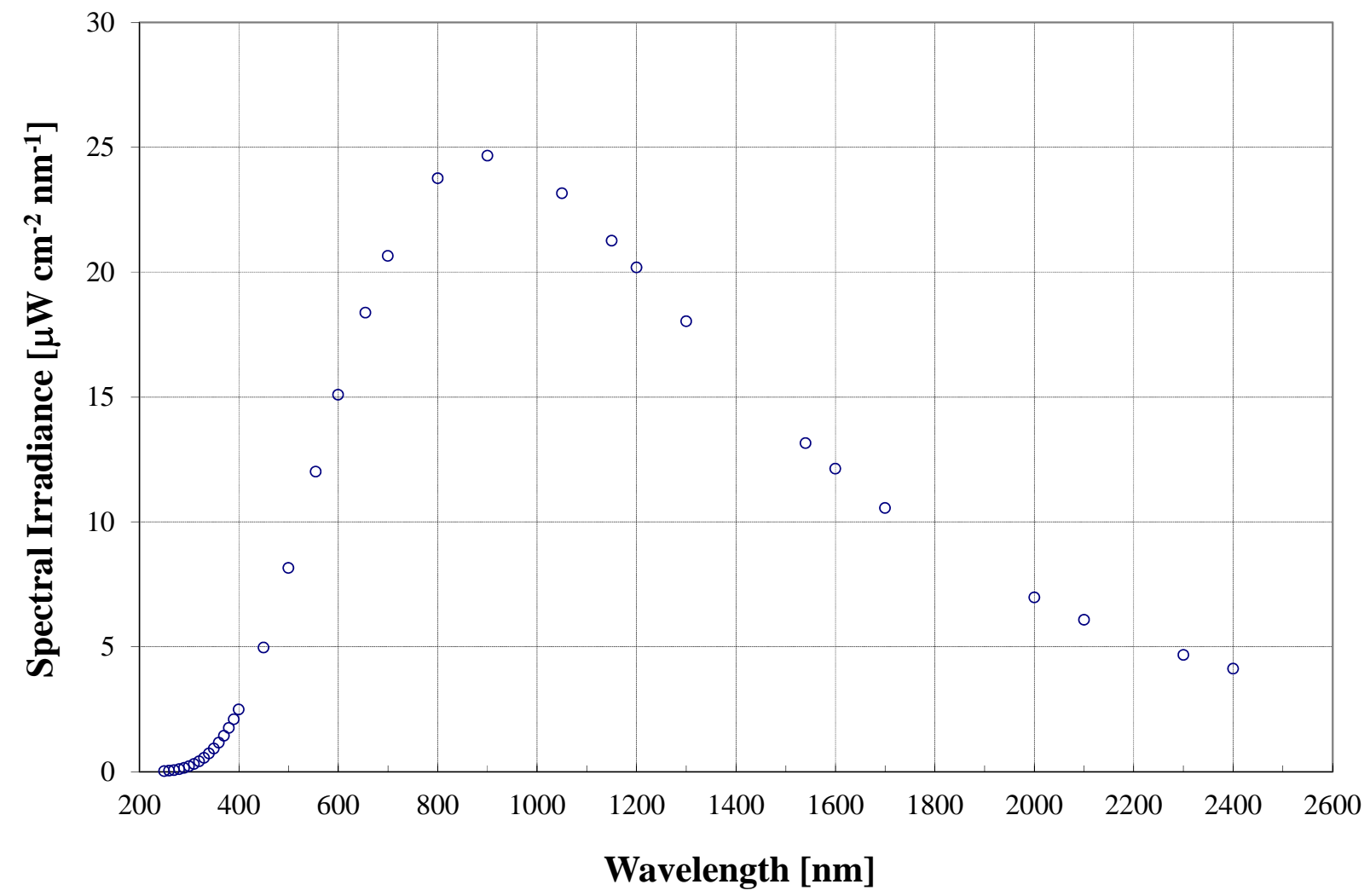

Figure 1. Calibration results of $1000 \mathrm{~W}$ Quartz Halogen Lamp

Calibration Date: March 31, 2011

NIST Test No: 685/123456-11 
Table 2. 2000 Spectral Irradiance Scale Uncertainties of the Primary Working Standards and the Test Standard

\begin{tabular}{|c|c|c|c|c|c|c|c|c|c|c|}
\hline \multirow[b]{2}{*}{ Source of Uncertainty } & \multicolumn{10}{|c|}{ Relative Expanded Uncertainties $(k=2)$ [\%] } \\
\hline & $\begin{array}{l}250 \\
\mathrm{~nm}\end{array}$ & $\begin{array}{c}350 \\
\mathrm{~nm}\end{array}$ & $\begin{array}{c}450 \\
\mathrm{~nm}\end{array}$ & $\begin{array}{c}555 \\
\mathrm{~nm}\end{array}$ & $\begin{array}{c}654.6 \\
\mathrm{~nm}\end{array}$ & $\begin{array}{l}900 \\
\mathrm{~nm}\end{array}$ & $\begin{array}{c}1600 \\
\mathrm{~nm}\end{array}$ & $\begin{array}{c}2000 \\
\mathrm{~nm}\end{array}$ & $\begin{array}{c}2300 \\
\mathrm{~nm}\end{array}$ & $\begin{array}{c}2400 \\
\mathrm{~nm}\end{array}$ \\
\hline 1. HTBB temperature uncertainty $(0.86 \mathrm{~K}$ at $2950 \mathrm{~K})(\mathrm{B})$ & 0.57 & 0.41 & 0.32 & 0.26 & 0.22 & 0.16 & 0.09 & 0.08 & 0.07 & 0.07 \\
\hline 2. HTBB spectral emissivity (B) & 0.10 & 0.10 & 0.10 & 0.10 & 0.10 & 0.10 & 0.10 & 0.10 & 0.10 & 0.10 \\
\hline 3. HTBB spatial uniformity (B) & 0.10 & 0.10 & 0.10 & 0.10 & 0.10 & 0.10 & 0.10 & 0.10 & 0.10 & 0.10 \\
\hline 4. HTBB temporal stability $(0.1 \mathrm{~K} / \mathrm{h})(\mathrm{B})$ & 0.07 & 0.05 & 0.04 & 0.03 & 0.03 & 0.02 & 0.01 & 0.01 & 0.01 & 0.01 \\
\hline 5. Geometric factors in irradiance transfer (B) & 0.10 & 0.10 & 0.10 & 0.10 & 0.10 & 0.10 & 0.10 & 0.10 & 0.10 & 0.10 \\
\hline 6. Spectroradiometer responsivity stability (B) & 0.60 & 0.60 & 0.30 & 0.30 & 0.30 & 0.30 & 0.30 & 0.30 & 0.30 & 1.00 \\
\hline 7. Wavelength accuracy $(0.1 \mathrm{~nm})(\mathrm{B})$ & 0.58 & 0.26 & 0.13 & 0.07 & 0.04 & 0.01 & 0.01 & 0.01 & 0.01 & 0.01 \\
\hline 8. Lamp/spectroradiometer transfer (B) & 0.10 & 0.10 & 0.10 & 0.10 & 0.10 & 0.10 & 0.10 & 0.10 & 0.10 & 0.10 \\
\hline 9. Lamp current stability (B) & 0.07 & 0.05 & 0.04 & 0.03 & 0.03 & 0.02 & 0.02 & 0.01 & 0.01 & 0.01 \\
\hline Total uncertainty of the primary working standards & 1.03 & 0.80 & 0.50 & 0.45 & 0.43 & 0.40 & 0.37 & 0.37 & 0.37 & 1.02 \\
\hline 10. Lamp-to-lamp transfer (A) & 0.50 & 0.30 & 0.20 & 0.20 & 0.20 & 0.20 & 0.20 & 0.30 & 0.30 & 0.40 \\
\hline 11. Long-term stability of primary working standards (B) & 1.31 & 0.94 & 0.73 & 0.59 & 0.50 & 0.36 & 0.20 & 0.16 & 0.14 & 0.14 \\
\hline Overall uncertainty of the test with respect to SI units & 1.74 & 1.27 & 0.91 & 0.77 & 0.69 & 0.57 & 0.47 & 0.50 & 0.49 & 1.11 \\
\hline
\end{tabular}

Note: The Type A or Type B evaluation of the uncertainty is indicated in parentheses. 
Appendix F. Irradiance Calibration Procedures Manual

Irradiance

Calibration Procedures Manual

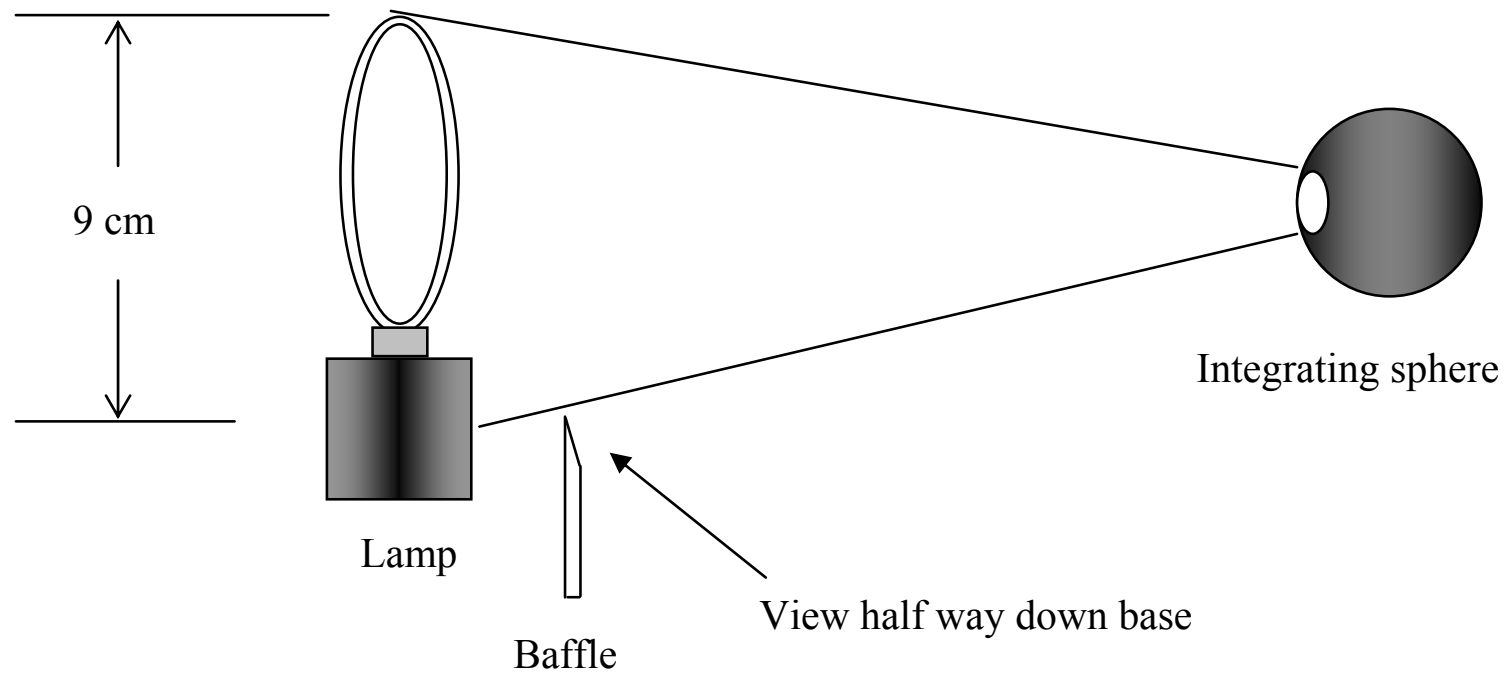




\section{Irradiance Calibration Procedure \\ IRR-CP-TOC-Table of Contents}

\section{Table of Contents}

0. Safety Precautions (IRR-CP-IRR0)

1. FASCAL2 Data Acquisition (DAQ) Program Operation (IRR-CP-IRR1)

2. Quartz Halogen Lamp (QHL) Alignment (IRR-CP-IRR2)

3. Quartz Halogen Lamp (QHL) Operation (IRR-CP-IRR3)

4. High Temperature Blackbody (HTBB) Alignment (IRR-CP-IRR4)

5. High Temperature Blackbody (HTBB) Operation (IRR-CP-IRR5)

6. Filter Radiometer (FR) Alignment (IRR-CP-IRR6)

7. Spectral Irradiance Scale Realization (IRR-CP-IRR7)

8. Spectral Irradiance Calibration (IRR-CP-IRR8)

9. Spectral Irradiance Data Reduction (IRR-CP-IRR9)

10. Calculate the Correlated Color Temperature (CCT) and Luminous Intensity (LI) from Spectral Irradiance Data (IRR-CP-IRR10)

11. Reset Linear Encoder (IRR-CP-IRR11)

12. Goniometric Scan (IRR-CP-IRR12)

13. Document History

\begin{tabular}{|c|c|c|c|c|c|c|c|}
\hline Version & $\begin{array}{c}\text { Version } \\
\text { Date }\end{array}$ & Author & $\begin{array}{c}\text { Page } \\
\text { Total }\end{array}$ & $\begin{array}{c}\text { Revision } \\
\text { Date }\end{array}$ & $\begin{array}{c}\text { Revision } \\
\text { Date }\end{array}$ & $\begin{array}{c}\text { Revision } \\
\text { Date }\end{array}$ & $\begin{array}{c}\text { Revision } \\
\text { Date }\end{array}$ \\
\hline 1.0 & 11-Jul-06 & C. Gibson & 1 & & & & \\
\hline & & & & & & & \\
\hline & & & & & & & \\
\hline & & & & & & & \\
\hline
\end{tabular}

\begin{tabular}{|c|c|c|c|c|c|}
\hline Procedure & Version & Date & Author & Pages & Filename \\
\hline IRR-CP-TOC & 1.0 & 11-Jul-06 & C. Gibson & 1 of 1 & $\begin{array}{c}\text { IRR-CP-TOC Table of Contents } \\
\text { v1.doc }\end{array}$ \\
\hline
\end{tabular}




\section{Irradiance Calibration Procedure \\ IRR-CP-IRR0-Safety Precautions}

\section{Safety Precautions}

Safety glasses are required in the lab depending on task performed.

The following hazards have been identified in this lab. Safety measures are in place to reduce the risk of injury from the hazards below.

\section{BRIGHT SOURCE}

Avoid staring at the source

Retina damage possible

If source viewing is necessary, then use the correct neutral density filter

\section{BURN}

Keep body and clothes away

\section{COLLISION}

Keep the source table path clear

Do not hang cables from source table

\section{ELECTROCUTION}

High voltage connections present

Do not touch electrical parts

Have a $2^{\text {nd }}$ party present when working on a high power/voltage source

\section{LASER}

Retina damage from viewing the direct and indirect laser beam, and skin burns if the laser is powerful enough

Contain or block laser beam and turn off when not in use

If the laser beam is powerful enough and not contained then laser glasses/goggles are required.

Do not wear reflective items that may fall into the laser beam

OZONE

Avoid long exposure and get plenty of fresh air

Over exposure to ozone can cause head aches

\begin{tabular}{|c|c|c|c|c|c|}
\hline Procedure & Version & Date & Author & Pages & Filename \\
\hline IRR-CP-IRR0 & 1.0 & 08-Jun-06 & C. Gibson & 1 of 2 & $\begin{array}{c}\text { IRR-CP-IRR0 Safety } \\
\text { Precautions v1.doc }\end{array}$ \\
\hline
\end{tabular}




\section{Irradiance Calibration Procedure \\ IRR-CP-IRR0-Safety Precautions}

UV

Avoid skin and eye exposure

Can burn skin and eyes

Symbols, similar to the one below, are used throughout this document to alert the operator to potential hazards.

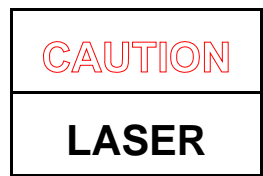

Document History

\begin{tabular}{|c|c|c|c|c|c|c|c|}
\hline Version & $\begin{array}{c}\text { Version } \\
\text { Date }\end{array}$ & Author & $\begin{array}{c}\text { Page } \\
\text { Total }\end{array}$ & $\begin{array}{c}\text { Revision } \\
\text { Date }\end{array}$ & $\begin{array}{c}\text { Revision } \\
\text { Date }\end{array}$ & $\begin{array}{c}\text { Revision } \\
\text { Date }\end{array}$ & $\begin{array}{c}\text { Revision } \\
\text { Date }\end{array}$ \\
\hline 1.0 & 08 -Jun-06 & C. Gibson & 2 & & & & \\
\hline & & & & & & & \\
\hline & & & & & & & \\
\hline & & & & & & & \\
\hline
\end{tabular}

\begin{tabular}{|c|c|c|c|c|c|}
\hline Procedure & Version & Date & Author & Pages & Filename \\
\hline IRR-CP-IRR0 & 1.0 & 08-Jun-06 & C. Gibson & 2 of 2 & $\begin{array}{c}\text { IRR-CP-IRR0 Safety } \\
\text { Precautions v1.doc }\end{array}$ \\
\hline
\end{tabular}




\section{Irradiance Calibration Procedure IRR-CP-IRR1-FASCAL2 Data Acquisition Program Operation}

\section{FASCAL2 Data Acquisition (DAQ) Program Operation}

1. DAQ program (FEL Transfer.vi)

1.1. The DAQ program communicates with the Lamp Current Control program (see IRR-CPIRR3) to ramp up the lamp, waits 20 minutes for the lamp to stabilize, measures the lamp and then ramps down the lamp. Measurements are performed for the lamps entered into the DAQ program.

1.2. The DAQ program uses SubVIs to perform the various tasks

1.3. Load the LabVIEW program: $\boldsymbol{c}: \mid F C 2$ Docs $\mid$ DAQ Program $\backslash$ FEL Transfer.vi (do one of the following)

1.3.1. From the start menu

\subsubsection{Click Start}

\subsubsection{Click FEL Transfer}

1.3.2. From Windows Explorer

1.3.2.1.Locate FEL Transfer.vi and double click to open

\subsubsection{From LabVIEW}

\subsubsection{Open LabVIEW}

\subsubsection{Click FEL Transfer.vi}

1.4. Run the program (do one of the following)

\subsubsection{Press Ctrl+R}

1.4.2. Click the Run icon on the tool bar

1.4.3. Click the menu item Operate then Run

\subsection{Enter Lamp Serial Numbers}

\subsection{Click Start Scan}

2. Lamp scan program (Lamp Scan.vi)

2.1. The lamp scan program scans the dark signal then the full scale signal at each wavelength for one spectral range determined by the detector used

2.2. The lamp scan program does not communicate with the lamp current control program

\begin{tabular}{|c|c|c|c|c|c|}
\hline Procedure & Version & Date & Author & Pages & Filename \\
\hline IRR-CP-IRR1 & 1.0 & 29-Jun-06 & C. Gibson & 1 of 12 & $\begin{array}{c}\text { IRR-CP-IRR1 FC2 DAQ } \\
\text { Program Operation v1.doc }\end{array}$ \\
\hline
\end{tabular}




\section{Irradiance Calibration Procedure IRR-CP-IRR1-FASCAL2 Data Acquisition Program Operation}

2.3. The DAQ program runs the lamp scan program three times to cover the entire calibration range. Each run creates one raw data file and formatted data file. The three formatted data files are combined into a new file which contains the net signals and percent standard deviation of the net signal data for all three ranges.

2.3.1. Format of raw data file

2.3.1.1. Filename: F000xmmddyyyya.raw

2.3.1.2. Wavelength [nm], McPherson absolute encoder reading, date, time

2.3.1.3. Lamp station, lamp serial number, Heidehain linear encoder reading

2.3.1.4. Dark signals [V], wavelength [nm], McPherson absolute encoder reading, Aerotech Z-axis position [mm], dark signal mean [V], percent standard deviation of the dark signal

2.3.1.5. Station 1 current [A], station 2 current [A], station 3 current [A], station 4 current $[\mathrm{A}]$, station 1 voltage [V], station 2 voltage $[\mathrm{V}]$, station 3 voltage $[\mathrm{V}]$, station 4 voltage [V]

2.3.1.6. Full scale signals [V], wavelength [nm], McPherson absolute encoder reading, Aerotech Z-axis position [mm], full scale signal mean [V], percent standard deviation of the full scale signal [\%]

2.3.2. Format of formatted data file

2.3.2.1. Filename: F000xmmddyyyya.fmt

2.3.2.2. Wavelength [nm], McPherson absolute encoder reading, date, time, lamp station, lamp serial number, Heidehain linear encoder reading, wavelength $[\mathrm{nm}]$, net signal mean [V], percent standard deviation of the net signal [\%]

2.3.3. Format of combined data file

2.3.3.1. Filename: F000xmmddyyyya.-F000xmmddyyyyb.F000xmmddyyyyc.-prs

2.3.3.2. Wavelength [nm], net signal [V], percent standard deviation of the net signal $[\%]$

2.4. The lamp scan program can run alone to measure one spectral range for one lamp

2.5. The DAQ program sets up the monochromator for each spectral range. Use the motion control program to set up the monochromator when using the lamp scan program as a stand-alone program.

\subsection{Select the Grating}

\begin{tabular}{|c|c|c|c|c|c|}
\hline Procedure & Version & Date & Author & Pages & Filename \\
\hline IRR-CP-IRR1 & 1.0 & 29-Jun-06 & C. Gibson & 2 of 12 & $\begin{array}{c}\text { IRR-CP-IRR1 FC2 DAQ } \\
\text { Program Operation v1.doc }\end{array}$ \\
\hline
\end{tabular}




\section{Irradiance Calibration Procedure \\ IRR-CP-IRR1-FASCAL2 Data Acquisition Program Operation}

2.7. Select the Lamp Station

2.8. Enter the Lamp $\mathbf{S} / \mathbf{N}$

2.9. Select the Detector

2.10. Run the program

3. Motion control program (Motionmenu.vi)

3.1. Run the motion control program to load the menu options

3.2. The menu options

3.2.1. Enable Axis

3.2.1.1. Detector Stage

3.2.1.2. Wavelength

3.2.1.3. Main Table

3.2.2. Home Axis

3.2.2.1. Detector Stage

3.2.2.2. Wavelength

3.2.2.3. Main Table

3.2.3. Move Axis

3.2.3.1. Detector Stage

3.2.3.1.1. Silicon

3.2.3.1.2. InGaAs

3.2.3.1.3. HeNe Laser

3.2.3.2. Wavelength

3.2.3.3. Main Table

3.2.4. Shutter

3.2.4.1. Lamp 1

3.2.4.1.1. Open

3.2.4.1.2. Close

\begin{tabular}{|c|c|c|c|c|c|}
\hline Procedure & Version & Date & Author & Pages & Filename \\
\hline IRR-CP-IRR1 & 1.0 & 29-Jun-06 & C. Gibson & 3 of 12 & $\begin{array}{c}\text { IRR-CP-IRR1 FC2 DAQ } \\
\text { Program Operation v1.doc }\end{array}$ \\
\hline
\end{tabular}




\section{Irradiance Calibration Procedure}

IRR-CP-IRR1-FASCAL2 Data Acquisition Program Operation

3.2.4.2. Lamp 2

3.2.4.2.1. Open

3.2.4.2.2. Close

3.2.4.3. Lamp 3

3.2.4.3.1. Open

3.2.4.3.2. Close

3.2.4.4. Lamp 4

3.2.4.4.1. Open

3.2.4.4.2. Close

3.2.4.5. Open All

3.2.4.6. Close All

3.2.5. Monochromator

3.2.5.1. Grating

3.2.5.1.1. UV-VIS

3.2.5.1.2. IR

3.2.5.2. Wavelength

3.2.5.3. Exit mirrors

3.2.5.3.1. Single monochromator

3.2.5.3.2. Double monochromator

3.2.5.3.2.1. PMT

3.2.5.3.2.2. Si, InGaAs, $\mathrm{HeNe}$

3.2.5.4. Filter wheel

3.2.5.4.1. 1

3.2.5.4.2. 2

3.2.5.4.3. 3

3.2.5.4.4. 4

3.2.5.4.5. $\quad 5$

\begin{tabular}{|c|c|c|c|c|c|}
\hline Procedure & Version & Date & Author & Pages & Filename \\
\hline IRR-CP-IRR1 & 1.0 & 29-Jun-06 & C. Gibson & 4 of 12 & $\begin{array}{c}\text { IRR-CP-IRR1 FC2 DAQ } \\
\text { Program Operation v1.doc }\end{array}$ \\
\hline
\end{tabular}




\section{Irradiance Calibration Procedure IRR-CP-IRR1-FASCAL2 Data Acquisition Program Operation}

\subsection{6}

4. Lamp stability program (FEL Stability.vi)

4.1. The lamp stability program measures selected lamps periodically (usually once an hour over a 22 hour period)

4.2. This program communicates with the lamp current control program and starts the stability measurements after the lamps have operated for 20 minutes

4.3. This program does not ramp down the lamps at the end of the measurement

4.4. Run program

4.5. Select Lamps to be Measured

4.6. Click Press to Run

4.7. Enter filename

5. Document History

\begin{tabular}{|c|c|c|c|c|c|c|c|}
\hline Version & $\begin{array}{c}\text { Version } \\
\text { Date }\end{array}$ & Author & $\begin{array}{c}\text { Page } \\
\text { Total }\end{array}$ & $\begin{array}{c}\text { Revision } \\
\text { Date }\end{array}$ & $\begin{array}{c}\text { Revision } \\
\text { Date }\end{array}$ & $\begin{array}{c}\text { Revision } \\
\text { Date }\end{array}$ & $\begin{array}{c}\text { Revision } \\
\text { Date }\end{array}$ \\
\hline 1.0 & 29-Jun-06 & C. Gibson & 12 & & & & \\
\hline & & & & & & & \\
\hline & & & & & & & \\
\hline & & & & & & & \\
\hline & & & & & & & \\
\hline
\end{tabular}

\begin{tabular}{|c|c|c|c|c|c|}
\hline Procedure & Version & Date & Author & Pages & Filename \\
\hline IRR-CP-IRR1 & 1.0 & 29-Jun-06 & C. Gibson & 5 of 12 & $\begin{array}{c}\text { IRR-CP-IRR1 FC2 DAQ } \\
\text { Program Operation v1.doc }\end{array}$ \\
\hline
\end{tabular}




\section{Irradiance Calibration Procedure IRR-CP-IRR1-FASCAL2 Data Acquisition Program Operation}

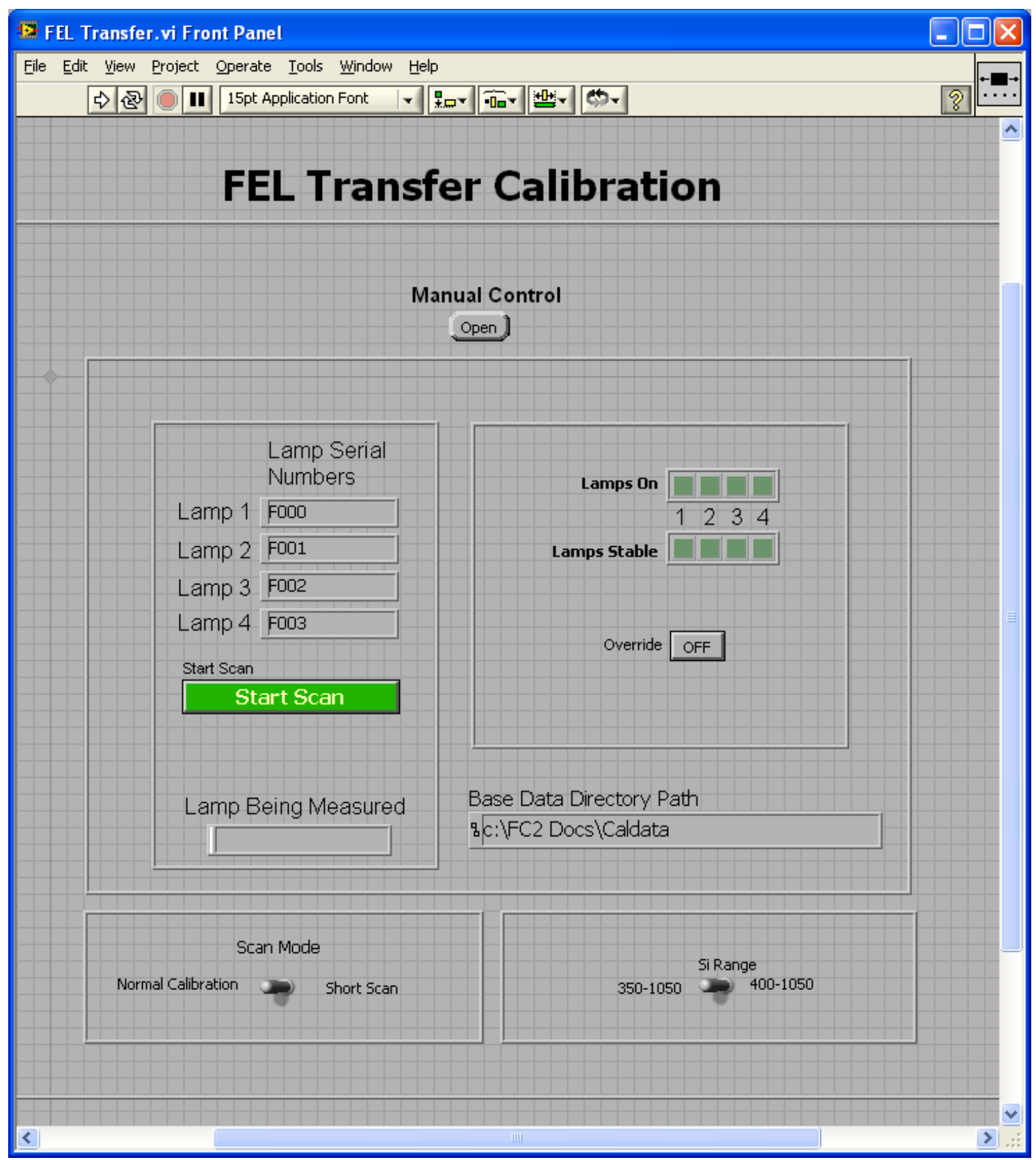

Figure Irr1.1. Front panel of FEL Transfer.vi

\begin{tabular}{|c|c|c|c|c|c|}
\hline Procedure & Version & Date & Author & Pages & Filename \\
\hline IRR-CP-IRR1 & 1.0 & 29-Jun-06 & C. Gibson & 6 of 12 & $\begin{array}{c}\text { IRR-CP-IRR1 FC2 DAQ } \\
\text { Program Operation v1.doc }\end{array}$ \\
\hline
\end{tabular}




\section{Irradiance Calibration Procedure IRR-CP-IRR1-FASCAL2 Data Acquisition Program Operation}

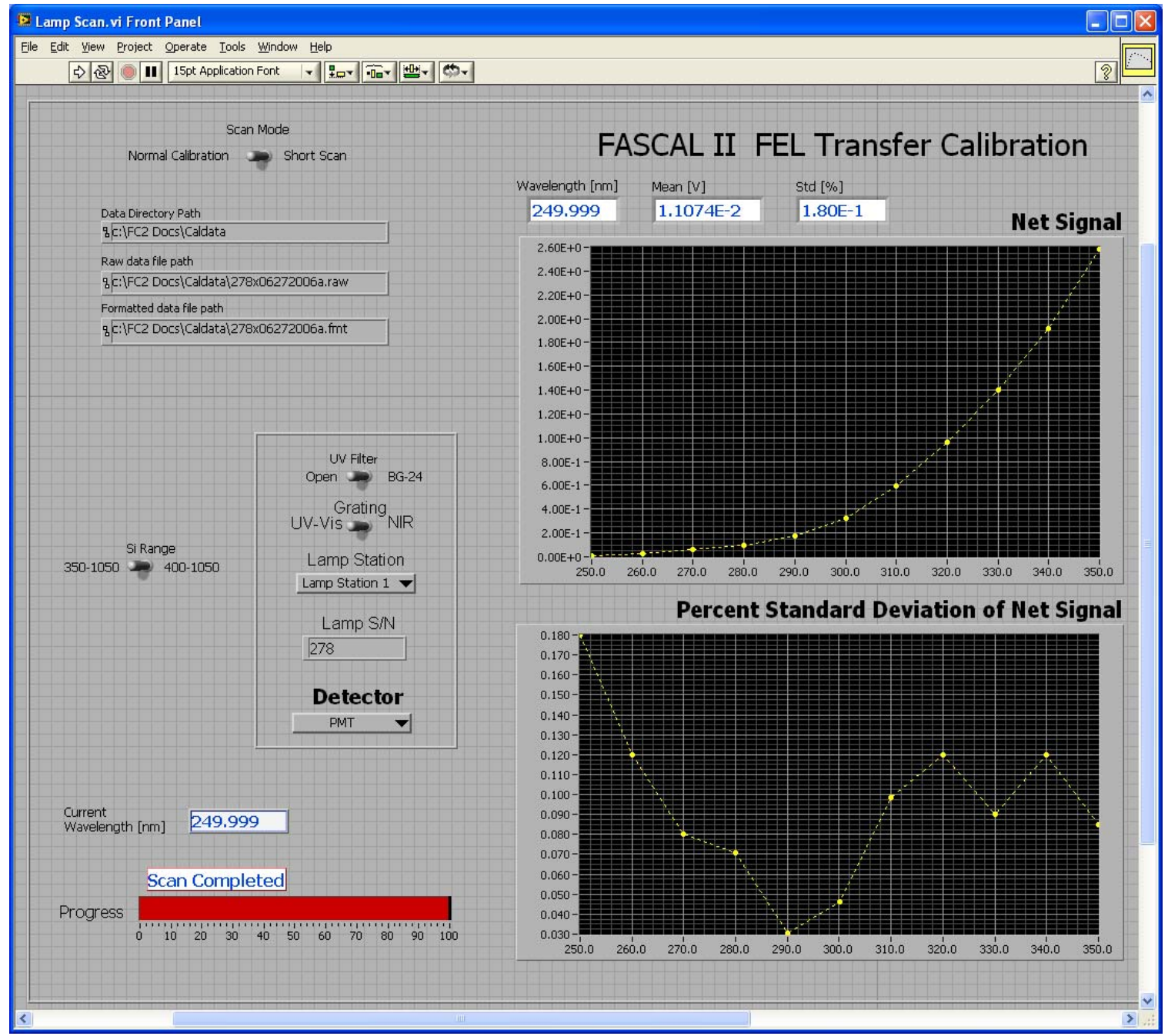

Figure Irr1.2. Front panel of Lamp Scan.vi

\begin{tabular}{|c|c|c|c|c|c|}
\hline Procedure & Version & Date & Author & Pages & Filename \\
\hline IRR-CP-IRR1 & 1.0 & 29-Jun-06 & C. Gibson & 7 of 12 & $\begin{array}{c}\text { IRR-CP-IRR1 FC2 DAQ } \\
\text { Program Operation v1.doc }\end{array}$ \\
\hline
\end{tabular}




\section{Irradiance Calibration Procedure IRR-CP-IRR1-FASCAL2 Data Acquisition Program Operation}

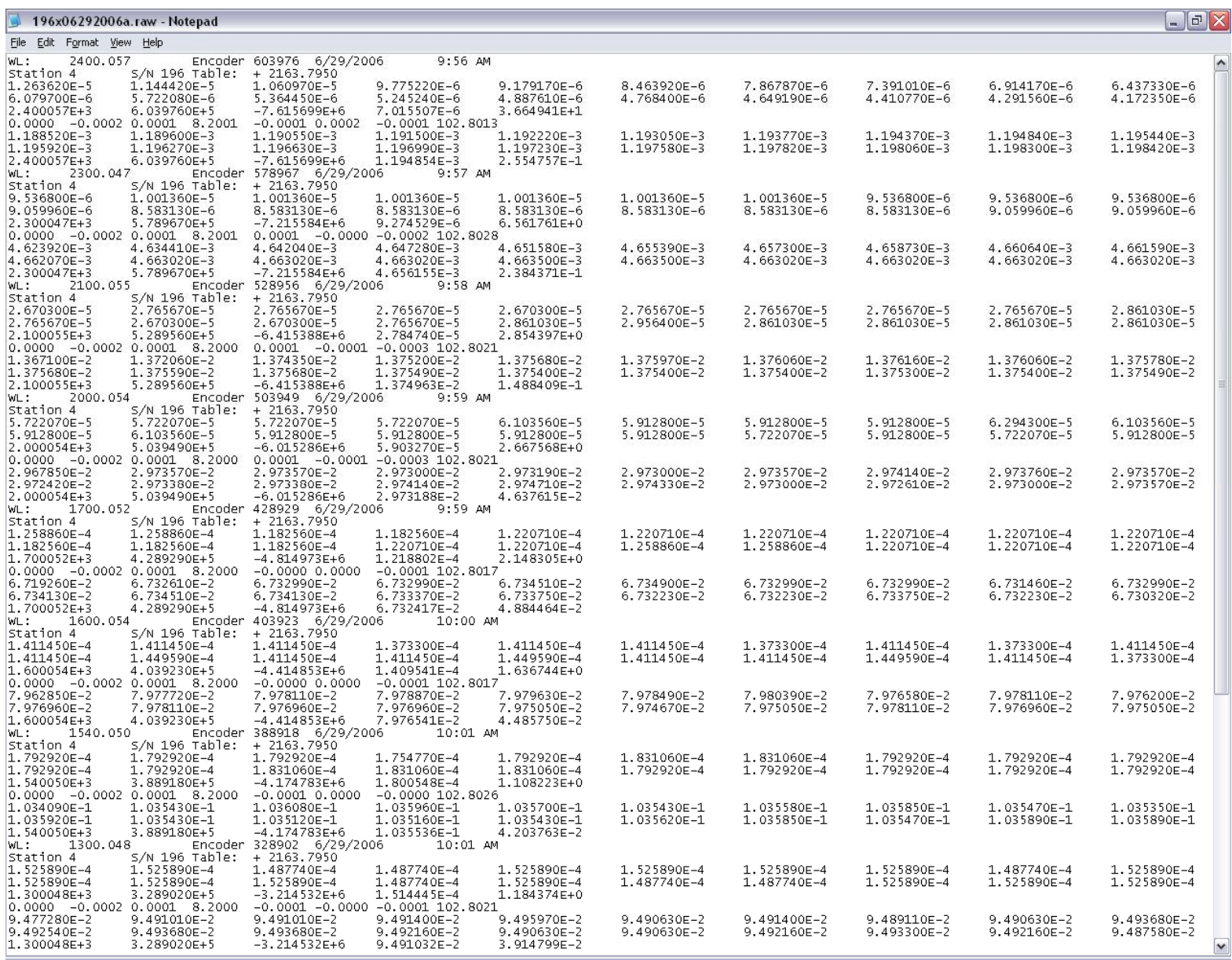

Figure Irr1.3. Sample raw data from lamp scan program

\begin{tabular}{|c|c|c|c|c|c|}
\hline Procedure & Version & Date & Author & Pages & Filename \\
\hline IRR-CP-IRR1 & 1.0 & 29-Jun-06 & C. Gibson & 8 of 12 & $\begin{array}{c}\text { IRR-CP-IRR1 FC2 DAQ } \\
\text { Program Operation v1.doc }\end{array}$ \\
\hline
\end{tabular}




\section{Irradiance Calibration Procedure IRR-CP-IRR1-FASCAL2 Data Acquisition Program Operation}

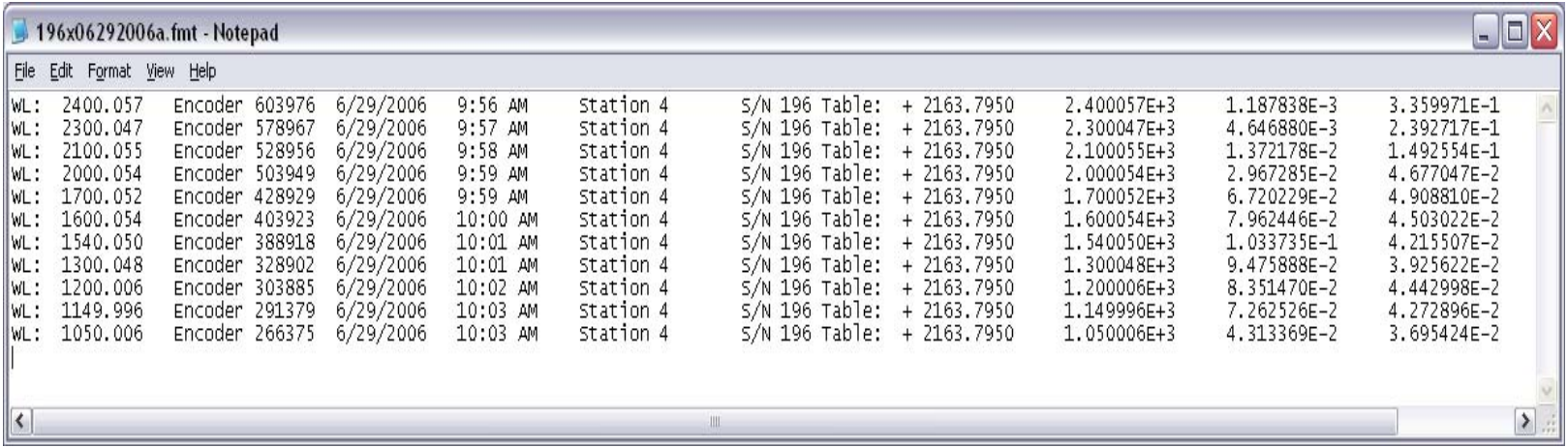

Figure Irr1.4. Sample formatted data from lamp scan program

\begin{tabular}{|c|c|c|c|c|c|}
\hline Procedure & Version & Date & Author & Pages & Filename \\
\hline IRR-CP-IRR1 & 1.0 & 29-Jun-06 & C. Gibson & 9 of 12 & $\begin{array}{c}\text { IRR-CP-IRR1 FC2 DAQ } \\
\text { Program Operation v1.doc }\end{array}$ \\
\hline
\end{tabular}




\section{Irradiance Calibration Procedure IRR-CP-IRR1-FASCAL2 Data Acquisition Program Operation}

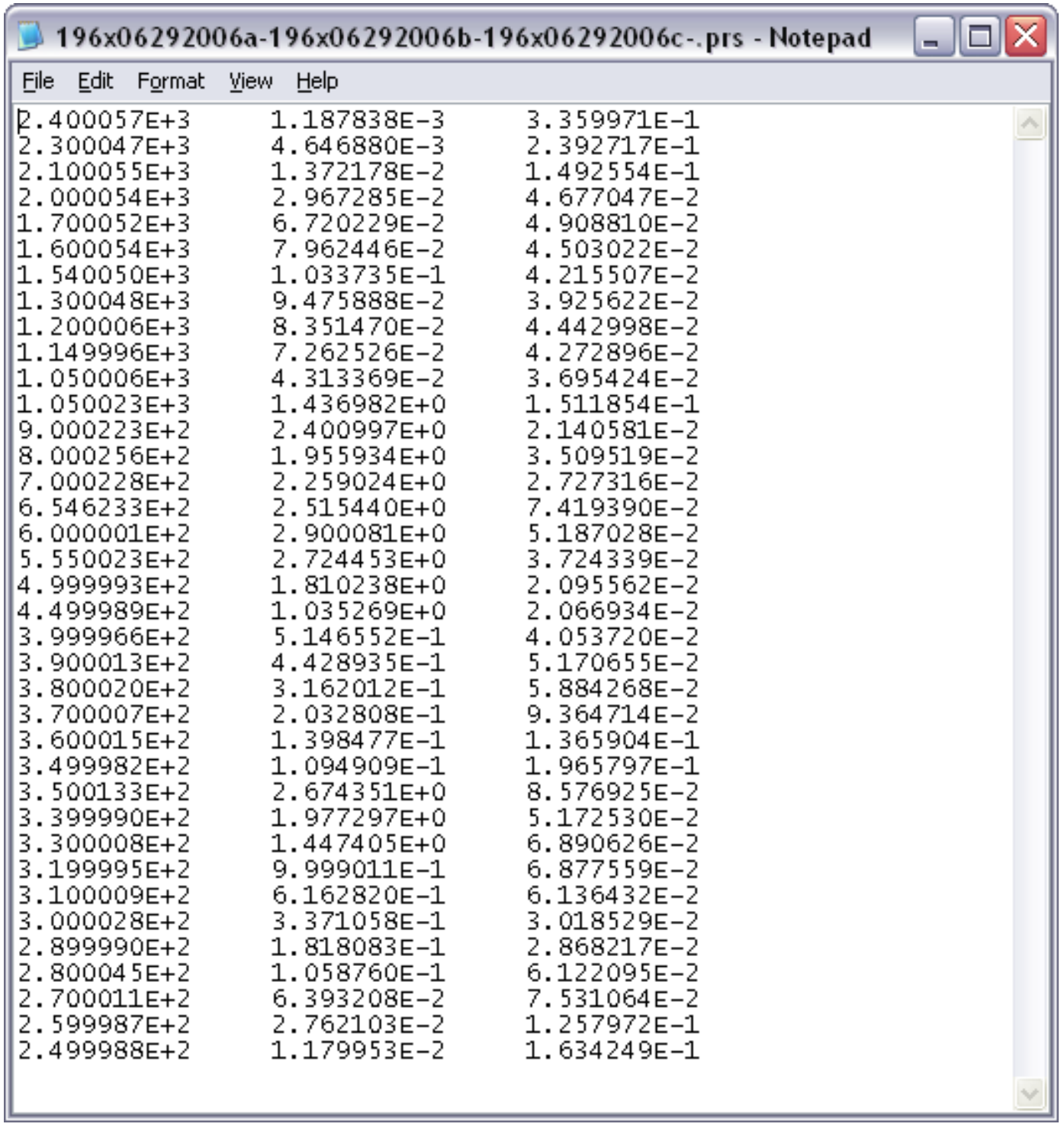

Figure Irr1.5. Sample combined formatted data from DAQ program. The three formatted data files from the lamp scan program are combined into a single file.

\begin{tabular}{|c|c|c|c|c|c|}
\hline Procedure & Version & Date & Author & Pages & Filename \\
\hline IRR-CP-IRR1 & 1.0 & 29-Jun-06 & C. Gibson & 10 of 12 & $\begin{array}{c}\text { IRR-CP-IRR1 FC2 DAQ } \\
\text { Program Operation v1.doc }\end{array}$ \\
\hline
\end{tabular}




\section{Irradiance Calibration Procedure IRR-CP-IRR1-FASCAL2 Data Acquisition Program Operation}

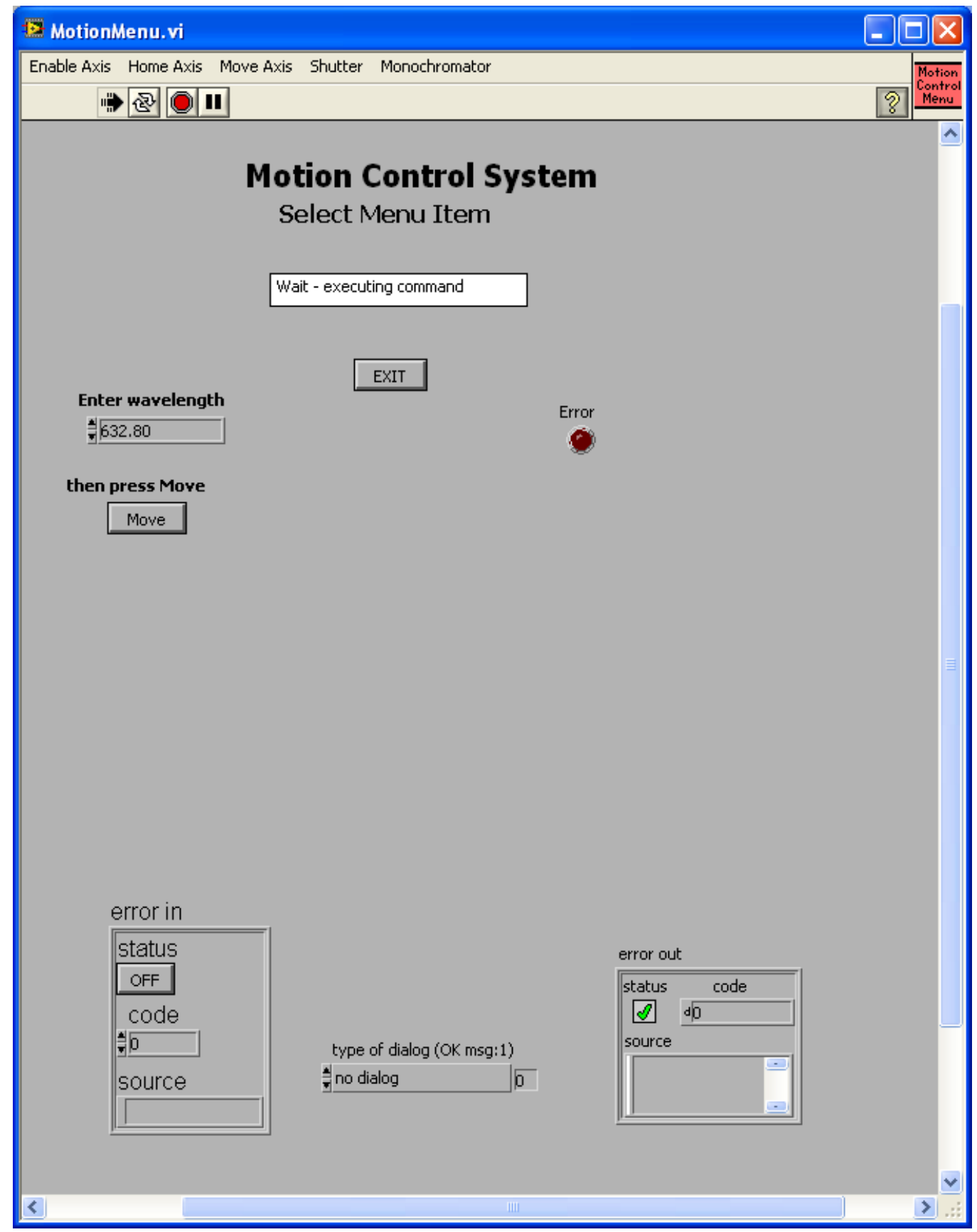

Figure Irr1.6. Front panel of MotionMenu.vi

\begin{tabular}{|c|c|c|c|c|c|}
\hline Procedure & Version & Date & Author & Pages & Filename \\
\hline IRR-CP-IRR1 & 1.0 & 29-Jun-06 & C. Gibson & 11 of 12 & $\begin{array}{c}\text { IRR-CP-IRR1 FC2 DAQ } \\
\text { Program Operation v1.doc }\end{array}$ \\
\hline
\end{tabular}




\section{Irradiance Calibration Procedure IRR-CP-IRR1-FASCAL2 Data Acquisition Program Operation}

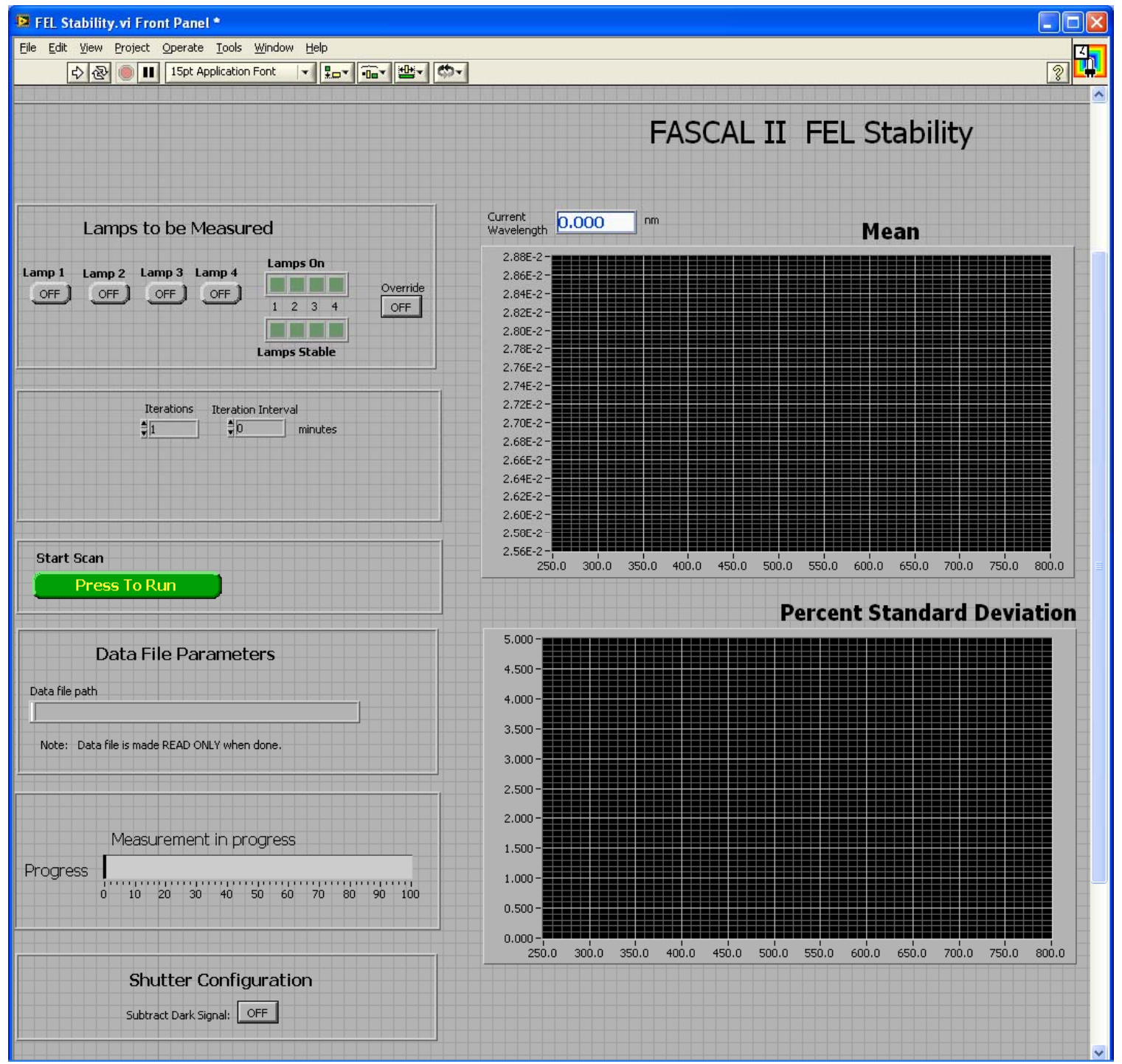

Figure Irr1.7. Front panel of FEL Stability.vi

\begin{tabular}{|c|c|c|c|c|c|}
\hline Procedure & Version & Date & Author & Pages & Filename \\
\hline IRR-CP-IRR1 & 1.0 & 29-Jun-06 & C. Gibson & 12 of 12 & $\begin{array}{c}\text { IRR-CP-IRR1 FC2 DAQ } \\
\text { Program Operation v1.doc }\end{array}$ \\
\hline
\end{tabular}




\section{Irradiance Calibration Procedure \\ IRR-CP-IRR2-Quartz Halogen Lamp Alignment}

Quartz Halogen Lamp (QHL) Alignment

\begin{tabular}{|c|}
\hline CAOTION \\
\hline BRIGHT SOURCE \\
\hline BURN \\
\hline COLLISION \\
\hline ELECTROCUTION \\
\hline
\end{tabular}

1. The spectral irradiance is measured at $50 \mathrm{~cm}$ from the receiving aperture of the spectroradiometer to the front surface of the lamp bi-posts.

2. The lamp is operated in a kinematic lamp socket.

3. Lamp alignment overview

3.1. The lamp is measured at a distance of $50 \mathrm{~cm}$ from the entrance aperture of the integrating sphere with an aperture area of $1.0027 \mathrm{~cm}^{2}$. The sphere views approximately a $9 \mathrm{~cm}$ diameter target in the plane of the front surface of the lamp bi-posts. With this geometry, the entire lamp is viewed from the top of the lamp envelope down to the top half of the black lamp base. Light baffling is used between the lamp and the spectroradiometer integrating sphere to minimize effects of scattered light.

3.2. The lamp is mounted vertically, base down with the brass identification plate facing away from the spectroradiometer. The lamp serial number and electrical polarity are indicated on the plate. An alignment jig is placed in the kinematic lamp socket and aligned. This is accomplished by placing a spirit level on top of the jig and then by adjusting the angle about the optical axis until the level is balanced. The alignment jig target area, which is indicated by cross hairs, is centered between the bi-posts and located $9.5 \mathrm{~cm}$ above the bottom of the jig bi-posts. This target area is centered vertically and horizontally onto the optical axis. The jig is set perpendicular to the optical axis by reflecting the spectroradiometer laser beam back onto itself. The distance along the optical axis from the target area surface to the surface of the sphere aperture is set at $50 \mathrm{~cm}$. The target area surface is in the plane with the front surface of the bi-posts. This alignment procedure sets the alignment jig bi-posts relative to the optical axis of the spectroradiometer. The jig is removed and the lamp is placed in the aligned socket.

4. Run the motion control (see IRR-CP-IRR1)

5. Align the integrating sphere

5.1. Put a dummy lamp in lamp station 4

\begin{tabular}{|c|c|c|c|c|c|}
\hline Procedure & Version & Date & Author & Pages & Filename \\
\hline IRR-CP-IRR2 & 1.0 & 27-Jun-06 & C. Gibson & 1 of 4 & $\begin{array}{c}\text { IRR-CP-IRR2 Quartz Halogen } \\
\text { Lamp Alignment v1.doc }\end{array}$ \\
\hline
\end{tabular}




\section{Irradiance Calibration Procedure IRR-CP-IRR2-Quartz Halogen Lamp Alignment}

\subsection{Turn on the lamp}

5.3. Move the main table to lamp station 4

5.4. Use the scope to view the image of the integrating sphere exit port on the monochromator slit

5.5. Adjust the spherical mirror to center the image of the integrating sphere exit port on the monochromator slit

6. Align the lamp sockets

6.1. Use the motion control program to position the internal laser (see IRR-CP-IRR1)

6.2. Set grating to UV-VIS (grating \#1)

6.3. Set exit mirror to double monochromator ( $\mathrm{Si}$, InGaAs, HeNe setting)

6.4. Set filter wheel to position 6

6.5. Set wavelength to 632.8

6.6. Turn on internal laser

6.7. Check that laser illuminates the sphere (this verifies the spectroradiometer settings)

6.8. Turn off internal laser

6.9. Put alignment jig in lamp station 1

6.10. Move the main table to lamp station 1

6.11. Turn on external laser

6.12. Install beam splitter

6.13. Align external laser on the center of the integrating sphere (IS) aperture

6.14. Move the main table to lamp station 0

6.15. Remove integrating sphere

6.16. Put in mirror

6.17. Turn on internal laser

6.18. Move the main table to lamp station 1

6.19. Align internal laser onto external laser by adjusting the mirror

6.20. Align alignment jig using the internal laser

6.21. Remove mirror

\begin{tabular}{|c|c|c|c|c|c|}
\hline Procedure & Version & Date & Author & Pages & Filename \\
\hline IRR-CP-IRR2 & 1.0 & 27-Jun-06 & C. Gibson & 2 of 4 & $\begin{array}{c}\text { IRR-CP-IRR2 Quartz Halogen } \\
\text { Lamp Alignment v1.doc }\end{array}$ \\
\hline
\end{tabular}




\section{Irradiance Calibration Procedure IRR-CP-IRR2-Quartz Halogen Lamp Alignment}

6.22. Put in integrating sphere

6.23. Use the distance gauge to measure $50 \mathrm{~cm}$ from the aperture of the integrating sphere to the front surface of the alignment jig

7. Repeat alignment for lamp stations 2 thru 4

8. Insert the lamp(s) in the lamp socket(s)

8.1. Do not touch lamp envelope

8.2. Place lamp in the socket

\subsubsection{Check lamp polarity}

8.2.1.1. Polarity is indicated on the brass plate

8.2.2. Set brass plate with lamp serial number away from the spectroradiometer

8.2.3. Use your left hand to place the lamp in the socket

8.2.4. Hold the left post lightly against the socket terminal

8.2.5. Turn the left socket knob counterclockwise to fasten the lamp

8.2.6. Turn the right socket knob counterclockwise to fasten the lamp

9. Document History

\begin{tabular}{|c|c|c|c|c|c|c|c|}
\hline Version & $\begin{array}{c}\text { Version } \\
\text { Date }\end{array}$ & Author & $\begin{array}{c}\text { Page } \\
\text { Total }\end{array}$ & $\begin{array}{c}\text { Revision } \\
\text { Date }\end{array}$ & $\begin{array}{c}\text { Revision } \\
\text { Date }\end{array}$ & $\begin{array}{c}\text { Revision } \\
\text { Date }\end{array}$ & $\begin{array}{c}\text { Revision } \\
\text { Date }\end{array}$ \\
\hline 1.0 & 27-Jun-06 & C. Gibson & 4 & & & & \\
\hline & & & & & & & \\
\hline & & & & & & & \\
\hline & & & & & & & \\
\hline & & & & & & & \\
\hline
\end{tabular}

\begin{tabular}{|c|c|c|c|c|c|}
\hline Procedure & Version & Date & Author & Pages & Filename \\
\hline IRR-CP-IRR2 & 1.0 & 27-Jun-06 & C. Gibson & 3 of 4 & $\begin{array}{c}\text { IRR-CP-IRR2 Quartz Halogen } \\
\text { Lamp Alignment v1.doc }\end{array}$ \\
\hline
\end{tabular}




\section{Irradiance Calibration Procedure

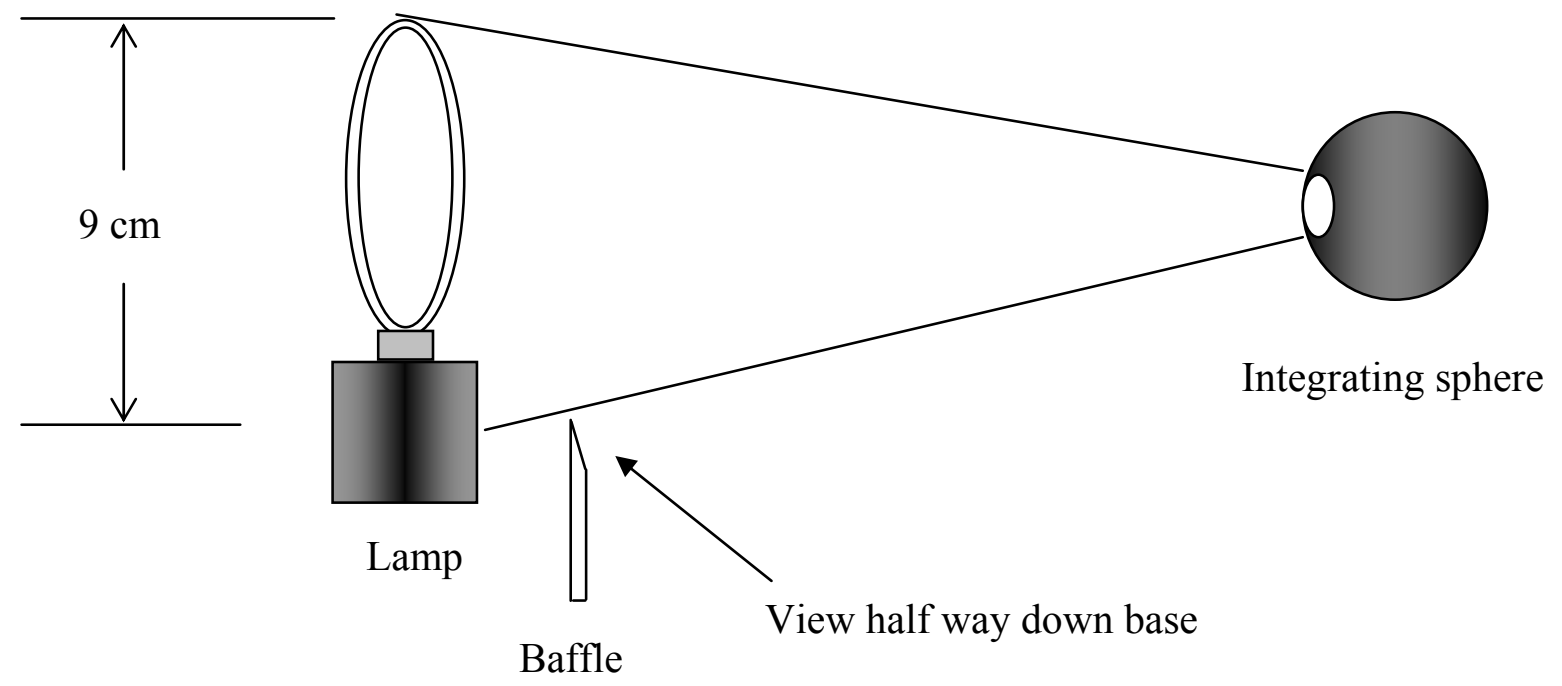

Figure Irr2. This drawing shows the target area viewed by the spectroradiometer integrating sphere.

\begin{tabular}{|c|c|c|c|c|c|}
\hline Procedure & Version & Date & Author & Pages & Filename \\
\hline IRR-CP-IRR2 & 1.0 & 27-Jun-06 & C. Gibson & 4 of 4 & $\begin{array}{c}\text { IRR-CP-IRR2 Quartz Halogen } \\
\text { Lamp Alignment v1.doc }\end{array}$ \\
\hline
\end{tabular}




\section{Irradiance Calibration Procedure \\ IRR-CP-IRR3-Quartz Halogen Lamp Operation}

Quartz Halogen Lamp (QHL) Operation

\begin{tabular}{|c|}
\hline CAUTION \\
\hline BRIGHT SOURCE \\
\hline BURN \\
\hline COLLISION \\
\hline ELECTROCUTION \\
\hline
\end{tabular}

1. Operating conditions

1.1. The lamp is slowly ramped up to $8.2 \mathrm{~A}$ DC over 5 minutes.

1.2. The lamp current is maintained at $(8.2000 \pm 0.0002)$ A during the calibration.

1.3. Measurements are started after the lamp has stabilized for $20 \mathrm{~min}$.

2. Align the lamp sockets (See IRR-CP-IRR2)

3. Do not touch lamp envelope

4. Place $\operatorname{lamp}(\mathrm{s})$ in the lamp socket(s)

5. Turn on the digital multimeter (DMM)

6. Turn on the digital-to-analog converter (D/A converter)

7. Check that the correct lamp power cable is connected to the power supply

8. Turn on all four power supplies

9. Load the lamp current control program (Lamp Current Control.vi)

9.1. The lamp current control program ramps up, regulates, and ramps down the lamp currents. The serial number, date, time, lamp current, lamp voltage, and burning time are stored in a summary file. The serial number, date, lamp current, lamp voltage, and total burning time are stored in a lamp time file.

9.2. Turn on the computer

9.3. Load the LabVIEW program: c:|FC2 PS Docs $\mid$ Lamp Control Program $\backslash$ Lamp Current Control.vi (do one of the following)

9.3.1. From the start menu

9.3.1.1. Click Start

9.3.1.2. Click Lamp Current Control

\begin{tabular}{|c|c|c|c|c|c|}
\hline Procedure & Version & Date & Author & Pages & Filename \\
\hline IRR-CP-IRR3 & 1.0 & 27-Jun-06 & C. Gibson & 1 of 6 & $\begin{array}{c}\text { IRR-CP-IRR3 Quartz Halogen } \\
\text { Lamp Operation v1.doc }\end{array}$ \\
\hline
\end{tabular}




\section{Irradiance Calibration Procedure IRR-CP-IRR3-Quartz Halogen Lamp Operation}

\subsubsection{From Windows Explorer}

9.3.2.1.Locate Lamp Current Control.vi and double click to open

\subsubsection{From LabVIEW}

\subsubsection{Open LabVIEW}

\subsubsection{Click Lamp Current Control.vi}

9.4. Enter Lamp serial number

\subsection{Enter Lamp Current [A]}

9.6. Click the Enable button for the lamp(s) to ramp up

9.6.1. The power output to the unselected lamps is disabled

9.7. If also running the DAQ program (FEL Transfer.vi) (See IRR-CP-IRR1), enable only the first lamp. The DAQ program communicates with the Lamp Current Control program to ramp up the lamp, wait 20 minutes for the lamp to stabilize, measure the lamp and then ramp down the lamp. Measurements are performed for the lamps entered into the DAQ program.

10. Run the program (do one of the following)

\subsection{Press Ctrl+R}

10.2. Click the Run icon on the tool bar

10.3. Click the menu item Operate then Run

11. Enter the lamp data filename (psdatayyyymmdd.txt)

12. Turn off lamps

12.1. Enter Lamp Current [A] (value $=\mathbf{0})$

12.2. Click the Enable button for the lamp(s) to ramp down

\section{MANUAL TURN OFF}

\subsection{Go to the supply}

13.2. Press the LCL button to set the power supply to the local mode

13.3. Press the Output Adjust button and toggle to Voltage

13.4. Press and hold the Display setting button

13.5. Turn the Output Adjust knob counterclockwise until the display reads 0.00 volts

13.6. Turn off the supply

\begin{tabular}{|c|c|c|c|c|c|}
\hline Procedure & Version & Date & Author & Pages & Filename \\
\hline IRR-CP-IRR3 & 1.0 & 27-Jun-06 & C. Gibson & 2 of 6 & $\begin{array}{c}\text { IRR-CP-IRR3 Quartz Halogen } \\
\text { Lamp Operation v1.doc }\end{array}$ \\
\hline
\end{tabular}




\section{Irradiance Calibration Procedure IRR-CP-IRR3-Quartz Halogen Lamp Operation}

\section{MANUAL RESET AFTER ERROR}

14.1. Reset power supply if Yellow LED is lit

14.2. Turn off the power supply

14.3. Turn on the power supply

14.4. Press the Output Adjust button and toggle to Voltage

14.5. Press and hold the Display setting button

14.6. Set the voltage limit by turning the Output Adjust knob clockwise until the display reads the target voltage limit (122.0 volts)

14.7. The constant current (CC) indicator light should now be lit

15. Document History

\begin{tabular}{|c|c|c|c|c|c|c|c|}
\hline Version & $\begin{array}{c}\text { Version } \\
\text { Date }\end{array}$ & Author & $\begin{array}{c}\text { Page } \\
\text { Total }\end{array}$ & $\begin{array}{c}\text { Revision } \\
\text { Date }\end{array}$ & $\begin{array}{c}\text { Revision } \\
\text { Date }\end{array}$ & $\begin{array}{c}\text { Revision } \\
\text { Date }\end{array}$ & $\begin{array}{c}\text { Revision } \\
\text { Date }\end{array}$ \\
\hline 1.0 & 27-Jun-06 & C. Gibson & 6 & & & & \\
\hline & & & & & & & \\
\hline & & & & & & & \\
\hline & & & & & & & \\
\hline
\end{tabular}

\begin{tabular}{|c|c|c|c|c|c|}
\hline Procedure & Version & Date & Author & Pages & Filename \\
\hline IRR-CP-IRR3 & 1.0 & 27-Jun-06 & C. Gibson & 3 of 6 & $\begin{array}{c}\text { IRR-CP-IRR3 Quartz Halogen } \\
\text { Lamp Operation v1.doc }\end{array}$ \\
\hline
\end{tabular}




\section{Irradiance Calibration Procedure IRR-CP-IRR3-Quartz Halogen Lamp Operation}

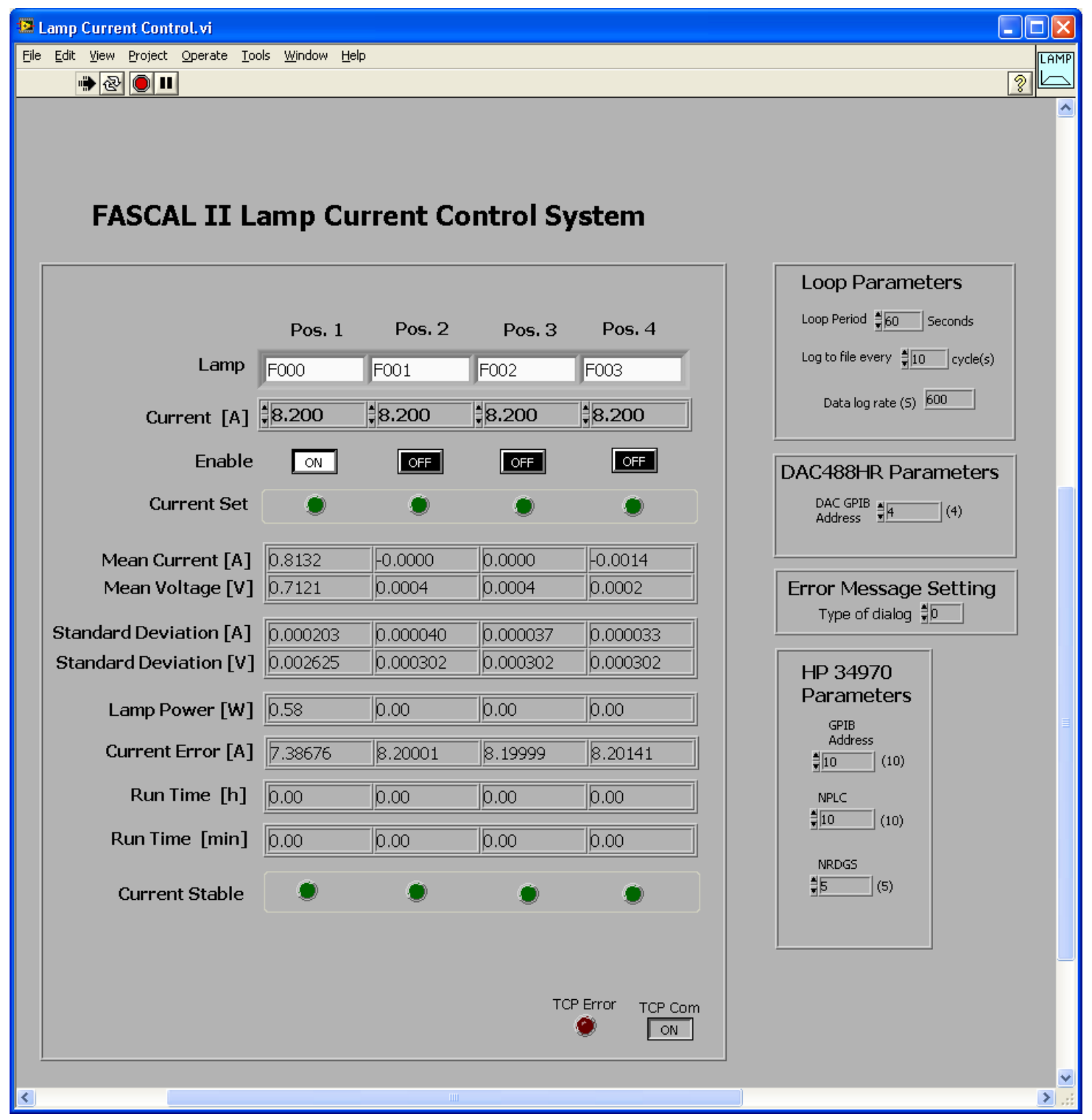

Figure Irr3.1. Front panel of Lamp Current Control.vi

\begin{tabular}{|c|c|c|c|c|c|}
\hline Procedure & Version & Date & Author & Pages & Filename \\
\hline IRR-CP-IRR3 & 1.0 & 27-Jun-06 & C. Gibson & 4 of 6 & $\begin{array}{c}\text { IRR-CP-IRR3 Quartz Halogen } \\
\text { Lamp Operation v1.doc }\end{array}$ \\
\hline
\end{tabular}




\section{Irradiance Calibration Procedure IRR-CP-IRR3-Quartz Halogen Lamp Operation}

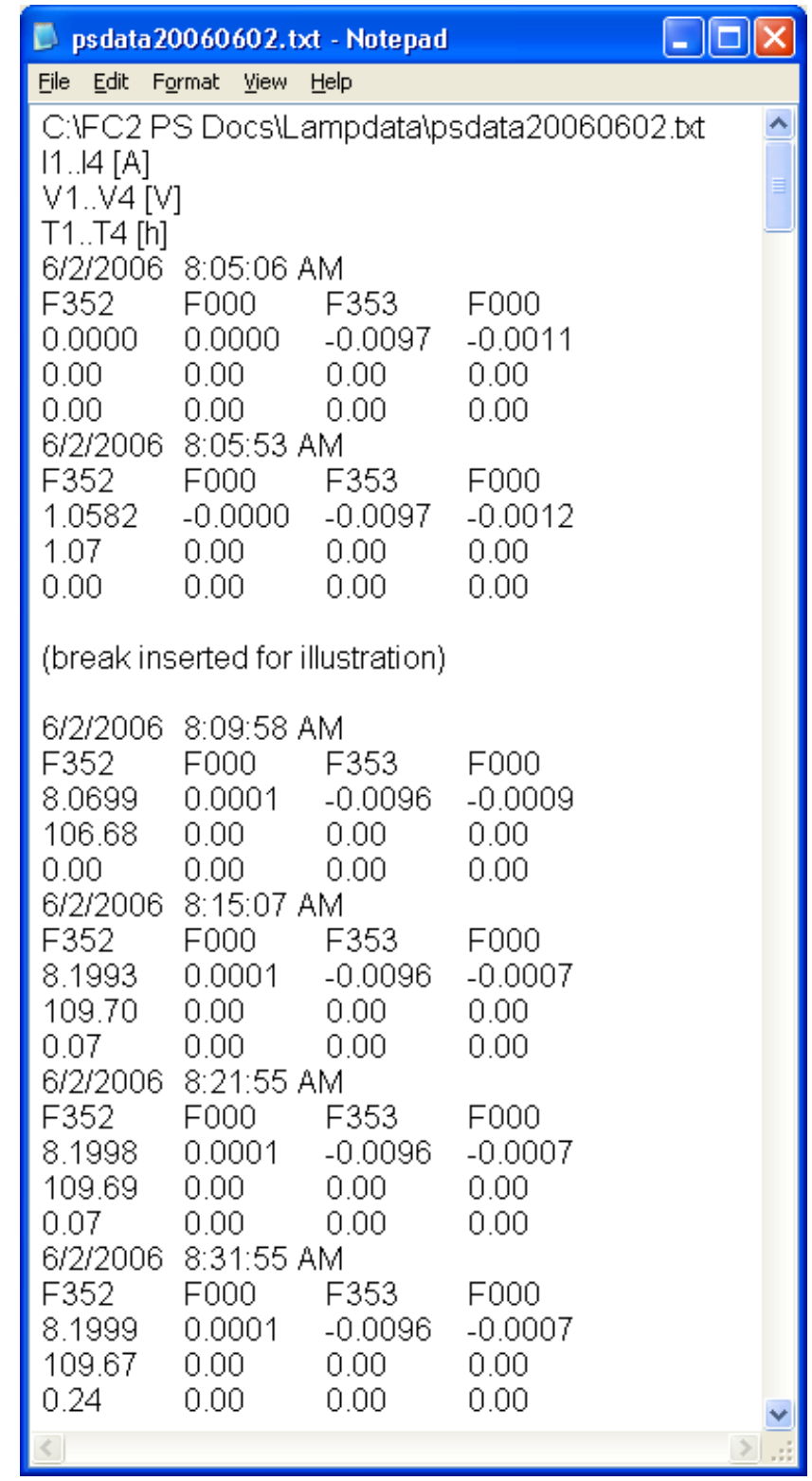

Figure Irr3.2. Sample lamp summary file

\begin{tabular}{|c|c|c|c|c|c|}
\hline Procedure & Version & Date & Author & Pages & Filename \\
\hline IRR-CP-IRR3 & 1.0 & 27-Jun-06 & C. Gibson & 5 of 6 & $\begin{array}{c}\text { IRR-CP-IRR3 Quartz Halogen } \\
\text { Lamp Operation v1.doc }\end{array}$ \\
\hline
\end{tabular}




\section{Irradiance Calibration Procedure IRR-CP-IRR3-Quartz Halogen Lamp Operation}

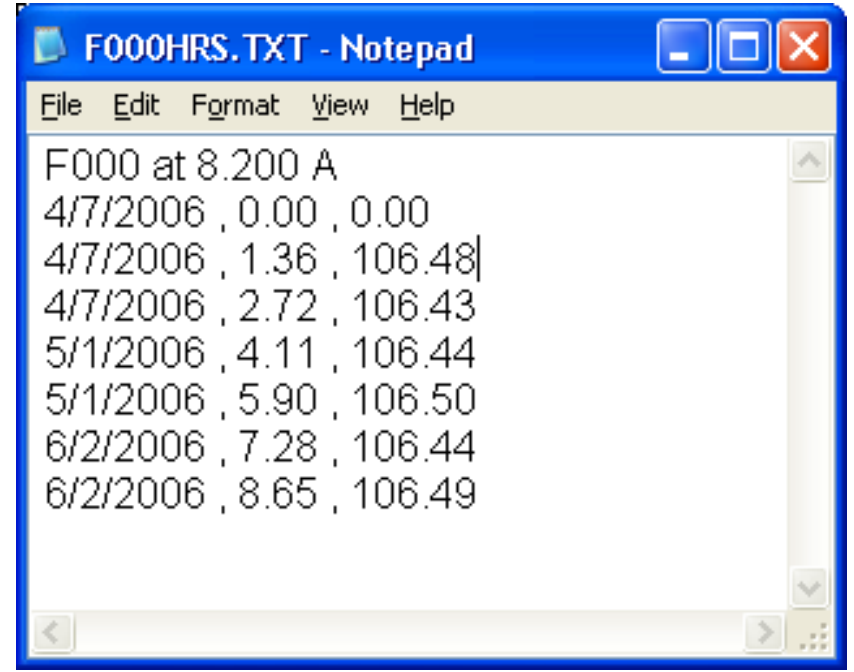

Figure Irr3.3. Sample lamp time file

\begin{tabular}{|c|c|c|c|c|c|}
\hline Procedure & Version & Date & Author & Pages & Filename \\
\hline IRR-CP-IRR3 & 1.0 & 27-Jun-06 & C. Gibson & 6 of 6 & $\begin{array}{c}\text { IRR-CP-IRR3 Quartz Halogen } \\
\text { Lamp Operation v1.doc }\end{array}$ \\
\hline
\end{tabular}




\section{Irradiance Calibration Procedure IRR-CP-IRR4-High Temperature Blackbody (HTBB) Alignment}

High Temperature Blackbody (HTBB) Alignment

\begin{tabular}{|c|}
\hline CAUTION \\
\hline BRIGHT SOURCE \\
\hline BURN \\
\hline COLLISION \\
\hline ELECTROCUTION \\
\hline
\end{tabular}

1. Run the motion control program (see IRR-CP-IRR1)

2. Align the integrating sphere (IS)

2.1. Put a dummy lamp in lamp station 4

2.2. Turn on the lamp

2.3. Move the main table to lamp station 4

2.4. Use the scope to view the image of the integrating sphere exit port on the monochromator slit

2.5. Adjust the spherical mirror to center the image of the integrating sphere exit port on the monochromator slit

2.6. Turn off the lamp

3. Define the HTBB optical axis

3.1. Move the main table to lamp station 5

3.2. Position the HTBB window approximately $50 \mathrm{~cm}$ from the IS aperture

3.3. Level the HTBB housing

3.4. Install a beam splitter (microscope slide cover) between the HTBB and the IS

3.5. Install an external laser perpendicular to the optical axis

3.6. Turn on the external laser

3.7. Center the HTBB on the laser

3.8. Adjust the HTBB until the laser goes through the center of the HTBB window and the center of the cavity bottom

\begin{tabular}{|c|c|c|c|c|c|}
\hline Procedure & Version & Date & Author & Pages & Filename \\
\hline IRR-CP-IRR4 & 1.0 & 20-Sep-06 & C. Gibson & 1 of 3 & $\begin{array}{c}\text { IRR-CP-IRR4 HTBB Alignment } \\
\text { v1.doc }\end{array}$ \\
\hline
\end{tabular}




\section{Irradiance Calibration Procedure IRR-CP-IRR4-High Temperature Blackbody (HTBB) Alignment}

4. Align the water-cooled aperture (WCA)

4.1. Use double stick tape to attach a microscope slide to the HTBB water-cooled aperture

4.2. Position the WCA approximately $45 \mathrm{~cm}$ from the IS aperture

4.3. Center the WCA on the optical axis

4.4. Adjust the WCA until it is centered on the laser and normal to it

5. Align the HTBB

5.1. Use double stick tape to attach a microscope slide to the IS aperture mount

5.2. Align the external laser on the center of the integrating sphere (IS) aperture

\subsubsection{Do not make any adjustments to the IS}

5.2.2. Translate the main table to translate the IS in the horizontal axis

5.3. Adjust the laser and/or the beam splitter until the laser is centered on the IS aperture and normal to it

6. Repeat sections 3 and 4 to realign the HTBB and WCA on the optical axis defined by the IS

7. Remove the beam splitter (microscope slide cover)

8. Remove the microscope slides from the apertures

9. Measure the distance between the WCA and the IS

10. Document History

\begin{tabular}{|c|c|c|c|c|c|c|c|}
\hline Version & $\begin{array}{c}\text { Version } \\
\text { Date }\end{array}$ & Author & $\begin{array}{c}\text { Page } \\
\text { Total }\end{array}$ & $\begin{array}{c}\text { Revision } \\
\text { Date }\end{array}$ & $\begin{array}{c}\text { Revision } \\
\text { Date }\end{array}$ & $\begin{array}{c}\text { Revision } \\
\text { Date }\end{array}$ & $\begin{array}{c}\text { Revision } \\
\text { Date }\end{array}$ \\
\hline 1.0 & 20 -Sep-06 & C. Gibson & 3 & & & & \\
\hline & & & & & & & \\
\hline & & & & & & & \\
\hline & & & & & & & \\
\hline & & & & & & & \\
\hline
\end{tabular}

\begin{tabular}{|c|c|c|c|c|c|}
\hline Procedure & Version & Date & Author & Pages & Filename \\
\hline IRR-CP-IRR4 & 1.0 & 20-Sep-06 & C. Gibson & 2 of 3 & $\begin{array}{c}\text { IRR-CP-IRR4 HTBB Alignment } \\
\text { V1.doc }\end{array}$ \\
\hline
\end{tabular}




\section{Irradiance Calibration Procedure IRR-CP-IRR4-High Temperature Blackbody (HTBB) Alignment}

Precision aperture

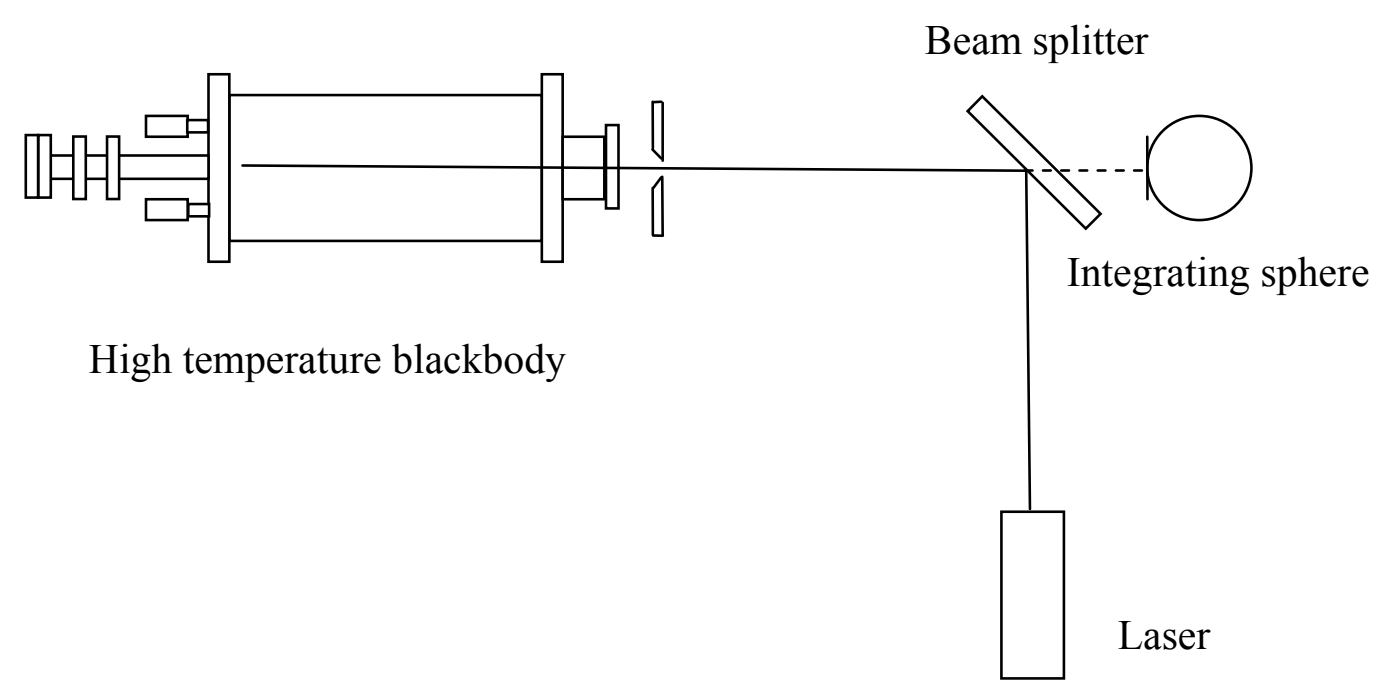

Figure Irr4. This drawing shows the optical layout for the HTBB alignment

\begin{tabular}{|r|c|c|c|c|c|}
\hline Procedure & Version & Date & Author & Pages & Filename \\
\hline IRR-CP-IRR4 & 1.0 & 20-Sep-06 & C. Gibson & 3 of 3 & $\begin{array}{c}\text { IRR-CP-IRR4 HTBB Alignment } \\
\text { V1.doc }\end{array}$ \\
\hline
\end{tabular}




\section{Irradiance Calibration Procedure IRR-CP-IRR5-High Temperature Blackbody (HTBB) Operation}

High Temperature Blackbody (HTBB) Operation

\begin{tabular}{|c|}
\hline CAOTION \\
\hline BRIGHT SOURCE \\
\hline BURN \\
\hline COLLISION \\
\hline ELECTROCUTION \\
\hline
\end{tabular}

\section{HTBB Preparation}

1.1. Turn on the argon supply (set flow rate to $0.5 \mathrm{~L} / \mathrm{min}$ (11 on the flow meter))

1.2. Close the argon needle valve on the rear of the HTBB

1.3. Turn on cold water to HTBB furnace (20 psi)

1.4. Turn on chilled water $\left(55^{\circ} \mathrm{F}\right)$ to power supply (20 psi)

1.5. Turn on cold water to the water-cooled aperture

1.6. Purge the HTBB

1.6.1. Install the vacuum plate and window cap on the front of the HTBB

1.6.2. Check the vacuum fitting

1.6.3. Connect the vacuum hose

1.6.4. Open the valve to the vacuum pump

1.6.5. Pump down the HTBB with the rough vacuum pump until the pressure reaches $-100 \mathrm{kPa}$

1.6.6. Close valve to vacuum pump

1.6.7. Turn off vacuum pump

1.6.8. Open the HTBB argon needle valve to the FULL position

1.6.9. Close the HTBB argon needle valve when the pressure reaches $20 \mathrm{kPa}$

1.6.10. Repeat the purging sequence two more times

2. Turn On Procedure

2.1. Remove the vacuum plate and window cap from the front of HTBB

2.2. Turn on the main circuit breaker

\begin{tabular}{|c|c|c|c|c|c|}
\hline Procedure & Version & Date & Author & Pages & Filename \\
\hline IRR-CP-IRR5 & 1.0 & 22-Sep-06 & C. Gibson & 1 of 6 & $\begin{array}{c}\text { IRR-CP-IRR5 HTBB Operation } \\
\text { v1.doc }\end{array}$ \\
\hline
\end{tabular}




\section{Irradiance Calibration Procedure IRR-CP-IRR5-High Temperature Blackbody (HTBB) Operation}

2.3. Power supply specifications

2.3.1. Input: $480 \mathrm{VAC}, 3$ Phase, 4 wire, Wye, $60 \mathrm{~Hz}, 27 \mathrm{kVA}$

2.3.2. Output: $600 \mathrm{~A}$ at $30 \mathrm{VDC}$

2.3.3. Current regulation: $0.0005 \%$ of maximum

2.3.4. Voltage ripple: $55 \mathrm{mV}$ peak to peak into resistive load

2.3.5. Cooling: 5 GPM water at 50 PSID nominally

2.3.6. Physical: 60 " high x 23.25" wide x 28.25 " deep

2.3.7. Weight: $900 \mathrm{lbs}$

2.4. Turn power supply switch clockwise to the $\mathbf{O N}$ position (1)

2.5. Press the Start button on the power supply keypad

2.6. The Red LED is lit indicating that the power supply is $\mathbf{O N}$

3. Operating Procedure

3.1. Load the Digital Multimeter Feedback Program: $c: \mid$ FC2 HTBB

Docs $\backslash$ HTBB $\backslash 22 \_h p 3457 \_f e e d b a c k . v i$

3.2. Note: The Digital Multimeter Feedback Program stores the HTBB detector signal in a global variable that is read by the HTBB Control Program

3.2.1. Enter the GPIB address

3.2.2. Enter the channel

3.2.3. Enter the NPLC

3.2.4. Select Function

3.2.4.1. Initialize device

3.2.4.2. Measurement

3.2.4.3. Release device

3.2.5. Run the Digital Multimeter Feedback Program

3.3. Load the HTBB Control Program: c:|FC2 HTBB Docs $\mid$ HTBB $\mid$ BB3200_(main.exe).vi

\begin{tabular}{|c|c|c|c|c|c|}
\hline Procedure & Version & Date & Author & Pages & Filename \\
\hline IRR-CP-IRR5 & 1.0 & 22-Sep-06 & C. Gibson & 2 of 6 & $\begin{array}{c}\text { IRR-CP-IRR5 HTBB Operation } \\
\text { v1.doc }\end{array}$ \\
\hline
\end{tabular}




\section{Irradiance Calibration Procedure IRR-CP-IRR5-High Temperature Blackbody (HTBB) Operation}

3.4. The HTBB control program starts in the current control mode and ramps the HTBB from room temperature to $1700{ }^{\circ} \mathrm{C}$ by ramping the current which corresponds to a nominal temperature. After the temperature set point is reached, the operator starts the PID control mode. In the PID mode, the program uses a moving set point to increase the temperature to approximately $2677^{\circ} \mathrm{C}$. When the final temperature set point is achieved, the program maintains the set point for the duration of the measurements. At end of the measurements, the operator starts the current control mode and the program ramps the current to $0 \mathrm{~A}$.

3.5. Ramp current from zero (Current Control Mode)

3.5.1. Click the power supply on button (green)

3.5.2. Enter the current slew rate $\mathrm{A} / \mathrm{sec}: 0.1$

3.5.3. Enter the target temperature, ${ }^{\circ} \mathrm{C}$

3.5.4. Enter the moving set temperature (enter the same value as the target temperature)

3.5.5. Click the PID button off (red)

3.5.6. Enter the Output filename

3.5.7. Run the HTBB control program

3.6. Ramp temperature to the final set point and monitor set point (PID Control Mode)

3.6.1. Enter the temperature rate, ${ }^{\circ} \mathrm{C} / \mathrm{s}$ (usually 1 to $3{ }^{\circ} \mathrm{C}$ per second)

3.6.2. Enter upper limit

3.6.3. Enter lower limit

3.6.4. Click the PID button on (green)

3.6.5. Enter new moving set temperature, ${ }^{\circ} \mathrm{C}$

4. Turn Off Procedure (Current Control Mode)

4.1. Enter current slew rate A/sec: 0.1

4.2. Click the PID button off (red)

4.3. Enter zero (0) for the Target Temperature, ${ }^{\circ} \mathrm{C}$

4.4. Power supply will ramp down HTBB over 2 hours

4.5. Turn power supply switch counter clockwise to the OFF position (0)

4.6. Turn off the main circuit breaker

4.7. Turn off cold water to the HTBB furnace

\begin{tabular}{|c|c|c|c|c|c|}
\hline Procedure & Version & Date & Author & Pages & Filename \\
\hline IRR-CP-IRR5 & 1.0 & 22-Sep-06 & C. Gibson & 3 of 6 & $\begin{array}{c}\text { IRR-CP-IRR5 HTBB Operation } \\
\text { v1.doc }\end{array}$ \\
\hline
\end{tabular}




\section{Irradiance Calibration Procedure IRR-CP-IRR5-High Temperature Blackbody (HTBB) Operation}

4.8. Turn off cold water to the HTBB aperture

4.9. Turn off chilled water to the power supply

4.10. Install vacuum plate and cap on front of HTBB

4.11. Turn off argon

5. Document History

\begin{tabular}{|c|c|c|c|c|c|c|c|}
\hline Version & $\begin{array}{c}\text { Version } \\
\text { Date }\end{array}$ & Author & $\begin{array}{c}\text { Page } \\
\text { Total }\end{array}$ & $\begin{array}{c}\text { Revision } \\
\text { Date }\end{array}$ & $\begin{array}{c}\text { Revision } \\
\text { Date }\end{array}$ & $\begin{array}{c}\text { Revision } \\
\text { Date }\end{array}$ & $\begin{array}{c}\text { Revision } \\
\text { Date }\end{array}$ \\
\hline 1.0 & 22-Sep-06 & C. Gibson & 6 & & & & \\
\hline & & & & & & & \\
\hline & & & & & & & \\
\hline & & & & & & & \\
\hline & & & & & & & \\
\hline
\end{tabular}

\begin{tabular}{|c|c|c|c|c|c|}
\hline Procedure & Version & Date & Author & Pages & Filename \\
\hline IRR-CP-IRR5 & 1.0 & 22-Sep-06 & C. Gibson & 4 of 6 & $\begin{array}{c}\text { IRR-CP-IRR5 HTBB Operation } \\
\text { V1.doc }\end{array}$ \\
\hline
\end{tabular}




\section{Irradiance Calibration Procedure IRR-CP-IRR5-High Temperature Blackbody (HTBB) Operation}

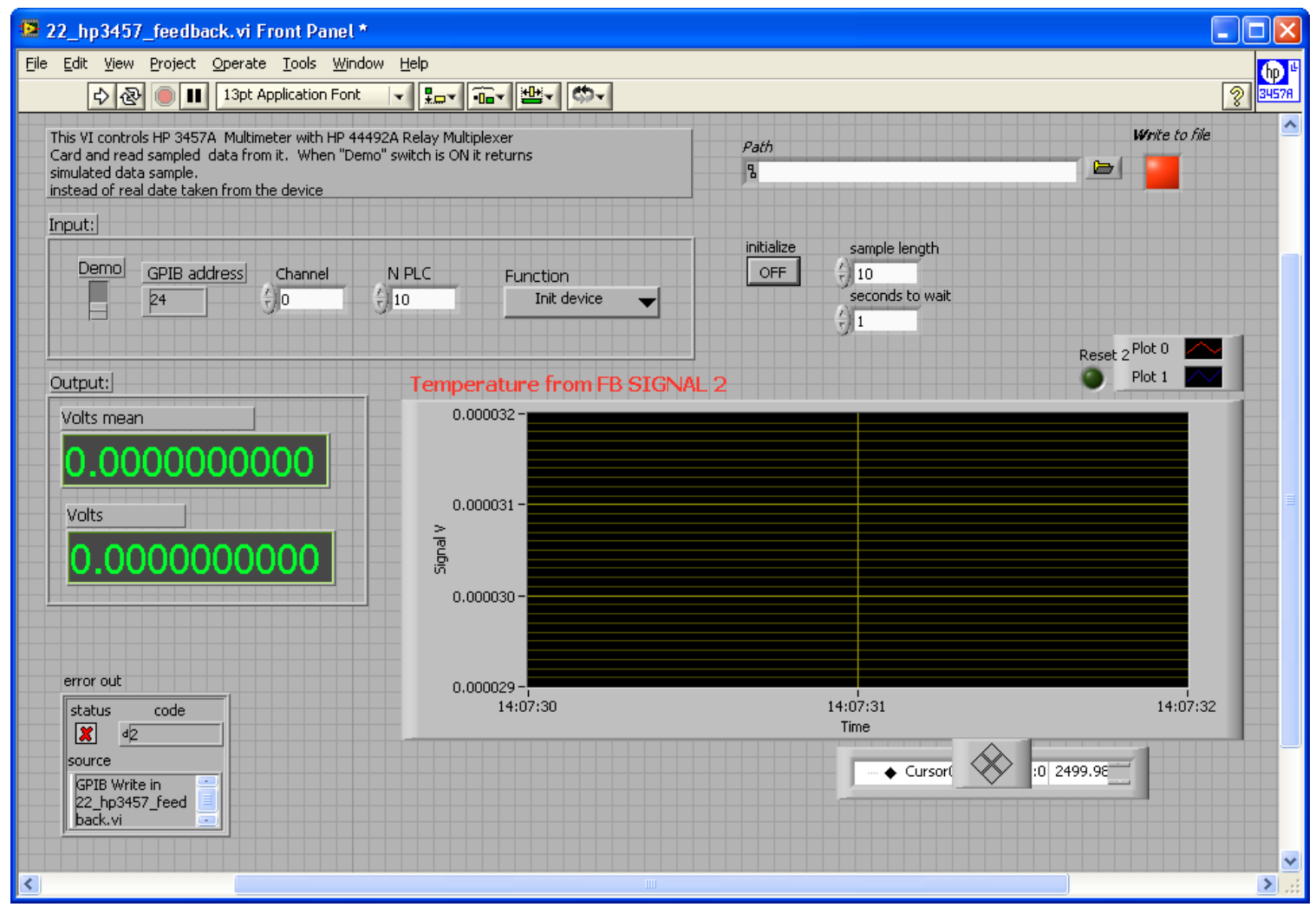

Figure Irr5.1. Front panel of the Digital Multimeter Feedback Program (22_hp3457_feedback.vi)

\begin{tabular}{|c|c|c|c|c|c|}
\hline Procedure & Version & Date & Author & Pages & Filename \\
\hline IRR-CP-IRR5 & 1.0 & 22-Sep-06 & C. Gibson & 5 of 6 & $\begin{array}{c}\text { IRR-CP-IRR5 HTBB Operation } \\
\text { v1.doc }\end{array}$ \\
\hline
\end{tabular}




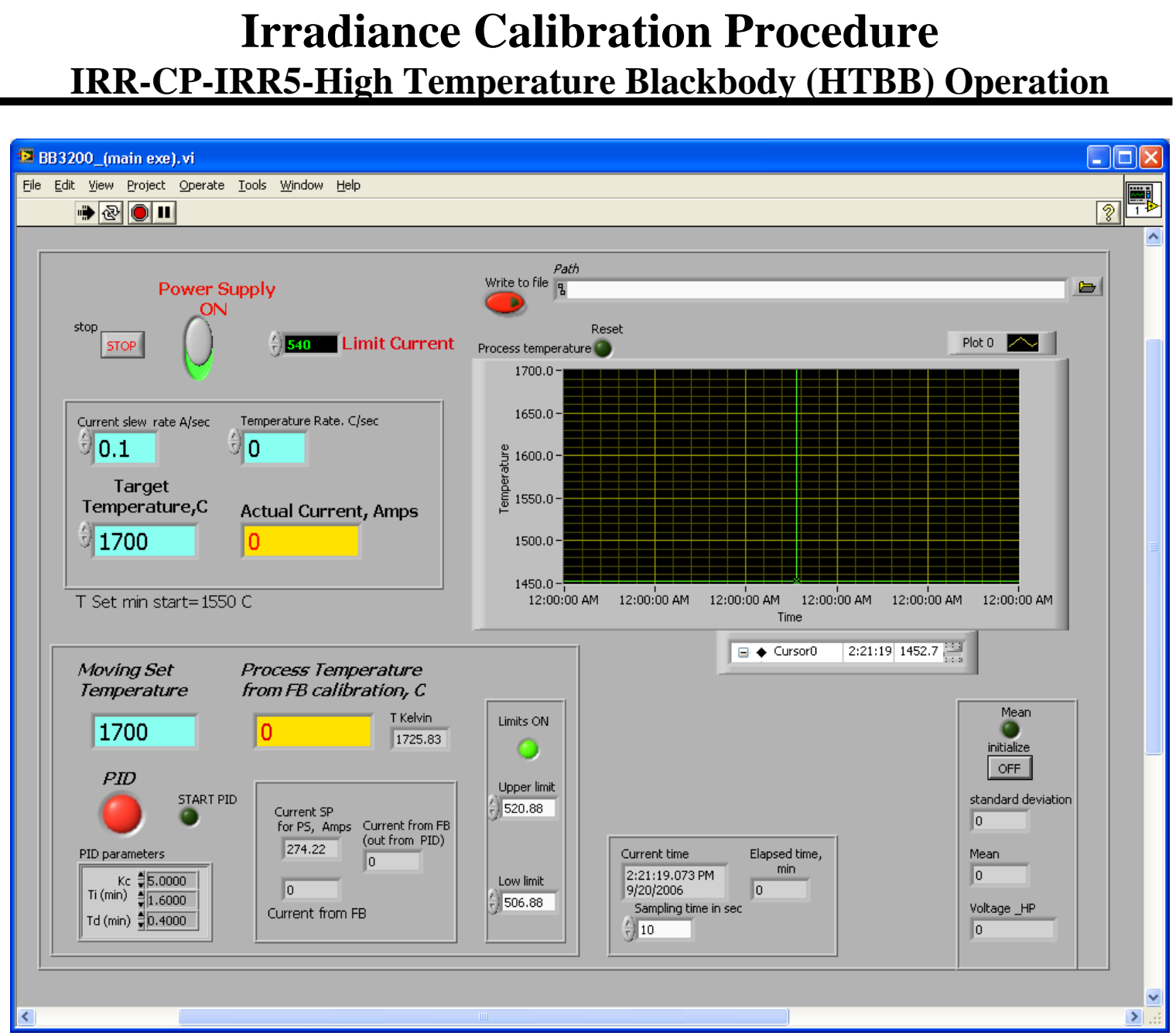

Figure Irr5.2. Front panel of the HTBB Control Program (BB3200_(main.exe).vi)

\begin{tabular}{|c|c|c|c|c|c|}
\hline Procedure & Version & Date & Author & Pages & Filename \\
\hline IRR-CP-IRR5 & 1.0 & 22-Sep-06 & C. Gibson & 6 of 6 & $\begin{array}{c}\text { IRR-CP-IRR5 HTBB Operation } \\
\text { v1.doc }\end{array}$ \\
\hline
\end{tabular}




\section{Irradiance Calibration Procedure IRR-CP-IRR6-Filter Radiometer (FR) Alignment}

\section{Filter Radiometer (FR) Alignment}

\begin{tabular}{|c|}
\hline CAUTION \\
\hline BRIGHT SOURCE \\
\hline BURN \\
\hline COLLISION \\
\hline ELECTROCUTION \\
\hline
\end{tabular}

1. Run the motion control program (see IRR-CP-IRR1)

2. Align the high temperature blackbody (HTBB) (see IRR-CP-IRR4)

3. Use double stick tape to attach a microscope slide to the HTBB water-cooled aperture

4. Use double stick tape to attach a microscope slide to the FR aperture mount

5. Align the filter radiometer (FR)

5.1. Move the FR to the HTBB position

5.2. Align the FR on the HTBB optical axis

5.3. Adjust the FR until the FR aperture is centered on the laser and normal to it

6. Repeat align for all filter radiometers

7. Remove the beam splitter (microscope slide cover)

8. Remove the microscope slides from the apertures

9. Measure the distance between the HTBB water-cooled aperture and the FR

10. Document History

\begin{tabular}{|c|c|c|c|c|c|c|c|}
\hline Version & $\begin{array}{c}\text { Version } \\
\text { Date }\end{array}$ & Author & $\begin{array}{c}\text { Page } \\
\text { Total }\end{array}$ & $\begin{array}{c}\text { Revision } \\
\text { Date }\end{array}$ & $\begin{array}{c}\text { Revision } \\
\text { Date }\end{array}$ & $\begin{array}{c}\text { Revision } \\
\text { Date }\end{array}$ & $\begin{array}{c}\text { Revision } \\
\text { Date }\end{array}$ \\
\hline 1.0 & 20 -Sep-06 & C. Gibson & 2 & & & & \\
\hline & & & & & & & \\
\hline & & & & & & & \\
\hline & & & & & & & \\
\hline & & & & & & & \\
\hline
\end{tabular}

\begin{tabular}{|c|c|c|c|c|c|}
\hline Procedure & Version & Date & Author & Pages & Filename \\
\hline IRR-CP-IRR6 & 1.0 & 20-Sep-06 & C. Gibson & 1 of 2 & $\begin{array}{c}\text { IRR-CP-IRR6 FR Alignment } \\
\text { V1.doc }\end{array}$ \\
\hline
\end{tabular}




\section{Irradiance Calibration Procedure IRR-CP-IRR6-Filter Radiometer (FR) Alignment}

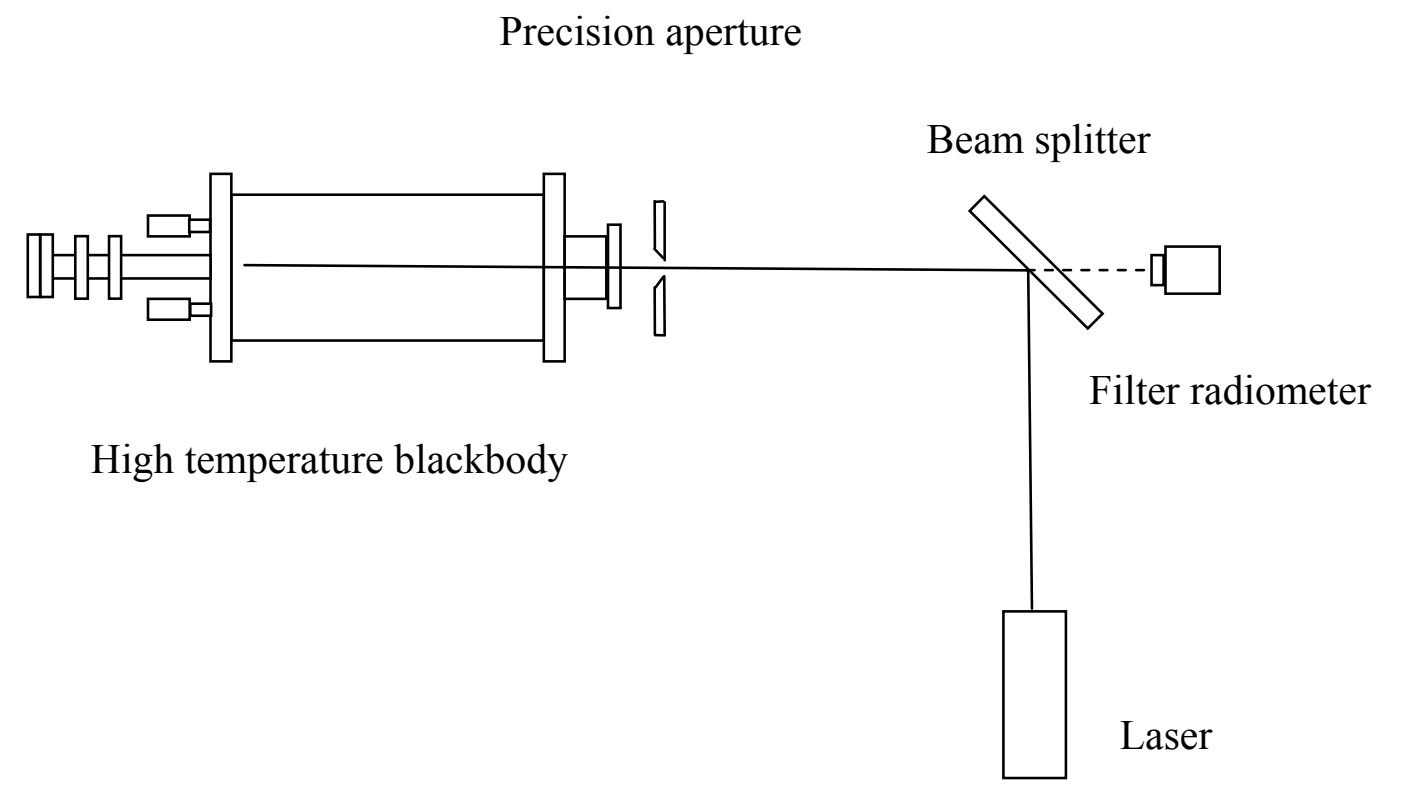

Figure Irr6. This drawing shows the optical layout for the HTBB and FR alignment

\begin{tabular}{|c|c|c|c|c|c|}
\hline Procedure & Version & Date & Author & Pages & Filename \\
\hline IRR-CP-IRR6 & 1.0 & 20 -Sep-06 & C. Gibson & 2 of 2 & $\begin{array}{c}\text { IRR-CP-IRR6 FR Alignment } \\
\text { V1.doc }\end{array}$ \\
\hline
\end{tabular}




\section{Irradiance Calibration Procedure IRR-CP-IRR7-Spectral Irradiance Scale Realization}

Spectral Irradiance Scale Realization

\begin{tabular}{|c|}
\hline CAUTION \\
\hline BRIGHT SOURCE \\
\hline BURN \\
\hline COLLISION \\
\hline ELECTROCUTION \\
\hline
\end{tabular}

1. Run the motion control program (see IRR-CP-IRR1)

2. Align the quartz halogen lamp(s) (QHL) (see IRR-CP-IRR2)

3. Align the high temperature blackbody (HTBB) (see IRR-CP-IRR4)

4. Align the filter radiometer(s) (FR) (see IRR-CP-IRR6)

5. Turn on the HTBB (See IRR-CP-IRR5)

6. Measure the temperature of the HTBB using the FRs

6.1. Load the Visual Basic program: c:|FASCAL Docs $\mid$ DataAcQ|FASCAL.vbp

6.2. Run the program

6.3. Load the Filter radiometer measurements program (Frmeas.frm)

6.3.1. Click HTBB vs. FRs from the Hardware.frm menu

6.3.2. Enter the filter radiometer setup data

6.3.2.1. Select the Use button(s)

6.3.2.2. Enter the filter radiometer name(s)

6.3.2.3. Enter the station (position in steps)

6.3.2.4. Enter the digital multimeter channel

6.3.3. Click the Set Pos. button to move the selected FR to the HTBB

6.3.4. Click the Read Pos. button to read the current position of the selected FR and store the value in the station text box

6.3.5. Select measurement mode (do one of the following)

6.3.5.1. Measure $\mathrm{N}$ times

6.3.5.1.1. Enter value in text box for $\mathrm{N}$ (typically $\mathrm{N}=5$ )

\begin{tabular}{|c|c|c|c|c|c|}
\hline Procedure & Version & Date & Author & Pages & Filename \\
\hline IRR-CP-IRR7 & 1.0 & 20-Sep-06 & C. Gibson & 1 of 11 & $\begin{array}{c}\text { IRR-CP-IRR7 Spectral } \\
\text { Irradiance Scale Realization } \\
\text { v1.doc }\end{array}$ \\
\hline
\end{tabular}




\section{Irradiance Calibration Procedure IRR-CP-IRR7-Spectral Irradiance Scale Realization}

6.3.5.2. Measure once

6.3.6. Click the Save config. button

6.3.7. Enter the 3457A digital multimeter data

6.3.7.1. Click the Read Once or Read button to read a FR signal

6.4. Measure the full scale signal

6.4.1. Click the Measure FRs button

6.5. Put the rod shutter in front of the HTBB

6.6. Measure the dark signal

6.6.1. Click the Measure FRs button

6.7. Calculate the net signals (do one of the following)

6.7.1. Load the Visual Basic program: $\boldsymbol{c}: \mid F C$ Docs $\mid$ Ereal|Ereal.vbp and run it

6.7.1.1. Click Calc FR net signals from the FRTCalc.frm menu to load the FR net signal calculation program (FRSigCalc.frm)

6.7.1.2. Enter the input filename

6.7.1.3. Enter the output filename

6.7.1.4. Enter the number of groups of full scale signals

6.7.1.5. Enter the number of full scale signals per group

6.7.1.6. Enter the number of dark signals per group

6.7.1.7. Click the Reduce FR file button

6.7.2. Open the measurement data file for each filter radiometer in a spreadsheet and calculate the net signals

7. Measure the spectral irradiance of the HTBB using the spectroradiometer (see IRR-CP-IRR1)

8. Measure the spectral irradiance of the QHL(s) (see IRR-CP-IRR8)

9. Measure the temperature of the HTBB using the FRs (repeat section 6)

10. Calculate the HTBB temperature from the FR measurements

10.1. Load the Visual Basic program: $\boldsymbol{c}: \mid$ FC Docs $\mid$ Ereal|Ereal.vbp and run it

10.2. The Calculate HTBB temperature and irradiance program (FRTCalc.frm) is loaded

\begin{tabular}{|c|c|c|c|c|c|}
\hline Procedure & Version & Date & Author & Pages & Filename \\
\hline IRR-CP-IRR7 & 1.0 & 20-Sep-06 & C. Gibson & 2 of 11 & $\begin{array}{c}\text { IRR-CP-IRR7 Spectral } \\
\text { Irradiance Scale Realization } \\
\text { v1.doc }\end{array}$ \\
\hline
\end{tabular}




\section{Irradiance Calibration Procedure IRR-CP-IRR7-Spectral Irradiance Scale Realization}

10.3. Step 1: Load the FR parameter file

10.3.1. Select the FR button

10.3.2. Click the Load FR values button

10.4. Step 2: Calculate the HTBB temperature

10.4.1. Enter the FR measurement date

10.4.2. Enter the FR net signal

10.4.3. The other parameters are loaded in Step 1

10.4.3.1. The white boxes are used for data entry

10.4.3.2. The gray boxes display calculated values

10.4.4. Click the Calculate BB Temperature button

11. Calculate the HTBB spectral irradiance from the FR measurements

11.1. Perform steps in Section 10

11.2. Step 3: Calculate the HTBB spectral irradiance

11.2.1. Enter the temperature $[\mathrm{K}]$

11.2.1.1. The HTBB temperature is determined for each FR. Use the average of the group of temperature determinations. If the temperature is measured before and after the spectral irradiance measurements then there will be two temperature averages.

11.2.2. Select the spectral range (do one of the following)

11.2.2.1. Click the Calibration service $250 \mathrm{~nm}$ to $2400 \mathrm{~nm}$ button

11.2.2.2. Click the CCPR $250 \mathrm{~nm}$ to $2500 \mathrm{~nm}$ button

11.2.2.3. Click the Other button

11.2.3. Enter the output filename

11.2.4. Enter the integrating sphere aperture (ISR) to HTBB aperture distance [cm]

11.2.5. Enter the integrating sphere aperture (ISR) diameter [cm]

11.2.6. Click the Calculate Irradiance button

\begin{tabular}{|c|c|c|c|c|c|}
\hline Procedure & Version & Date & Author & Pages & Filename \\
\hline IRR-CP-IRR7 & 1.0 & 20-Sep-06 & C. Gibson & 3 of 11 & $\begin{array}{c}\text { IRR-CP-IRR7 Spectral } \\
\text { Irradiance Scale Realization } \\
\text { V1.doc }\end{array}$ \\
\hline
\end{tabular}




\section{Irradiance Calibration Procedure IRR-CP-IRR7-Spectral Irradiance Scale Realization}

12. Document History

\begin{tabular}{|c|c|c|c|c|c|c|c|}
\hline Version & $\begin{array}{c}\text { Version } \\
\text { Date }\end{array}$ & Author & $\begin{array}{c}\text { Page } \\
\text { Total }\end{array}$ & $\begin{array}{c}\text { Revision } \\
\text { Date }\end{array}$ & $\begin{array}{c}\text { Revision } \\
\text { Date }\end{array}$ & $\begin{array}{c}\text { Revision } \\
\text { Date }\end{array}$ & $\begin{array}{c}\text { Revision } \\
\text { Date }\end{array}$ \\
\hline 1.0 & 20 -Sep-06 & C. Gibson & 11 & & & & \\
\hline & & & & & & & \\
\hline & & & & & & & \\
\hline & & & & & & & \\
\hline & & & & & & & \\
\hline
\end{tabular}

G. Filter radiometer meaurements

Irradiance (Scan) Configure Hardware Configure Software View dvm log Stop Exit

Facility for Automated Spectroradiometric Calibrations (FASCAL)

Filter Radiometer Setup

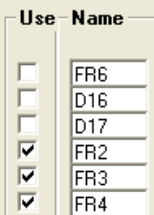

Set Pos.

Station

1700

3007

3129
5215

5215
$\mid 5877$

|6537

$\checkmark$ Measure N Times $\sqrt{5}$ Counter 0

C Measure once

r Stop

Measure FRs

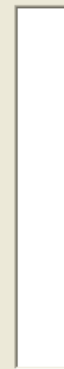

Status

Frmeas.frm Ver. 6.0.32 Mar. 1, 2002
3457A Digital Multimeter

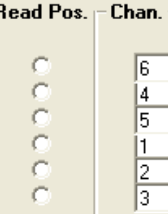

Use custom config.

Use default config

Save config

DVM name $\longdiv { \text { DVM7 } }$

NRDGS 5

Channel 7

Range $30 \mathrm{~V}$.

NPLC 10
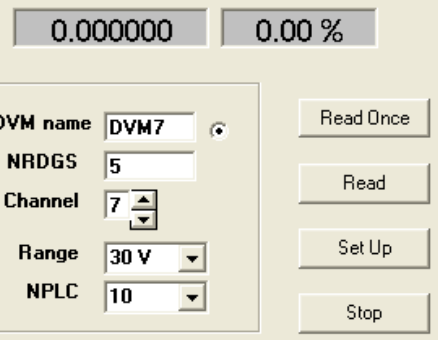

HTBB Position

$\longdiv { 4 0 5 0 0 0 } \odot$ Filter radiometer

$\longdiv { 5 8 0 0 0 0 } \Upsilon$ Radiance

$\longdiv { 4 0 5 0 0 0 } \bigcirc$ Irradiance

c Home

Set HTBB Pos

Read HTBB Pos

Figure Irr7.1. Front panel of the filter radiometer measurement program (Frmeas.frm)

\begin{tabular}{|c|c|c|c|c|c|}
\hline Procedure & Version & Date & Author & Pages & Filename \\
\hline IRR-CP-IRR7 & 1.0 & 20-Sep-06 & C. Gibson & 4 of 11 & $\begin{array}{c}\text { IRR-CP-IRR7 Spectral } \\
\text { Irradiance Scale Realization } \\
\text { v1.doc }\end{array}$ \\
\hline
\end{tabular}




\section{Irradiance Calibration Procedure IRR-CP-IRR7-Spectral Irradiance Scale Realization}

\begin{tabular}{|c|c|c|c|c|}
\hline \multicolumn{3}{|c|}{ 区 Microsoft Excel - FR2051006.cs } & & $\square$ \\
\hline \multicolumn{5}{|c|}{ 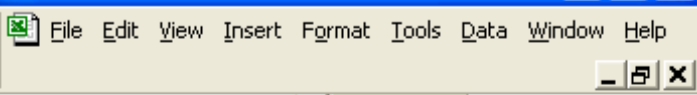 } \\
\hline \multicolumn{2}{|c|}{$\mathrm{C} 3$} & \multirow{2}{*}{$\frac{-1}{\mathrm{~B}}$} & \multicolumn{2}{|c|}{$=\mathrm{Std}$} \\
\hline & A & & $\mathrm{C}$ & $\Gamma$ \\
\hline \multicolumn{5}{|c|}{1 FR2051006.csv } \\
\hline \multicolumn{5}{|c|}{$25 / 10 / 2006$} \\
\hline 3 & Time & Signal $N$ & Std & \\
\hline 4 & $15: 59: 06$ & $-5.527691 \mathrm{E}-01$ & $0.00 \%$ & \\
\hline 5 & 16:01:10 & $-5.529112 \mathrm{E}-01$ & $0.00 \%$ & \\
\hline 6 & $16: 03: 13$ & $-5.531688 \mathrm{E}-01$ & $0.00 \%$ & \\
\hline 7 & $16: 05: 13$ & $-5.532091 \mathrm{E}-01$ & $0.00 \%$ & \\
\hline 8 & $16: 07: 20$ & $-5.533463 \mathrm{E}-01$ & $0.00 \%$ & \\
\hline 9 & $16: 10: 14$ & $-5.534425 \mathrm{E}-01$ & $0.00 \%$ & \\
\hline 10 & $16: 12: 15$ & $-5.535478 \mathrm{E}-01$ & $0.00 \%$ & \\
\hline 11 & $16: 14: 16$ & $-5.536449 \mathrm{E}-01$ & $0.00 \%$ & \\
\hline 12 & $16: 16: 19$ & $-5.537164 \mathrm{E}-01$ & $0.00 \%$ & \\
\hline 13 & $16: 18: 24$ & $-5.537917 \mathrm{E}-01$ & $0.00 \%$ & \\
\hline 14 & $16: 21: 49$ & $-2.703264 \mathrm{E}-04$ & $0.52 \%$ & \\
\hline 15 & $16: 23: 50$ & $-2.887799 \mathrm{E}-04$ & $0.59 \%$ & \\
\hline 16 & $16: 25: 58$ & $-2.669130 \mathrm{E}-04$ & $1.37 \%$ & \\
\hline 17 & $16: 28: 01$ & $-3.234504 \mathrm{E}-04$ & $1.42 \%$ & \\
\hline 18 & $16: 30: 02$ & $-2.658651 \mathrm{E}-04$ & $1.48 \%$ & \\
\hline 19 & $16: 54: 18$ & $-5.552238 \mathrm{E}-01$ & $0.00 \%$ & \\
\hline 20 & $16: 56: 20$ & $-5.552501 \mathrm{E}-01$ & $0.00 \%$ & \\
\hline 21 & 17:03:03 & $-5.555266 \mathrm{E}-01$ & $0.00 \%$ & \\
\hline 22 & 17:05:03 & $-5.555574 \mathrm{E}-01$ & $0.00 \%$ & \\
\hline 23 & $17: 08: 09$ & $-3.203884 \mathrm{E}-04$ & $0.14 \%$ & \\
\hline 24 & $17: 10: 12$ & $-3.199937 \mathrm{E}-04$ & $0.26 \%$ & \\
\hline 25 & $17: 12: 16$ & $-3.035164 \mathrm{E}-04$ & $0.88 \%$ & \\
\hline 26 & $17: 14: 21$ & $-3.299986 \mathrm{E}-04$ & $0.23 \%$ & \\
\hline 27 & - $\backslash$ FR2 & $5 1 0 0 6 \longdiv { \square }$ & & 15 \\
\hline & & & NUM & \\
\hline
\end{tabular}

Figure Irr7.2. Sample measurement data for Filter Radiometer \#2

\begin{tabular}{|c|c|c|c|c|c|}
\hline Procedure & Version & Date & Author & Pages & Filename \\
\hline IRR-CP-IRR7 & 1.0 & 20-Sep-06 & C. Gibson & 5 of 11 & $\begin{array}{c}\text { IRR-CP-IRR7 Spectral } \\
\text { Irradiance Scale Realization } \\
\text { V1.doc }\end{array}$ \\
\hline
\end{tabular}




\section{Irradiance Calibration Procedure \\ IRR-CP-IRR7-Spectral Irradiance Scale Realization}

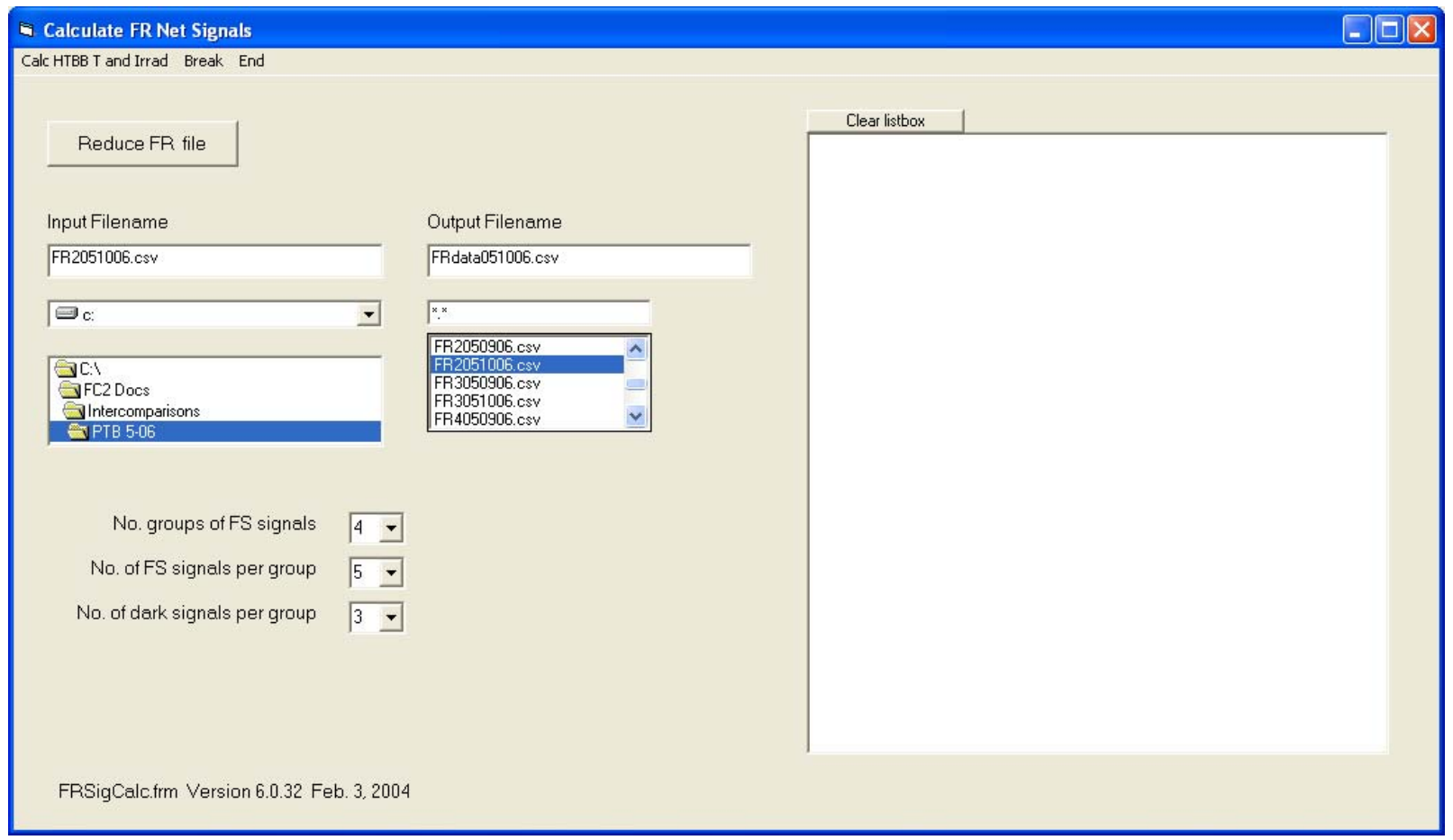

Figure Irr7.3. Front panel of the calculate FR net signals program (FRSigCalc.frm)

\begin{tabular}{|c|c|c|c|c|c|}
\hline Procedure & Version & Date & Author & Pages & Filename \\
\hline IRR-CP-IRR7 & 1.0 & 20-Sep-06 & C. Gibson & 6 of 11 & $\begin{array}{c}\text { IRR-CP-IRR7 Spectral } \\
\text { Irradiance Scale Realization } \\
\text { v1.doc }\end{array}$ \\
\hline
\end{tabular}




\section{Irradiance Calibration Procedure IRR-CP-IRR7-Spectral Irradiance Scale Realization}

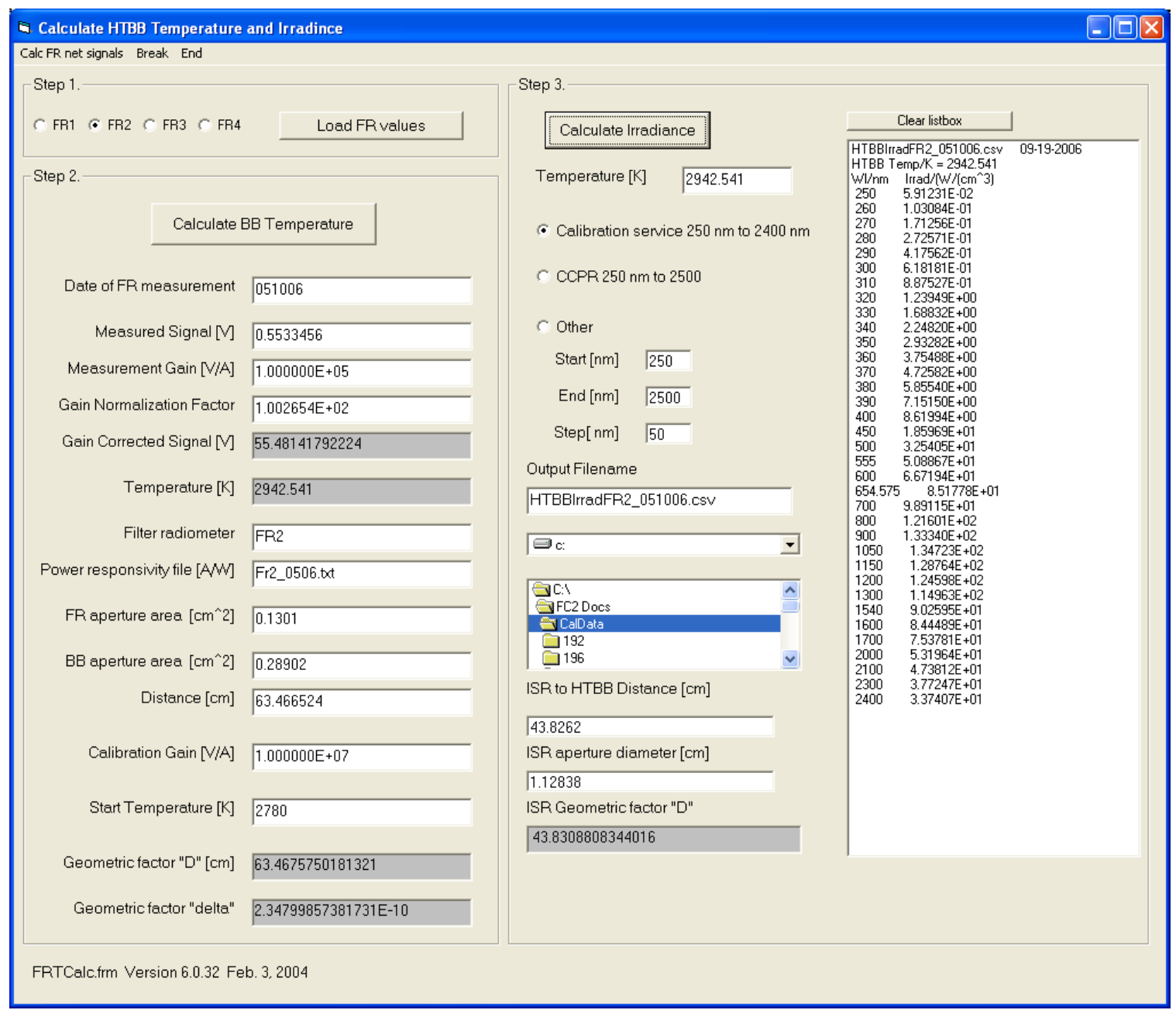

Figure Irr7.4. Front panel of the calculate HTBB temperature and irradiance program (FRTCalc.frm)

\begin{tabular}{|c|c|c|c|c|c|}
\hline Procedure & Version & Date & Author & Pages & Filename \\
\hline IRR-CP-IRR7 & 1.0 & 20-Sep-06 & C. Gibson & 7 of 11 & $\begin{array}{c}\text { IRR-CP-IRR7 Spectral } \\
\text { Irradiance Scale Realization } \\
\text { v1.doc }\end{array}$ \\
\hline
\end{tabular}




\section{Irradiance Calibration Procedure IRR-CP-IRR7-Spectral Irradiance Scale Realization}

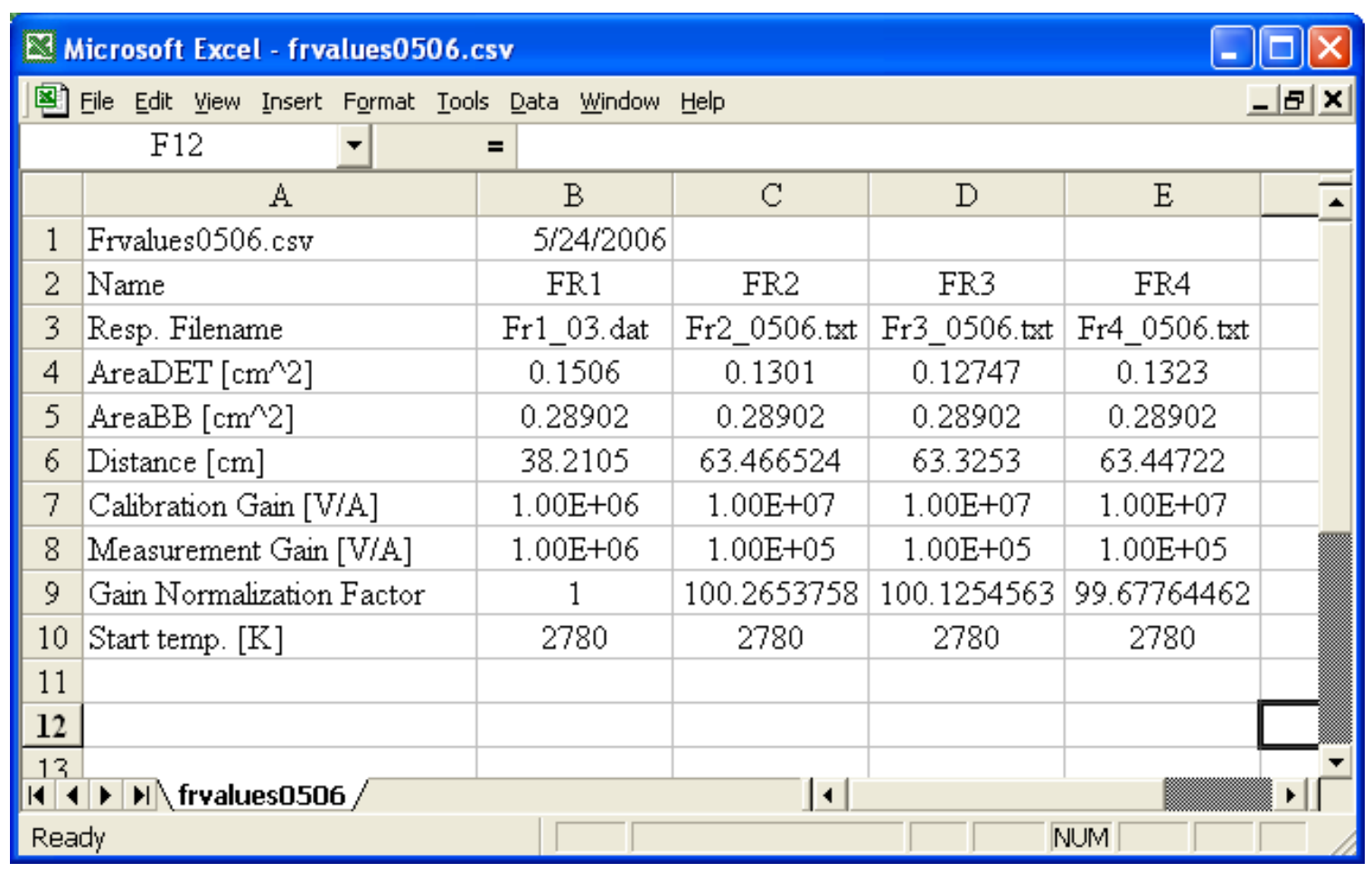

Figure Irr7.5. Sample FR parameter file used by the calculate HTBB temperature and irradiance program (FRTCalc.frm)

\begin{tabular}{|c|c|c|c|c|c|}
\hline Procedure & Version & Date & Author & Pages & Filename \\
\hline IRR-CP-IRR7 & 1.0 & 20-Sep-06 & C. Gibson & 8 of 11 & $\begin{array}{c}\text { IRR-CP-IRR7 Spectral } \\
\text { Irradiance Scale Realization } \\
\text { V1.doc }\end{array}$ \\
\hline
\end{tabular}




\section{Irradiance Calibration Procedure IRR-CP-IRR7-Spectral Irradiance Scale Realization}

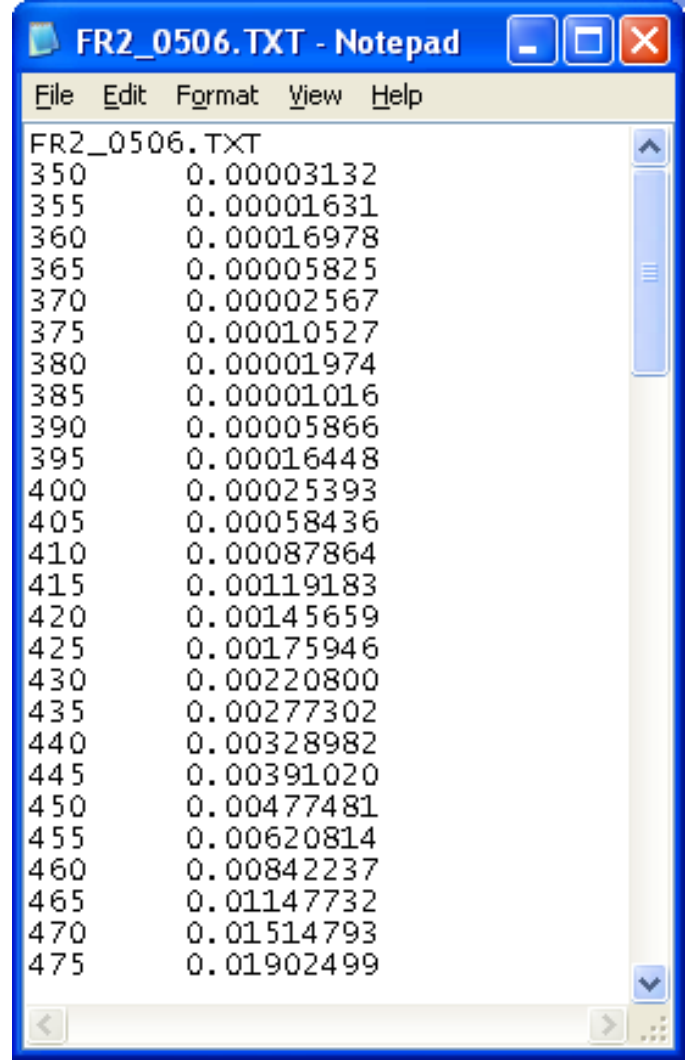

Figure Irr7.6. Sample power responsivity data for Filter Radiometer \#2 used by the calculate HTBB temperature and irradiance program (FRTCalc.frm)

\begin{tabular}{|c|c|c|c|c|c|}
\hline Procedure & Version & Date & Author & Pages & Filename \\
\hline IRR-CP-IRR7 & 1.0 & 20-Sep-06 & C. Gibson & 9 of 11 & $\begin{array}{c}\text { IRR-CP-IRR7 Spectral } \\
\text { Irradiance Scale Realization } \\
\text { v1.doc }\end{array}$ \\
\hline
\end{tabular}




\section{Irradiance Calibration Procedure IRR-CP-IRR7-Spectral Irradiance Scale Realization}

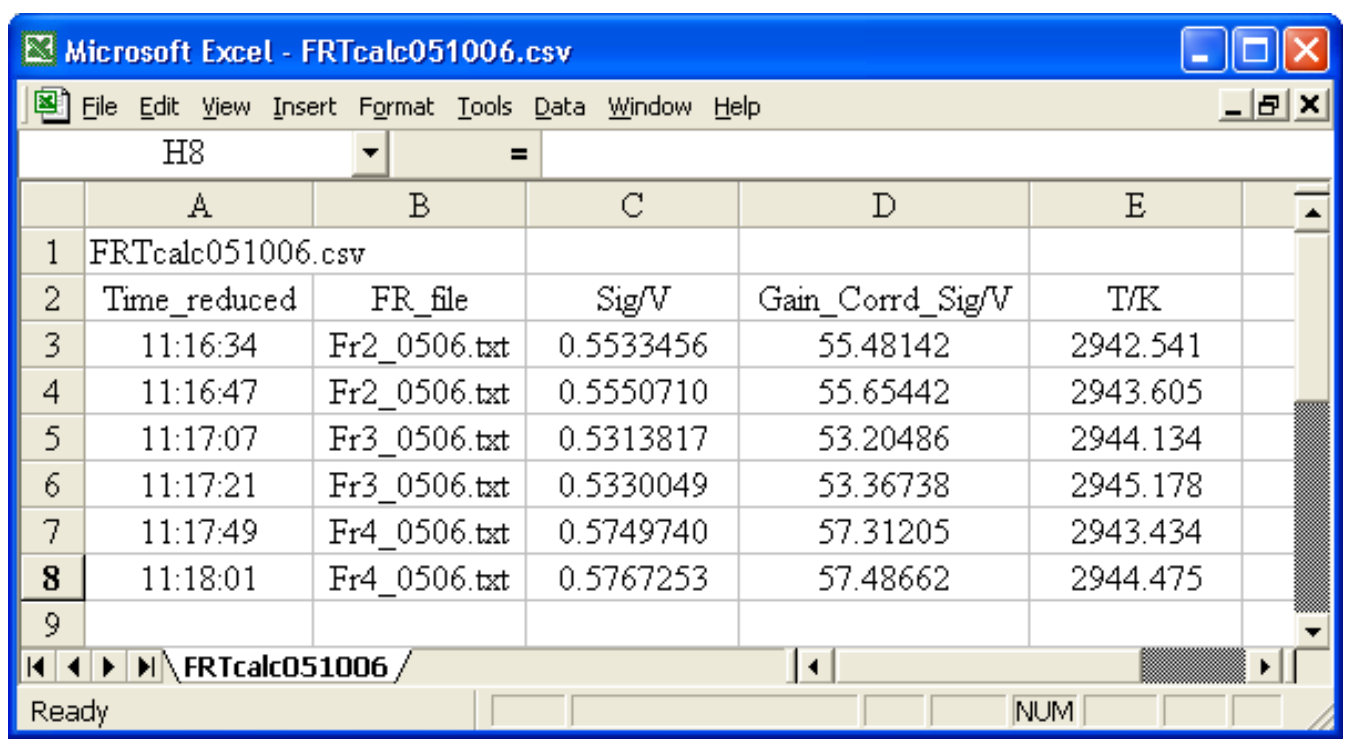

Figure Irr7.7. Sample temperature data Filter Radiometers \#2, \#3, and \#4 which is the output from the calculate HTBB temperature and irradiance program (FRTCalc.frm)

\begin{tabular}{|c|c|c|c|c|c|}
\hline Procedure & Version & Date & Author & Pages & Filename \\
\hline IRR-CP-IRR7 & 1.0 & 20-Sep-06 & C. Gibson & 10 of 11 & $\begin{array}{c}\text { IRR-CP-IRR7 Spectral } \\
\text { Irradiance Scale Realization } \\
\text { v1.doc }\end{array}$ \\
\hline
\end{tabular}




\section{Irradiance Calibration Procedure IRR-CP-IRR7-Spectral Irradiance Scale Realization}

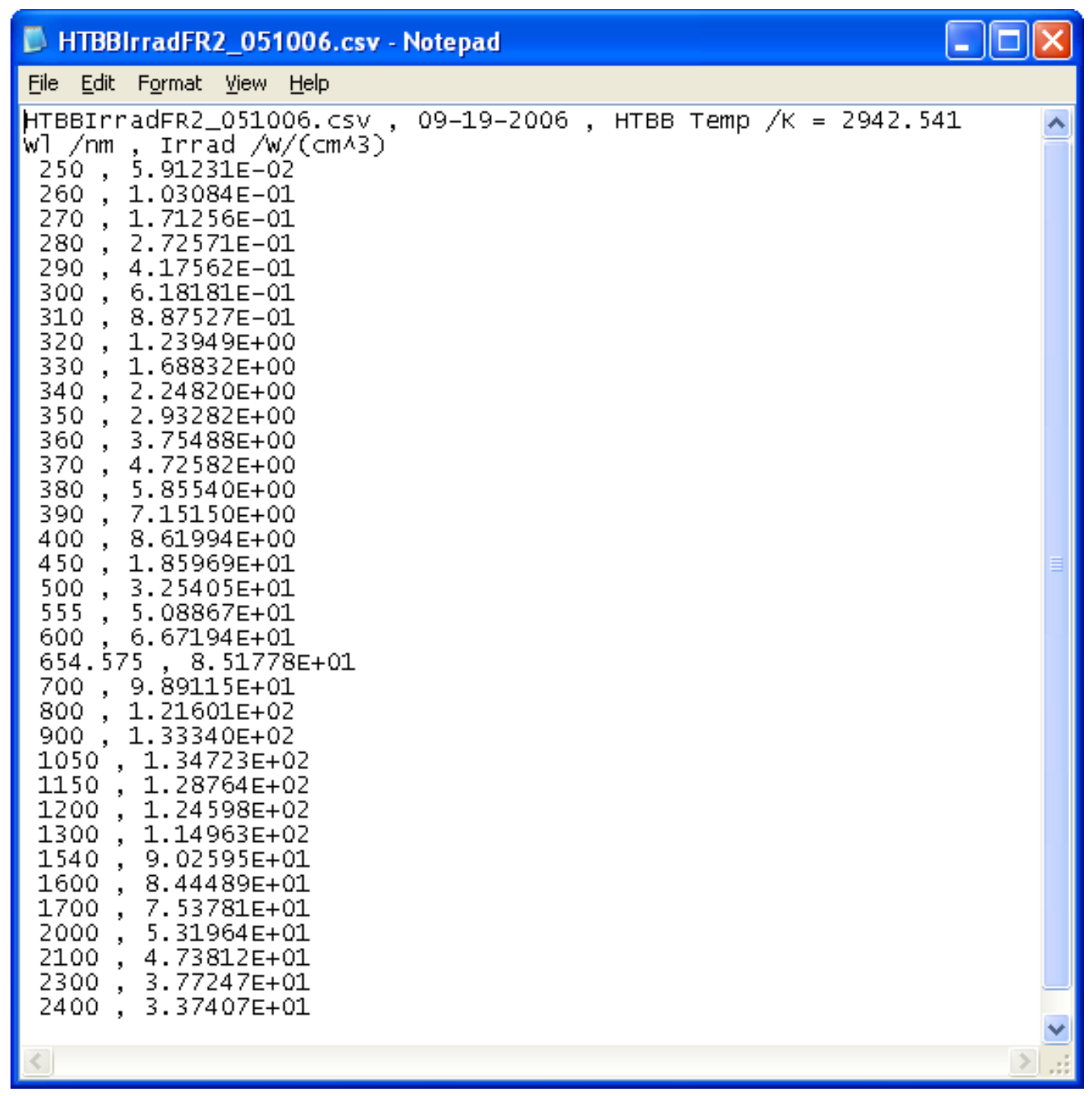

Figure Irr7.8. Sample HTBB spectral irradiance data calculated from calculate HTBB temperature and irradiance program (FRTCalc.frm)

\begin{tabular}{|c|c|c|c|c|c|}
\hline Procedure & Version & Date & Author & Pages & Filename \\
\hline IRR-CP-IRR7 & 1.0 & 20-Sep-06 & C. Gibson & 11 of 11 & $\begin{array}{c}\text { IRR-CP-IRR7 Spectral } \\
\text { Irradiance Scale Realization } \\
\text { V1.doc }\end{array}$ \\
\hline
\end{tabular}




\section{Irradiance Calibration Procedure \\ IRR-CP-IRR8-Spectral Irradiance Calibration}

\section{Spectral Irradiance Calibration}

\begin{tabular}{|c|}
\hline CAUTION \\
\hline BRIGHT SOURCE \\
\hline BURN \\
\hline COLLISION \\
\hline ELECTROCUTION \\
\hline
\end{tabular}

1. Align the lamps (See IRR-CP-IRR2)

2. Run the Lamp Current Control Program (see IRR-CP-IRR3)

3. Run the FASCAL2 Data Acquisition Program (see IRR-CP-IRR1)

4. Reduce the calibration data (see IRR-CP-IRR9)

5. Document History

\begin{tabular}{|c|c|c|c|c|c|c|c|}
\hline Version & $\begin{array}{c}\text { Version } \\
\text { Date }\end{array}$ & Author & $\begin{array}{c}\text { Page } \\
\text { Total }\end{array}$ & $\begin{array}{c}\text { Revision } \\
\text { Date }\end{array}$ & $\begin{array}{c}\text { Revision } \\
\text { Date }\end{array}$ & $\begin{array}{c}\text { Revision } \\
\text { Date }\end{array}$ & $\begin{array}{c}\text { Revision } \\
\text { Date }\end{array}$ \\
\hline 1.0 & 27-Jun-06 & C. Gibson & 1 & & & & \\
\hline & & & & & & & \\
\hline & & & & & & & \\
\hline & & & & & & & \\
\hline & & & & & & & \\
\hline
\end{tabular}

\begin{tabular}{|c|c|c|c|c|c|}
\hline Procedure & Version & Date & Author & Pages & Filename \\
\hline IRR-CP-IRR8 & 1.0 & 27-Jun-06 & C. Gibson & 1 of 1 & $\begin{array}{c}\text { IRR-CP-IRR8 Spectral } \\
\text { Irradiance Calibration v1.doc }\end{array}$ \\
\hline
\end{tabular}




\section{Irradiance Calibration Procedure IRR-CP-IRR9-Spectral Irradiance Data Reduction}

\section{Spectral Irradiance Data Reduction}

1. Calculate the calibration factor $(\mathrm{CF})$

1.1. Open the primary working standards (PWS) irradiance spreadsheet: $\boldsymbol{c}: \mid \boldsymbol{F C} 2$ Docs $\mid$ Irrad PWS $\backslash P W S$ irradiances 1003.xIs

1.2. Open the calibration factor spreadsheet: $\boldsymbol{c}: \mid$ FC2 Docs $\mid$ Irrad PWS $\mid$ CalFactor mmddyy.xls

1.3. Save CF spreadsheet with new name

\subsection{Edit CF spreadsheet}

1.4.1. Enter new spreadsheet name

1.4.2. Enter current date

1.4.3. Enter PWS serial numbers

1.4.4. Edit chart titles

1.4.5. Save spreadsheet

1.5. Edit irradiance values in the CF spreadsheet

1.5.1. Copy irradiances from the PWS irradiance spreadsheet

1.5.2. Save CF spreadsheet

1.6. Open PWS signal files in Excel

1.6.1. Plot data

1.6.2. Review, don't save

1.7. Edit signal values in the CF spreadsheet

1.7.1. Copy PWS signal values from the PWS signal files

1.7.2. Save CF spreadsheet

1.8. Print CF spreadsheet

2. Calculate the irradiance of test lamp

2.1. Open the test irradiance spreadsheet: c: $\mid$ FC2 Docs $\mid$ Irrad PWS $\mid$ F000 mmddyy cal.xIs

2.2. Save test irradiance spreadsheet with new name

\begin{tabular}{|c|c|c|c|c|c|}
\hline Procedure & Version & Date & Author & Pages & Filename \\
\hline IRR-CP-IRR9 & 1.0 & 28-Jun-06 & C. Gibson & 1 of 9 & $\begin{array}{c}\text { IRR-CP-IRR9 Spectral } \\
\text { Irradiance Data Reduction } \\
\text { V1.doc }\end{array}$ \\
\hline
\end{tabular}




\section{Irradiance Calibration Procedure IRR-CP-IRR9-Spectral Irradiance Data Reduction}

2.3. Edit test irradiance spreadsheet

2.3.1. Enter new spreadsheet name

2.3.2. Enter current date

2.3.3. Edit chart titles

2.3.4. Copy Mean CF from the CF spreadsheet

2.3.5. Edit CF date

2.3.6. Save spreadsheet

2.4. Open test signal files in Excel

2.4.1. Plot data

2.4.2. Review, don't save

2.5. Edit signal values in the test signal spreadsheet

2.5.1. Copy test signal values from the test signal files

2.5.2. Save test irradiance spreadsheet

2.6. Prepare data for calibration report

2.6.1. Copy test irradiance from the Data reduction worksheet to the Final data worksheet

2.6.2. Edit lamp current and lamp voltage

2.7. Print test irradiance spreadsheet

3. Document History

\begin{tabular}{|c|c|c|c|c|c|c|c|}
\hline Version & $\begin{array}{c}\text { Version } \\
\text { Date }\end{array}$ & Author & $\begin{array}{c}\text { Page } \\
\text { Total }\end{array}$ & $\begin{array}{c}\text { Revision } \\
\text { Date }\end{array}$ & $\begin{array}{c}\text { Revision } \\
\text { Date }\end{array}$ & $\begin{array}{c}\text { Revision } \\
\text { Date }\end{array}$ & $\begin{array}{c}\text { Revision } \\
\text { Date }\end{array}$ \\
\hline 1.0 & 28-Jun-06 & C. Gibson & 9 & & & & \\
\hline & & & & & & & \\
\hline & & & & & & & \\
\hline & & & & & & & \\
\hline & & & & & & & \\
\hline
\end{tabular}

\begin{tabular}{|c|c|c|c|c|c|}
\hline Procedure & Version & Date & Author & Pages & Filename \\
\hline IRR-CP-IRR9 & 1.0 & 28-Jun-06 & C. Gibson & 2 of 9 & $\begin{array}{c}\text { IRR-CP-IRR9 Spectral } \\
\text { Irradiance Data Reduction } \\
\text { v1.doc }\end{array}$ \\
\hline
\end{tabular}




\section{Irradiance Calibration Procedure IRR-CP-IRR9-Spectral Irradiance Data Reduction}

\begin{tabular}{|c|c|c|c|c|c|c|c|c|}
\hline$\$ \mathrm{Mi}$ & icrosoft E & cel - PWS irra & diances 1003 . & xIs [Read-On! & & & $\square \square$ & $x$ \\
\hline : 줄 & Edit & Innsert & Format & Window & Adobe & & -5 & \\
\hline & B3 & $\checkmark$ & $f_{x} 40$ & & & & & \\
\hline & A & B & $\mathrm{C}$ & D & E & $F$ & G & $\hat{\imath}$ \\
\hline 1 & PWS irra & iances $1003 x$ & & $3 / 3 / 2004(\mathrm{Fa}$ & scal 2 calib sta & arted $9 / 17 / 04)$ & & \\
\hline 2 & & F350 & F351 & F352 & F353 & F354 & F355 & \\
\hline 3 & 2400 & $4.022 \mathrm{E}+01$ & $4.060 \mathrm{E}+01$ & $4.041 \mathrm{E}+01$ & $4.066 \mathrm{E}+01$ & $3.884 \mathrm{E}+01$ & $4.039 \mathrm{E}+01$ & \\
\hline 4 & 2300 & $4.526 \mathrm{E}+01$ & $4.610 \mathrm{E}+01$ & $4.619 \mathrm{E}+01$ & $4.656 \mathrm{E}+01$ & $4.458 \mathrm{E}+01$ & $4.628 \mathrm{E}+01$ & \\
\hline 5 & 2100 & $5.895 \mathrm{E}+01$ & $5.995 \mathrm{E}+01$ & $6.003 \mathrm{E}+01$ & $6.047 \mathrm{E}+01$ & $5.784 \mathrm{E}+01$ & $5.986 \mathrm{E}+01$ & \\
\hline 6 & 2000 & $6.730 \mathrm{E}+01$ & $6.872 \mathrm{E}+01$ & $6.875 \mathrm{E}+01$ & $6.911 \mathrm{E}+01$ & $6.616 \mathrm{E}+01$ & $6.857 \mathrm{E}+01$ & \\
\hline 7 & 1700 & $1.016 \mathrm{E}+02$ & $1.035 \mathrm{E}+02$ & $1.033 \mathrm{E}+02$ & $1.039 \mathrm{E}+02$ & $9.963 \mathrm{E}+01$ & $1.033 \mathrm{E}+02$ & \\
\hline 8 & 1600 & $1.163 \mathrm{E}+02$ & $1.186 \mathrm{E}+02$ & $1.184 \mathrm{E}+02$ & $1.192 \mathrm{E}+02$ & $1.142 \mathrm{E}+02$ & 1.184E+02 & \\
\hline 9 & 1540 & $1.263 \mathrm{E}+02$ & $1.287 \mathrm{E}+02$ & $1.285 \mathrm{E}+02$ & $1.294 \mathrm{E}+02$ & $1.240 \mathrm{E}+02$ & $1.284 \mathrm{E}+02$ & \\
\hline 10 & 1300 & $1.721 \mathrm{E}+02$ & $1.755 \mathrm{E}+02$ & $1.752 \mathrm{E}+02$ & $1.765 \mathrm{E}+02$ & $1.687 \mathrm{E}+02$ & $1.750 \mathrm{E}+02$ & \\
\hline 11 & 1200 & $1.926 \mathrm{E}+02$ & $1.964 \mathrm{E}+02$ & $1.960 \mathrm{E}+02$ & $1.977 \mathrm{E}+02$ & $1.889 \mathrm{E}+02$ & $1.960 \mathrm{E}+02$ & \\
\hline 12 & 1150 & $2.027 \mathrm{E}+02$ & $2.064 \mathrm{E}+02$ & $2.062 \mathrm{E}+02$ & $2.080 \mathrm{E}+02$ & $1.987 \mathrm{E}+02$ & $2.062 \mathrm{E}+02$ & \\
\hline 13 & 1050 & $2.203 \mathrm{E}+02$ & $2.244 \mathrm{E}+02$ & $2.240 \mathrm{E}+02$ & $2.261 E+02$ & $2.155 \mathrm{E}+02$ & $2.241 \mathrm{E}+02$ & \\
\hline 14 & 1050 & $2.203 \mathrm{E}+02$ & $2.244 \mathrm{E}+02$ & $2.240 \mathrm{E}+02$ & $2.261 E+02$ & $2.155 \mathrm{E}+02$ & $2.241 \mathrm{E}+02$ & \\
\hline 15 & 900 & $2.334 \mathrm{E}+02$ & $2.376 \mathrm{E}+02$ & $2.369 \mathrm{E}+02$ & $2.398 \mathrm{E}+02$ & $2.278 \mathrm{E}+02$ & $2.370 \mathrm{E}+02$ & \\
\hline 16 & 800 & $2.239 \mathrm{E}+02$ & $2.284 \mathrm{E}+02$ & $2.268 \mathrm{E}+02$ & $2.311 E+02$ & $2.187 \mathrm{E}+02$ & $2.276 \mathrm{E}+02$ & \\
\hline 17 & 700 & $1.940 \mathrm{E}+02$ & $1.976 \mathrm{E}+02$ & $1.966 \mathrm{E}+02$ & $2.005 \mathrm{E}+02$ & $1.890 \mathrm{E}+02$ & $1.964 \mathrm{E}+02$ & \\
\hline 18 & 654.6 & $1.722 \mathrm{E}+02$ & $1.757 \mathrm{E}+02$ & $1.745 \mathrm{E}+02$ & $1.782 \mathrm{E}+02$ & $1.672 \mathrm{E}+02$ & $1.749 \mathrm{E}+02$ & \\
\hline 19 & 600 & $1.405 \mathrm{E}+02$ & $1.432 \mathrm{E}+02$ & $1.426 \mathrm{E}+02$ & $1.461 \mathrm{E}+02$ & $1.362 \mathrm{E}+02$ & $1.422 \mathrm{E}+02$ & \\
\hline 20 & 555 & $1.114 \mathrm{E}+02$ & $1.137 \mathrm{E}+02$ & $1.132 \mathrm{E}+02$ & $1.160 \mathrm{E}+02$ & $1.081 \mathrm{E}+02$ & $1.127 \mathrm{E}+02$ & \\
\hline 21 & 500 & $7.531 \mathrm{E}+01$ & $7.675 \mathrm{E}+01$ & $7.663 \mathrm{E}+01$ & $7.871 \mathrm{E}+01$ & $7.289 \mathrm{E}+01$ & $7.599 \mathrm{E}+01$ & \\
\hline 22 & 450 & $4.555 \mathrm{E}+01$ & $4.657 \mathrm{E}+01$ & $4.637 \mathrm{E}+01$ & $4.780 \mathrm{E}+01$ & $4.399 \mathrm{E}+01$ & $4.591 \mathrm{E}+01$ & \\
\hline 23 & 400 & $2.257 \mathrm{E}+01$ & $2.310 \mathrm{E}+01$ & $2.301 \mathrm{E}+01$ & $2.387 \mathrm{E}+01$ & $2.176 \mathrm{E}+01$ & $2.273 \mathrm{E}+01$ & \\
\hline 24 & 390 & $1.906 \mathrm{E}+01$ & $1.947 \mathrm{E}+01$ & $1.945 \mathrm{E}+01$ & $2.017 \mathrm{E}+01$ & $1.834 \mathrm{E}+01$ & $1.914 \mathrm{E}+01$ & \\
\hline 25 & 380 & $1.585 \mathrm{E}+01$ & $1.618 \mathrm{E}+01$ & $1.614 \mathrm{E}+01$ & $1.678 \mathrm{E}+01$ & $1.521 \mathrm{E}+01$ & $1.588 \mathrm{E}+01$ & \\
\hline 26 & 370 & $1.298 \mathrm{E}+01$ & $1.331 \mathrm{E}+01$ & $1.328 \mathrm{E}+01$ & $1.379 \mathrm{E}+01$ & $1.247 \mathrm{E}+01$ & $1.303 \mathrm{E}+01$ & \\
\hline 27 & 360 & $1.051 \mathrm{E}+01$ & $1.075 \mathrm{E}+01$ & $1.075 \mathrm{E}+01$ & $1.117 \mathrm{E}+01$ & $1.008 \mathrm{E}+01$ & $1.053 \mathrm{E}+01$ & \\
\hline 28 & 350 & $8.341 E+00$ & $8.545 \mathrm{E}+00$ & $8.544 \mathrm{E}+00$ & $8.880 \mathrm{E}+00$ & $8.007 \mathrm{E}+00$ & $8.352 \mathrm{E}+00$ & \\
\hline 29 & 350 & $8.341 \mathrm{E}+00$ & $8.545 \mathrm{E}+00$ & $8.544 \mathrm{E}+00$ & $8.880 \mathrm{E}+00$ & $8.007 \mathrm{E}+00$ & $8.352 \mathrm{E}+00$ & \\
\hline 30 & 340 & $6.505 \mathrm{E}+00$ & $6.675 \mathrm{E}+00$ & $6.661 \mathrm{E}+00$ & $6.934 \mathrm{E}+00$ & $6.222 \mathrm{E}+00$ & $6.499 \mathrm{E}+00$ & \\
\hline 31 & 330 & $4.976 \mathrm{E}+00$ & $5.106 \mathrm{E}+00$ & $5.100 \mathrm{E}+00$ & $5.316 \mathrm{E}+00$ & $4.760 \mathrm{E}+00$ & $4.970 \mathrm{E}+00$ & \\
\hline 32 & 320 & $3.730 \mathrm{E}+00$ & $3.824 \mathrm{E}+00$ & $3.818 \mathrm{E}+00$ & $3.985 \mathrm{E}+00$ & $3.560 \mathrm{E}+00$ & $3.709 \mathrm{E}+00$ & \\
\hline 33 & 310 & $2.731 \mathrm{E}+00$ & $2.792 \mathrm{E}+00$ & $2.794 \mathrm{E}+00$ & $2.922 \mathrm{E}+00$ & $2.596 \mathrm{E}+00$ & $2.717 \mathrm{E}+00$ & \\
\hline 34 & 300 & $1.943 \mathrm{E}+00$ & $1.983 \mathrm{E}+00$ & $1.988 \mathrm{E}+00$ & $2.080 \mathrm{E}+00$ & $1.842 \mathrm{E}+00$ & $1.922 \mathrm{E}+00$ & \\
\hline 35 & 290 & $1.339 \mathrm{E}+00$ & $1.373 \mathrm{E}+00$ & $1.369 \mathrm{E}+00$ & $1.438 \mathrm{E}+00$ & $1.268 \mathrm{E}+00$ & $1.321 \mathrm{E}+00$ & \\
\hline 36 & 280 & $8.872 \mathrm{E}-01$ & $9.138 \mathrm{E}-01$ & $9.134 \mathrm{E}-01$ & $9.594 \mathrm{E}-01$ & $8.408 \mathrm{E}-01$ & $8.783 \mathrm{E}-01$ & \\
\hline 37 & 270 & $5.685 \mathrm{E}-01$ & $5.838 \mathrm{E}-01$ & $5.833 \mathrm{E}-01$ & $6.143 \mathrm{E}-01$ & $5.389 \mathrm{E}-01$ & $5.581 \mathrm{E}-01$ & \\
\hline 38 & 260 & $3.449 \mathrm{E}-01$ & $3.540 \mathrm{E}-01$ & $3.539 \mathrm{E}-01$ & $3.728 \mathrm{E}-01$ & $3.246 \mathrm{E}-01$ & $3.398 \mathrm{E}-01$ & \\
\hline 39 & 250 & $1.977 \mathrm{E}-01$ & $2.031 \mathrm{E}-01$ & $2.027 \mathrm{E}-01$ & $2.132 \mathrm{E}-01$ & $1.855 \mathrm{E}-01$ & $1.944 \mathrm{E}-01$ & \\
\hline 40 & & & & & & & & \\
\hline $\begin{array}{l}11 \\
14\end{array}$ & $M \backslash 5$ & & & & |< & & & \\
\hline Ready & & & & & & NL & JM & \\
\hline
\end{tabular}

Figure Irr9.1. Primary working standard spreadsheet with spectral irradiance values in $\mathrm{W} \mathrm{cm}^{-3}$. The wavelength is in $\mathrm{nm}$.

\begin{tabular}{|c|c|c|c|c|c|}
\hline Procedure & Version & Date & Author & Pages & Filename \\
\hline IRR-CP-IRR9 & 1.0 & 28-Jun-06 & C. Gibson & 3 of 9 & $\begin{array}{c}\text { IRR-CP-IRR9 Spectral } \\
\text { Irradiance Data Reduction } \\
\text { v1.doc }\end{array}$ \\
\hline
\end{tabular}




\section{Irradiance Calibration Procedure IRR-CP-IRR9-Spectral Irradiance Data Reduction}

\begin{tabular}{|c|c|c|}
\hline (7) $F 000 \times 06022$ & $d-F 000 \times 06022$ & $F 000 \times 06 \ldots=$ \\
\hline File Édit Format & $w$ Help & \\
\hline $\begin{array}{l}2.400057 \mathrm{E}+3 \\
2.300051 \mathrm{E}+3 \\
2.100055 \mathrm{E}+3 \\
2.000054 \mathrm{E}+3 \\
1.700052 \mathrm{E}+3 \\
1.600050 \mathrm{E}+3 \\
1.540050 \mathrm{E}+3 \\
1.300048 \mathrm{E}+3 \\
1.200006 \mathrm{E}+3 \\
1.150000 \mathrm{E}+3 \\
1.050002 \mathrm{E}+3 \\
1.050023 \mathrm{E}+3 \\
9.000223 \mathrm{E}+2 \\
8.000276 \mathrm{E}+2 \\
7.000228 \mathrm{E}+2 \\
6.546253 \mathrm{E}+2 \\
6.000041 \mathrm{E}+2 \\
5.550003 \mathrm{E}+2 \\
5.000013 \mathrm{E}+2 \\
4.499989 \mathrm{E}+2 \\
4.000006 \mathrm{E}+2 \\
3.899993 \mathrm{E}+2 \\
3.800020 \mathrm{E}+2 \\
3.700027 \mathrm{E}+2 \\
3.600035 \mathrm{E}+2 \\
3.499982 \mathrm{E}+2 \\
3.500012 \mathrm{E}+2 \\
3.400010 \mathrm{E}+2 \\
3.300008 \mathrm{E}+2 \\
3.199995 \mathrm{E}+2 \\
3 \\
3\end{array}$ & $\begin{array}{l}1.017919 \mathrm{E}-3 \\
3.814951 \mathrm{E}-3 \\
1.174480 \mathrm{E}-2 \\
2.455168 \mathrm{E}-2 \\
5.250821 \mathrm{E}-2 \\
6.268454 \mathrm{E}-2 \\
8.116158 \mathrm{E}-2 \\
7.416851 \mathrm{E}-2 \\
6.511832 \mathrm{E}-2 \\
5.663285 \mathrm{E}-2 \\
3.370290 \mathrm{E}-2 \\
1.124967 \mathrm{E}+0 \\
1.874430 \mathrm{E}+0 \\
1.532427 \mathrm{E}+0 \\
1.766575 \mathrm{E}+0 \\
1.974823 \mathrm{E}+0 \\
2.283468 \mathrm{E}+0 \\
2.158301 \mathrm{E}+0 \\
1.451392 \mathrm{E}+0 \\
8.328217 \mathrm{E}-1 \\
4.030962 \mathrm{E}-1 \\
3.402757 \mathrm{E}-1 \\
2.336532 \mathrm{E}-1 \\
1.339092 \mathrm{E}-1 \\
8.153869 \mathrm{E}-2 \\
5.998714 \mathrm{E}-2 \\
1.452055 \mathrm{E}+0 \\
1.039393 \mathrm{E}+0 \\
7.620603 \mathrm{E}-1 \\
5.358771 \mathrm{E}-1 \\
3.334336 \mathrm{E}-1 \\
1.737545 \mathrm{E}-1 \\
9.221828 \mathrm{E}-2 \\
5.360468 \mathrm{E}-2 \\
3.412196 \mathrm{E}-2 \\
1.355358 \mathrm{E}-2 \\
5.415924 \mathrm{E}-3\end{array}$ & $\begin{array}{l}3.264188 \mathrm{E}-1 \\
2.146048 \mathrm{E}-1 \\
1.319953 \mathrm{E}-1 \\
5.620660 \mathrm{E}-2 \\
4.382486 \mathrm{E}-2 \\
4.806402 \mathrm{E}-2 \\
3.570625 \mathrm{E}-2 \\
6.136365 \mathrm{E}-2 \\
4.855454 \mathrm{E}-2 \\
3.335337 \mathrm{E}-2 \\
4.035394 \mathrm{E}-2 \\
1.532978 \mathrm{E}-1 \\
3.097425 \mathrm{E}-2 \\
4.9090577 \mathrm{E}-2 \\
3.468647 \mathrm{E}-2 \\
3.221846 \mathrm{E}-2 \\
2.169371 \mathrm{E}-2 \\
6.709759 \mathrm{E}-2 \\
2.580857 \mathrm{E}-2 \\
2.041169 \mathrm{E}-2 \\
6.059084 \mathrm{E}-2 \\
6.064778 \mathrm{E}-2 \\
5.287465 \mathrm{E}-2 \\
2.118646 \mathrm{E}-1 \\
4.047097 \mathrm{E}-1 \\
4.553392 \mathrm{E}-1 \\
5.781238 \mathrm{E}-2 \\
7.959316 \mathrm{E}-2 \\
8.974343 \mathrm{E}-2 \\
6.324439 \mathrm{E}-2 \\
1.753404 \mathrm{E}-1 \\
5.125018 \mathrm{E}-2 \\
6.690750 \mathrm{E}-2 \\
9.404503 \mathrm{E}-2 \\
6.383373 \mathrm{E}-2 \\
1.697317 \mathrm{E}-1 \\
3.013322 \mathrm{E}-1\end{array}$ \\
\hline$<$ & & \\
\hline
\end{tabular}

Figure Irr9.2. Sample signal file. The first column is wavelength in $\mathrm{nm}$. The second column is the net signal in V. The last column is the percent standard deviation of the net signal.

\begin{tabular}{|c|c|c|c|c|c|}
\hline Procedure & Version & Date & Author & Pages & Filename \\
\hline IRR-CP-IRR9 & 1.0 & 28-Jun-06 & C. Gibson & 4 of 9 & $\begin{array}{c}\text { IRR-CP-IRR9 Spectral } \\
\text { Irradiance Data Reduction } \\
\text { v1.doc }\end{array}$ \\
\hline
\end{tabular}




\section{Irradiance Calibration Procedure IRR-CP-IRR9-Spectral Irradiance Data Reduction}

\begin{tabular}{|c|c|c|c|c|c|c|c|c|c|c|c|c|c|}
\hline \multicolumn{11}{|c|}{ 国 Microsoft Excel-CalFactor mmddyy.xls [Read-Only] } & \multicolumn{3}{|c|}{$=\square X$} \\
\hline \multicolumn{2}{|c|}{ : 질 File } & \multirow{2}{*}{$\begin{array}{l}\text { Eddit } \quad \text { View } \\
\text { A2 }\end{array}$} & \multirow{2}{*}{$\begin{array}{cc}\text { Insert Format } \\
\text { - }\end{array}$} & \multirow{2}{*}{$f_{x}^{\text {Iools }}$} & \multicolumn{2}{|c|}{ Data window } & \multicolumn{2}{|c|}{ Adobe PDF } & \multicolumn{2}{|c|}{ Type a question for help } & \multicolumn{3}{|c|}{ - $-5 x$} \\
\hline & A & & & & & & & & & & & & \\
\hline & $\mathrm{A}$ & B & $\mathrm{C}$ & $\mathrm{D}$ & E & F & $\mathrm{G}$ & $\mathrm{H}$ & I & $\mathrm{J}$ & $\mathrm{K}$ & & ^ \\
\hline 1 & CalFactor & \multirow{2}{*}{ 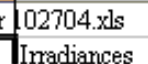 } & & \multicolumn{2}{|l|}{$10 / 28 / 2004$} & & & & & & & & \\
\hline 2 & & & & & Signals & & & \multicolumn{2}{|c|}{ Calib Factors } & & \multirow[b]{2}{*}{ MeanCF } & & \\
\hline 3 & & F354 & F350 & F353 & F354 & F350 & F353 & F354 & $\mathrm{F} 350$ & F353 & & & \\
\hline 4 & 2400.057 & $3.884 \mathrm{E}+01$ & $4.022 \mathrm{E}+01$ & $4.066 \mathrm{E}+01$ & 0.001 & 0.001018 & 0.001043 & 38840 & 39508.84 & 38983.701 & \multicolumn{2}{|l|}{$3.911 \mathrm{E}+04$} & \\
\hline 5 & 2300.051 & $4.458 \mathrm{E}+01$ & $4.526 \mathrm{E}+01$ & $4.656 \mathrm{E}+01$ & 0.003763 & 0.003836 & 0.003933 & 11846.93 & 11798.75 & 11838.291 & \multicolumn{3}{|c|}{$1.183 \mathrm{E}+04$} \\
\hline 6 & 2100.051 & $5.784 \mathrm{E}+01$ & $5.895 \mathrm{E}+01$ & $6.047 \mathrm{E}+01$ & 0.011378 & 0.011589 & 0.011884 & 5083.494 & 5086.72 & 5088.3541 & \multicolumn{3}{|l|}{$5.086 \mathrm{E}+03$} \\
\hline 7 & 2000.054 & $6.616 \mathrm{E}+01$ & $6.730 \mathrm{E}+01$ & $6.911 \mathrm{E}+01$ & 0.023679 & 0.024129 & 0.024732 & \begin{tabular}{|l|}
2794.037 \\
\end{tabular} & 2789.175 & 2794.3555 & \multicolumn{3}{|l|}{$2.793 \mathrm{E}+03$} \\
\hline 8 & 1700.056 & $9.963 \mathrm{E}+01$ & $1.016 \mathrm{E}+02$ & $1.039 \mathrm{E}+02$ & 0.050843 & 0.051746 & 0.053051 & 1959.562 & 1963.437 & 1958.4928 & $1.960 \mathrm{E}+0$ & & \\
\hline 9 & 1600.05 & $1.142 \mathrm{E}+02$ & $1.163 \mathrm{E}+02$ & $1.192 \mathrm{E}+02$ & 0.060502 & 0.061614 & 0.063133 & 1887.541 & 1887.558 & 1888.0776 & $1.888 \mathrm{E}+0$. & & \\
\hline 10 & 1540.05 & $1.240 \mathrm{E}+02$ & $1.263 \mathrm{E}+02$ & $1.294 \mathrm{E}+02$ & 0.078574 & 0.080023 & 0.081999 & 1578.13 & 1578.296 & 1578.068 & $1.578 \mathrm{E}+0$. & & \\
\hline 11 & 1300.04 & $1.687 \mathrm{E}+02$ & $1.721 \mathrm{E}+02$ & $1.765 \mathrm{E}+02$ & 0.073036 & 0.07441 & 0.07627 & 2309.82 & 2312.861 & 2314.1471 & $2.312 \mathrm{E}+0$. & & \\
\hline 12 & 1200.002 & $1.889 \mathrm{E}+02$ & $1.926 \mathrm{E}+02$ & $1.977 \mathrm{E}+02$ & 0.065013 & 0.066238 & 0.067919 & 2905.573 & 2907.696 & 2910.8202 & $2.908 \mathrm{E}+0$. & & \\
\hline 13 & 1149.996 & $1.987 \mathrm{E}+02$ & $2.027 \mathrm{E}+02$ & $2.080 \mathrm{E}+02$ & 0.056722 & 0.057827 & 0.05932 & 3503.05 & 3505.283 & 3506.4059 & $3.505 \mathrm{E}+0$. & & \\
\hline 14 & 1050.006 & $2.155 \mathrm{E}+02$ & $2.203 \mathrm{E}+02$ & $2.261 \mathrm{E}+02$ & 0.034386 & 0.035071 & 0.036002 & 6267.085 & 6281.543 & 6280.2067 & $6.276 \mathrm{E}+0$. & & \\
\hline 15 & 1050.023 & $2.155 \mathrm{E}+02$ & $2.203 \mathrm{E}+02$ & $2.261 \mathrm{E}+02$ & 1.119943 & 1.142278 & 1.173118 & 192.4205 & 192.8602 & 192.73423 & $1.927 \mathrm{E}+02$ & & \\
\hline 16 & 900.0243 & $2.278 \mathrm{E}+02$ & $2.334 \mathrm{E}+02$ & $2.398 \mathrm{E}+02$ & 1.879519 & 1.920646 & 1.97588 & 121.2012 & 121.5216 & 121.36365 & $1.214 \mathrm{E}+02$ & & \\
\hline 17 & 800.0256 & $2.187 \mathrm{E}+02$ & $2.239 \mathrm{E}+02$ & $2.311 \mathrm{E}+02$ & 1.550098 & 1.588585 & 1.638075 & 141.0879 & 140.943 & 141.08023 & $1.410 \mathrm{E}+0 ?$ & & \\
\hline 18 & 700.0228 & $1.890 \mathrm{E}+02$ & $1.940 \mathrm{E}+02$ & $2.005 \mathrm{E}+02$ & 1808501 & & 1015537 & 1045064 & & 10467030 & $10 \Delta G \mathrm{~F}+0 ?$ & & \\
\hline 19 & 654.6253 & $1.672 \mathrm{E}+02$ & $1.722 \mathrm{E}+02$ & $1.782 \mathrm{E}+02$ & & & & & & & 1 & & \\
\hline 20 & 600.0061 & $1.362 \mathrm{E}+02$ & $1.405 \mathrm{E}+02$ & $1.461 \mathrm{E}+02$ & & & wi & geas 1 & & & & & \\
\hline 21 & 555.0023 & $1.081 \mathrm{E}+02$ & $1.114 \mathrm{E}+02$ & $1.160 \mathrm{E}+02$ & & & & & & & 11 & & \\
\hline 22 & 500.0013 & $7.289 \mathrm{E}+01$ & $7.531 \mathrm{E}+01$ & $7.871 \mathrm{E}+01$ & 10 & & & & & & & & \\
\hline 23 & 450.0009 & $4.399 \mathrm{E}+01$ & $4.555 \mathrm{E}+01$ & $4.780 \mathrm{E}+01$ & & & & & & & 11 & & \\
\hline 24 & 399.9986 & $2.176 \mathrm{E}+01$ & $2.257 \mathrm{E}+01$ & $2.387 \mathrm{E}+01$ & & & & & & & 11 & & \\
\hline 25 & 390.0013 & $1.834 \mathrm{E}+01$ & $1.906 \mathrm{E}+01$ & $2.017 \mathrm{E}+01$ & & & & & & & 11 & & \\
\hline 26 & 380.004 & $1.521 \mathrm{E}+01$ & $1.585 \mathrm{E}+01$ & $1.678 \mathrm{E}+01$ & & & & & & & & & \\
\hline 27 & 370.0027 & $1.247 \mathrm{E}+01$ & $1.298 \mathrm{E}+01$ & $1.379 \mathrm{E}+01$ & & & & & & & & & \\
\hline 28 & 360.0015 & $1.008 \mathrm{E}+01$ & $1.051 \mathrm{E}+01$ & $1.117 \mathrm{E}+01$ & & & & & & & & & \\
\hline 29 & 349.9982 & $8.007 \mathrm{E}+00$ & $8.341 \mathrm{E}+00$ & $8.880 \mathrm{E}+00$ & 0.01 & & & & & & & & \\
\hline 30 & 350.0032 & $8.007 \mathrm{E}+00$ & $8.341 \mathrm{E}+00$ & $8.880 \mathrm{E}+00$ & & & & & & & 10 & & \\
\hline 31 & 340.001 & $6.222 \mathrm{E}+00$ & $6.505 \mathrm{E}+00$ & $6.934 \mathrm{E}+00$ & 0.001 & & & & & & & & \\
\hline 32 & 330.0008 & $4.760 \mathrm{E}+00$ & $4.976 \mathrm{E}+00$ & $5.316 \mathrm{E}+00$ & 0 & & & 15000 & 2000 & 2500 & 3000 & & \\
\hline 33 & 319.9975 & $3.560 \mathrm{E}+00$ & $3.730 \mathrm{E}+00$ & $3.985 \mathrm{E}+00$ & & & & & & & & & \\
\hline 34 & 310.0009 & $2.596 \mathrm{E}+00$ & $2.731 \mathrm{E}+00$ & $2.922 \mathrm{E}+00$ & 0.410013 & 0.429596 & 0.460171 & 6.331507 & 6.357136 & 6.3498134 & $6.346 \mathrm{E}+00$ & & \\
\hline 35 & 300.0048 & $1.842 \mathrm{E}+00$ & $1.943 \mathrm{E}+00$ & $2.080 \mathrm{E}+00$ & 0.222852 & 0.233845 & 0.250905 & 8.265575 & 8.308923 & 8.2899902 & $8.288 \mathrm{E}+00$ & & \\
\hline 36 & 289.999 & $1.268 \mathrm{E}+00$ & $1.339 \mathrm{E}+00$ & $1.438 \mathrm{E}+00$ & 0.120976 & 0.127169 & 0.136745 & 10.48142 & 10.5293 & 10.515924 & $1.051 \mathrm{E}+01$ & & \\
\hline 37 & 280.0045 & $8.408 \mathrm{E}-01$ & $8.872 \mathrm{E}-01$ & $9.594 \mathrm{E}-01$ & 0.07104 & 0.074721 & 0.080536 & 11.83559 & 11.8735 & 11.912685 & $1.187 \mathrm{E}+01$ & & \\
\hline 38 & 270.0011 & $5.389 \mathrm{E}-01$ & $5.685 \mathrm{E}-01$ & $6.143 \mathrm{E}-01$ & 0.042598 & 0.044816 & 0.048296 & 12.65083 & 12.6852 & 12.71948 & $1.269 \mathrm{E}+01$ & & \\
\hline 39 & 259.9987 & $3.246 \mathrm{E}-01$ & $3.449 \mathrm{E}-01$ & $3.728 \mathrm{E}-01$ & 0.018945 & 0.020065 & 0.021625 & 17.13381 & 17.18914 & 17.239306 & $1.719 \mathrm{E}+01$ & & \\
\hline 40 & 249.9988 & $1.855 \mathrm{E}-01$ & $1.977 \mathrm{E}-01$ & 2.132E-01 & 0.008235 & 0.00877 & 0.00944 & 22.5258 & 22.54276 & 22.584746 & $2.255 \mathrm{E}+01$ & & \\
\hline 41 & & & & & & & & & & & & & \\
\hline & 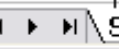 & & & & & & |< & & & & & & \\
\hline Reac & & & & & & & & & & NUM & & & \\
\hline
\end{tabular}

Figure Irr9.3. Left side of sample calibration spreadsheet

\begin{tabular}{|c|c|c|c|c|c|}
\hline Procedure & Version & Date & Author & Pages & Filename \\
\hline IRR-CP-IRR9 & 1.0 & 28-Jun-06 & C. Gibson & 5 of 9 & $\begin{array}{c}\text { IRR-CP-IRR9 Spectral } \\
\text { Irradiance Data Reduction } \\
\text { V1.doc }\end{array}$ \\
\hline
\end{tabular}


Irradiance Calibration Procedure IRR-CP-IRR9-Spectral Irradiance Data Reduction

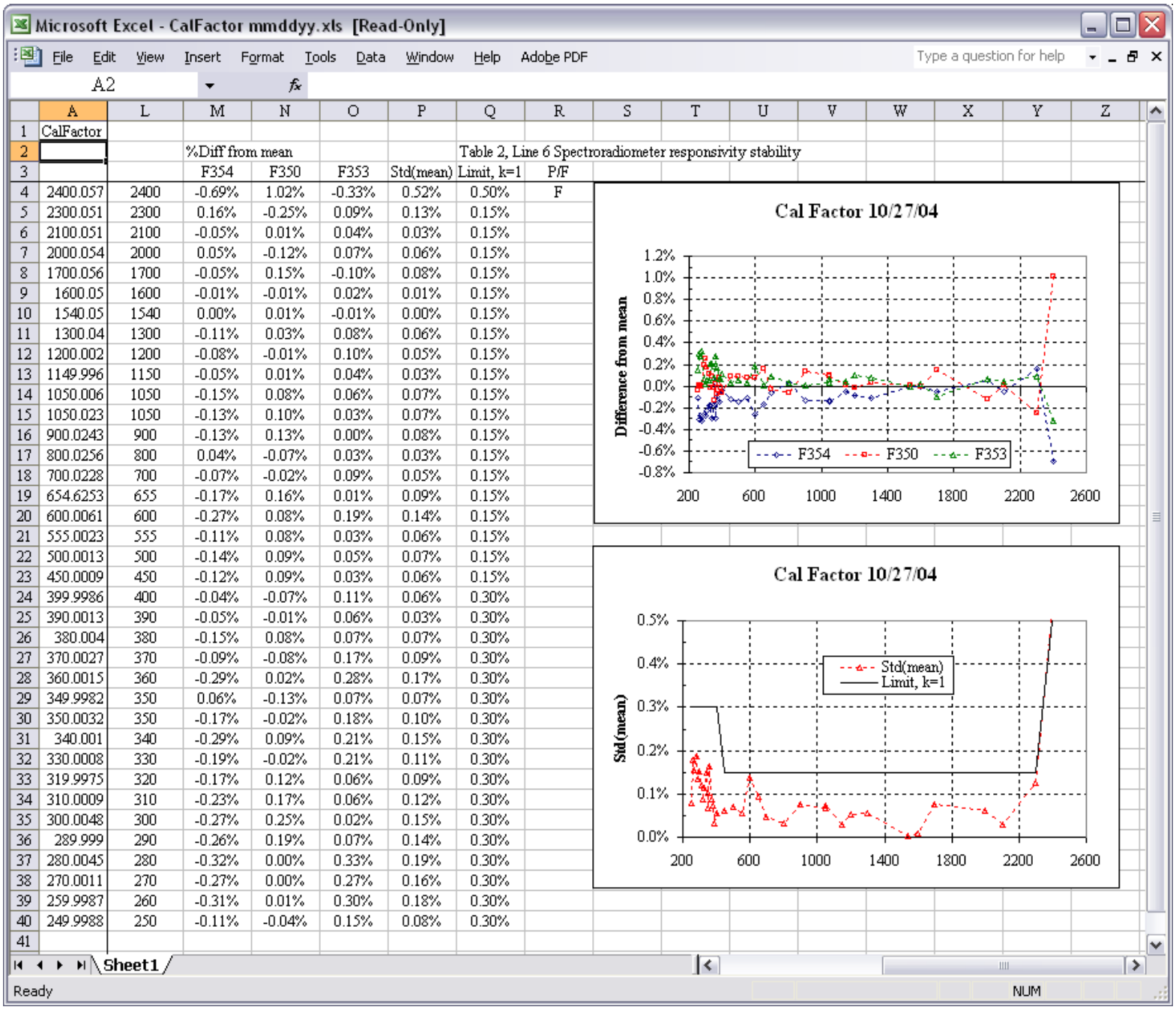

Figure Irr9.4. Right side of sample calibration spreadsheet

\begin{tabular}{|c|c|c|c|c|c|}
\hline Procedure & Version & Date & Author & Pages & Filename \\
\hline IRR-CP-IRR9 & 1.0 & 28-Jun-06 & C. Gibson & 6 of 9 & $\begin{array}{c}\text { IRR-CP-IRR9 Spectral } \\
\text { Irradiance Data Reduction } \\
\text { V1.doc }\end{array}$ \\
\hline
\end{tabular}




\section{Irradiance Calibration Procedure IRR-CP-IRR9-Spectral Irradiance Data Reduction}

\begin{tabular}{|c|c|c|c|c|c|c|c|c|c|c|c|c|}
\hline$\$ M$ & licrosoft Exc & $\mathrm{cel}-\mathrm{F} 000 \mathrm{mn}$ & nddyy cal.xls & {$[$ Read-Only] } & & & & & & & & $\sqrt{x}$ \\
\hline : 婂 & Eile É Edit & Yiew Insert & Format Iools & 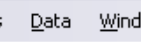 & low Help & sbe PDF & & & Type & a question for hel & & $\theta \times$ \\
\hline & A1 & r & $f_{x} F$ & 000091704 & cal.xls & & & & & & & \\
\hline & A & B & $\mathrm{C}$ & D & $E$ & $\mathrm{~F}$ & G & $\mathrm{H}$ & I & $\mathrm{J}$ & $\mathrm{K}$ & $\hat{\imath}$ \\
\hline 1 & F000 0917 & 44 cal.xls & & $10 / 25 / 2004$ & & & & & & & & \\
\hline 2 & & Signals & & & & $\%$ Diff from & nean & & & Table 2, Line & $10 \mathrm{Lan}$ & \\
\hline 3 & & Run 1 & Run 2 & Run 3 & MeanSig & Run 1 & Run 2 & Run 3 & Std(mean) & Limit, $\mathrm{k}=1$ & $\mathrm{P} / \mathrm{F}$ & \\
\hline 4 & 2400.053 & 0.000618 & 0.000617 & 0.000618 & $6.177 \mathrm{E}-04$ & $0.05 \%$ & $-0.11 \%$ & $0.05 \%$ & $0.05 \%$ & $0.20 \%$ & & \\
\hline 5 & 2300.051 & 0.002325 & 0.002323 & 0.002324 & $2.324 \mathrm{E}-03$ & $0.04 \%$ & $-0.04 \%$ & $0.00 \%$ & $0.02 \%$ & $0.15 \%$ & & \\
\hline 6 & 2100.055 & 0.007034 & 0.007027 & 0.007029 & $7.030 \mathrm{E}-03$ & $0.06 \%$ & $-0.04 \%$ & $-0.01 \%$ & $0.03 \%$ & $0.15 \%$ & & \\
\hline 7 & 2000.05 & 0.014619 & 0.01462 & 0.014626 & $1.462 \mathrm{E}-02$ & $-0.02 \%$ & $-0.01 \%$ & $0.03 \%$ & $0.01 \%$ & $0.15 \%$ & & \\
\hline 8 & 1700.056 & 0.031436 & 0.03142 & 0.031437 & 3.143E-02 & $0.02 \%$ & $-0.03 \%$ & $0.02 \%$ & $0.02 \%$ & $0.15 \%$ & & \\
\hline 9 & 1600.054 & 0.037312 & 0.037305 & 0.037314 & $3.731 \mathrm{E}-02$ & $0.00 \%$ & $-0.01 \%$ & $0.01 \%$ & $0.01 \%$ & $0.10 \%$ & & \\
\hline 10 & 1540.05 & 0.048501 & 0.048489 & 0.0485 & $4.850 \mathrm{E}-02$ & $0.01 \%$ & $-0.02 \%$ & $0.01 \%$ & $0.01 \%$ & $0.10 \%$ & & \\
\hline 11 & 1300.044 & 0.044423 & 0.04438 & 0.044394 & $4.440 \mathrm{E}-02$ & $0.05 \%$ & $-0.04 \%$ & $-0.01 \%$ & $0.03 \%$ & $0.10 \%$ & & \\
\hline 12 & 1200.006 & 0.039071 & 0.039065 & 0.039084 & $3.907 \mathrm{E}-02$ & $-0.01 \%$ & $-0.02 \%$ & $0.03 \%$ & $0.01 \%$ & $0.10 \%$ & & \\
\hline 13 & 1150.004 & 0.033465 & 0.03351 & 0.033511 & $3.350 \mathrm{E}-02$ & $-0.09 \%$ & $0.04 \%$ & $0.05 \%$ & $0.05 \%$ & $0.10 \%$ & & \\
\hline 14 & 1050.006 & 0.020199 & 0.020197 & 0.020188 & $2.019 \mathrm{E}-02$ & $0.02 \%$ & $0.01 \%$ & $-0.03 \%$ & $0.02 \%$ & $0.10 \%$ & & \\
\hline 15 & 1050.021 & 0.673983 & 0.671951 & 0.672713 & $6.729 \mathrm{E}-01$ & $0.16 \%$ & $-0.14 \%$ & $-0.03 \%$ & $0.09 \%$ & $0.10 \%$ & & \\
\hline 16 & 900.0203 & 1.114949 & 1.11304 & 1.113573 & $1.114 \mathrm{E}+00$ & $0.10 \%$ & $-0.07 \%$ & $-0.03 \%$ & $0.05 \%$ & $0.10 \%$ & & \\
\hline 17 & 800.0276 & 0.917936 & 0.918898 & 0.919693 & $9.188 \mathrm{E}-01$ & $-0.10 \%$ & $0.01 \%$ & $0.09 \%$ & $0.06 \%$ & $0.10 \%$ & & \\
\hline 18 & 700.0228 & 1.049694 & 1.049542 & 1.049108 & $1.049 \mathrm{E}+00$ & $0.02 \%$ & $0.01 \%$ & $-0.03 \%$ & $0.02 \%$ & $0.10 \%$ & & \\
\hline 19 & 654.6233 & 1.186049 & 1.184359 & 1.186226 & $1.186 \mathrm{E}+00$ & $0.04 \%$ & $-0.10 \%$ & $0.06 \%$ & $0.05 \%$ & $0.10 \%$ & & \\
\hline 20 & 600.0021 & 1.377616 & 1.376657 & 1.377712 & $1.377 \mathrm{E}+00$ & $0.02 \%$ & $-0.05 \%$ & $0.03 \%$ & $0.02 \%$ & $0.10 \%$ & & \\
\hline 21 & 555.0003 & 1.305852 & 1.305668 & 1.306786 & $1.306 \mathrm{E}+00$ & $-0.02 \%$ & $-0.03 \%$ & $0.05 \%$ & $0.03 \%$ & $0.10 \%$ & & \\
\hline 22 & 499.9993 & 0.878818 & 0.878478 & 0.879286 & $8.789 \mathrm{E}-01$ & $0.00 \%$ & $-0.04 \%$ & $0.05 \%$ & $0.03 \%$ & $0.10 \%$ & & \\
\hline 23 & 450.0009 & 0.512074 & 0.512544 & 0.512815 & $5.125 \mathrm{E}-01$ & $-0.08 \%$ & $0.01 \%$ & $0.07 \%$ & $0.04 \%$ & $0.10 \%$ & & \\
\hline 24 & 399.9986 & 0.255278 & 0.255675 & 0.255887 & $2.556 \mathrm{E}-01$ & $-0.13 \%$ & $0.02 \%$ & $0.11 \%$ & $0.07 \%$ & $0.10 \%$ & & \\
\hline 25 & 390.0013 & 0.218278 & 0.218513 & 0.218659 & $2.185 \mathrm{E}-01$ & $-0.09 \%$ & $0.01 \%$ & $0.08 \%$ & $0.05 \%$ & $0.15 \%$ & & \\
\hline 26 & 380.002 & 0.152996 & 0.153096 & 0.15319 & $1.531 \mathrm{E}-01$ & $-0.06 \%$ & $0.00 \%$ & $0.06 \%$ & $0.04 \%$ & $0.15 \%$ & & \\
\hline 27 & 370.0027 & 0.093148 & 0.093228 & 0.093159 & $9.318 \mathrm{E}-02$ & $-0.03 \%$ & $0.05 \%$ & $-0.02 \%$ & $0.03 \%$ & $0.15 \%$ & & \\
\hline 28 & 360.0035 & 0.060313 & 0.060158 & 0.060127 & $6.020 \mathrm{E}-02$ & $0.19 \%$ & $-0.07 \%$ & $-0.12 \%$ & $0.10 \%$ & $0.15 \%$ & & \\
\hline 29 & 349.9982 & 0.045457 & 0.045301 & 0.045229 & $4.533 \mathrm{E}-02$ & $0.28 \%$ & $-0.06 \%$ & $-0.22 \%$ & $0.15 \%$ & $0.15 \%$ & & \\
\hline 30 & 350.0133 & 0.727598 & 0.724219 & 0.723541 & $7.251 \mathrm{E}-01$ & $0.34 \%$ & $-0.12 \%$ & $-0.22 \%$ & $0.17 \%$ & $0.15 \%$ & $\mathrm{~F}$ & \\
\hline 31 & 340.001 & 0.522592 & 0.520226 & 0.520179 & $5.210 \mathrm{E}-01$ & $0.31 \%$ & $-0.15 \%$ & $-0.16 \%$ & $0.15 \%$ & $0.15 \%$ & $\mathrm{~F}$ & \\
\hline 32 & 330.0008 & 0.378935 & 0.377402 & 0.377389 & $3.779 \mathrm{E}-01$ & $0.27 \%$ & $-0.13 \%$ & $-0.14 \%$ & $0.14 \%$ & $0.15 \%$ & & \\
\hline 33 & 319.9975 & 0.260532 & 0.260057 & 0.259985 & $2.602 \mathrm{E}-01$ & $0.13 \%$ & $-0.05 \%$ & $-0.08 \%$ & $0.07 \%$ & $0.15 \%$ & & \\
\hline 34 & 310.0029 & 0.158621 & 0.158268 & 0.158529 & $1.585 \mathrm{E}-01$ & $0.09 \%$ & $-0.13 \%$ & $0.04 \%$ & $0.07 \%$ & $0.15 \%$ & & \\
\hline 35 & 300.0028 & 0.083466 & 0.083306 & 0.083221 & $8.333 \mathrm{E}-02$ & $0.16 \%$ & $-0.03 \%$ & $-0.13 \%$ & $0.09 \%$ & $0.15 \%$ & & \\
\hline 36 & 289.999 & 0.043943 & 0.043872 & 0.04386 & $4.389 \mathrm{E}-02$ & $0.12 \%$ & $-0.04 \%$ & $-0.07 \%$ & $0.06 \%$ & $0.15 \%$ & & \\
\hline 37 & 280.0045 & 0.025969 & 0.025957 & 0.025944 & $2.596 \mathrm{E}-02$ & $0.05 \%$ & $0.00 \%$ & $-0.05 \%$ & $0.03 \%$ & $0.15 \%$ & & \\
\hline 38 & 270.0011 & 0.016305 & 0.016266 & 0.01627 & $1.628 \mathrm{E}-02$ & $0.15 \%$ & $-0.09 \%$ & $-0.06 \%$ & $0.08 \%$ & $0.15 \%$ & & \\
\hline 39 & 259.9987 & 0.006104 & 0.0061 & 0.006121 & $6.108 \mathrm{E}-03$ & $-0.07 \%$ & $-0.14 \%$ & $0.21 \%$ & $0.11 \%$ & $0.20 \%$ & & \\
\hline 40 & 249.9988 & 0.002565 & 0.002555 & 0.002555 & $2.558 \mathrm{E}-03$ & $0.26 \%$ & $-0.13 \%$ & $-0.13 \%$ & $0.13 \%$ & $0.25 \%$ & & \\
\hline & W $\backslash$ Final & $\lambda$ Data reduc & tion & & & & $k$ & IIII & 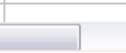 & & & \\
\hline Ready & & & & & & & & & & NUM & & \\
\hline
\end{tabular}

Figure Irr9.5. Left side of sample test irradiance spreadsheet

\begin{tabular}{|c|c|c|c|c|c|}
\hline Procedure & Version & Date & Author & Pages & Filename \\
\hline IRR-CP-IRR9 & 1.0 & 28-Jun-06 & C. Gibson & 7 of 9 & $\begin{array}{c}\text { IRR-CP-IRR9 Spectral } \\
\text { Irradiance Data Reduction } \\
\text { V1.doc }\end{array}$ \\
\hline
\end{tabular}




\section{Irradiance Calibration Procedure IRR-CP-IRR9-Spectral Irradiance Data Reduction}

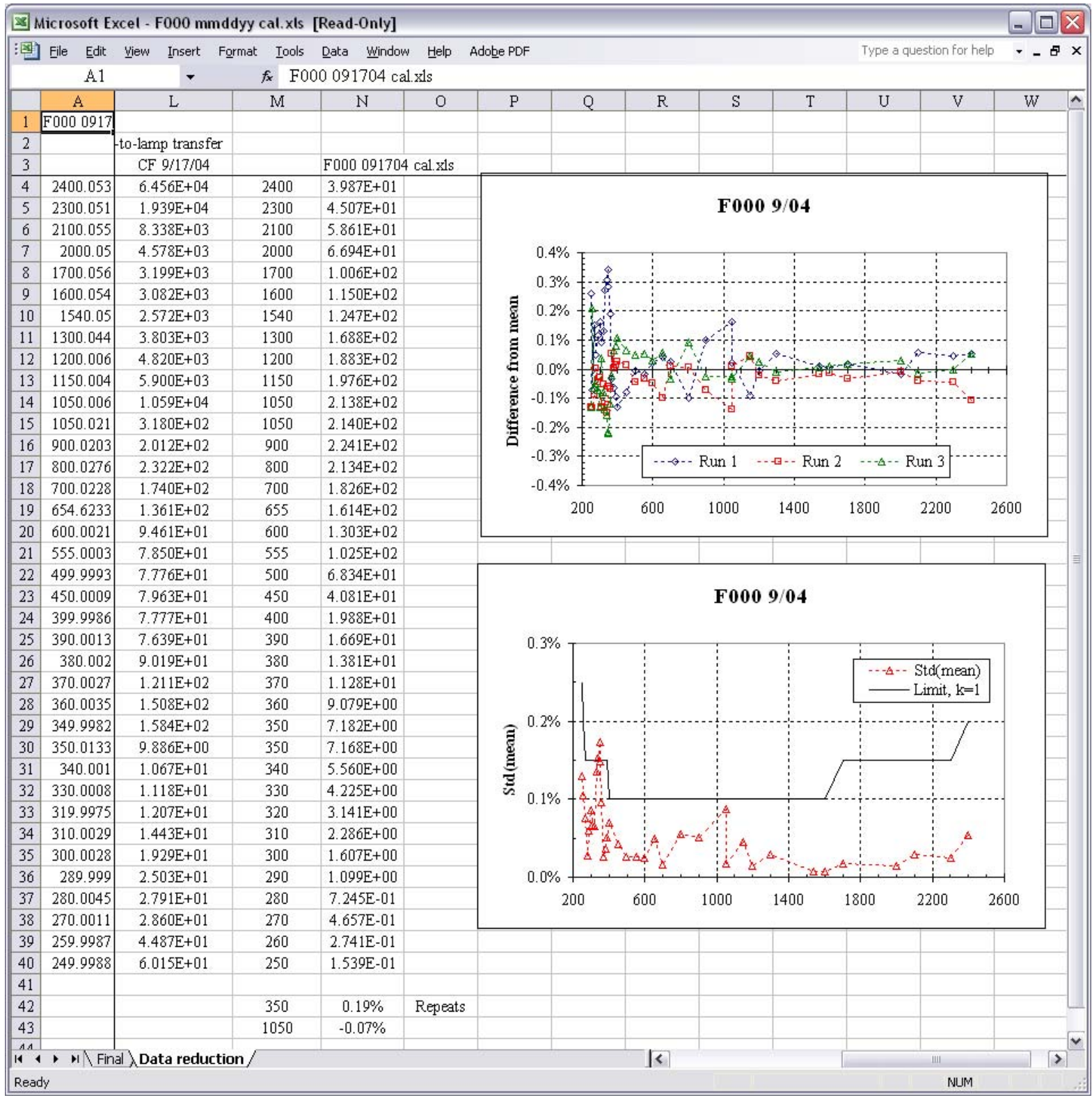

Figure Irr9.6. Right side of sample test irradiance spreadsheet

\begin{tabular}{|c|c|c|c|c|c|}
\hline Procedure & Version & Date & Author & Pages & Filename \\
\hline IRR-CP-IRR9 & 1.0 & 28-Jun-06 & C. Gibson & 8 of 9 & $\begin{array}{c}\text { IRR-CP-IRR9 Spectral } \\
\text { Irradiance Data Reduction } \\
\text { v1.doc }\end{array}$ \\
\hline
\end{tabular}




\section{Irradiance Calibration Procedure IRR-CP-IRR9-Spectral Irradiance Data Reduction}

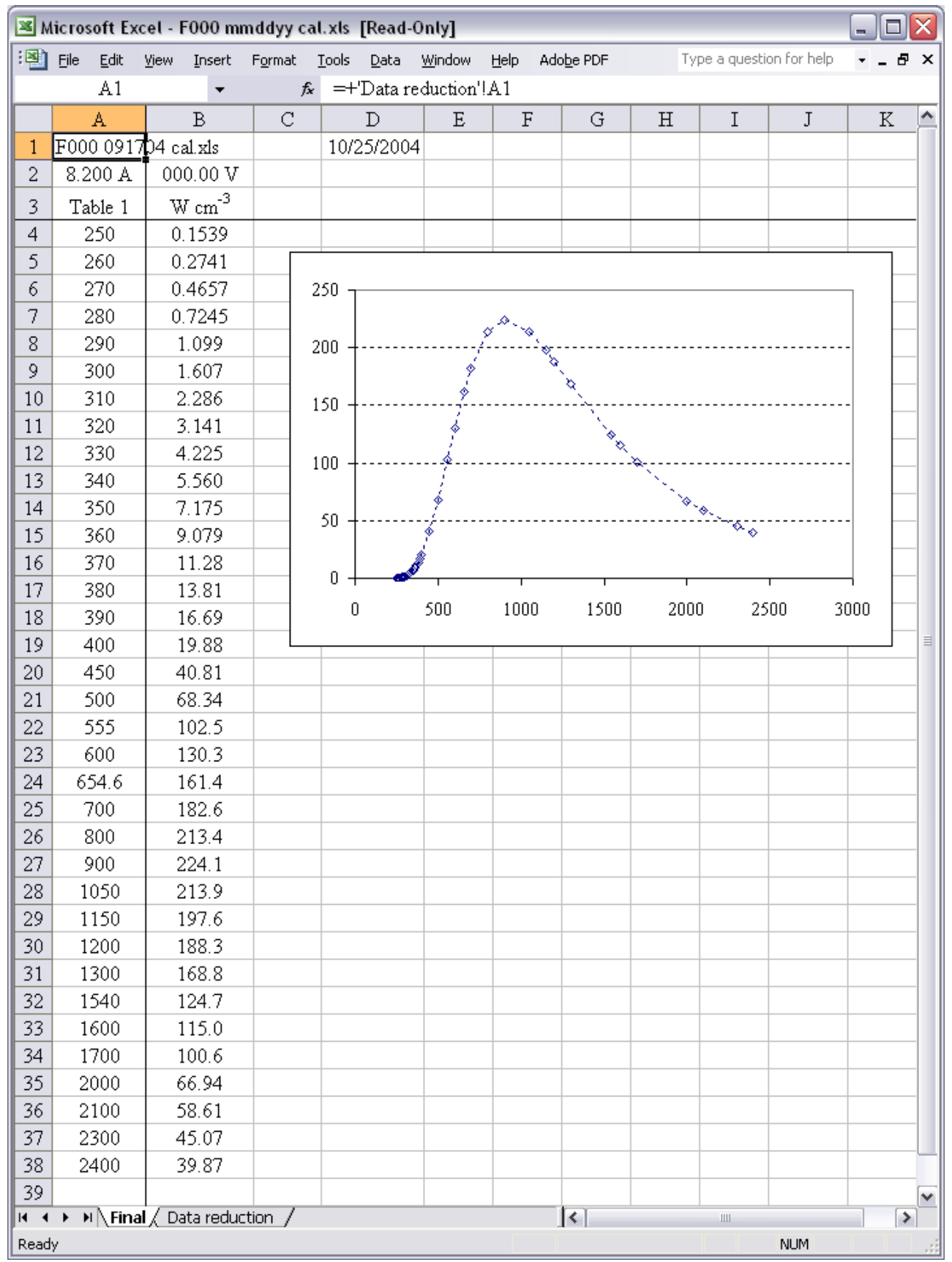

Figure Irr9.7. Final data worksheet of sample test irradiance spreadsheet

\begin{tabular}{|c|c|c|c|c|c|}
\hline Procedure & Version & Date & Author & Pages & Filename \\
\hline IRR-CP-IRR9 & 1.0 & 28-Jun-06 & C. Gibson & 9 of 9 & $\begin{array}{c}\text { IRR-CP-IRR9 Spectral } \\
\text { Irradiance Data Reduction } \\
\text { V1.doc }\end{array}$ \\
\hline
\end{tabular}




\section{Irradiance Calibration Procedure IRR-CP-IRR10-Calculate the Correlated Color Temperature (CCT) and Luminous Intensity (LI) from Spectral Irradiance Data}

Calculate the Correlated Color Temperature (CCT) and Luminous Intensity (LI) from Spectral Irradiance Data

1. Fit data to determine the spectral irradiance value at a $10 \mathrm{~nm}$ interval

1.1. Load the Visual Basic program: $\boldsymbol{c}: \mid F C 2$ Docs $\mid$ fitdata $\mid$ Fitirrad.vbp (do one of the following)

1.1.1. From the start menu

1.1.1.1. Click Start then Data Interpolation shortcut

1.1.2. From Windows Explorer

1.1.2.1. Locate Fitirrad.vbp and double click to open

1.2. Run the program (do one of the following)

\subsubsection{Press F5}

1.2.2. Click the Start icon on the tool bar

1.2.3. Click on the menu item Run then on Start

1.3. Blackbody fit program (Part 1 Calculate fit coefficients) (Fitdata.frm)

1.3.1. Click Calculate fit coefficients from the menu

1.3.1.1. Enter fit parameters

1.3.1.1.1. Enter the Wavelength (min) [nm]

1.3.1.1.2. Enter the Wavelength (max) [nm]

1.3.1.1.3. Enter the Degrees of freedom

1.3.1.2. Select file to reduce

\subsection{Enter Input File}

1.3.1.2.2. Select Input file format

1.3.1.2.2.1. Option 1: Input file begins with Data

1.3.1.2.2.2. Option 2: Input file begins with a title line and a unit line

1.3.1.3. Click the Calculate fit coefficients button

\begin{tabular}{|c|c|c|c|c|c|}
\hline Procedure & Version & Date & Author & Pages & Filename \\
\hline IRR-CP-IRR10 & 1.0 & 29-Jun-06 & C. Gibson & 1 of 9 & $\begin{array}{c}\text { IRR-CP-IRR10 CCT and LI from } \\
\text { Irradiance v1.doc }\end{array}$ \\
\hline
\end{tabular}




\section{Irradiance Calibration Procedure \\ IRR-CP-IRR10-Calculate the Correlated Color Temperature (CCT) and Luminous Intensity (LI) from Spectral Irradiance Data}

1.4. Blackbody fit program (Part 2 Compute irradiance) (Calcirr.frm)

1.4.1. Click Calculate spectral irradiance from blackbody fit from the menu

1.4.1.1. Enter fit parameters

1.4.1.1.1. Enter the Wavelength (min) [nm]

1.4.1.1.2. Enter the Wavelength (max) [nm]

1.4.1.1.3. Enter the Increment [nm]

1.4.1.2. Select file to reduce

1.4.1.2.1. Enter Input File

1.4.1.3.Click the Compute irradiance button

2. Calculate the photometric units

2.1. Load the Visual Basic program: $\boldsymbol{c}: \mid \boldsymbol{F C} 2$ Docs|photmet $\mid$ Photomet.vbp (do one of the following)

2.1.1. From the start menu

2.1.1.1. Click Start then Calculate CCT shortcut

2.1.2. From Windows Explorer

2.1.2.1. Locate Photmet.vbp and double click to open

2.2. Run the program (do one of the following)

2.2.1. Press F5

2.2.2. Click the Start icon on the tool bar

2.2.3. Click on the menu item Run then on Start

2.3. Photometric unit calculation program is loaded (Photomet.frm)

2.4. Enter lamp information

2.4.1. Enter Lamp name

2.4.2. Enter Current [A]

2.4.3. Enter Voltage [V]

2.4.4. Enter Distance [m]

\begin{tabular}{|c|c|c|c|c|c|}
\hline Procedure & Version & Date & Author & Pages & Filename \\
\hline IRR-CP-IRR10 & 1.0 & 29-Jun-06 & C. Gibson & 2 of 9 & $\begin{array}{c}\text { IRR-CP-IRR10 CCT and LI from } \\
\text { Irradiance v1.doc }\end{array}$ \\
\hline
\end{tabular}




\section{Irradiance Calibration Procedure}

\section{IRR-CP-IRR10-Calculate the Correlated Color Temperature (CCT) and}

Luminous Intensity (LI) from Spectral Irradiance Data

2.5. Select file to reduce

\subsubsection{Enter Input File}

\subsubsection{Select Input file format}

\subsection{Option 1: Input file begins with Data}

2.5.1.1.2. Option 2: Input file begins with a title line and a unit line

2.6. Click the Compute Color Temperature button

3. Document History

\begin{tabular}{|c|c|c|c|c|c|c|c|}
\hline Version & $\begin{array}{c}\text { Version } \\
\text { Date }\end{array}$ & Author & $\begin{array}{l}\text { Page } \\
\text { Total }\end{array}$ & $\begin{array}{c}\text { Revision } \\
\text { Date }\end{array}$ & $\begin{array}{c}\text { Revision } \\
\text { Date }\end{array}$ & $\begin{array}{c}\text { Revision } \\
\text { Date }\end{array}$ & $\begin{array}{c}\text { Revision } \\
\text { Date }\end{array}$ \\
\hline 1.0 & 29-Jun-06 & C. Gibson & 9 & & & & \\
\hline & & & & & & & \\
\hline & & & & & & & \\
\hline & & & & & & & \\
\hline & & & & & & & \\
\hline
\end{tabular}

\begin{tabular}{|c|c|c|c|c|c|}
\hline Procedure & Version & Date & Author & Pages & Filename \\
\hline IRR-CP-IRR10 & 1.0 & 29-Jun-06 & C. Gibson & 3 of 9 & $\begin{array}{c}\text { IRR-CP-IRR10 CCT and LI from } \\
\text { Irradiance v1.doc }\end{array}$ \\
\hline
\end{tabular}




\section{Irradiance Calibration Procedure IRR-CP-IRR10-Calculate the Correlated Color Temperature (CCT) and Luminous Intensity (LI) from Spectral Irradiance Data}

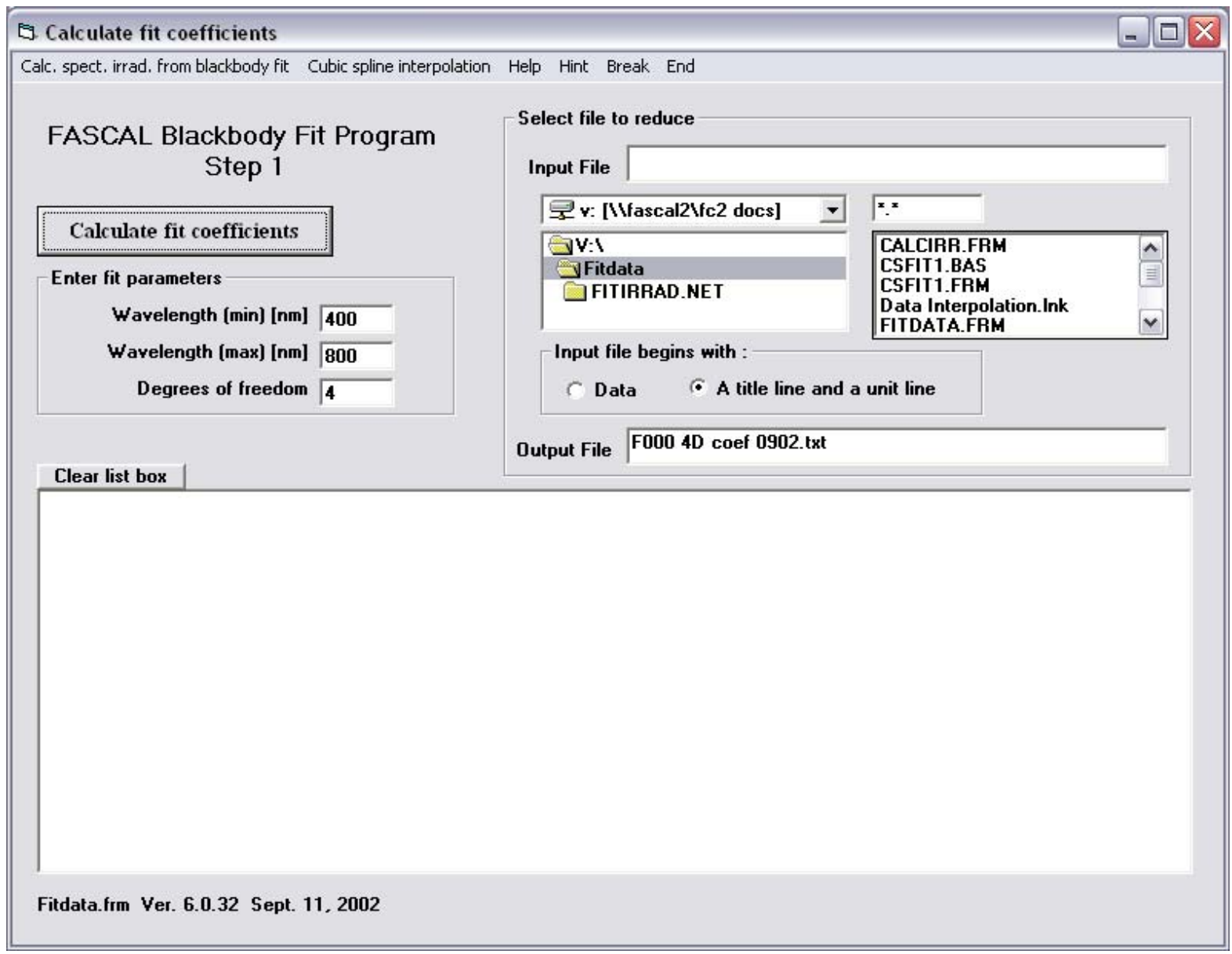

Figure Irr10.1. Front panel of Fitdata.frm

\begin{tabular}{|c|c|c|c|c|c|}
\hline Procedure & Version & Date & Author & Pages & Filename \\
\hline IRR-CP-IRR10 & 1.0 & 29-Jun-06 & C. Gibson & 4 of 9 & $\begin{array}{c}\text { IRR-CP-IRR10 CCT and LI from } \\
\text { Irradiance v1.doc }\end{array}$ \\
\hline
\end{tabular}




\section{Irradiance Calibration Procedure IRR-CP-IRR10-Calculate the Correlated Color Temperature (CCT) and Luminous Intensity (LI) from Spectral Irradiance Data}

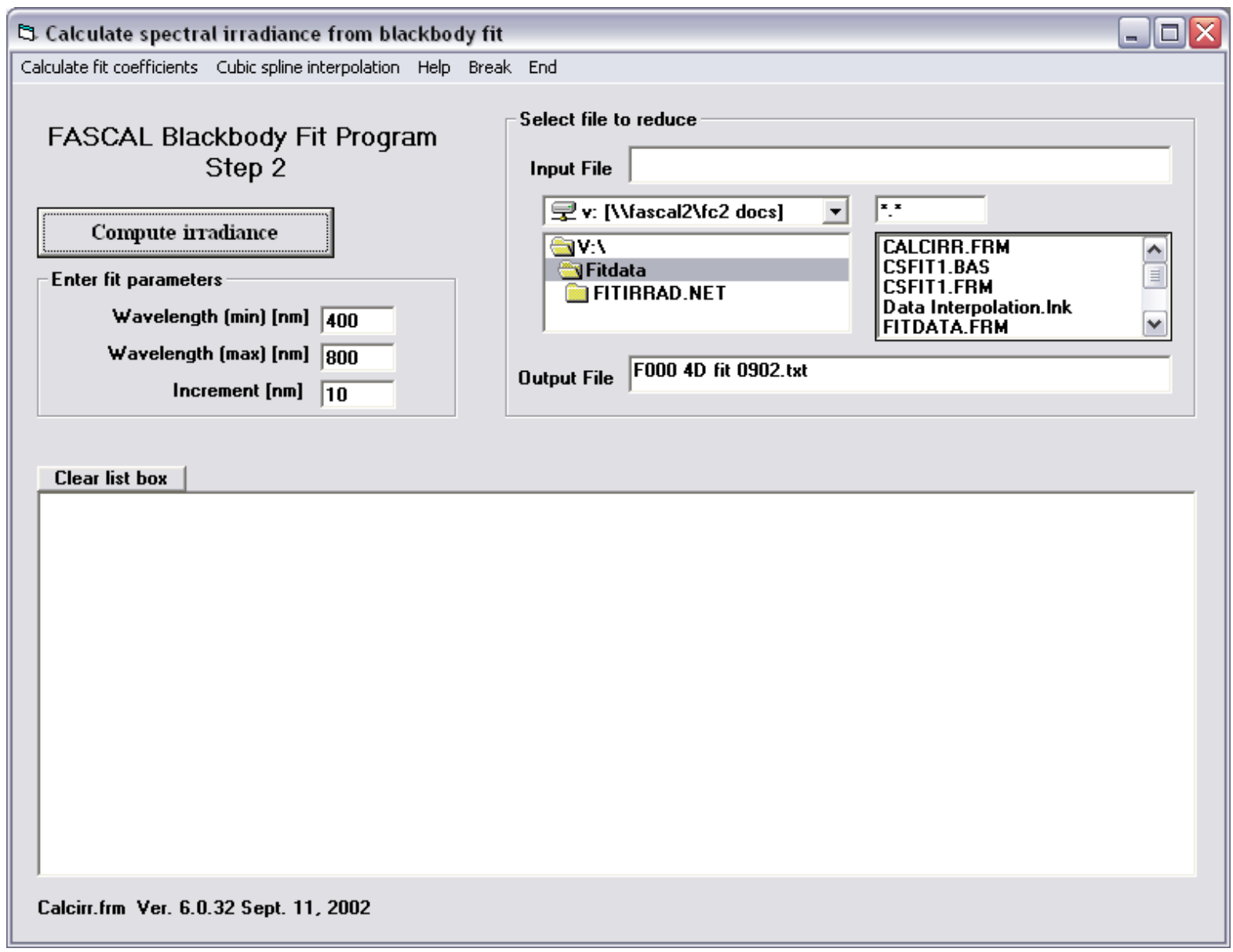

Figure Irr10.2. Front panel of Calcirr.frm

\begin{tabular}{|c|c|c|c|c|c|}
\hline Procedure & Version & Date & Author & Pages & Filename \\
\hline IRR-CP-IRR10 & 1.0 & 29-Jun-06 & C. Gibson & 5 of 9 & $\begin{array}{c}\text { IRR-CP-IRR10 CCT and LI from } \\
\text { Irradiance v1.doc }\end{array}$ \\
\hline
\end{tabular}




\section{Irradiance Calibration Procedure IRR-CP-IRR10-Calculate the Correlated Color Temperature (CCT) and Luminous Intensity (LI) from Spectral Irradiance Data}

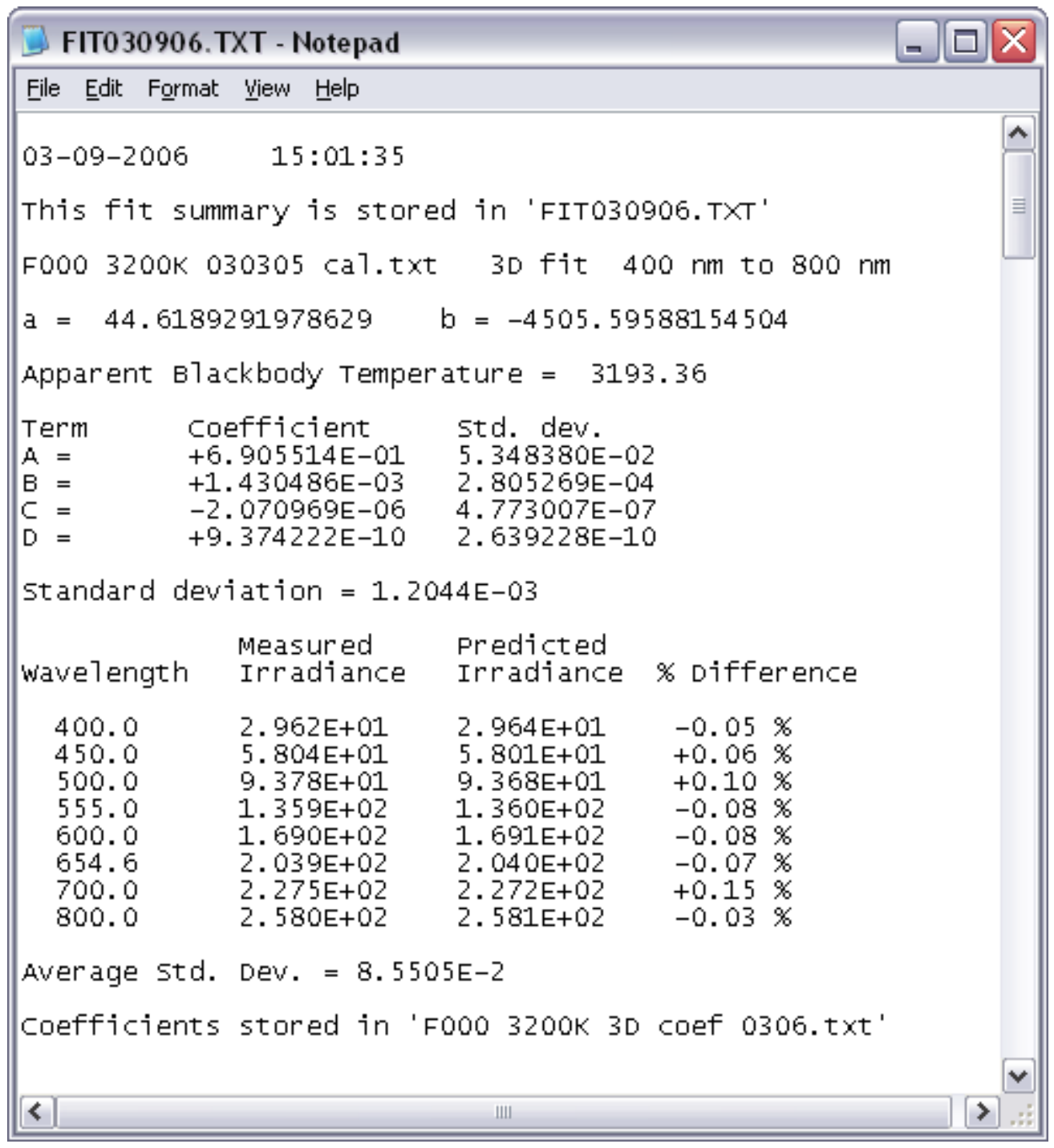

Figure Irr10.3. Sample fit coefficients from data interpolation program

\begin{tabular}{|c|c|c|c|c|c|}
\hline Procedure & Version & Date & Author & Pages & Filename \\
\hline IRR-CP-IRR10 & 1.0 & 29-Jun-06 & C. Gibson & 6 of 9 & $\begin{array}{c}\text { IRR-CP-IRR10 CCT and LI from } \\
\text { Irradiance v1.doc }\end{array}$ \\
\hline
\end{tabular}




\section{Irradiance Calibration Procedure IRR-CP-IRR10-Calculate the Correlated Color Temperature (CCT) and Luminous Intensity (LI) from Spectral Irradiance Data}

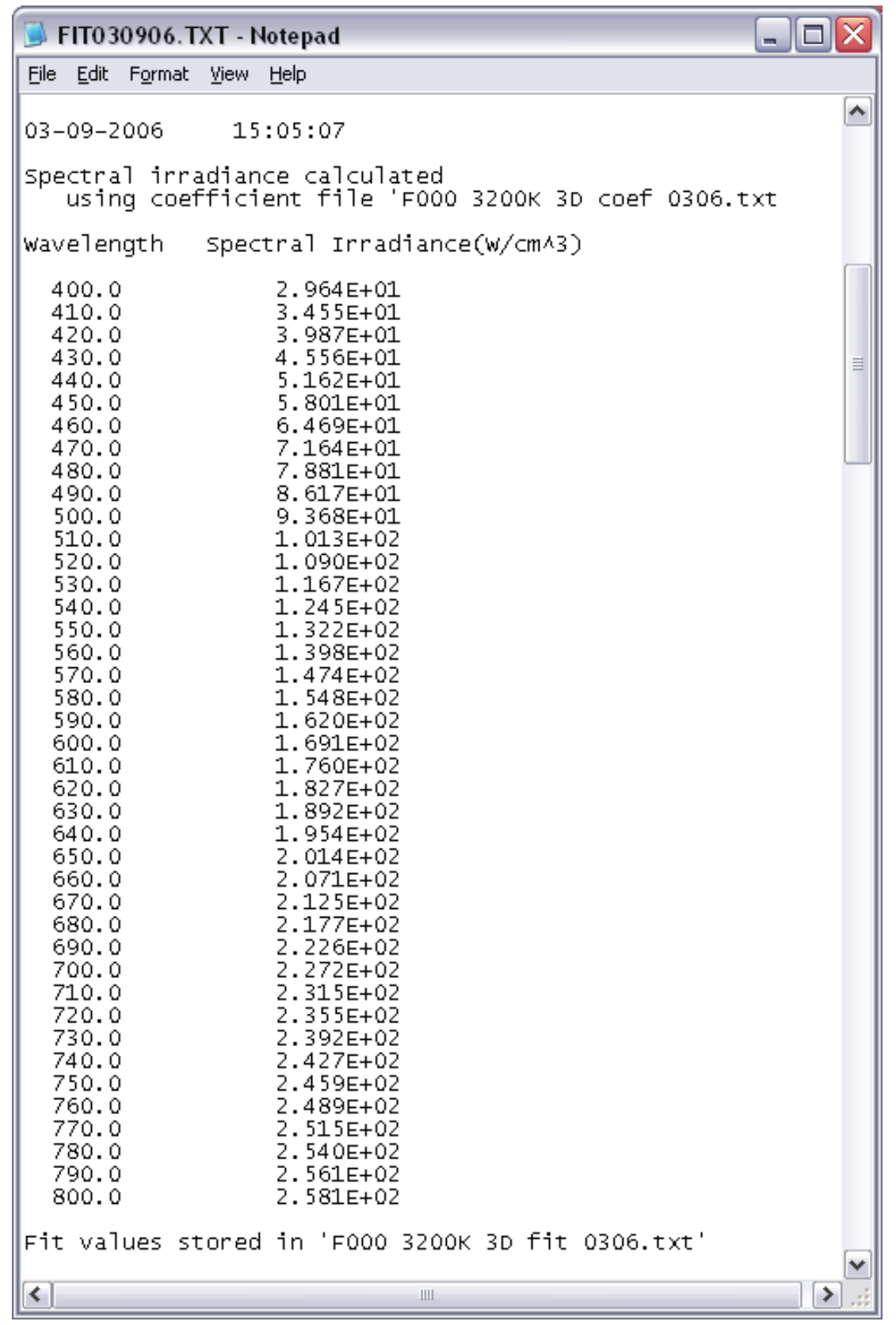

Figure Irr10.4. Sample spectral irradiance data from blackbody fit

\begin{tabular}{|c|c|c|c|c|c|}
\hline Procedure & Version & Date & Author & Pages & Filename \\
\hline IRR-CP-IRR10 & 1.0 & 29-Jun-06 & C. Gibson & 7 of 9 & $\begin{array}{c}\text { IRR-CP-IRR10 CCT and LI from } \\
\text { Irradiance v1.doc }\end{array}$ \\
\hline
\end{tabular}




\section{Irradiance Calibration Procedure IRR-CP-IRR10-Calculate the Correlated Color Temperature (CCT) and Luminous Intensity (LI) from Spectral Irradiance Data}

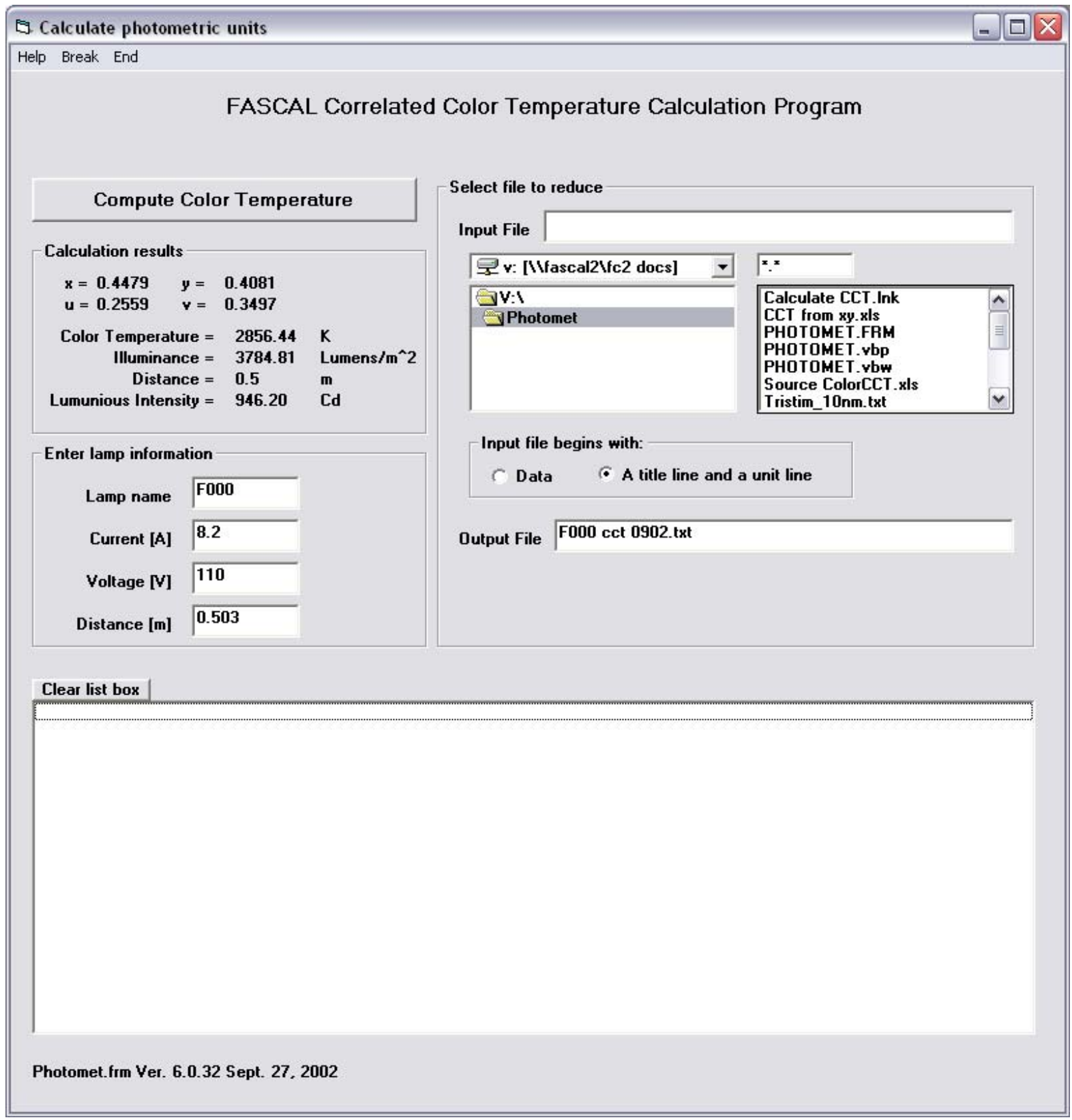

Figure Irr10.5. Front panel of Photomet.frm

\begin{tabular}{|c|c|c|c|c|c|}
\hline Procedure & Version & Date & Author & Pages & Filename \\
\hline IRR-CP-IRR10 & 1.0 & 29-Jun-06 & C. Gibson & 8 of 9 & $\begin{array}{c}\text { IRR-CP-IRR10 CCT and LI from } \\
\text { Irradiance v1.doc }\end{array}$ \\
\hline
\end{tabular}




\section{Irradiance Calibration Procedure}

\section{IRR-CP-IRR10-Calculate the Correlated Color Temperature (CCT) and Luminous Intensity (LI) from Spectral Irradiance Data}

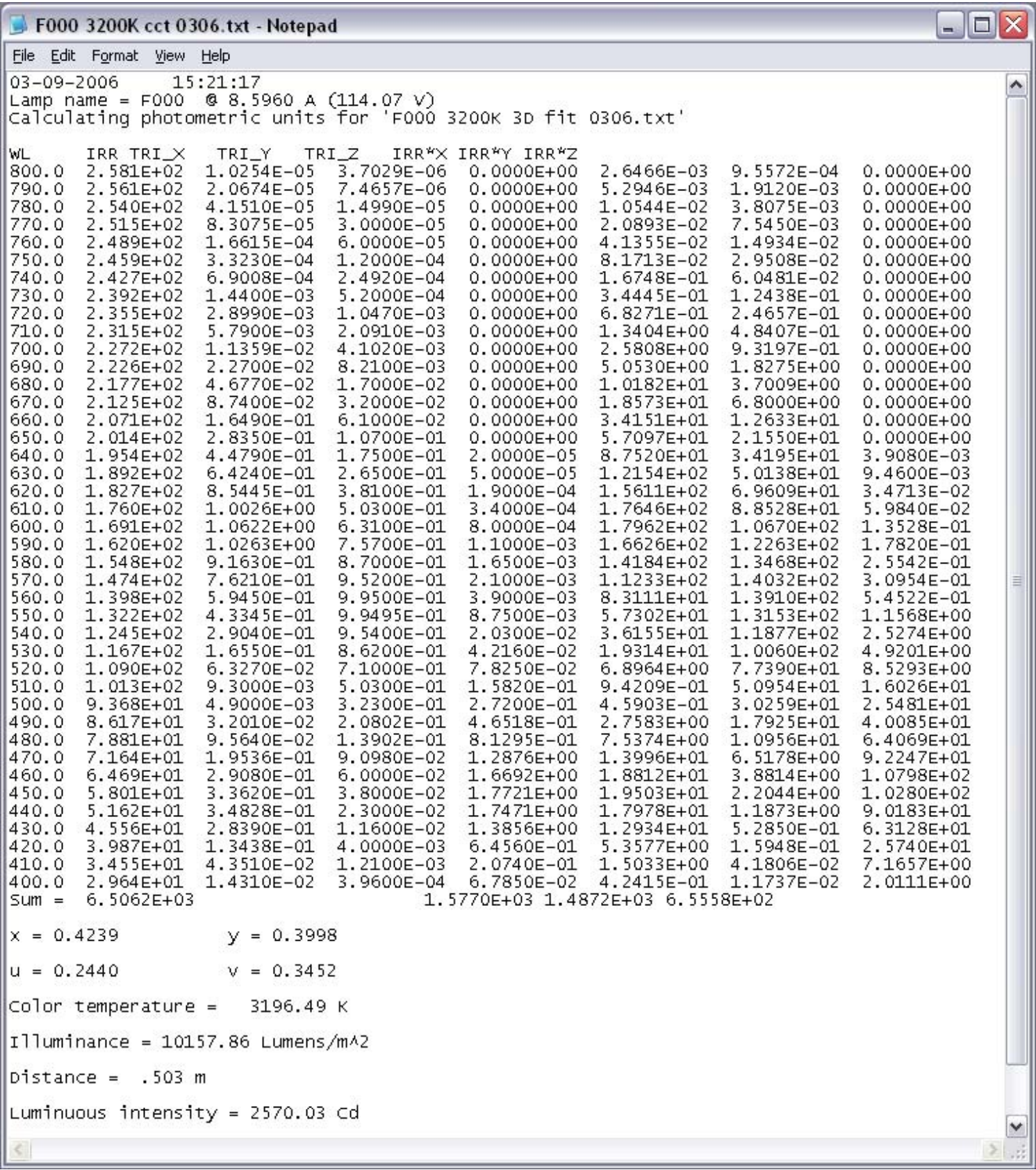

Figure Irr10.6. Sample correlated color temperature and luminous intensity data

\begin{tabular}{|c|c|c|c|c|c|}
\hline Procedure & Version & Date & Author & Pages & Filename \\
\hline IRR-CP-IRR10 & 1.0 & 29-Jun-06 & C. Gibson & 9 of 9 & $\begin{array}{c}\text { IRR-CP-IRR10 CCT and LI from } \\
\text { Irradiance v1.doc }\end{array}$ \\
\hline
\end{tabular}




\section{Irradiance Calibration Procedure}

IRR-CP-IRR11-Reset Linear Encoder

\section{Reset Linear Encoder}

1. The Linear Encoder requires resetting when the Reference Mark is lost.

2. When the HEIDENHAIN display unit is powered on, the blinking REF indicator shows that the display is waiting for reference mark traversing

3. Press the ENT (Enter) key

4. The display shows $\mathbf{1 4 . 0 0 0 . 0}$ with blinking decimal points

5. Use the Unidex 511 motion controller to move the boxcar to the reference mark

6. If the Red LED above the controller is lit then toggle the switch next to the LED to reconnect AC power to the unit. The LED is off during normal operation.

7. Turn on the controller

8. Press F5 (MDI) on the keypad or keyboard

9. Press F2 (JOG) on the keypad or keyboard

10. Use the keypad or keyboard arrows (up/down) to select axis $\mathbf{U}$

11. Press F3 (ENABLE) on the keypad or the keyboard

12. Press F1 (HIGH SPEED) on the keypad or the keyboard

13. Use the keypad or keyboard arrows (left/right) to move the boxcar to the reference position

14. After traversing the reference mark, the HEIDENHAIN display shows the measured value with non-blinking decimal points and non-blinking REF indicator

15. System is ready for remote control (computer control)

16. Document History

\begin{tabular}{|c|c|c|c|c|c|c|c|}
\hline $\begin{array}{c}\text { Versio } \\
\mathrm{n}\end{array}$ & $\begin{array}{c}\text { Version } \\
\text { Date }\end{array}$ & Author & $\begin{array}{l}\text { Page } \\
\text { Total } \\
\end{array}$ & $\begin{array}{c}\text { Revision } \\
\text { Date }\end{array}$ & $\begin{array}{c}\text { Revision } \\
\text { Date }\end{array}$ & $\begin{array}{c}\text { Revision } \\
\text { Date }\end{array}$ & $\begin{array}{c}\text { Revision } \\
\text { Date }\end{array}$ \\
\hline 1.0 & 26-Jun-06 & C. Gibson & 2 & & & & \\
\hline & & & & & & & \\
\hline & & & & & & & \\
\hline & & & & & & & \\
\hline & & & & & & & \\
\hline
\end{tabular}

\begin{tabular}{|c|c|c|c|c|c|}
\hline Procedure & Version & Date & Author & Pages & Filename \\
\hline IRR-CP-IRR11 & 1.0 & 26-Jun-06 & C. Gibson & 1 of 2 & $\begin{array}{c}\text { IRR-CP-IRR11 Reset Linear } \\
\text { Encoder v1.doc }\end{array}$ \\
\hline
\end{tabular}




\section{Irradiance Calibration Procedure IRR-CP-IRR11-Reset Linear Encoder}

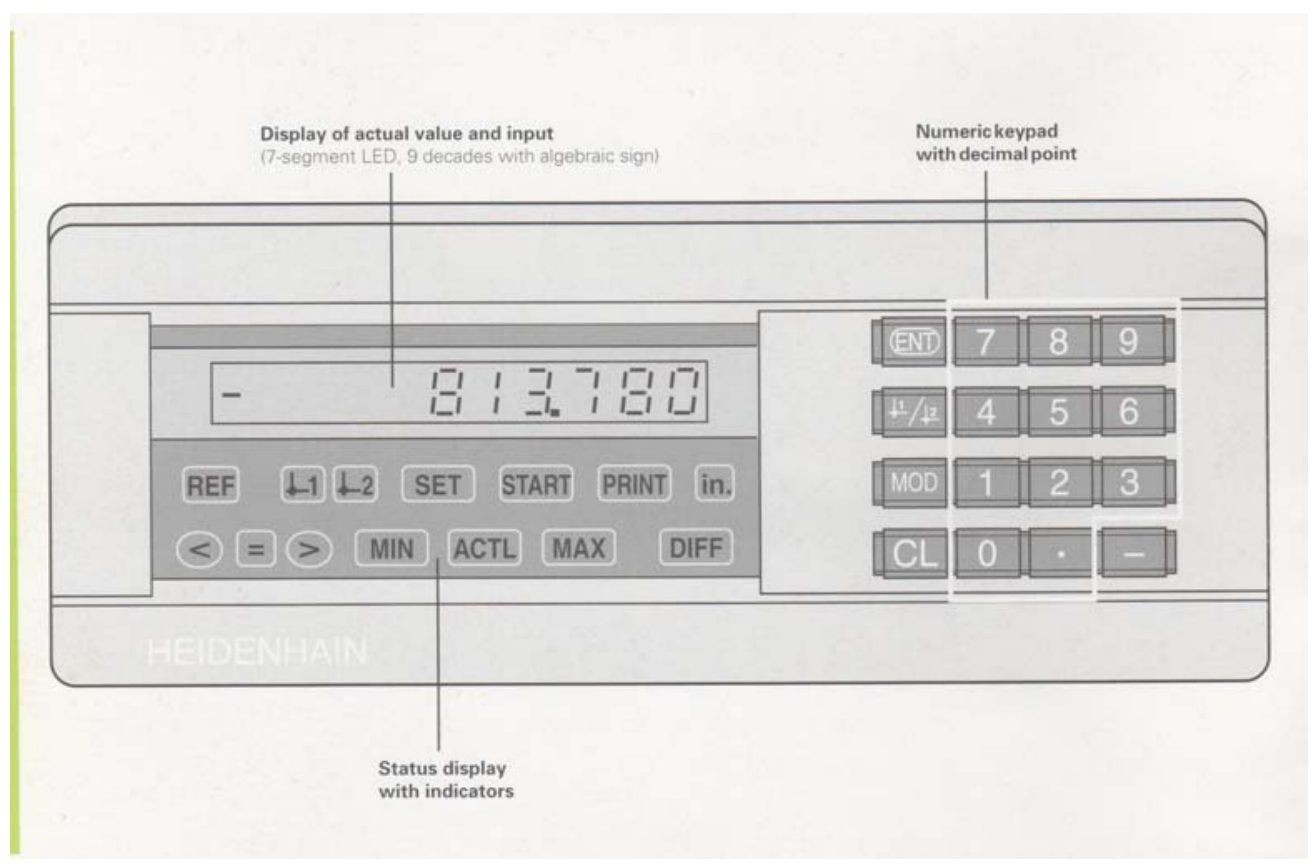

Figure IRR11.1 Front panel of HEIDENHAIN Linear Encoder Display Unit

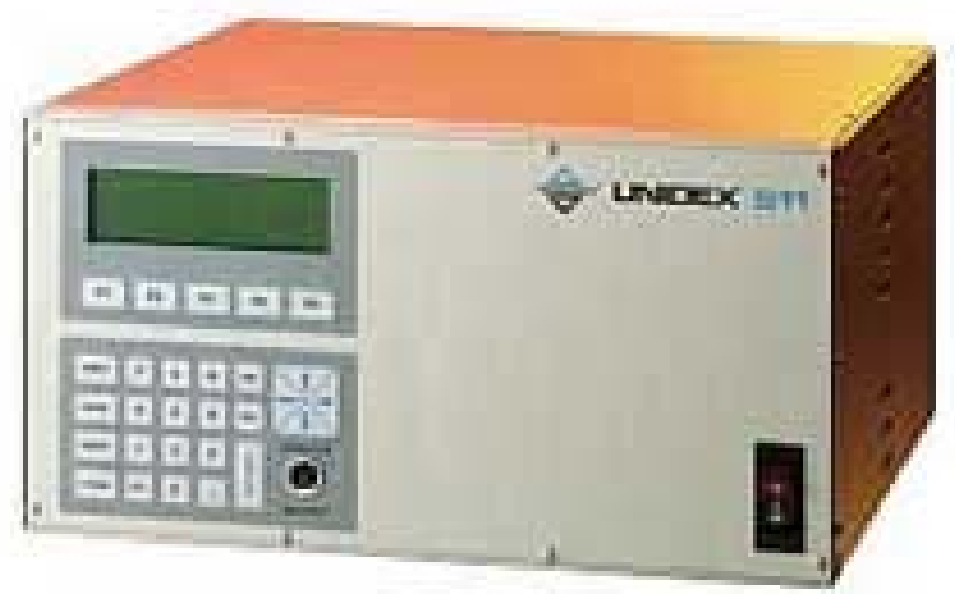

Figure IRR11.2 Front panel of UNIDEX 511 Motion Controller

\begin{tabular}{|c|c|c|c|c|c|}
\hline Procedure & Version & Date & Author & Pages & Filename \\
\hline IRR-CP-IRR11 & 1.0 & 26-Jun-06 & C. Gibson & 2 of 2 & $\begin{array}{c}\text { IRR-CP-IRR11 Reset Linear } \\
\text { Encoder v1.doc }\end{array}$ \\
\hline
\end{tabular}




\section{Irradiance Calibration Procedure}

IRR-CP-IRR12-Goniometric Scan

\section{Goniometric scan}

\begin{tabular}{|c|}
\hline CAUTION \\
\hline LASER \\
\hline COLLISION \\
\hline
\end{tabular}

1. The quartz halogen lamp (QHL) is spatially mapped by rotating the about the vertical and horizontal axes. This method approximates the irradiance in a plane $50 \mathrm{~cm}$ in front of the lamp. The center of rotation of the NIST-designed gonio stage is determined and then the QHL lamp is placed at the center of rotation of the stage. The QHL is placed at the center of rotation to measure irradiance differences attributed to the QHL uniformity. If the lamp is not located at the center of rotation of the stage then the lamp will translate along the vertical and horizontal axes resulting in measurements of different portions of the lamp.

2. Align the QHL alignment jig at $50 \mathrm{~cm}$ in test position \#4

3. Leave the spectroradiometer laser on

4. Place the pointer in the lamp socket

5. Set the pointer height to the center of the laser using the translation stage above the gonio stage

6. Install the scope in test position \#1

7. Align the scope normal to the optical axis

8. Align the scope target on the pointer tip

9. Center the pointer about the vertical axis

9.1. Place a card in front of pointer to view the pointer shadow formed by the laser beam

9.2. Center the pointer on the laser beam

9.2.1. If the pointer is not centered on the laser beam then re-center the pointer by adjusting half the distance using the translation stage above the gonio stage and the other half using translation stage below the gonio stage

9.3. Rotate the mount $+90^{\circ}$ about the vertical axis

9.4. Repeat steps until pointer is centered as it rotates about the vertical axis

\begin{tabular}{|c|c|c|c|c|c|}
\hline Procedure & Version & Date & Author & Pages & Filename \\
\hline IRR-CP-IRR12 & 1.0 & 30-Jun-06 & C. Gibson & 1 of 5 & $\begin{array}{c}\text { IRR-CP-IRR12 Goniometric } \\
\text { Scan v1.doc }\end{array}$ \\
\hline
\end{tabular}




\section{Irradiance Calibration Procedure}

IRR-CP-IRR12-Goniometric Scan

10. Center the pointer about the horizontal axis

10.1. Rotate the pointer $+7^{\circ}$ about the horizontal axis

10.2. Look through the scope

10.3. Rotate back to the center

10.4. If the center of rotation is below the optical axis then raise the translation stage above the gonio stage and lower the translation stage below the gonio stage

10.5. If the center of rotation is above the optical axis then lower the translation stage above the gonio stage and lower the translation stage raise the gonio stage

10.6. Rotate the pointer $-7^{\circ}$ about the horizontal axis

10.7. Look through the scope

10.8. Rotate back to the center

10.9. If the center of rotation is below the optical axis then raise the translation stage above the gonio stage and lower the translation stage below the gonio stage

10.10. If the center of rotation is above the optical axis then lower the translation stage above the gonio stage and lower the translation stage raise the gonio stage

10.11. Repeat steps until pointer tip is centered as it rotates about the horizontal axis

11. Align the alignment jig on the optical axis

11.1. Align the scope target on the pointer tip

11.2. Tape down the translation stage handles for the stage below the gonio stage (No further adjustments are made to this stage)

11.3. Remove the rotation stage handle

11.4. Attach the DC motor to the rotation stage

11.5. Install the alignment jig and align

11.6. Set distance using position indicated by scope

11.7. Use translation stage below the gonio stage to translate along the optical axis

11.8. Re-tape the translation stage handle for the stage below the gonio stage

11.9. For other adjustments, use the translation stage above the gonio stage or the gonio stage to align the jig on the optical axis

11.10. Reset the scope to center on the alignment jig

11.11. Set the rotation stage dial to zero

\begin{tabular}{|c|c|c|c|c|c|}
\hline Procedure & Version & Date & Author & Pages & Filename \\
\hline IRR-CP-IRR12 & 1.0 & 30-Jun-06 & C. Gibson & 2 of 5 & $\begin{array}{c}\text { IRR-CP-IRR12 Goniometric } \\
\text { Scan v1.doc }\end{array}$ \\
\hline
\end{tabular}




\section{Irradiance Calibration Procedure}

IRR-CP-IRR12-Goniometric Scan

11.12. Mark the starting position of the gonio stage horizontal dial with a piece of masking tape

11.13. Connect motor cables

11.14. Turn on Aerotech controller if necessary

12. Remove alignment jig

13. Install lamp in lamp socket

14. Turn on lamp

15. Run goniometric scan program

15.1. From Hardware.frm, click Tests then Spatial Scan in the program menu

15.2. Enter the Filename

15.3. Select the Increment size [deg]

15.4. Enter the Number of reading per Trigger

15.5. Enter Degrees of rotation about the vertical axis $(<\mathbf{Y})$

15.6. Enter Degrees of pitch about the horizontal axis $(<\mathbf{X})$

15.7. Select axis to measure

15.7.1. The program by default select the following when the program is run

15.7.2. $<\mathrm{X}$ - Rotation about the horizontal axis

15.7.3. $<\mathbf{Y}$ - Rotation about the vertical axis

15.8. Select scan type

15.8.1. Select Goniometric scan

15.9. Click Start Scan to run program

15.10. Click Test Motor to text motor selected in select axis to measure

15.11. Click Initialize AERO3 to initialize stepper motor controller

15.11.1. Program initializes this controller when Start Scan is clicked

\begin{tabular}{|c|c|c|c|c|c|}
\hline Procedure & Version & Date & Author & Pages & Filename \\
\hline IRR-CP-IRR12 & 1.0 & 30-Jun-06 & C. Gibson & 3 of 5 & $\begin{array}{c}\text { IRR-CP-IRR12 Goniometric } \\
\text { Scan v1.doc }\end{array}$ \\
\hline
\end{tabular}




\section{Irradiance Calibration Procedure \\ IRR-CP-IRR12-Goniometric Scan}

16. Document History

\begin{tabular}{|c|c|c|c|c|c|c|c|}
\hline Version & $\begin{array}{c}\text { Version } \\
\text { Date }\end{array}$ & Author & $\begin{array}{c}\text { Page } \\
\text { Total }\end{array}$ & $\begin{array}{c}\text { Revision } \\
\text { Date }\end{array}$ & $\begin{array}{c}\text { Revision } \\
\text { Date }\end{array}$ & $\begin{array}{c}\text { Revision } \\
\text { Date }\end{array}$ & $\begin{array}{c}\text { Revision } \\
\text { Date }\end{array}$ \\
\hline 1.0 & $30-J u n-06$ & C. Gibson & 5 & & & & \\
\hline & & & & & & & \\
\hline & & & & & & & \\
\hline & & & & & & & \\
\hline & & & & & & & \\
\hline
\end{tabular}

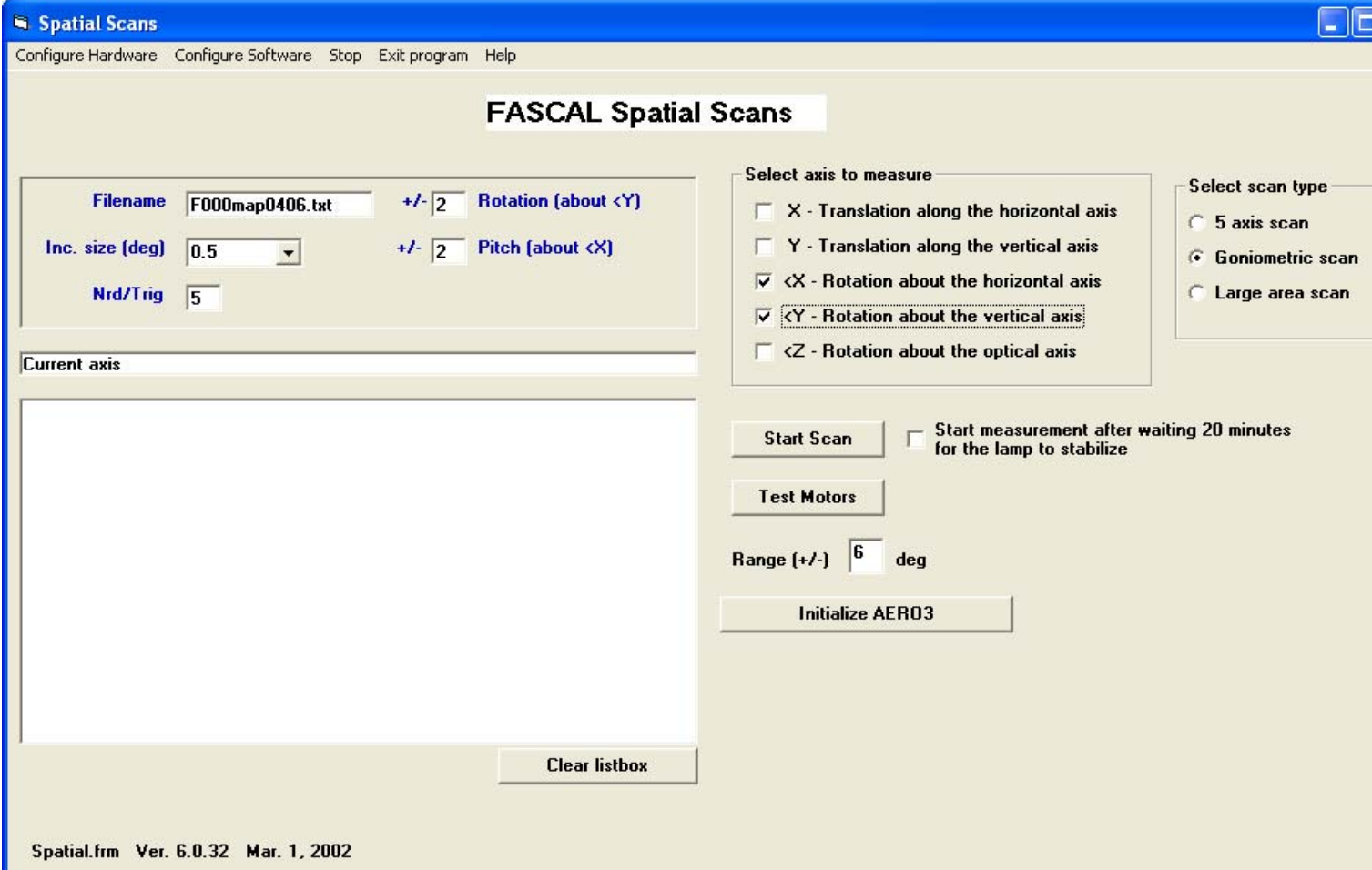

Figure IRR12.1. Front panel of Spatial.frm

\begin{tabular}{|c|c|c|c|c|c|}
\hline Procedure & Version & Date & Author & Pages & Filename \\
\hline IRR-CP-IRR12 & 1.0 & 30-Jun-06 & C. Gibson & 4 of 5 & $\begin{array}{c}\text { IRR-CP-IRR12 Goniometric } \\
\text { Scan v1.doc }\end{array}$ \\
\hline
\end{tabular}




\section{Irradiance Calibration Procedure \\ IRR-CP-IRR12-Goniometric Scan}

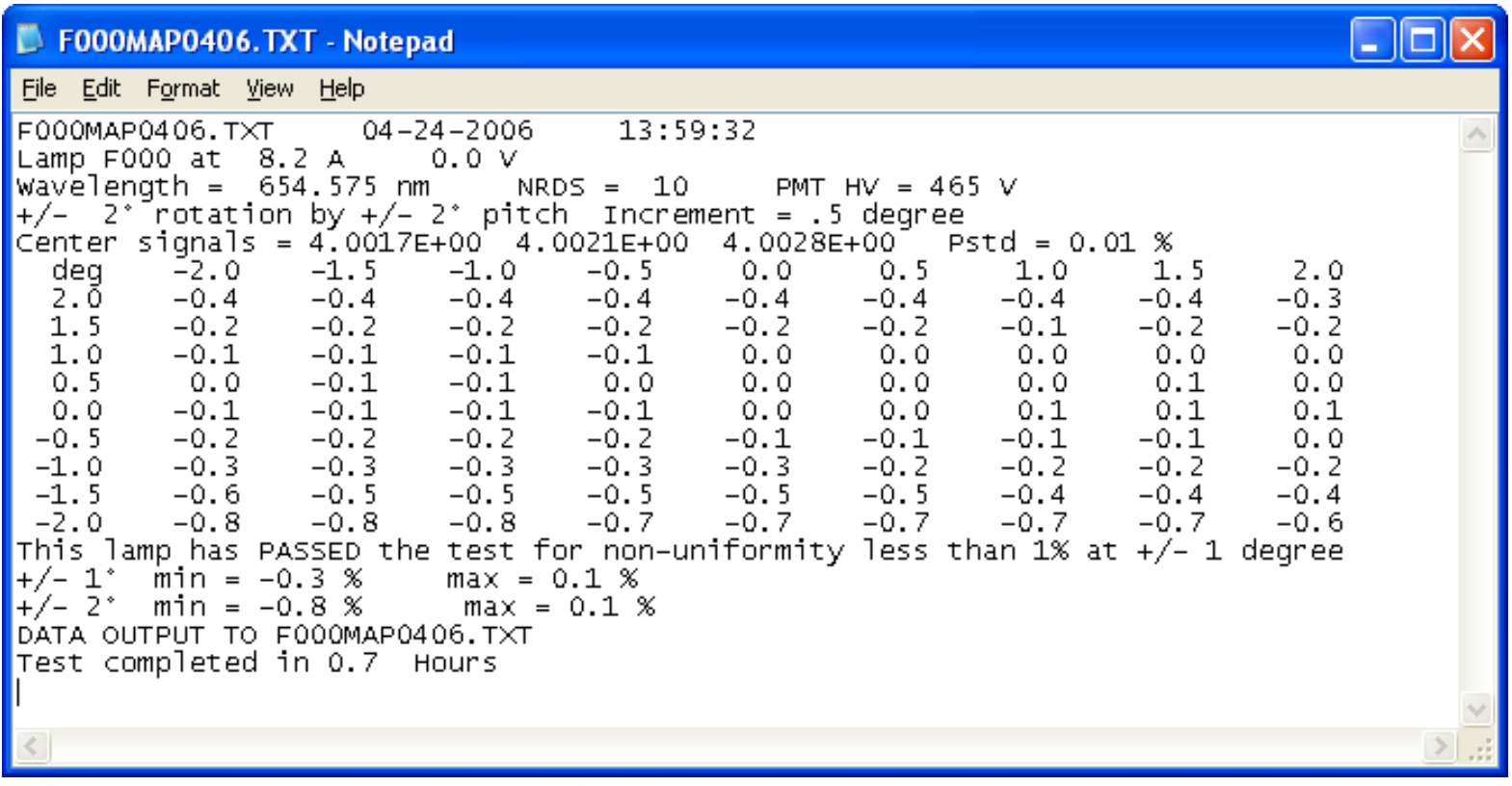

Figure IRR12.2. Sample goniometric scan data

\begin{tabular}{|c|c|c|c|c|c|}
\hline Procedure & Version & Date & Author & Pages & Filename \\
\hline IRR-CP-IRR12 & 1.0 & 30-Jun-06 & C. Gibson & 5 of 5 & $\begin{array}{c}\text { IRR-CP-IRR12 Goniometric } \\
\text { Scan v1.doc }\end{array}$ \\
\hline
\end{tabular}




\section{Appendix G. Radiation constants}

$c=$ speed of light in vacuum

$c_{1 \mathrm{~L}}=$ first radiation constant for spectral radiance $=2 h c^{2}$

$c_{2}=$ second radiation constant $=h c k^{-1}$

$h=$ Planck constant $=6.62606957(29) \times 10^{-34} \mathrm{~J} \mathrm{~s}=6.62606957 \times 10^{-34} \mathrm{~W} \mathrm{~s}^{2}$

$k=$ Boltzmann constant $=1.3806488(13) \times 10^{-23} \mathrm{~J} \mathrm{~K}^{-1}=1.3806488 \times 10^{-23} \mathrm{~W} \mathrm{~s} \mathrm{~K}^{-1}$

$\mathrm{n}=$ refractive index of air at $655 \mathrm{~nm}$ at $15^{\circ} \mathrm{C}$ and $101325 \mathrm{~Pa}=1.00028$

\begin{tabular}{|c|c|c|c|}
\hline & $c_{1 \mathrm{~L}}$ & $c_{2}$ & $c$ \\
\hline Area in $\mathrm{m}^{2}$, wavelength in $\mathrm{m}$ & $1.191042869(53) \times 10^{-16} \mathrm{~W} \mathrm{~m}^{2} \mathrm{sr}^{-1}$ & $1.4387770(13) \times 10^{-2} \mathrm{~m} \mathrm{~K}$ & $2.99792458 \times 10^{8} \mathrm{~m} \mathrm{~s}^{-1}$ \\
\hline Area in $\mathrm{m}^{2}$, wavelength in $\mathrm{cm}$ & $1.191042869 \times 10^{-8} \mathrm{~W} \mathrm{~m}^{2} \mathrm{sr}^{-1}$ & $1.4387770 \mathrm{~cm} \mathrm{~K}$ & $2.99792458 \times 10^{10} \mathrm{~cm} \mathrm{~s}^{-1}$ \\
\hline Area in $\mathrm{m}^{2}$, wavelength in $\mu \mathrm{m}$ & $1.191042869 \times 10^{8} \mathrm{~W} \mathrm{~m}^{2} \mathrm{sr}^{-1}$ & $1.4387770 \times 10^{4} \mu \mathrm{m} \mathrm{K}$ & $2.99792458 \times 10^{14}{\mu \mathrm{m} \mathrm{s}^{-1}}^{-1}$ \\
\hline Area in $\mathrm{m}^{2}$, wavelength in $\mathrm{nm}$ & $1.191042869 \times 10^{20} \mathrm{~W} \mathrm{~m}^{2} \mathrm{sr}^{-1}$ & $1.4387770 \times 10^{7} \mathrm{~nm} \mathrm{~K}$ & $2.99792458 \times 10^{17} \mathrm{~nm} \mathrm{~s}^{-1}$ \\
\hline Area in $\mathrm{cm}^{2}$, wavelength in $\mathrm{cm}$ & $1.191042869 \times 10^{-12} \mathrm{~W} \mathrm{~cm}^{2} \mathrm{sr}^{-1}$ & $1.4387770 \mathrm{~cm} \mathrm{~K}$ & $2.99792458 \times 10^{10} \mathrm{~cm} \mathrm{~s}^{-1}$ \\
\hline Area in $\mathrm{cm}^{2}$, wavelength in $\mu \mathrm{m}$ & $1.191042869 \times 10^{4} \mathrm{~W} \mathrm{~cm}^{2} \mathrm{sr}^{-1}$ & $1.4387770 \times 10^{4} \mu \mathrm{m} \mathrm{K}$ & $2.99792458 \times 10^{14}{\mu \mathrm{m} \mathrm{s}^{-1}}^{-1}$ \\
\hline Area in $\mathrm{cm}^{2}$, wavelength in $\mathrm{nm}$ & $1.191042869 \times 10^{16} \mathrm{~W} \mathrm{~cm}^{2} \mathrm{sr}^{-1}$ & $1.4387770 \times 10^{7} \mathrm{~nm} \mathrm{~K}$ & $2.99792458 \times 10^{17} \mathrm{~nm} \mathrm{~s}^{-1}$ \\
\hline Area in $\mu \mathrm{m}^{2}$, wavelength in $\mu \mathrm{m}$ & $1.191042869 \times 10^{-4} \mathrm{~W} \mu \mathrm{m}^{2} \mathrm{sr}^{-1}$ & $1.4387770 \times 10^{4} \mu \mathrm{m} \mathrm{K}$ & $2.99792458 \times 10^{14} \mu \mathrm{m} \mathrm{s}^{-1}$ \\
\hline Area in $\mathrm{nm}^{2}$, wavelength in $\mathrm{nm}$ & $1.191042869 \times 10^{2} \mathrm{~W} \mathrm{~nm}^{2} \mathrm{sr}^{-1}$ & $1.4387770 \times 10^{7} \mathrm{~nm} \mathrm{~K}$ & $2.99792458 \times 10^{17} \mathrm{~nm} \mathrm{~s}^{-1}$ \\
\hline
\end{tabular}

Source of the CODATA internationally recommended values

The values of the constants provided at this table are recommended for international use by CODATA and are the latest available. Termed the "2010 CODATA recommended values," they are generally recognized worldwide for use in all fields of science and technology. The values became available on 2 June 2011 and replaced the 2006 CODATA set. They are based on all of the data available through 31 December 2010. The 2010 adjustment was carried out under the auspices of the CODATA Task Group on Fundamental Constants. 


\section{Appendix H. Conversion factors}

\begin{tabular}{|c|c|c|c|}
\hline & Spectral radiance & Spectral irradiance & $\begin{array}{l}\text { To convert } \\
\text { from } \mathrm{cm}^{-2} \mathrm{~cm}^{-1} \\
\text { multiply by }\end{array}$ \\
\hline Area in $\mathrm{m}^{2}$, wavelength in $\mathrm{m}$ & $\mathrm{W} \mathrm{m} \mathrm{m}^{-2} \mathrm{sr}^{-1}$ & $\mathrm{~W} \mathrm{~m} \mathrm{~m}^{-1}$ & $10^{6}$ \\
\hline Area in $\mathrm{m}^{2}$, wavelength in $\mathrm{cm}$ & $\mathrm{W} \mathrm{m} \mathrm{m}^{-2} \mathrm{~cm}^{-1} \mathrm{sr}^{-1}$ & $\mathrm{~W} \mathrm{~m} \mathrm{~m}^{-2} \mathrm{~cm}^{-1}$ & $10^{4}$ \\
\hline Area in $\mathrm{m}^{2}$, wavelength in $\mu \mathrm{m}$ & $\mathrm{W} \mathrm{m} \mathrm{m}^{-2} \mu \mathrm{m}^{-1} \mathrm{sr}^{-1}$ & $\mathrm{~W} \mathrm{~m}{ }^{-2} \mu \mathrm{m}^{-1}$ & 1 \\
\hline Area in $\mathrm{m}^{2}$, wavelength in $\mathrm{nm}$ & $\mathrm{W} \mathrm{m} \mathrm{mm}^{-1} \mathrm{sr}^{-1}$ & $\mathrm{~W} \mathrm{~m} \mathrm{~mm}^{-1}$ & $10^{-3}$ \\
\hline Area in $\mathrm{cm}^{2}$, wavelength in $\mathrm{cm}$ & $\mathrm{W} \mathrm{cm}{ }^{-2} \mathrm{~cm}^{-1} \mathrm{sr}^{-1}$ & $\mathrm{~W} \mathrm{~cm}{ }^{-2} \mathrm{~cm}^{-1}$ & 1 \\
\hline Area in $\mathrm{cm}^{2}$, wavelength in $\mu \mathrm{m}$ & $\mathrm{W} \mathrm{cm}{ }^{-2} \mu \mathrm{m}^{-1} \mathrm{sr}^{-1}$ & $\mathrm{~W} \mathrm{~cm}{ }^{-2} \mu \mathrm{m}^{-1}$ & $10^{-4}$ \\
\hline Area in $\mathrm{cm}^{2}$, wavelength in $\mu \mathrm{m}$ & 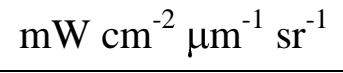 & $\mathrm{mW} \mathrm{cm}{ }^{-2} \mu \mathrm{m}^{-1}$ & $10^{-1}$ \\
\hline Area in $\mathrm{cm}^{2}$, wavelength in $\mathrm{nm}$ & $\mathrm{W} \mathrm{cm}{ }^{-2} \mathrm{~nm}^{-1} \mathrm{sr}^{-1}$ & $\mathrm{~W} \mathrm{~cm}{ }^{-2} \mathrm{~nm}^{-1}$ & $10^{-7}$ \\
\hline Area in $\mathrm{cm}^{2}$, wavelength in $\mathrm{nm}$ & 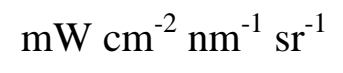 & $\mathrm{mW} \mathrm{cm} \mathrm{nm}^{-1}$ & $10^{-4}$ \\
\hline Area in $\mathrm{cm}^{2}$, wavelength in $\mathrm{nm}$ & $\mu \mathrm{W} \mathrm{cm}{ }^{-2} \mathrm{~nm}^{-1} \mathrm{sr}^{-1}$ & $\mu \mathrm{W} \mathrm{cm} \mathrm{nm}^{-1}$ & $10^{-1}$ \\
\hline
\end{tabular}




\section{Appendix I. Alignment jig}

Front view

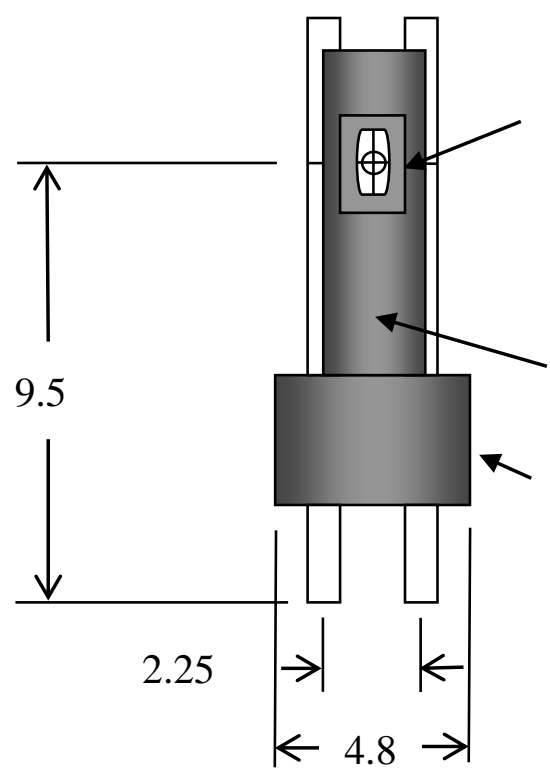

Side view

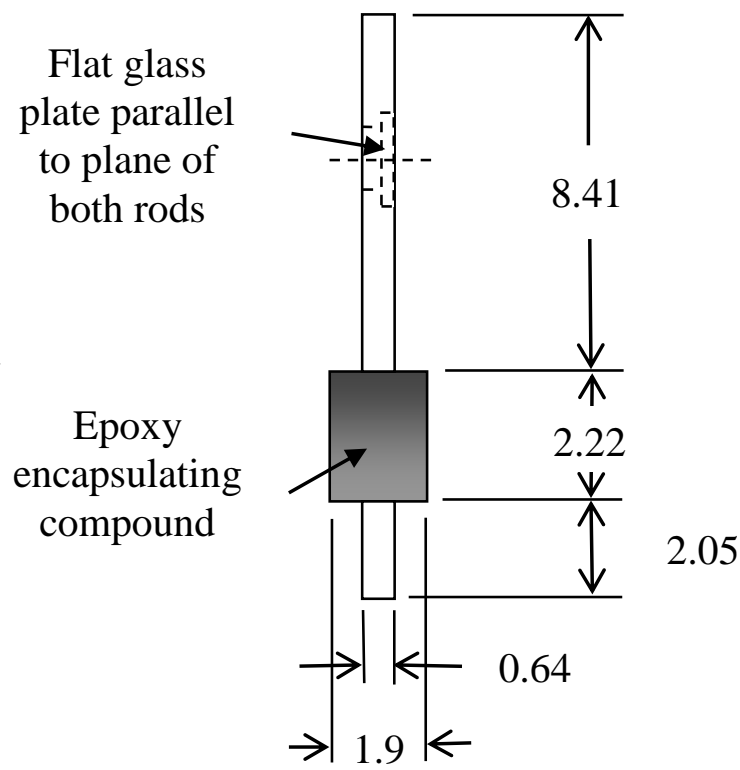

All dimensions in $\mathrm{cm}$

Figure I1. Dimensional drawing of alignment jig 
Appendix J. Kinematic lamp socket

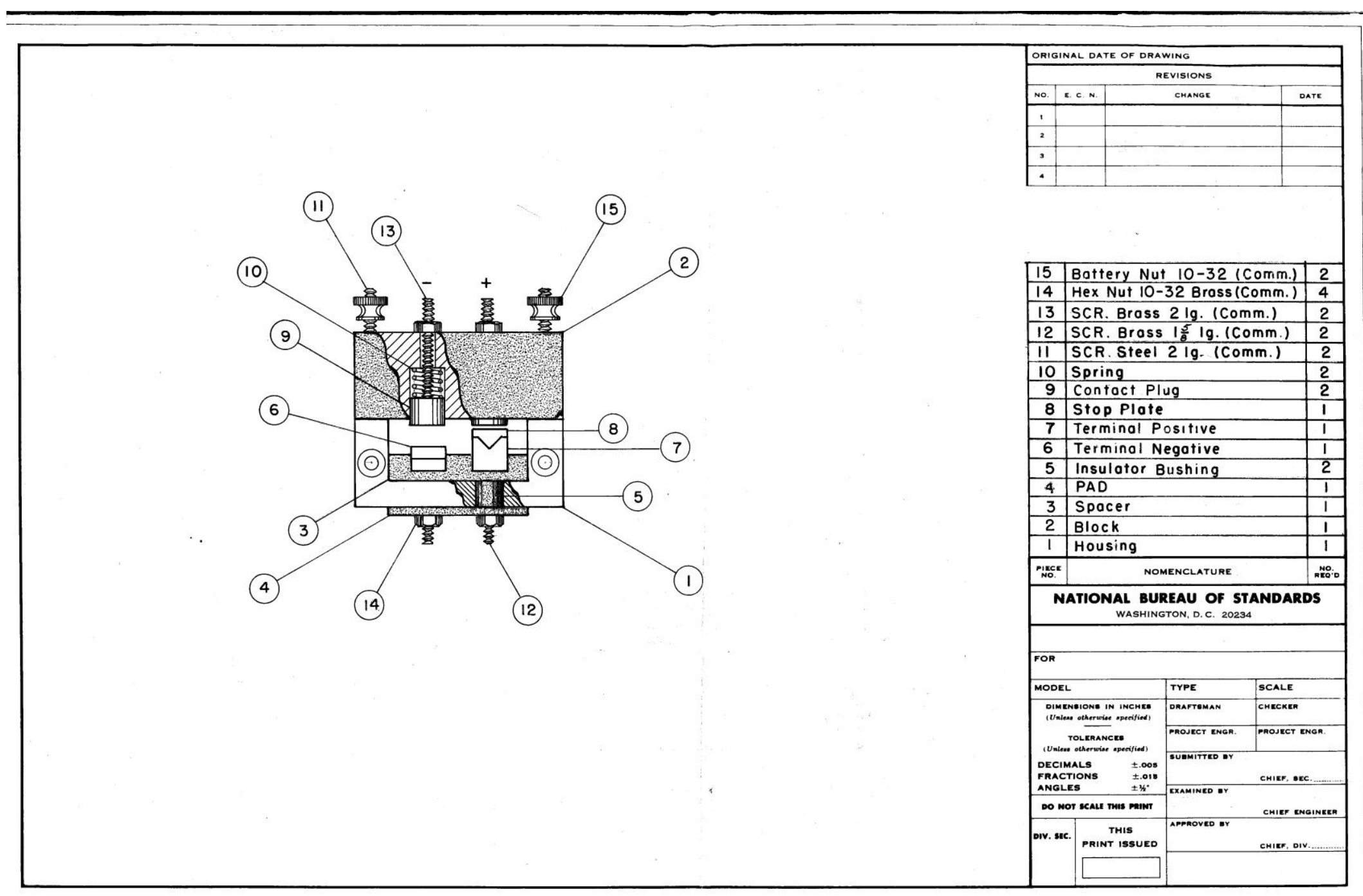




\section{Appendix K. Calibration data points}

Spectral irradiance is measured at the following wavelengths

\begin{tabular}{|c|c|}
\hline Wavelength [nm] & Wavelength [nm] \\
\hline 250 & 555 \\
\hline 260 & 600 \\
\hline 270 & 654.6 \\
\hline 280 & 700 \\
\hline 290 & 800 \\
\hline 300 & 900 \\
\hline 310 & 1050 \\
\hline 320 & 1150 \\
\hline 330 & 1200 \\
\hline 340 & 1300 \\
\hline 350 & 1540 \\
\hline 360 & 1600 \\
\hline 370 & 1700 \\
\hline 380 & 2000 \\
\hline 390 & 2100 \\
\hline 400 & 2300 \\
\hline 450 & 2400 \\
\hline 500 & \\
\hline & \\
\hline
\end{tabular}




\section{Appendix L. Calibration services}

The Spectroradiometric Sources Calibration services include the following.

\begin{tabular}{|c|c|}
\hline $\begin{array}{l}\text { Service } \\
\text { ID } \\
\text { Number }\end{array}$ & Description of Services \\
\hline \multicolumn{2}{|c|}{$\begin{array}{l}\text { NIST calibrates and issues a } 1000 \mathrm{~W} \text {, tungsten quartz-halogen lamp } \\
\text { mounted in a medium bi-post base. The calibrations are performed at } \\
50 \mathrm{~cm} \text {. }\end{array}$} \\
\hline $39030 \mathrm{C}$ & $\begin{array}{l}\text { Spectral Irradiance Standard, } 1000 \mathrm{~W} \text { Tungsten Quartz- } \\
\text { Halogen Lamp ( } 250 \mathrm{~nm} \text { to } 450 \mathrm{~nm})\end{array}$ \\
\hline $39031 \mathrm{C}$ & $\begin{array}{l}\text { Recalibration of } 1000 \mathrm{~W} \text { Tungsten Quartz-Halogen Lamp } \\
(250 \mathrm{~nm} \text { to } 450 \mathrm{~nm})\end{array}$ \\
\hline $39032 \mathrm{C}$ & $\begin{array}{l}\text { Spectral Irradiance Standard, } 1000 \text { W Tungsten Quartz- } \\
\text { Halogen Lamp ( } 350 \mathrm{~nm} \text { to } 800 \mathrm{~nm})\end{array}$ \\
\hline $39033 \mathrm{C}$ & $\begin{array}{l}\text { Recalibration of } 1000 \mathrm{~W} \text { Tungsten Quartz-Halogen Lamp } \\
(350 \mathrm{~nm} \text { to } 800 \mathrm{~nm})\end{array}$ \\
\hline $39040 \mathrm{C}$ & $\begin{array}{l}\text { Spectral Irradiance Standard, } 1000 \mathrm{~W} \text { Tungsten Quartz- } \\
\text { Halogen Lamp ( } 250 \mathrm{~nm} \text { to } 1600 \mathrm{~nm})\end{array}$ \\
\hline $39041 \mathrm{C}$ & $\begin{array}{l}\text { Recalibration of } 1000 \mathrm{~W} \text { Tungsten Quartz-Halogen Lamp } \\
(250 \mathrm{~nm} \text { to } 1600 \mathrm{~nm})\end{array}$ \\
\hline $39045 \mathrm{C}$ & $\begin{array}{l}\text { Spectral Irradiance Standard, } 1000 \mathrm{~W} \text { Tungsten Quartz- } \\
\text { Halogen Lamp ( } 250 \mathrm{~nm} \text { to } 2400 \mathrm{~nm})\end{array}$ \\
\hline $39046 \mathrm{C}$ & $\begin{array}{l}\text { Recalibration of } 1000 \mathrm{~W} \text { Tungsten Quartz-Halogen Lamp } \\
(250 \mathrm{~nm} \text { to } 2400 \mathrm{~nm})\end{array}$ \\
\hline $39060 \mathrm{~S}$ & Special Tests of Radiometric Sources \\
\hline
\end{tabular}

Descriptions of these services can be found on the NIST Calibrations webpage.

Spectroradiometric Calibration Services

(http://www.nist.gov/calibrations/spectroradiometric.cfm) 